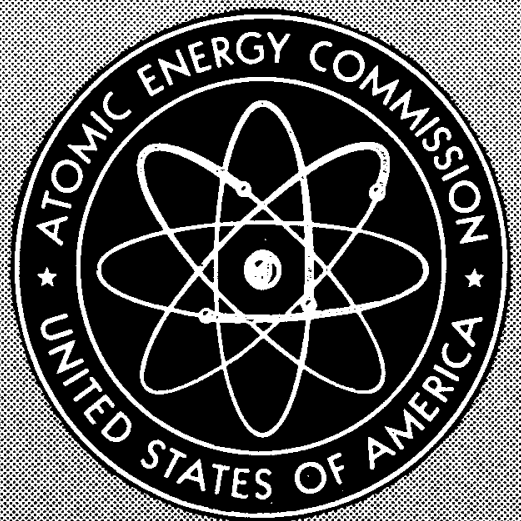

NMI-2807

\title{
SUMMARY REPORT ON THE STUDY OF BETA TREATMENT OF URANIUM
}

By

R. B. Russell

A. K. Wolff

April 1, 1963

Nuclear Metals, Inc.

West Concord, Massachusetts 


\section{DISCLAIMER}

This report was prepared as an account of work sponsored by an agency of the United States Government. Neither the United States Government nor any agency Thereof, nor any of their employees, makes any warranty, express or implied, or assumes any legal liability or responsibility for the accuracy, completeness, or usefulness of any information, apparatus, product, or process disclosed, or represents that its use would not infringe privately owned rights. Reference herein to any specific commercial product, process, or service by trade name, trademark, manufacturer, or otherwise does not necessarily constitute or imply its endorsement, recommendation, or favoring by the United States Government or any agency thereof. The views and opinions of authors expressed herein do not necessarily state or reflect those of the United States Government or any agency thereof. 


\section{DISCLAIMER}

Portions of this document may be illegible in electronic image products. Images are produced from the best available original document. 


\section{LEGAL NOTICE}

This report was prepared as an account of Government sponsored work. Neither the United States, nor the Commission, nor any person acting on behalf of the Commission:

A. Makes any warranty or representation, expressed or implled, with respect to the accuracy, completeness, or usefulness of the information contained in this report, or that the use of any information, apparatus, method, or process disclosed in this report may not infringe privately owned rights; or

B. Assumes any llabllities with respect to the use of, or for damages resulting from the use of any information, apparatus, method, or process disclosed in this report.

As used in the above, "person acting on behalf of the Commission" includes any employee or contractor of the Commission, or employee of such contractor, to the extent that such employee or contractor of the Commission, or employee of such contractor prepares, disseminates, or provides access to, any information pursuant to his employment or contract with the Commission, or his employment with such contractor.

This report has been reproduced directly from the best avallable copy.

Printed in USA. Price $\$ 2.75$. Avallable from the Office of Technical Services, Department of Commerce, Washington 25, D. C. 
Summary Report on the Study of

Beta Treatment of Uranium

R. B. Russell and A. K. Wolff

April 1, 1963

A. R. Kaufmann

Technical Director

Contract No. AT (30-1)-2784

Nuclear Metals, Inc.

West Concord, Massachusetts 


\section{OUTLINE AND TABLE OF CONTENTS}

Page No.

I. INTRODUCTION

$1-2$

II. SHORT SUMMARY OF RESULTS OF BETA TREATMENT PROGRAM 3

A. Grain Size and Shape 3

1. Delta Condition 3

2. Beta Treatment Time and Temperature 3

3. Cooling Rate 3

4. Air Delay Before Oil Quenching 4

5. Recrystallization 4

6. Applied Stress 4

B. Distortion 4

C. Texture and Growth Index 5

1. Radial Texture Distribution 5

2. Beta Treatment Time and Temperature 5

3. Prior Delta Condition 6

4. Cooling Rate from Beta Phase 6

5. Comparison of OD and ID Tube Integrated
Textures

6. Air Delay Before Oil Quench 7

7. Hot-salt Quenching of Thin Discs 7

8. Hot-salt Quench of Tubes 7

9. Internal Free Surfaces 8

10. Applied Stress 8

III. RESULTS AND DISCUSSION 9

A. Thermal Data 9 
Page No.

1. Effect of Composition

10-11 Table I

2. Effect of Prior Condition

3. Effect of Geometry

$12-15$

14

Fig, 1

4. Effect of Heat Treatment

$16-19$

17

Fig. 2

5. Effect of Stress

20

B. Grain Size and Shape 20

1. Effect of Composition 20

2. Effect of Prior Condition 21-25

23 Fig. 3A

24 Fig. 3B

3. Effect of Geometry 25

4. Effect of Heat Treatment 26-30

$27 \quad$ Fig. 4

$28 \quad$ Fig. 5

5. Effect of Applied Stress During and After Heat Treatment

C. Distortion

30

1. Effect of Texture Changes on Distortion in Rods

$32-36$

33-34 Fig. 7

$35 \quad$ Fig. 8

2. Re1ative Effect of Severity of Cooling on Distortion 


\section{Page No.}

3. Effect of Texture Changes on Distortion in Tubes

D. Texture and Growth Index $\left(G_{3}\right)$

1. Growth Index

2. Texture and Thermal Gradient

Fig. 9

41

Fig. 10

3. Sensitivity of Radial $G_{3}$

4. Relation Between $G_{3}$ and Grain Size

5. Distribution of Radial $\mathrm{G}_{3}$, Radial Merit, Integrated Radial Texture

a. Effect of Composition

b. Prior Condition

c. Geometry

48

49

Fig. 13

d. Heat Treatment

48

(1) Delta Treatment

(2) Beta Temperature

(3) Time at Beta Temperature

50

(4) Continuous Cooling to Room Temperature

(a) Radial Merit vs. Cooling Medium 
(b). Radial Merit vs. Cooling Rate

(c) Integrated Radia 1 Texture in Tubes

56 Fig. 17

58

Table II

(d) Normalized Radial $\mathrm{G}_{3}$

(5) Interrupted Cooling to Room Temperature (air delays and hot salt quenching)

(a) Air Delay

(b) The Possibility of Isotherma1 Transformation 61-63

(c) Hot Salt Quencining of Dingot and Ingot

(6) A Comparison Between Continuous and Interrupted Cooling

(7) Post-Beta-Treatment Annealing at $600^{\circ} \mathrm{C}$

(8) The Effect of a Double Beta Treatment

e. Effect of Stress Applied in Beta, Beta-Alpha, and in High-Temperature Alpha Phases 
Page No.

(1) Effect of the Application

of Bending Stresses During

Cooling From the Beta Phase 68

$69 \quad$ Fig. 23

(2) The Effect of Externa11y Applied Tensile Stress During and After Cooling from the Beta Phase

70

$71 \quad$ Fig. 24

f. Effect of Internal Free Surface 72

(1) In a Jointed Ingot Bar (C-11) 72-77

$73 \quad$ Fig. 25

$74 \quad$ Fig. 26

$75 \quad$ Fig. 27

$76 \quad$ Fig. 28

(2) Under Nickel or Zircaloy II Cladding

78

$79 \quad$ Fig. 29

80 Fig. 30

IV. RECOMMENDATIONS FOR FURTHER STUDY

$81-83$

V. ACKNOWLEDGMENTS 84

VI. REFERENCES 85-86

APPENDIX A $A-1$

Figs. A-1 - A-24

APPENDIX B, Technical Description and Tabular Data

B-1

I. EQUIPMENT

$\mathrm{B}-1-\mathrm{B}-2$

II. INVENTORY AND CHEMICAL ANALYSES OF METAL RECEIVED

$B-3$

III. EXPERIMENTAL METHODS

$B-3-B-5$

IV. EXPERIMENTAL DATA

$B-6-B-24$

V. REFERENCES FOR APPENDIX B

B -25 
Page No.

$10-11$

Treatment of Uranium Rods and Tubes

58

Total (OD + ID) Radial Integrated Absolute

Texture in Tubes

\section{LIST OF APPENDIX TABLES}

TABLE B-1 - Designation, Dimensions, Weights of Uranium Received for Beta Treatment Study

$\mathrm{B}-7$

TABLE B-2 - Chemical Analyses and Densities of Unalloyed Dingot and Ingot Received for NMI Beta

Treatment Study

$B-8$

TABLE B-3 - $2 \theta$ Positions for Diffraction Profiles and Backgrounds, Calculated Intensities $\left(I_{o_{i}}\right)$,
Area Weight Factors $\left(A_{W_{i}}\right)$ and $\operatorname{Cos}^{2}{ }^{2}$,

Factors Needed to Compute $G_{3}$

TABLE B-4a - Thermal Data for Continuous Cooling of Uranium Tubes and Rods from $720 / 730^{\circ}$ Molten Salt

(Houghton LH-980)

$B-10$

TABLE B-4b - Thermal Data for Interrupted Cooling of Uranium Tubes and Rods

B -14

TABLE B-5 - Grain Sizes of Uranium Rods and Tubes After Beta Treatment at $725^{\circ} \mathrm{C}$ for $10-15$ Minutes

B -15

TABLE B-6a - Relation Between Texture and Dimensiona1 Changes Caused by Beta Treatment of Rods

TABLE B-6b - Same as Table B-6 except for Tubes [Table shows $\%$ changes in length $(\triangle L)$, OD $(\triangle O D)$, Wa11 $(\Delta W)$ ]

TABLE B-7 - Integrated Radial Texture, $\mathrm{II}_{\mathrm{r}}$, in Tubes Cooled from the Beta Phase in Different Media

TABLE B-8 - Effect of Cooling Medium on Certain Characteristics of Radial Texture Distribution in Dingot and Ingot Tubes 
Page No.

Fig. 1 - Thermal gradients and temperature distributions found in 1.1-inch diameter ingot bar during cooling from the beta phase.

Fig. 2 - Relation of TTT characteristics to OD and center cooling curve of 1.1-inch diameter ingot rod.

Fig. $3 \mathrm{~A}$ - Grain size coarsening of $645^{\circ} \mathrm{C}$ annealed ingot after beta treatment.

Fig. 3B - Same as Fig. 3A except without the $645^{\circ} \mathrm{C}$ prior anneal.

Fig. 4 - The effect of beta time and temperature on the FEDC grain size.

Fig. 5 - The relation between growth index $\left(G_{3}\right)$ and FEDC grain size.

Fig. 6 - Dimensional changes in OD and wall thickness with length in ingor tube.

Fig. 7 - Schematic of length changes resulting from beta treatments of cold-swaged and hot-extruded rod.

Fig. 8 - Relation between prior axial $G_{3}$ and dimensional changes caused by beta treatment of rods.

Fig. 9 - Crystallographic (inverse) radial pcle figure at ID surface of ingot tube.

Fig. 10 - Same as Fig. 9, but at midwa11.

Fig. 11A - Radial distribution of radial $G_{3}$ in beta quenched ingot rod as affected by different prior delta treatments.

Fig. 11B - Same as Fig. 11A, except dingot rod.

Fig. 12 - Relation between cooling rate in beta phase $\left(R_{\beta}\right)$ and radial merit in ingot and dingot rod and tube.

Fig. 13 - Effect of thickness on surface $G_{3}$ of beta treated ingot discs.

Fig. 14 - Effect of method of cooling ingot after beta treatment, on the radial merit. 
Page No.

Fig. 15 - Same as Fig. 14, except for dingot.

Fig. 16 - Relation between cooling rate $\left(R_{\beta}\right)$ and integrated net radial texture.

Fig. 17 - Relation between cooling rate $\left(R_{\beta}\right)$ and integrated absolute radial texture.

Fig. 18 - Effect of air delay on $G_{3}$ distribution in ingot tube.

Fig. 19 - Same as Fig. 18, except in rod.

Fig. 20 - Effect of temperature and type of molten salt quench on surface $G_{3}$ of beta treated ingot and dingot discs.

Fig. 21 - Effect of temperature of hot salt quench on $G_{3}$ distribution in dingot tube.

Fig. 22 - Same as Fig. 21, except in ingot.

Fig. 23 - Effect of high temperature bend stress on radial $\mathrm{G}_{3}$ distribution air-cooled ingot rod.

Fig. 24 - Distribution of radial $G_{3}$ in length tensile samples, axially strained during cool from beta phase.

Fig. 25 - Design of jointed ingot bar.

Fig. 26 - Effect of internal "free surface" as shown by comparison between axial distribution of axial $\mathrm{G}_{3}$ in jointed and solid ingot bars. Free surface in high thermal gradient.

Fig. 27 - Effect of an internal free surface in a moderate radial thermal gradient shown in radial direction.

Fig. 28 - Effect of two free surfaces in very low axial thermal gradient at midlength of bar.

Fig. 29 - Distribution $G_{3}$ under bare and nickel-plated ingot and dingot bars.

Fig. 30 - Radial distribution of radial $\mathrm{G}_{3}$ under 0.020inch, 0.010-inch and 0.005-inch Zircaloy 2 clad ingot tube. 


\section{LIST OF APPENDIX FIGURES}

Figs. A-1 through $A-12$

Effect of different cooling media for same size as shown by radial distribution of radial $G_{3}$ in ingot and dingot rod and tubes.

Page No.

Fig. A-1: 1.1 in. diam. ingot rod (size $K$ ) A2

A-2: $1.8 \mathrm{in}$. diam. ingot rod (size $C$ )

A3

A-3: 1.8 in. diam. dingot rod (size DC)

A4

A-4: same as Fig. A-3 except with expanded abscissa

A5

$A-5: 2$ in. $O D \times 1.8$ in. ID ingot tube (size $T$ )

A6

$A-6: 3$ in. OD $\times 2.5$ in. ID ingot tube (size $M$ )

A7

A-7: same as Fig. A-6 except dingot tube (size DM(DG)) A8

$A-8: 4 \mathrm{in}$. OD $\times 3 \mathrm{in}$. ID ingot tube (size E) A9

A-9: $3 \mathrm{in}$. OD $\times 2$ in. ID dingot tube (size $D G$ ) A10

$A-10: 4$ in, OD $\times 2$ in. ID ingot tube (size $A$ ) A11

$A-11: 1.5$ in. OD $\times 0.5$ in. ID ingot tube (size $H) \quad A 12$

A-12: same as Fig. A-11, except dingot tube (size DH(DC) ) A13

Figs. A-13 through A-24

Effect of different sizes for same cooling media as shown by radial distribution of radial $G_{3}$ in ingot and dingot rods and tubes.

Fig. A-13: air cool: tubes

A-14: $30^{\circ} \mathrm{C}$ Houghto-Quench 4102: tubes

A-15: Houghton Sa1t Draw-Temp 275: ingot tubes

A-16: same as Fig. A-15, except dingot tubes

A-17: $25^{\circ} \mathrm{C}$ Poco No. 2 ofl quench: tubes

$\mathrm{A}-18$ : $25^{\circ} \mathrm{C}$ Houghto $\mathrm{K}$ oil quench: tubes

$\mathrm{A}-19$ : $55^{\circ} \mathrm{C}$ water: tubes

$\mathrm{A}-20: 13^{\circ} \mathrm{C}$ water: tubes A22

A-21: air: rods A. A23

A-22: $25^{\circ} \mathrm{C}$ Poco No. 2 and Houghto $\mathrm{K}$ : rods A24

A-23: $55^{\circ} \mathrm{C}$ water: rods A25

A-24: $13^{\circ} \mathrm{C}$ water and $25^{\circ} \mathrm{C}$ saturated brine A26 


\section{INTRODUCTION}

In recent years it has been realized that, although beta treatment does remove a large fraction of the texture of alpha fabricated uranium, yet there may be a substantial texture actually induced by the beta treatment. This study was begun for the Working Committee of the Fuel Element Development Committee to develop a systematic description of the effect of beta treatment variables influencing the texture, grain size and distortion in unalloyed dingot and ingot uranium. The aim of the program was to learn enough of the character of beta treatment so that anyone who wished to beta treat uranium could more easily select the best heat treatment consonant with the reactor requirements of texture and grain size. At the same time, it was hoped that some basic understanding of the results would emerge, but the primary effort was to be the collection of a spectrum of data which had previously been restricted to special sizes and heat treatments .

This report summarizes work performed since Nov. 1, 1959 on the study of the beta treatment of uranium. Owirg to the rather large number of variables studied, it was decided to construct a reference report in which a particular variable could be found readily. It is hoped that this has been accomplished by an outline and table of contents ( $\mathrm{p}, \mathrm{v}$ to $\mathrm{ix}$ ) as well as by subject headings at the top of each page, and marginal notes.

The report encompasses seven previous progress reports as well as work performed since the last progress report. The previous reports have described progress during the following periods: 


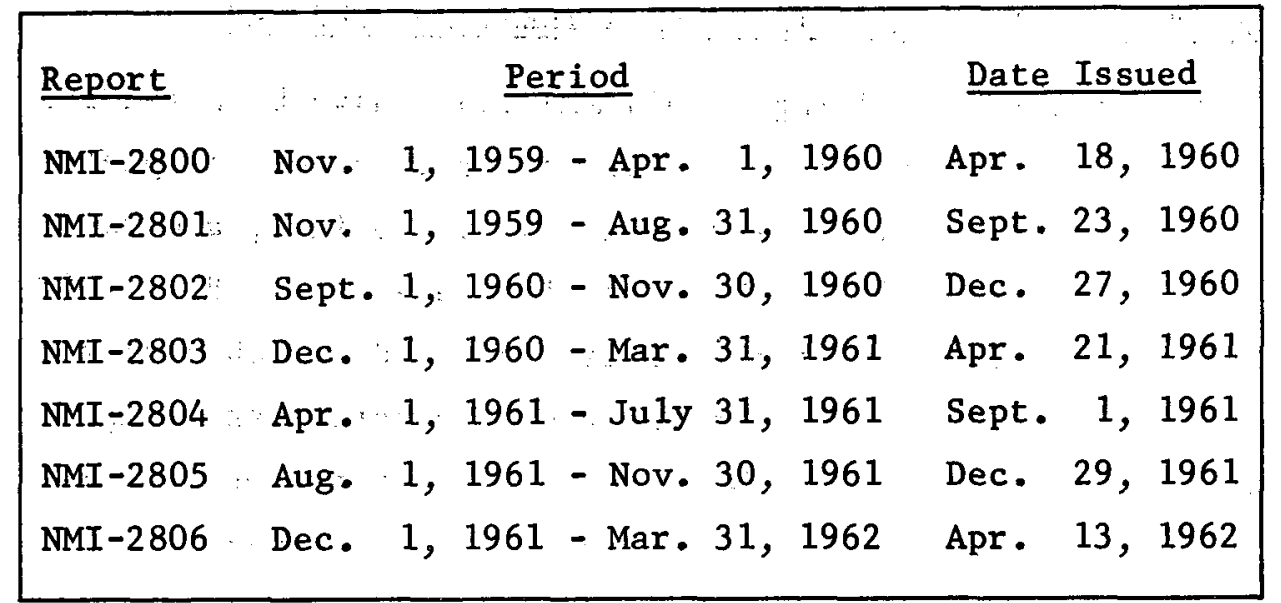

This final report summarizes the effect of composition of unalloyed uranium (ingot vs. dingot), prior delta condition, geometry, heat treatment and applied stress on cooling rate, grain size and texture observed in the beta treatment of rods and tubes. Al1 the data (except $G_{3}$ vs. position data) making up the graphs presented in the main text, as well as data on thermal behavior, grain size and distortion, chemical analyses, materials inventory received, and descriptions of experimental methods and equipment used are contained in Appendix B. Appendix A contains figures of the graphical relation between $G_{3}$ and radial depth of the range of rod and tube sizes studied. 


\section{SHORT SUMMARY OF RESULTS OF BETA TREATMENT PROGRAM}

Unalloyed dingot and ingot rods and tubes have been studied for a variety of beta treatments. Tube outer diameters ranged from 4 to 1 inch, inner diameters from 3.5 to $0.5 \mathrm{inch}$, and wa 11 thicknesses from 0.9 to 0.1 inch. Rod diameters were $1.8,1.1$ and 0.5 inch. Certain auxiliary studies involved 1-inch diameter discs 0.03 inch thick. Cooling rates from the beta phase ranged from about $800^{\circ} \mathrm{C}$ to $1^{\circ} \mathrm{C} / \mathrm{sec}$. The degree of preferred orientation (texture) has been described chiefly by the growth index, $G_{3}$,* which predicts the direction and extent of anisotropic growth in alpha uranium under neutron irradiation.

\section{A. Grain Size and Shape}

1. De1ta Condition (see page 20)

Unalloyed dingot and ingot uranium have been shown to be very sensitive to prior delta heat treatment. A change in delta treatment before a final water quench from the beta phase may cause a shift of about four FEDC grain size numbers.

2. Beta Treatment Time and Temperature (see page 26)

Grain sizes found after oil quenching 1-inch diameter by $1 / 4-i n c h$ thick ingot discs that were beta treated over ranges of 2 to 64 minutes at 690 to $755^{\circ} \mathrm{C}$ were slightly coarser ( $1 / 2$ to 1 FEDC grain size) in the region of 10 to 64 minutes at 690 to $735^{\circ}$.

\section{Cooling Rate (see page 29)}

For a given delta condition, the cooling rate from the beta phase is of major importance in determining the final alpha grain size, which is usually the finest for a water quench, intermediate for oil, and coarsest for an air cool. The macro (3X) grain size or shape does not provide a good indication of the extent or severity of texture present.

*For a definition of $G_{3}$, see Appendix B, p. B-5. 
4. Air Delay Before Oil Quenching (see page 29)

An air delay before oil quenching coarsens the

grain size towards the size realized by an ordinary air cool.

5. Recrystallization (see page 30 )

Post-beta treatment recrysta11ization at $600^{\circ} \mathrm{C}$

slightly refines the grain size, except in the case of air-

cooled specimens, which do not recrystallize.

6. Applied Stress (see page 30 )

Limited experiments on the application of stress

in the beta phase, beta-alpha phases and high alpha phase do not show any detectable effect on the final alpha grain size or shape.

B. Distortion (see page 30 )

Mos.t- of the dimensional changes seem to be caused by the difference in texture before and after beta treatment. The relation between percent length and diameter changes ( $\triangle \mathrm{L}$ and $\triangle \mathrm{D}$ ) in rods, and the axial $G_{3}$ before beta treatment, is given approximately by the relations

$$
\begin{aligned}
& \% \Delta \mathrm{L}=-2.2 \mathrm{G}_{3 A \mathrm{x}}-0.23 \\
& \% \Delta \mathrm{D}=+0.64 \mathrm{G}_{3 A \mathrm{x}}
\end{aligned}
$$

Distortion after beta treatment is more uniformly distributed with slower cooling rates from the beta phase; the effect, in rods, of increasing the cooling rate is generally to increase the tendency to lengthen or to decrease the tendency to shorten.

In tubes the relation between dimensional changes and $G_{3 A x}$ before beta treatment is not apparent from plots that show large scatters in this relationship.

No differences in distortion have so far been observed among beta-treated pieces with different delta histories.

In general, no differences in distortion can be attributed to compositional differences between dingot and ingot. 


\section{Texture and Growth Index (see page 37)}

\section{Radial Texture Distribution}

A preferred orientation (texture) of crystallites

is Induced by any cooling rate (within the range studied) from the beta phase. This texture is such that the $G_{3}$ is negative parallel to the thermal gradient experienced by the uranium during cooling from the beta phase. The induced texture tends to vanish ( $G_{3}$ approaches zero) when the thermal gradient vanishes, as in the radial direction near the midwall of tubes or near the center of rods. These characteristics of induced texture cause the radial distribution of radial $G_{3}$ to have a large negative value at the cooling surfaces and an approximately zero value at a tube midwall; accordingly, the $G_{3}$ distribution curve usually assumes an inverted " $U$ " shape in both dingot and ingot. In one case (beta quench of dingot into $500^{\circ} \mathrm{C}$ molten salt) a " $U$ " radial $G_{3}$ distribution was observed.

Parameters have been introduced to describe the degree of radial texture penetration or the extent of total texture induced by beta treatment:

radial merit $=\mathrm{w}_{\mathrm{o}} / 2 \mathrm{r}$

where $r$ is the radial depth where $G_{3}$ has increased to -0.10 .

integrated net radial texture, $\pi_{r}=\int_{0}^{w} G_{3}\left(2 r / w_{0}\right) d r$

integrated absolute radial texture, $\left|\Gamma_{r}\right|=\int_{0}^{w} q_{3}\left(2 r / w_{0}\right) d r \mid$

where $w_{0}$ is the wall thickness,

$\mathrm{G}_{3}\left(2 \mathrm{r} / \mathrm{w}_{\mathrm{o}}\right)$ is the experimental curve showing the dependence of radial $G_{3}$ on radial depth expressed as $2 \mathrm{r} / \mathrm{w}_{0}$.

Larger values of radial merit indicate shallower texture penetration.

\section{Beta Treatment Time and Temperature (see page 50)}

Beta treatment times longer than 8 minutes at beta temperature do not affect final $G_{3}$ after an oil quench, but shorter times seem to make $G_{3}$ slightly more negative. 
No effect of beta temperatures between $695^{\circ}$ and $755^{\circ} \mathrm{C}$

is observed on the $G_{3}$ after an oil quench.

Dingot was not studied under these conditions.

3. Prior Delta Condition (see page 42)

In drastically quenched ingot and dingot bars that have enough differences in delta histories to cause a grain size change, a $G_{3}$ increase of about 0.01 is associated with a unit decrease in FEDC grain size number.

\section{Cooling Rate from Beta Phase (see page 50)}

In ingot, the severity of induced radial texture penetration as judged by radial merit in influenced substantially by the cooling rate $R_{\beta}$, but in dingot is somewhat less influenced by cooling rate. Cooling rates of about $50^{\circ}$ to $100^{\circ} \mathrm{C}$ per second produce the shallowest texture penetration in ingot, but dingot seems less sensitive to this rate. However, a study of the effect of cooling rate in integrated radial texture in both ingot and dingot shows that slow cooling rates (less than about $2^{\circ} \mathrm{C}$ per second) and fast cooling rates (greater than about $200^{\circ} \mathrm{C}$ per second) produce substantially more integrated texture than intermediate cooling rates (about $50^{\circ} \mathrm{C}$ to $100^{\circ} \mathrm{C}$ per second).

5. Comparison of OD and ID Tube Integrated Textures (see p. 53)

In general, the asymmetry in radial $G_{3}$ radial distribution is greater in tubes with lower ID:wall ratios, where the circulation of the cooling medium is somewhat more restricted. A study of 45 tubes of different sizes and cooling rates showed that an average of about one half of the total integrated texture developed was formed on the outer cooling surfaces, and that there was about twice as much texture on the outer surfaces as on the inner surfaces of tubes. 


\section{Air Delay Before Oil Quench (see page 57)}

An air delay before an oil quench increased the radial texture penetration in ingot, and an increase in air delay increased the texture penetration toward the maximum found after an ordinary air cool.

\section{Hot-salt Quenching of Thin Discs (see page 61)}

A study of surface $G_{3}$ on thin (0.030-inch) ingot and dingot discs quenched from the beta phase into molten salt at 660 to $200^{\circ} \mathrm{C}$ for 10 minutes at temperature, then water quenched, indicated that there is a region of hot-salt quenching temperatures that produces the least textured transformation products by quenching in Houghton LH-235 salt at 550 to $425^{\circ} \mathrm{C}$; except, that the least textured products in ingot correspond to a surface $G_{3}$ of about -0.10 , and in dingot to a surface $G_{3}$ of about -0.16 at these temperatures. However, if a different molten salt (Houghton DT-275) is used on dingot discs at these temperatures, the texture appears to vanish at a quench temperature of about $535^{\circ} \mathrm{C}$. (Ingot discs have not been studied under the same conditions.)

The study of thin discs indicated strongly that a certain range of hot-salt quenches of dingot tubes would lead to a decreased penetration of radial texture as compared with that induced by continuous cooling.

\section{Hot-salt Quench of Tubes (see page 63)}

A limited study of hot-salt (Houghton Draw-Temp 275) quench ( 10 minutes in bath) of 1.5 inch-OD by 0.5 inch-ID ingot tubes at 400 or $200^{\circ} \mathrm{C}$ and dingot tubes at 500, 400 and $300^{\circ} \mathrm{C}$ showed that intermediate quenching rates $\left(R_{\beta}\right)$ can be obtained and that these intermediate rates, like those allowed by oil quenches, successfully produce shallow texture penetration and small values of integrated radial texture. Results on both ingot and dingot indicated that, for this size,hot-salt quench temperatures of 400 to $500^{\circ} \mathrm{C}$ induce less texture than do lower temperatures. 


\section{Interna1 Free Surfaces (see page 72)}

The insertion of internal free surfaces within ingot bar is found to cause a sharp positive increase in $G_{3}$ in a direction perpendicular to the free surface at the interface, after a drastic quench, when the interface is in a region of high thermal gradient and in a region believed to have a very low thermal gradient, but not at an intermediate gradient. A further study of drastically quenched ingot and dingot bars electroplated with 0.002 -inch nickel seems to confirm the sharp increase in $G_{3}$ in a high thermal gradient near the plating. The same results were not found in ingot tube under 0.020 to 0.005 inch of Zircaloy cladding, possibly because of a superior metallurgical Zircaloy-uranium interface, or a greater similarity of thermal conductivity between Zircaloy and uranium, which would not cause such a large interruption of the thermal gradient as may have occurred under the nickel electroplate.

\section{Applied Stress (see page 68)}

Stress applied during the beta-to-alpha transformation seems to be more effective in modifying induced textures than stress applied only in the beta phase, but the reason is not understood. 
III. RESULTS AND DISCUSSION

A summary of the work, listing basic sizes and cooling media used, is presented in Table $I$.

\section{A. Therma 1 Data}

The thermal behavior or uranium tubes and rods during beta treatment and quenching was determined by time-tempectature curves automatically recorded on a Brush oscillograph employing thermocouples located at various depths below the sample surface. A complete summary of the thermal behavior of all uranium samples, including both continuous and discontinuous cooling, is given in Appendix B, Table B-IV. The parameters of interest are:

(1) ${ }_{A_{C}}$, the heating time necessary to reach the alpha-tobeta transformation temperature from room temperature

(2) $t_{\beta / \alpha}$, the time during which the beta-to-alpha transformation takes place on cooling

(3) $A_{r}$, the mean temperature of transformation on cooling

(4) $R_{\beta}$, the cooling rate in the beta phase just before the beta-to-alpha transformation

(5) $\mathrm{R}_{\alpha}$, the cooling rate in the alpha phase just after the transformation.

\section{Effect of Composition}

It was not believed that the difference in compo-

apparent faster cooling of dingot sition between unalloyed dingot and unalloyed ingot has any substantial effect on the thermal behavior during beta treatment. However, there is a tendency for dingot uranium to exhibit faster heating rates in molten salt and faster cooling rates in all 
TABLE I

Summary of Experimenta 1 Progress on Beta Treatment of Uranium Rods and Tubes

\begin{tabular}{|c|c|c|c|c|c|c|c|c|}
\hline \multirow{3}{*}{$\begin{array}{l}\text { Desig- } \\
\text { nation }\end{array}$} & \multirow{2}{*}{\multicolumn{2}{|c|}{$\begin{array}{l}\text { Dimensions } \\
\text { (in) }\end{array}$}} & \multirow{3}{*}{ Chemistry } & \multirow{3}{*}{$\begin{array}{l}\text { Cooling } \\
\text { Medium }\end{array}$} & \multicolumn{4}{|c|}{ Data Obtained } \\
\hline & & & & & \multirow[b]{2}{*}{ The rma 1} & \multirow{2}{*}{ Distortion } & \multirow{2}{*}{$\begin{array}{l}\text { Grain } \\
\text { Size }\end{array}$} & \multirow{2}{*}{$\begin{array}{l}\text { Growth } \\
\text { Index }\end{array}$} \\
\hline & OD & Wa 11 & & & & & & \\
\hline $\mathrm{C}$ & 1.8 & Rod & Ingot & $\begin{array}{l}30^{\circ} \mathrm{C} \text { Air } \\
25^{\circ} \mathrm{C} \text { Poco } 2 \text { Oil } \\
25^{\circ} \mathrm{C} \text { Poco } 2 \text { Oil (a) } \\
25^{\circ} \mathrm{C} \text { Poco } 2 \text { Oil (b) } \\
25^{\circ} \mathrm{C} \text { Houghto K Oil } \\
55^{\circ} \mathrm{C} \text { Water } \\
12^{\circ} \mathrm{C} \text { Water }\end{array}$ & $\begin{array}{l}1 \\
1 \\
1 \\
1 \\
* \\
1 \\
1\end{array}$ & $\begin{array}{l}1 \\
1 \\
1 \\
1 \\
* \\
1 \\
1\end{array}$ & $\begin{array}{l}1 \\
/ \mathrm{X} \\
/ \mathrm{X} \\
/ \mathrm{X} \\
* \\
/ \mathrm{X} \\
/ \mathrm{X}\end{array}$ & $\begin{array}{l}1 \\
/ \mathrm{x} \\
/ \mathrm{x} \\
/ \mathrm{x} \\
* \\
/ \mathrm{x} \\
1\end{array}$ \\
\hline $\mathrm{DC}$ & 1.8 & Rod & Dingot & $\begin{array}{l}30{ }^{\circ} \mathrm{C} \text { Air } \\
25^{\circ} \mathrm{C} \text { Poco } 2 \text { oil } \\
25^{\circ} \mathrm{C} \text { Houghto K oil } \\
555^{\circ} \mathrm{C} \text { Water } \\
12{ }^{\circ} \mathrm{C} \text { Water } \\
25^{\circ} \mathrm{C} \text { Brine }\end{array}$ & $\begin{array}{l}1 \\
1 \\
* \\
1 \\
1 \\
1\end{array}$ & $\begin{array}{l}1 \\
1 \\
* \\
1 \\
1 \\
1\end{array}$ & $\begin{array}{l}/ \mathrm{X} \\
/ \mathrm{X} \\
* \\
/ \mathrm{X} \\
/ \mathrm{X} \\
/ \mathrm{X}\end{array}$ & $\begin{array}{l}/ \mathrm{X} \\
/ \mathrm{X} \\
* \\
/ \mathrm{X} \\
/ \mathrm{x} \\
/ \mathrm{X}\end{array}$ \\
\hline $\mathrm{K}$ & 1.2 & Rod & Ingot & $\begin{array}{l}30^{\circ} \mathrm{C} \text { Air } \\
25{ }^{\circ} \mathrm{C} \text { Poco } 2 \text { oil } \\
55{ }^{\circ} \mathrm{C} \text { Water } \\
12^{\circ} \mathrm{C} \text { Water }\end{array}$ & $\begin{array}{l}1 \\
1 \\
1 \\
1\end{array}$ & $\begin{array}{l}1 \\
1 \\
1 \\
1\end{array}$ & $\begin{array}{l}/ \mathrm{X} \\
/ \mathrm{x} \\
/ \mathrm{X} \\
/ \mathrm{X}\end{array}$ & $\begin{array}{l}/ \mathrm{X} \\
/ \mathrm{x} \\
/ \mathrm{X} \\
/ \mathrm{X}\end{array}$ \\
\hline A & 3.9 & 0.9 & Ingot & $\begin{array}{l}25^{\circ} \mathrm{C} \text { Houghto } 4102 \text { oil } \\
25^{\circ} \mathrm{C} \text { Houghto } \mathrm{K} 0 \mathrm{il} \\
12^{\circ} \mathrm{C} \text { Water }\end{array}$ & $\begin{array}{l}* \\
* \\
*\end{array}$ & $\begin{array}{l}* \\
* \\
*\end{array}$ & $\begin{array}{l}* \\
* \\
*\end{array}$ & $\begin{array}{l}* \\
* \\
*\end{array}$ \\
\hline E & 4.0 & 0.5 & Ingot & $\begin{array}{l}30^{\circ} \mathrm{C} \text { Air } \\
25^{\circ} \mathrm{C} \text { Poco } 2 \text { Oil } \\
25^{\circ} \mathrm{C} \text { Houghto K Oil } \\
55^{\circ} \mathrm{C} \text { Water } \\
12{ }^{\circ} \mathrm{C} \text { Water }\end{array}$ & $\begin{array}{l}1 \\
1 \\
* \\
1 \\
1\end{array}$ & $\begin{array}{l}1 \\
1 \\
* \\
1 \\
1\end{array}$ & $\begin{array}{l}/ \mathrm{x} \\
/ \mathrm{x} \\
* \\
1 \\
1\end{array}$ & $\begin{array}{l}/ \mathrm{x} \\
/ \mathrm{x} \\
* \\
1 \\
1\end{array}$ \\
\hline DG & 3.0 & 0.5 & Dingot & $\begin{array}{l}30^{\circ} \mathrm{C} \text { Air } \\
25^{\circ} \mathrm{C} \text { Poco } 2 \text { Oil } \\
55^{\circ} \mathrm{C} \text { Water }\end{array}$ & $\begin{array}{l}1 \\
1 \\
1\end{array}$ & $\begin{array}{l}1 \\
1 \\
1\end{array}$ & $\begin{array}{l}1 \\
1 \\
1\end{array}$ & $\begin{array}{l}1 \\
1 \\
1\end{array}$ \\
\hline $\mathrm{H}$ & 1.5 & 0.5 & Ingot & $\begin{array}{l}30^{\circ} \mathrm{C} \text { Air } \\
25^{\circ} \mathrm{C} \text { Houghto } 4102 \text { Oil } \\
55^{\circ} \mathrm{C} \text { Poco } 2 \text { Oil } \\
25^{\circ} \mathrm{C} \text { Poco } 2 \text { Oil } \\
25^{\circ} \mathrm{C} \text { Poco } 2 \text { Oil (a) } \\
25^{\circ} \mathrm{C} \text { Poco } 2 \text { Oil (b) } \\
25^{\circ} \mathrm{C} \text { Houghto K Oil } \\
55^{\circ} \mathrm{C} \text { Water } \\
12^{\circ} \mathrm{C} \text { Water } \\
400^{\circ} \mathrm{C} \text { Salt } \\
300^{\circ} \mathrm{C} \text { Salt } \\
200^{\circ} \mathrm{C} \text { Salt }\end{array}$ & 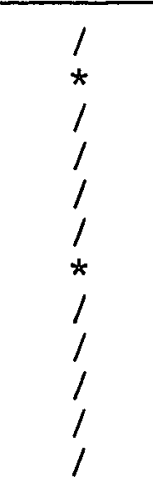 & 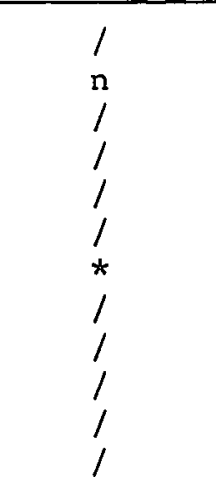 & $\begin{array}{l}1 \\
* \\
1 \\
1 \\
1 \\
1 \\
* \\
1 \\
1 \\
1 \\
1 \\
1\end{array}$ & $\begin{array}{l}\text { I } \\
\text { * } \\
\text { ' } \\
1 \\
1 \\
1 \\
\text { * } \\
1 \\
1 \\
1 \\
1 \\
1\end{array}$ \\
\hline
\end{tabular}




\begin{tabular}{|c|c|c|c|c|c|c|c|c|}
\hline \multirow{3}{*}{$\begin{array}{l}\text { Desig- } \\
\text { nation }\end{array}$} & \multirow{2}{*}{\multicolumn{2}{|c|}{$\begin{array}{l}\text { Dimensions } \\
\text { (in) }\end{array}$}} & \multirow{3}{*}{ Chemistry } & \multirow{3}{*}{$\begin{array}{l}\text { Cooling } \\
\text { Medium }\end{array}$} & \multicolumn{4}{|c|}{ Data Obtained } \\
\hline & & & & & \multirow{2}{*}{ Therma 1} & \multirow{2}{*}{ Distortion } & \multirow{2}{*}{$\begin{array}{l}\text { Grain } \\
\text { Size }\end{array}$} & \multirow{2}{*}{$\begin{array}{l}\text { Growth } \\
\text { Index }\end{array}$} \\
\hline & $O D$ & Wa11 & & & & & & \\
\hline $\begin{array}{l}\mathrm{DH} \\
(\mathrm{DC})\end{array}$ & 1.5 & 0.5 & Dingot & $\begin{array}{l}30^{\circ} \mathrm{C} \text { Air } \\
25^{\circ} \mathrm{C} \text { Houghto } 4102 \text { oil } \\
55^{\circ} \mathrm{C} \text { Poco } 2 \text { Oil } \\
25^{\circ} \mathrm{C} \text { Poco } 2 \text { Oil } \\
25{ }^{\circ} \mathrm{C} \text { Houghto K Oil } \\
55^{\circ} \mathrm{C} \text { Water } \\
122^{\circ} \mathrm{C} \text { Water } \\
500^{\circ} \mathrm{C} \text { Salt } \\
400^{\circ} \mathrm{C} \text { Salt } \\
300^{\circ} \mathrm{C} \text { Salt }\end{array}$ & $\begin{array}{l}\text { n } \\
* \\
\text { n } \\
1 \\
\text { * } \\
\text { n } \\
\text { n } \\
\text { * } \\
* \\
\text { * }\end{array}$ & $\begin{array}{l}1 \\
\text { n } \\
/ \\
1 \\
1 \\
1 \\
1 \\
\text { n } \\
\text { n } \\
\text { n }\end{array}$ & $\begin{array}{l}1 \\
* \\
1 \\
1 \\
1 \\
1 \\
1 \\
* \\
* \\
*\end{array}$ & $\begin{array}{l}1 \\
* \\
* \\
* \\
* \\
1 \\
1 \\
* \\
* \\
*\end{array}$ \\
\hline $\mathrm{N}$ & 2.0 & 0.3 & Ingot & $\begin{array}{l}30^{\circ} \mathrm{C} \text { Air } \\
25^{\circ} \mathrm{C} \text { Poco } 2 \text { Oil } \\
25^{\circ} \mathrm{C} \text { Poco Houghto } \mathrm{K} \text { 0il } \\
55^{\circ} \mathrm{C} \text { Water } \\
12^{\circ} \mathrm{C} \text { Water }\end{array}$ & $\begin{array}{l}* \\
* \\
* \\
\mathrm{n} \\
*\end{array}$ & $\begin{array}{l}* \\
* \\
* \\
\mathrm{n} \\
*\end{array}$ & $\begin{array}{c}* \\
* \\
* \\
\mathrm{n} \\
*\end{array}$ & $\begin{array}{l}\mathrm{n} \\
\mathrm{n} \\
\mathrm{n} \\
\mathrm{n} \\
\mathrm{n}\end{array}$ \\
\hline $\mathrm{P}$ & 1.0 & 0.25 & Ingot & $\begin{array}{l}30^{\circ} \mathrm{C} \text { Air } \\
25^{\circ} \mathrm{C} \text { Poco } 2 \text { Oil } \\
25^{\circ} \mathrm{C} \text { Houghto K Oil } \\
55^{\circ} \mathrm{C} \text { Water } \\
12^{\circ} \mathrm{C} \text { Water }\end{array}$ & $\begin{array}{l}* \\
\star \\
* \\
\mathbf{n} \\
\star\end{array}$ & $\begin{array}{l}* \\
* \\
* \\
\mathrm{n} \\
*\end{array}$ & $\begin{array}{l}* \\
* \\
* \\
\mathrm{n} \\
*\end{array}$ & $\begin{array}{l}\mathrm{n} \\
\mathrm{n} \\
\mathrm{n} \\
\mathrm{n} \\
\mathrm{n}\end{array}$ \\
\hline $\mathrm{L}$ & 3.9 & 0.2 & Ingot & $\begin{array}{l}30^{\circ} \mathrm{C} \text { Air } \\
25^{\circ} \mathrm{C} \text { Poco } 2 \text { Oil } \\
25^{\circ} \mathrm{C} \text { Houghto } \mathrm{K} \text { Oil } \\
55^{\circ} \mathrm{C} \text { Water } \\
12^{\circ} \mathrm{C} \text { Water }\end{array}$ & $\begin{array}{l}* \\
* \\
\star \\
\mathrm{n} \\
*\end{array}$ & $\begin{array}{l}* \\
* \\
* \\
\mathrm{n} \\
*\end{array}$ & $\begin{array}{l}* \\
\star \\
* \\
\mathrm{n} \\
\star\end{array}$ & $\begin{array}{l}\mathrm{n} \\
\mathrm{n} \\
\mathrm{n} \\
\mathrm{n} \\
\mathrm{n}\end{array}$ \\
\hline $\mathbf{M}$ & 3.0 & 0.2 & Ingot & $\begin{array}{l}30^{\circ} \mathrm{C} \text { Air } \\
25^{\circ} \mathrm{C} \text { Poco } 2 \text { Oil } \\
25^{\circ} \mathrm{C} \text { Houghto } \mathrm{K} \text { Oil } \\
55^{\circ} \mathrm{C} \text { Water } \\
12^{\circ} \mathrm{C} \text { Water }\end{array}$ & $\begin{array}{l}\mathrm{n} \\
\mathrm{n} \\
\mathrm{n} \\
\mathrm{n} \\
\mathrm{n}\end{array}$ & $\begin{array}{l}\mathrm{n} \\
\mathrm{n} \\
\mathrm{n} \\
\mathrm{n} \\
\mathrm{n}\end{array}$ & $\begin{array}{l}1 \\
1 \\
* \\
1 \\
1\end{array}$ & $\begin{array}{l}* \\
* \\
* \\
* \\
*\end{array}$ \\
\hline $\begin{array}{c}D M \\
(D G)\end{array}$ & 3.0 & 0.2 & Dingot & $\begin{array}{l}30^{\circ} \mathrm{C} \text { Air } \\
25^{\circ} \mathrm{C} \text { Poco } 2 \text { Oil } \\
25{ }^{\circ} \mathrm{C} \text { Houghto K Oil } \\
55^{\circ} \mathrm{C} \text { Water } \\
12{ }^{\circ} \mathrm{C} \text { Water }\end{array}$ & $\begin{array}{l}* \\
* \\
* \\
* \\
*\end{array}$ & $\begin{array}{l}\mathrm{n} \\
\mathrm{n} \\
\mathrm{n} \\
\mathrm{n} \\
\mathrm{n}\end{array}$ & $\begin{array}{l}* \\
* \\
* \\
* \\
*\end{array}$ & $\begin{array}{l}* \\
* \\
* \\
* \\
*\end{array}$ \\
\hline $\mathrm{T}$ & 2.0 & 0.1 & Ingot & $\begin{array}{l}30^{\circ} \mathrm{C} \text { Air } \\
25{ }^{\circ} \mathrm{C} \text { Poco } 2 \text { oil } \\
25^{\circ} \mathrm{C} \text { Houghto } \mathrm{K} \text { oil } \\
55^{\circ} \mathrm{C} \text { Water } \\
0^{\circ} \mathrm{C} \text { Brine }\end{array}$ & $\begin{array}{l}1 \\
1 \\
* \\
1 \\
1\end{array}$ & $\begin{array}{l}1 \\
1 \\
* \\
1\end{array}$ & $\begin{array}{l}1 \\
1 \\
* \\
1 \\
1\end{array}$ & $\begin{array}{l}1 \\
1 \\
* \\
1 \\
1\end{array}$ \\
\hline
\end{tabular}

(a) Air delay to beginning of $\beta \rightarrow \alpha$ transformation; (b) to end of $\beta \rightarrow \alpha$ transformation. / Data obtained before last report (NMI-2806). in No data obtained.

* Data obtained since last report. 
cooling media. It has been suggested by J. E. Minor (HAPO) that the higher oxidation rate of ingot increases the amount of thermal insulation between metal and thermocouple, thus yielding apparently slower cooling rates in ingot. The thermal differences between dingot and ingot are statistical at most and extremely sma11, even when compared with the deviations in results for repeated treatment of a single composition.

\section{Effect of Prior Condition}

It was not believed that prior condition has any significant effect on thermal behavior, although no thermal analyses were made on samples having different histories but identical geometries and compositions. However, samples machined from ingot tube and samples of identical geometry machined from dingot rod showed little difference in thermal properties. Since considerable textural differences presumably exist between these two materials, it may be inferred that at least in this respect prior condition does not significantly affect thermal properties.

\section{Effect of Geometry}

The heating time needed by the sample to reach

the alpha-beta transformation, $t_{A_{C}}$, varied from as little as 36 seconds for 2 -inch oD by 0.1 -inch wall ingot tube (size $T$ ) to about 200 seconds for 1.8-inch diameter rod (size $\mathrm{C}$ ) and 3.9-inch OD by 0.9-inch wall tube (size A). Cooling rates in a given quench medium showed correspondingly high variations with sample size. For rods, heating and cooling rates decreased with increasing depth from the surface, as would be expected.

tunnel effect in cooling
However, although the OD surface of tubes genera1ly exhibited the highest heating and cooling rates, the rates obtained at the ID were usually lower than those observed at midwall or other intermediate points. This is presumably due to a "tunnel" effect in which the circulation of the heating or cooling medium is restricted on the inner surface of the tube. Molten salt may even momentarily freeze at the end of the tube during heating 
Thermal Data

thermal gradients in 1 in. rods or quenching, thus further restricting the passage of the heating or cooling medium. This effect (faster cooling at midwa 11 than at ID) was most pronounced for 1.5 -inch oD by 0.5-inch ID (size H), 1-inch OD by 0.5-inch ID (size P), and 3-inch OD by 2.5-inch ID (size M) tubes. It appears that the tunnel effect is most pronounced in tubes having smaller inside diameters (where heat flow is most restricted) and thinner walls; (where midwall cooling does not lag substantially behind OD cooling).

Since the growth characteristics of beta treated uranium are associated with the direction (and perhaps magnitude) of the thermal gradients produced during cooling, a study was made to determine the type and size of thermal gradient produced at various depths below the cooling surface for three representative cooling media. By employing cooling curves obtained at different depths below the sample surface, it was possible to obtain thernal gradients $(\Delta \mathrm{T} / \Delta \mathrm{r}$ ) for the intervals between two successive thermocouple placements. These thermal gradients have been plotted versus cooling time in Fig. 1. Typical gradient curves are presented for water-quenched, oil-quenched, and air-cooled 1.1-inch diameter rods in Curves I, II and III respectively. Each one of the curves represents the thermal gradient across the indicated radial interval* as shown in Curve IV. Curve IV depicts the temperature distribution across the radius for each quench medium as derived from Curves I, II, and III for the specific times indicated. (Each time was arbitrarily chosen to show typical thermal behavior during a given quench. Owing to the wide variations in total cooling time associated with the three quenching media, it was not possible to select a common time which would illustrate the typical temperature distribution

*The calculations employed in this work assume a linear gradien: across the interval studied, which is not, of course, a true representation. However, these curves are qualitatively valid for determining the cooling behavior of the samples. 


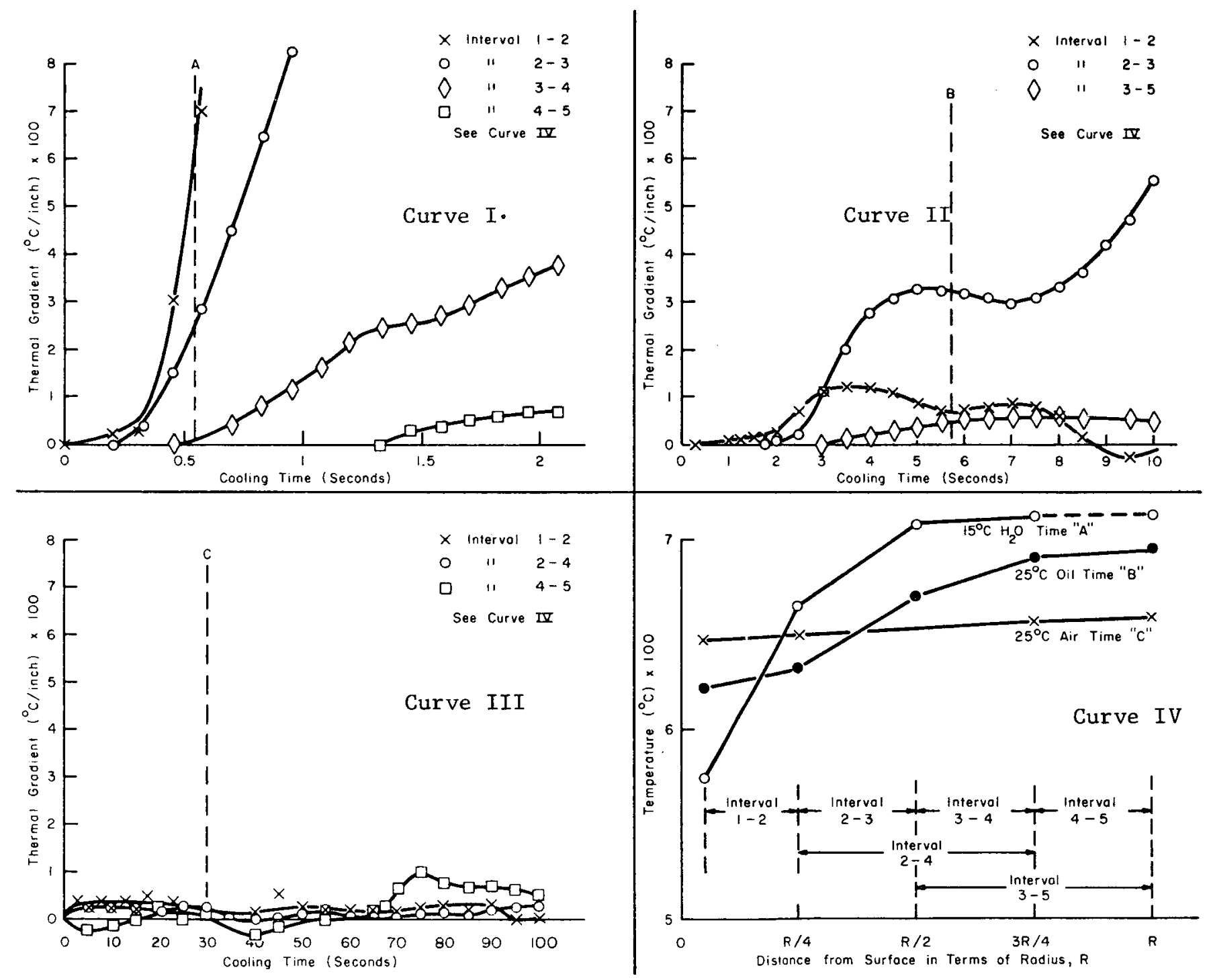

Fig. 1 - Thermal gradients and temperature distributions found in 1.1-inch diameter ingot bar during cooling from the beta phase. Drawing No. RB-1129

Curve I: Thermal gradient vs. cooling tịme for $15^{\circ} \mathrm{C}$ water quench.

Curve II: Thermal gradient vs. cooling time for $25^{\circ} \mathrm{C}$ Poco No. 2 0il quench.

Curve III: Thermal gradient vs, cooling time for $25^{\circ} \mathrm{C}$ air cool.

Curve IV: Temperature variation with depth below OD after specific times in various cooling media. 
for al1 three quenches.)

The fact that the maximum thermal gradients observed during oil quenching are not those nearest the sample surface: may be explained in terms of the effect of the beta-alpha transformation on the characteristic cooling curves of the con. centric annular increments, which may be considered to compose the full wall thickness of the cooling cylinder. With increasing distance from the surface, the cooling of each increment lags behind that of the overlaying increment by an amount determined by the rate of heat extraction by the quenching medium: the thermal conductivity of the uranium and the sample geometry. The temperature differential between adjacent annuli genera1ly decreased with increasing distance from the surface. However, during the transformation within a given annulus, the evolving heat of transformation retards the cooling process. Depending on the rate of heat extraction compared with the rate of trans-

recalescence

therma 1 gradients intermediate depths formation (evolution of recalescent heat), the cooling rate nay decelerate, be arrested, or reverse (recalescence). This re.tardation reduces the temperature differential between the transforming annulus and the underlying untransformed annulu:s, which continues to cool through the beta phase. If the effect of the recalescence on the temperature differential is sufficiently pronounced, the gradient between them can reach even a lower value than gradients observed at greater depths, thus accounting for the observation that the maximum thermal gradients found during an oil quench lie at some intermediate sample depth, rather than nearest the surface. In water quenching, the rate of heat extraction is so high that the retardation of cooling by heat of transformation is negligible, so that the maximum thermal gradients are nearest the surface. During air cooling; the rate of heat extraction is so small that recalescence doninates, and the thermal gradients are very small throughout the sample volume. 
typical cooling rates from $\beta$

cooling in air, oil, water plotted on ingot TTT diagram

\section{Effect of Heat Treatment}

For a given sample geometry, cooling rates increase in the order:air, oil, water (or brine). Althougt, considerable variation in cooling rate occurs with varying sample geometry and thermocouple location, the cooling rates in the beta phase can almost invariably be categorized as follows: air: 1 to $10^{\circ} \mathrm{C} / \mathrm{sec}$; oil: 10 to $100^{\circ} \mathrm{C} / \mathrm{sec}$; water: 100 to $1000^{\circ} \mathrm{C} / \mathrm{sec}$. Individual cooling rates range from about $800^{\circ} \mathrm{C} / \mathrm{sec}$. for a water-quenched 0.1 -inch wall ingot tube to $1^{\circ} \mathrm{C} / \mathrm{sec}$. for the interior of an air-cooled 1.8-inch diameter ingot rod.

The Importance of cooling rates in terms of transformation times and temperatures is shown graphically in Fig. 2 where the cooling curves for 1.1-inch diameter rods quenched in various media are superimposed on a time-temperature-transformation plot given by Jepson*(1) for ingot composition. Curves are shown in each case for the ob thermocouple (actually 0.06 inch below the surface) and the center thermocouple. No data were available for the TTT diagram for times less than 10 seconds; the "nose" of the curve, which is undetermined, is shown schematically by a dashed line. Because TTT characteristics may vary with small changes in composition, the Jepson curves (which are for ingot-like uranium) are not to be taken as exact values for these studies. However, it is readily seen that considerable variation in transformation

* Jepson determined the TTT diagram from dilatometric results on 1.8 inch diameter by 1 inch samples quenched from 30 minutes at $720^{\circ} \mathrm{C}$ into a lead bath for isothermal transformation. The typical composition was (ppm):

$\frac{\mathrm{C}}{700} \frac{\mathrm{O}}{15} \frac{\mathrm{N}}{20} \frac{\mathrm{H}}{2} \frac{\mathrm{Fe}}{100} \frac{\mathrm{Al}}{40} \frac{\mathrm{Si}}{20} \frac{\mathrm{Cr}}{5} \frac{\mathrm{Mn}}{15}$ 


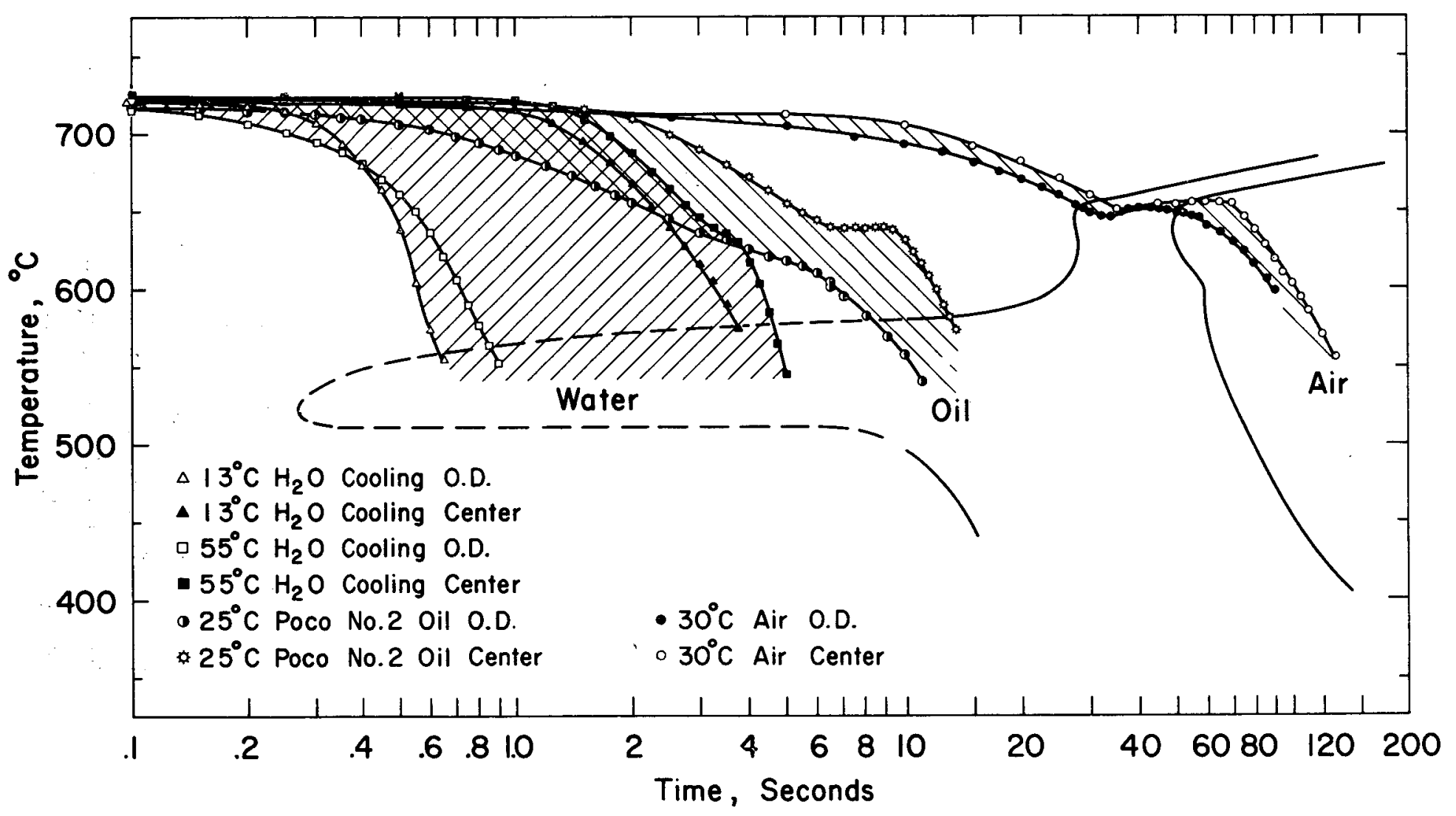

Fig. 2 - Relation of TTT characteristics to OD and center cooling curve of 1.1-inch diameter ingot rod cooled in different media. TTT characteristics are from Jepson(1) and are for composition including $700 \mathrm{ppm} \mathrm{C}, 100 \mathrm{ppm} \mathrm{Fe}, 40 \mathrm{ppm} \mathrm{A} 1,20 \mathrm{ppm} \mathrm{Si}$. Drawing No. $\mathrm{RC}-10 j 2$ 
time and temperature can be caused by varying the cooling medium. Since there are indications (see p. 61) that the isothermal transformation temperature can affect the $G_{3}$, and since transformation kinetics vary drastically in different regions of the TTT diagram, the cooling rates are undoubtedly very important.

The curves for the air-cooled sample agree well with the Jepson diagram, but his data are not complete enough to permit comparison with data for water-quenched samples. For the oil quench, the thermal arrests are considerably higher than the temperatures predicted by Jepson. It should be noted that his data are for $700 \mathrm{ppm}$ carbon, whereas the cooling curves shown represent metal containing about $440 \mathrm{ppm}$ carbon. This as well as size effects may explain the observed deviations from his TTT diagram.

Warm and cold water quenches are seen to have very similar cooling curves. The similarity of response of uranium to warm and cold water quenches has also been confirmed in $G_{3}$ analyses. On the other hand, the differences among the three media, air, oil, water, are quite prominent, and there is little or no overlap of the cooling curves for these media in the transformation regions. This implies that the transformation product in the full cross-section of a 1.1-inch diameter rod is unique for each medium. Moreover, this demarcation between air, oil and water appears to exist for all geometries studied.

An attempt to obtain intermediate cooling rates by cooling rates in heating of the Poco No. 2 oil to $55^{\circ} \mathrm{C}$ resulted in essentially different oils no changes in thermal behavior. Using room-temperature, Houghto $\mathrm{K}$ quenching oil resulted in slight increases in cooling rates, while the use of room temperature Houghto-Quench 4102 oil (containing a mica slurry) successfully achieved cooling 


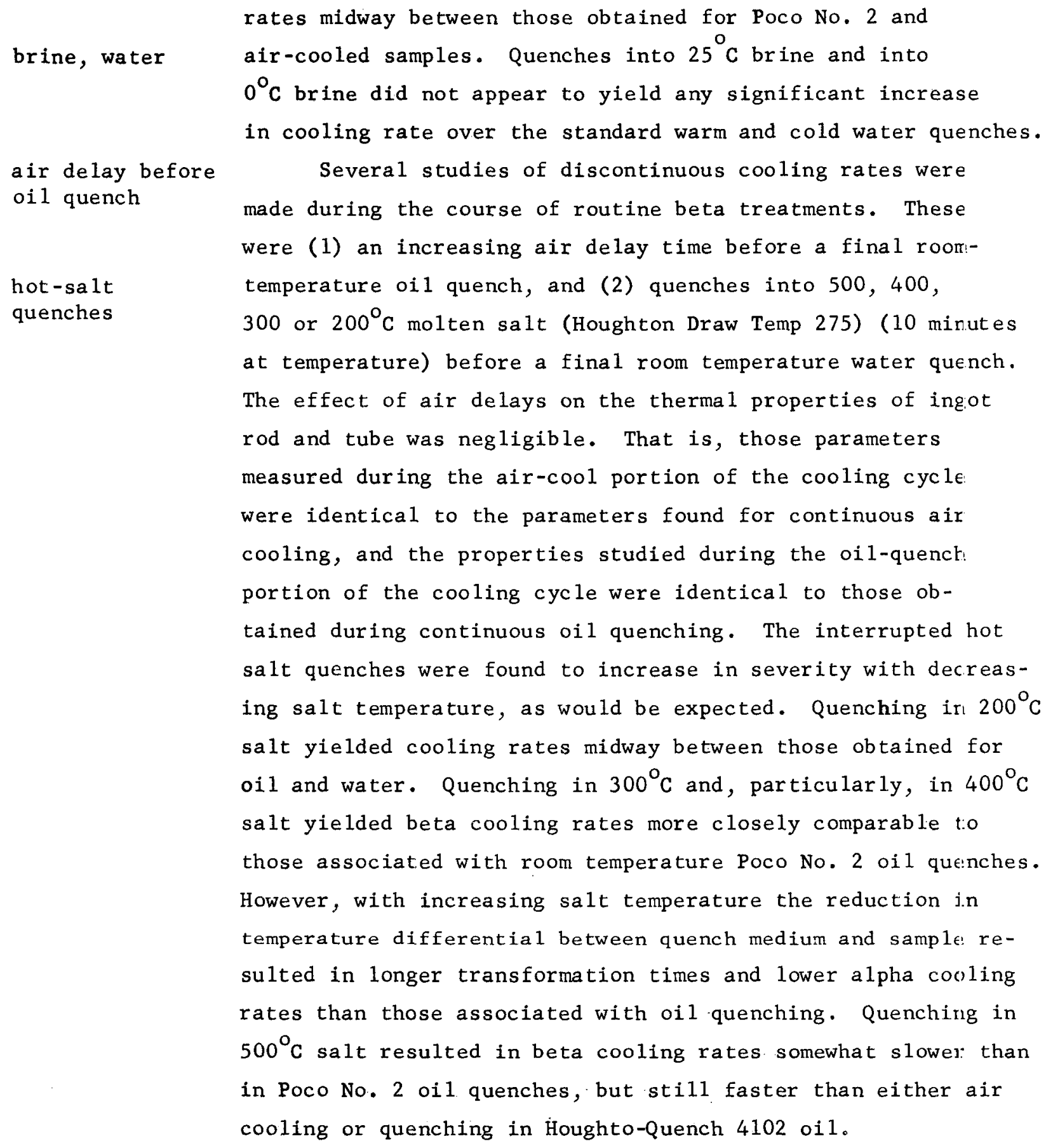

rates midway between those obtained for Poco No. 2 and air-cooled samples. Quenches into $25^{\circ} \mathrm{C}$ brine and into $0^{\circ} \mathrm{C}$ brine did not appear to yield any significant increase in cooling rate over the standard warm and cold water quenches. Several studies of discontinuous cooling rates were made during the course of routine beta treatments. These were (1) an increasing air delay time before a final room:temperature oil quench, and (2) quenches into 500, 400, 300 or $200^{\circ} \mathrm{C}$ molten salt (Houghton Draw Temp 275) (10 minutes at temperature) before a final room temperature water quench. The effect of air delays on the thermal properties of ingot rod and tube was negligible. That is, those parameters measured during the air-cool portion of the cooling cycle: were identical to the parameters found for continuous air cooling, and the properties studied during the oil-quenct: portion of the cooling cycle were identical to those obtained during continuous oil quenching. The interrupted hot salt quenches were found to increase in severity with decreasing salt temperature, as would be expected. Quenching ir $200^{\circ} \mathrm{C}$ salt yielded cooling rates midway between those obtained for oil and water. Quenching in $300^{\circ} \mathrm{C}$ and, particularly, in $400^{\circ} \mathrm{C}$ salt yielded beta cooling rates more closely comparable to those associated with room temperature Poco No. 2 oil quenches. However, with increasing salt temperature the reduction in temperature differential between quench medium and sample resulted in longer transformation times and lower alpha cooling rates than those associated with oil quenching. Quenching in $500^{\circ} \mathrm{C}$ salt resulted in beta cooling rates somewhat slowes: than in Poco No. 2 oil quenches, but still faster than either air cooling or quenching in Houghto-Quench 4102 oil. 


\section{Effect of Stress}

It is not expected that cooling rates will be affected by the application of stress during cooling. It is not known whether the application of stress might be expected to increase the transformation rate or/and change the transformation temperature. These two parameters could ex rrt a considerable influence on the beta-treated properties.

\section{B. Grain Size and Shape}

After each beta treatment, a hemicylinder was cut from the tube or rod. The cross-section exposed was macro-etched in $\mathrm{HCl}$ and $\mathrm{HNO}_{3}$ to reveal the macro-grain size. Photomacrographs ( $3 \mathrm{X}$ ) of this surface were then compared with standard $3 \mathrm{X}$ macro-grain size photomacrographs supplied by the FEDC. (2)* Although the assignment of grain size is a somewhat subjective matter, the deviation among different observers for the great majority of estimates is no more than $1 / 2$ grain size number.

\section{Effect of Composition}

It is recognized that no discussion of the effect of composition on grain size and shape is complete without a thorough knowledge of the prior delta condition ${ }^{* *}$ of the uranium under study. Since changes in composition may change the thermal treatment necessary to produce the "optimum"

delta condition delta condition ${ }^{* *}$, the criterion of identical prior heat treatments may not be a sufficient guarantee of equality of initial delta conditions.

grain size, unalloyed dingot and ingot

It is generally accepted that dingot, which usually con-

tains less impurities than ingot, will show coarser grain sizes than ingot. During this program, studies indicated that

* Four different sets (A-, B-, C- and D-), representing different sizes and cooling rates, are given. The grain size numbers increase with decreasing size.

** Delta condition refers to the distribution and particle size of the compounds formed between uranium and other elements present. By "optimum" is meant that delta condition that produces the finest alpha grain size after beta treatment. 
Grain Size and Shape

this assumption is not always reliable. It is true for some sizes and not for others. It is likely that the delta response differs somewhat between the two compositions, so that the final beta-treated grain size may be chiefly dependent, for example, upon the reduction and the temperature of fabrication.

The prior delta condition also appears to exert a marked effect on the occurrence of columnar grains. In instances where the prior condition was as-fabricated, several cases of pronounced columnar growth were observed at the cooling surfaces in beta treated ingot, but none were found in dingot. Although compositional differences seem to cause a somewhat decreased tendency to columnarization in dingot which experienced the same thermal gradients during beta quenching, it is not clear what part of the tendency is due to prior delta condition, which will be shown to have a considerable influence on columnarization.

\section{Effect of Prior Condition}

marked effect of delta treatment in ordinary dingot and ingot
Studies at Mallinckrodt have shown that dingot containing minor additions of iron and silicon can be heat treated (delta treated) to control grain size, ${ }^{(3)}$ by dissolving the delta compounds in beta uranium and by precipitating these compounds by heating at some suitable temperature in the alpha phase for several hours before a final beta treatment. Recent work in this NMI program has shown that delta treatment can cause a shift of about four FEDC (3X) grain size numbers in dingot ( $63 \mathrm{ppm} \mathrm{Fe}, 35 \mathrm{ppm} \mathrm{Si}$ ) and ingot ${ }^{(4)}$ (115 ppm Fe and $50 \mathrm{ppm} \mathrm{Si)} \mathrm{1.1-inch} \mathrm{diameter} \mathrm{rods} \mathrm{drastically} \mathrm{quenched} \mathrm{from}$ the beta phase after different prior delta treatments. For 
radial distribution of grain size example, a $645^{\circ} \mathrm{C} / 8$-hour anneal of as-fabricated ingot will produce very coarse (A-2 and A-3) FEDC grain sizes after a cold water quench from the beta (Fig. 3A) whereas the omission of the $645^{\circ} \mathrm{C}$ prior delta treatment will give much finer (A-5 to A-7) grain sizes in both compositions (Fig. 3B). An unsuccessful attempt was made to refine the grain size of beta-treated ingot from the as-fabricated condition by first beta treating (to dissolve delta), then reprecipitating delta for 8 hours at 525,425 or $325^{\circ} \mathrm{C}$ before a final beta treatment. The grain size due to the $425^{\circ} \mathrm{C}$ prior delta treatment gave the greatest refinement, approaching to within one or two FEDC numbers the grain size of the beta-treated sample, which had had an as-fabricated prior condition. It is understood that at NLO the rolling temperature of the ingot rod had been about $625^{\circ} \mathrm{C}\left(1155^{\circ}\right)$, and that this temperature was chosen as the temperature which would produce the finest grain size upon a final beta quench into water. Evidently the rolling conditions do not result in 'delta' times and temperatures too severe to achieve the best prior delta condition for the finest beta-treated grain size, even though our heat treatments indicated that $625^{\circ} \mathrm{C}$ would be too high. However, it would be expected that warm working during rolling could alter the precipitation rate and size of the delta particles. An interesting feature of the radial distribution of grain size throughout the crosssection of both the ingot and dingot bars was that the delta agglomerating treatment (without prior beta treatment) tended to produce much coarser grains after beta treatment at midradius than at either the OD or rod center (see Fig. 3-A). It is possible that at the OD the drastic cooling rate overwhelmed the effect of delta treatment, but that at mid-radius the effect of warm working (during fabrication) caused an 


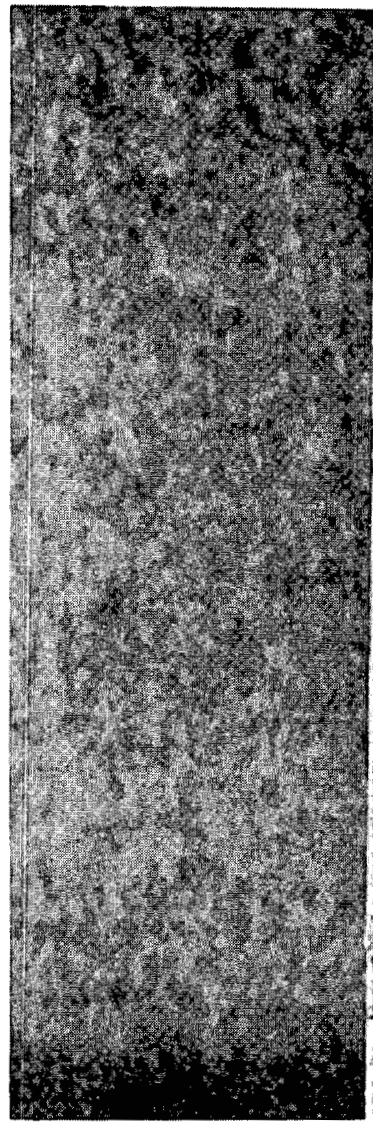

$3 \mathrm{X}$

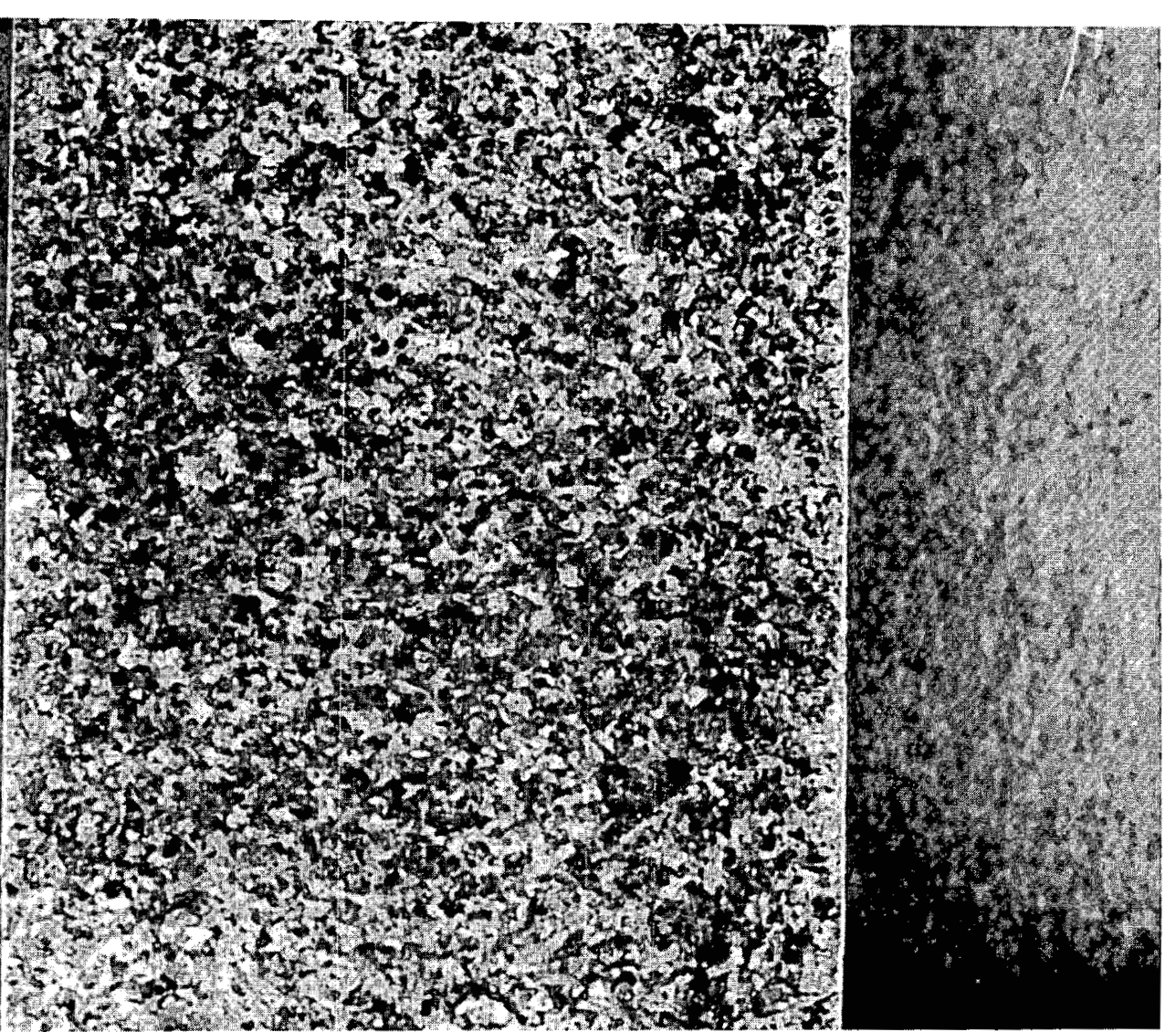

$\mathrm{RF}-8274$

Fig. 3A - Ful1 cross-section of 1.1-inch diameter by 4-inch long ingot rod (containing $115 \mathrm{ppm} \mathrm{Fe}$ and $50 \mathrm{ppm} \mathrm{Si}$ ) water quenched from the beta phase after a $645^{\circ} \mathrm{C}, 8$-hour delta agglomerating anneal of the as-fabricated condition $(\mathrm{K}-8)$.

Note: (1) mid-radius coarsening of grain size to about A-1.5, and (2) columnar grains at OD.

$*(\mathrm{~K}-8)$, and similar designations in the Figures to follow, refers to size code and sample number, e.g., size $\mathrm{K}$, sample number 8 . For interpretation of size code, see Table at inside back cover. 


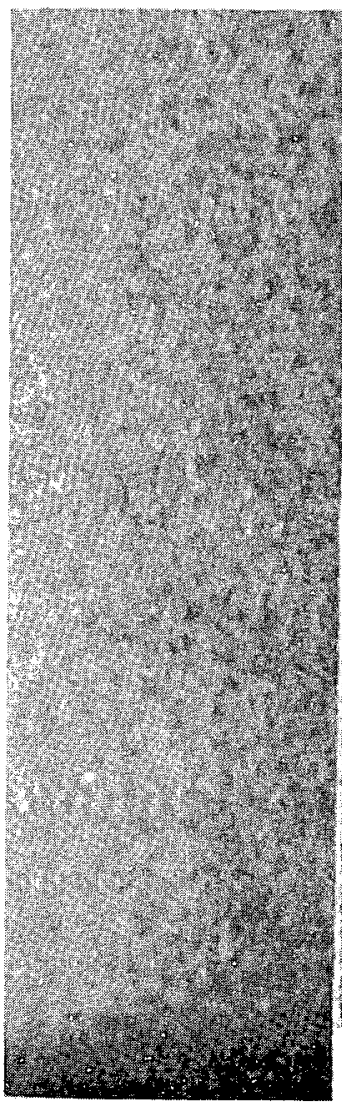

$3 \mathrm{X}$

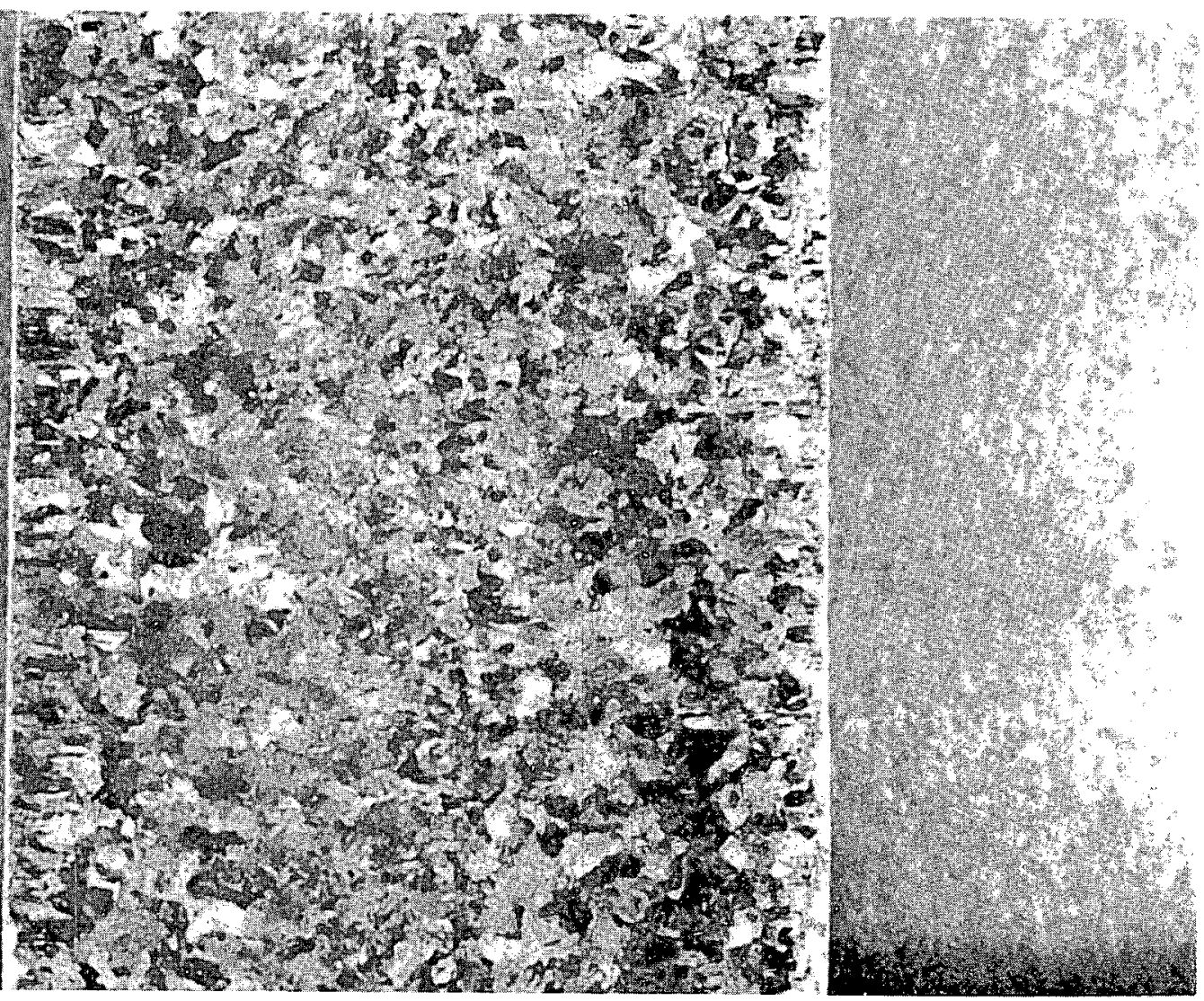

$\mathrm{RF}-8273$

Fig. 3B - Same as Fig. 3A, except without the $645^{\circ} \mathrm{C}$ prior anneal (K-7).

Note: (1) uniform grain size (A-6) throughout section, and (2) only shallow case of columnar grains at $O D$. 
acceleration in the delta agglomeration rate, and this, in turn, caused grain coarsening. In the center of the rod the degree of warm working would not have been so great; accordingly, it is possible that the delta agglomeration rate was less and the final beta-treated grain size finer.

With increased time and/or temperature of any prior delta agglomerization treatment, there is an increase in

columnar grains and delta treatment the extent of grain columnarization in ingot. The depth of columnarization after a beta quench increased by about five times (compare Fig. 3A with Fig, 3B) when an as-fabricated ingot rod was given a $645^{\circ} \mathrm{C} / 8$ hour prior annea 1 (4) No explanation can be offered for this effect, or for the fact that the dingot rod of the same dimensions and with the same heat treatment exhibited much less columnarization.

\section{Effect of Geometry}

In general, grain sizes were observed to be finer at the cooling surface of the sample and coarser with increasing distance from the surface. This was particularly true of the heavier samples, where the greatest variations in cooling rate occurred through the cross-section. With thinner sections, the grain size throughout the crosssections became more uniform. It was also abserved that, for a given quench medium, the samples with the smaller sections had generally finer over-all grain sizes. In most cases, the coarse.s grains were found at the center of rois and at the midwall position in tubes: The exceptions to this observation were the ingot and dingot rods that were delta treated prior to beta treatment, where the coarsest grain sizes were observed at the mid-radius position. 


\section{Effect of Heat Treatment}

grain size and shape rather insensitive to $\beta$ temp. and time

grain size very sensitive to cooling rate from $\beta$ phase
Grain size and shape appear to be relatively insensitive to variations in beta treatment time and temperature. A number of 1-inch diameter by 1/4-inch thick ingot discs were beta treated over a wide range of temperatures and times and quenched into room temperature oil. The betatreated discs were then polished to a depth of $1 / 16$ inch below the surface and the grain sizes determined. The results of this study are shown in Fig. 4, where beta temperature is plotted against time at temperature, and the grain size is given for the various heat treating conditions. A1though the cver-a11 change in grain size is smal1 throughout the ranges of time and temperature, some systematic variations in grain size may be noted. With decreasing beta temperature and increasing time at temperature there is a slight tendency towards coarsening of the grain size. This region of coarsening appears to be defined for beta-treating temperatures of $690^{\circ}$ to $735^{\circ} \mathrm{C}$ and for times of 10 to 64 minutes.

There is also a tendency for those samples lying within this region and having coarser grain sizes to exhibit more positive growth indices. This may be seen in Fig. 5 where growth index $\left(G_{3}\right)$ is plotted against beta temperature and the grain sizes are indicated next to the corresponding data. points.

Within the ranges of beta temperature and time studied, the conditions of beta treatment do not appear to influence grain size significantly.

Grain size and shape are extremely sensitive to the severity of quench after beta treatment. The grain size invariably decreases with increasing severity of quench for a given sample geometry, composition, and prior delta condition. 


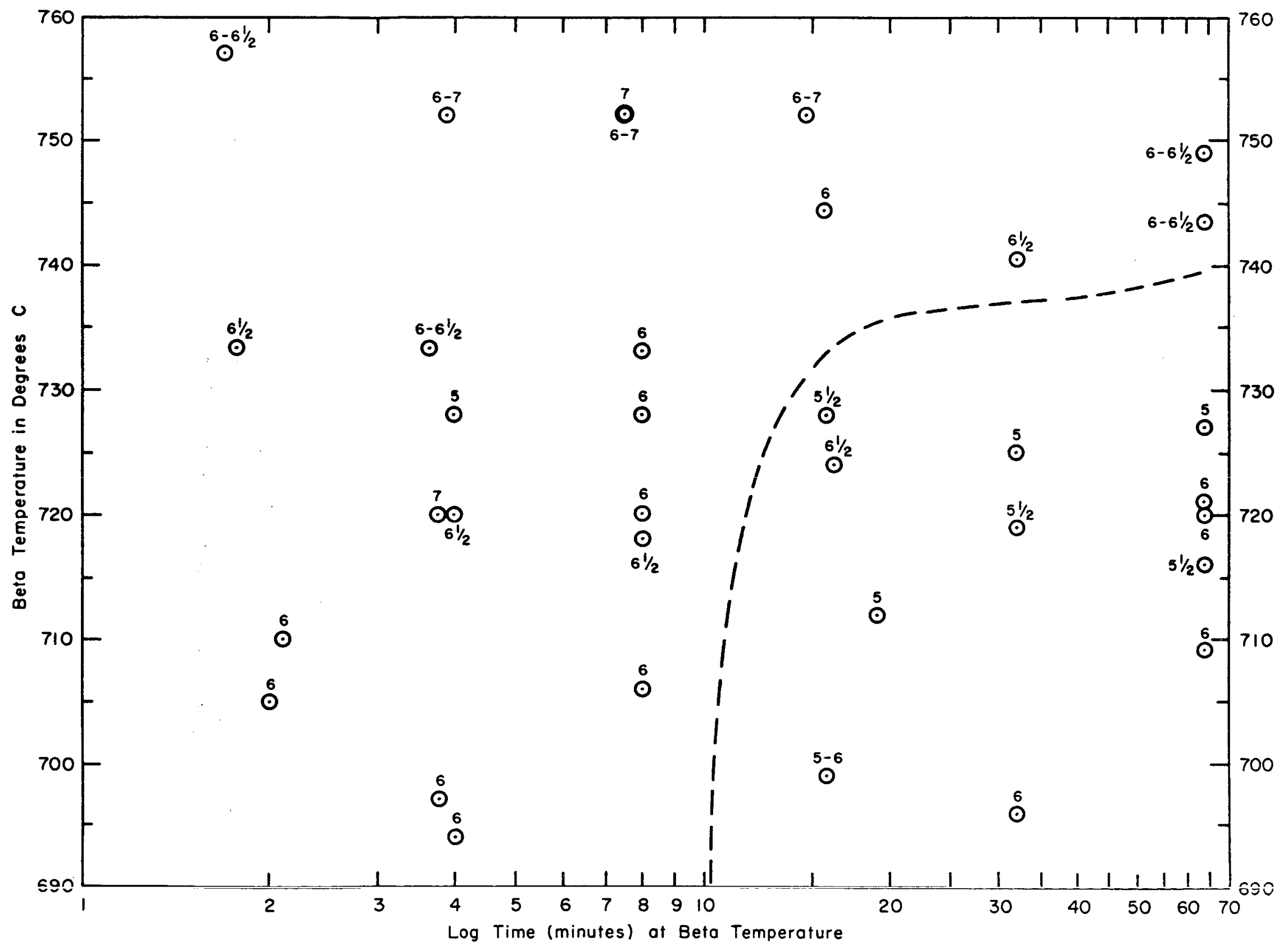

Fig. 4 - The effect of beta time and temperature on the FEDC grain size 1/16 inch below the surface in 1-inch diameter by $1 / 4-$ inch ingot discs quenched into $25^{\circ} \mathrm{C}$ Poco No. 2 Quenching Oil. Drawing No. RA-2139. 


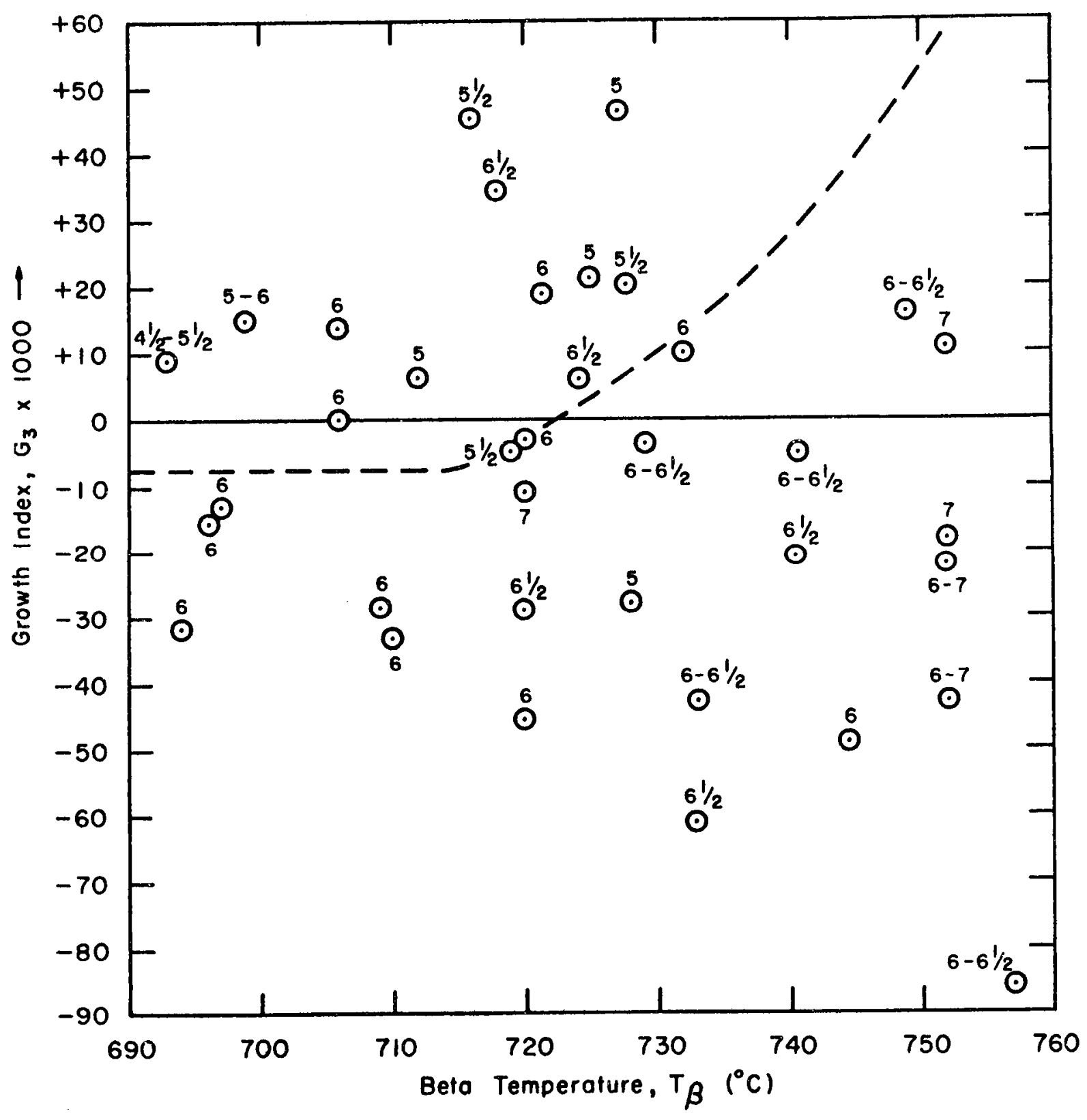

Fig. 5 - The relation between growth index $\left(G_{3}\right)$ and FEDC grain size of the ingot discs (represented in Fig. 4) for different beta temperatures. Drawing No. RA-2138 
Air cooling always yielded a coarse grain size, varying from FEDC A-1 to A-3. Even in the thinnest section (2:0-inch OD by 0.1 -inch wall tubing), where al1 other quenching media yielded extremely fine grain sizes, the air-cooled sample had a grain size of only $\mathrm{A}-3$ 1/2. In some instances, an extremely thin she11 of fine grains (about A-5) was observed after air cooling, but this shell was very small compared with the bulk of the sample. No columnar grains were observed after air cooling.

In a few cases, columnar grains in ingot were observed after oil quenching of samples having large cross-sections. Genera1ly, however, columnarization was absent after oil quenching.

Oil quenches resulted in a very uniform intermediate grain size (A-4 to A-5) throughout the cross-section. The exceptions to this observation were the 2 a-inch oD by 0.1 -inch wall ingot tube, which exhibited a uniform fine grain size of A-7, and the extremely heavy sections (1,8-inch diameter ingot and dingot rods [sizes $\mathrm{C}$ and $\mathrm{DC}$ ] and 4.0-inch $\mathrm{OD}$ by 0.5 -inch wal1 ingot tube [size E]), where the grain sizes in the interior were quite coarse (A-2 to $A-3)$.

Further confirmation that the grain size is largely established (other parameters being equal) by the rate of cooling through the transformation was obtained by examination of the results of air delays before oil quenching of 1.8-inch diameter ingot $\mathrm{r}$ od and 1,5-inch oD by 0.5 -inch wal1 ingot tubing. An air delay to the beginning of the beta-alpha transformation followed by a room temperature Poco No: 2 oil quench gave a grain size virtually the same as that obtained by a direct quench into this oil. An air delay to the end of transformation, then an oil quench, resulted in a grain size the same as that achieved by a direct air cool to room temperature. 
slight refinement of $\beta$ quenched grain by $600^{\circ} \mathrm{C}$ annea 1 distortion related to change of texture
Water- and brine-quenched samples generally exhibit a uniform fine grain size of A-5 to A-7. A few of the heavier sections exhibit interior grain sizes as coarse as A-3 after water quenching, presumably because of the greatly decreased cooling rates in the interior of these samples. Columnar grains were observed to varying degrees in about half the water-quenched samples, the differences in response being probably due to variations in prior delta condition.

The effect of a post-beta anneal ( 1 hour at $600^{\circ} \mathrm{C}$ ) on the grain size of both dingot and ingot quenched in oil and waterwas found to be slight. The usual result was a small (slightly more than one grain size number) over-all decrease in grain size accompanied by a slight decrease in, but not elimination of, the amount of columnar grains in those rods. where columnarization was evident.

5. Effect of Applied Stress During and After Heat Treatment

Several studies have been made on the effect of applied stress during and after slow cooling of samples from the beta phase. However, the macrograin size is essentially unaffected by applied stress (either bending or tensile straining) in the alpha-plus-beta or alpha phases.

\section{Distortion}

Permanent dimensional changes occur during beta treatment of nearly all cold-, warm-, or hot-fabricated rods and tubes. Analysis strongly indicates that the major causes of the direction and degree of distortion are texture and stress changes caused by beta treatment and the associated cooling rate. Nearly all the radial distortion observed in rods and tubes is distributed lengthwise in a "U"-shaped curve, such as is shown for a cold-water quenched ingot tube $(1.5$-inch OD by 0.5 -inch ID by 4.0 inches long $[\mathrm{H}-5]$ ) in Fig. 6. The bulk of the tube length (the 3 -inch middle section) has contracted radially (except for the end effect) and there has been an expansion in length. 

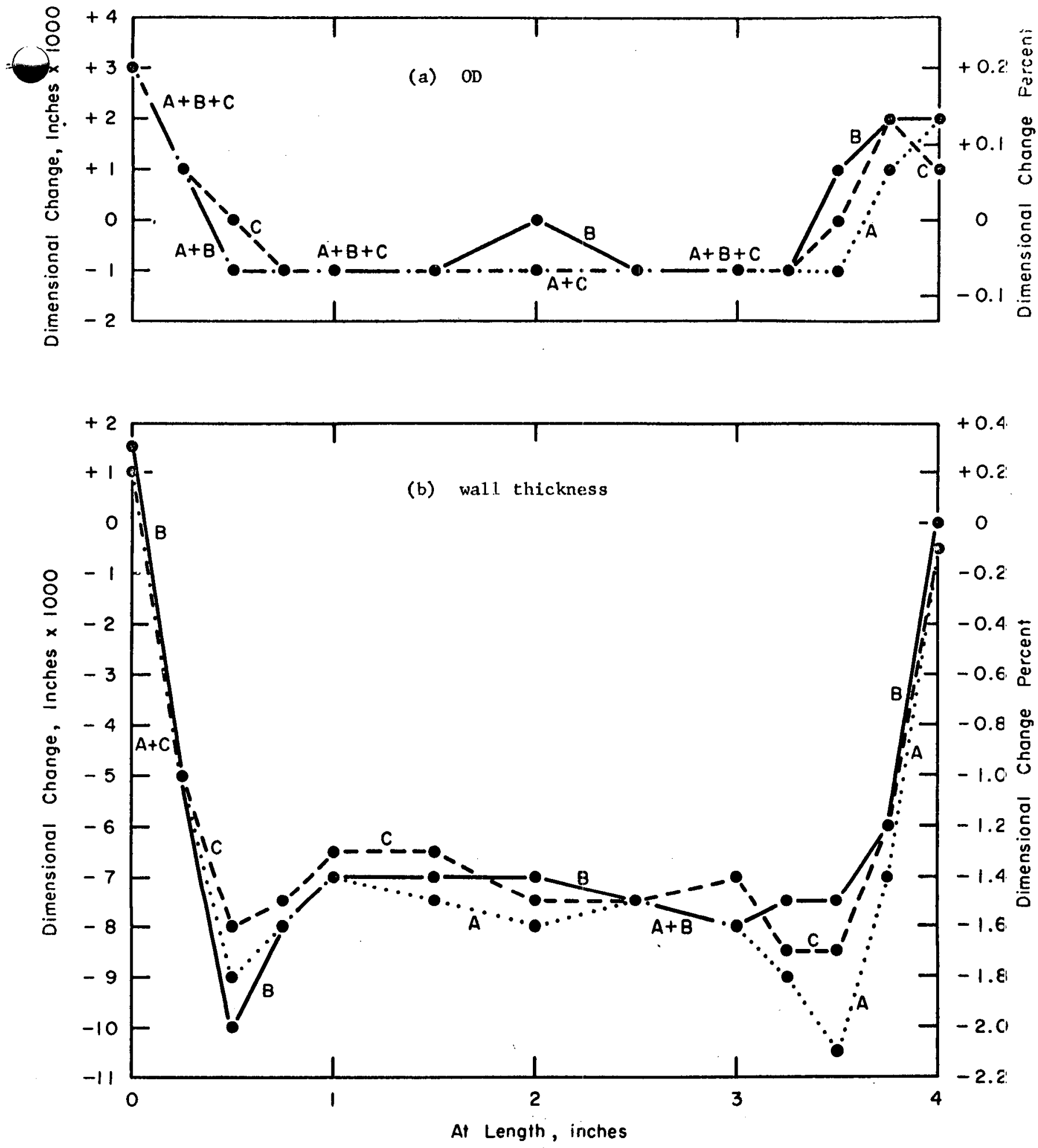

Fig. 6 - Dimensional changes in ob and wail thickness with length in a 1.5inch $O D$ by $0.5-$ inch ID by 4.0-inch long ingot tube quenched from the beta phase into $12^{\circ} \mathrm{C}$ water (H-5). Drawing No: RA-2232

Note: Length changes: $+0.24 /+0.029$ inch $(+0.60 /+0.73 \%)$. 
Distortion

1. Effect of Texture Changes on Distortion in Rods

It is found that the axial $G_{3}$ 's of a series of as-fabricated rods can be correlated with their subsequent length changes on beta treatment. For example, in the following group, for the same cooling medium, a decrease of prior axial $G_{3}$ is associated with an increasing length change:

\begin{tabular}{|c|c|c|c|c|c|c|c|}
\hline \multirow[b]{2}{*}{ Type } & \multirow[b]{2}{*}{$\begin{array}{c}\text { Fabrication and } \\
\text { Size Code }\end{array}$} & \multirow[b]{2}{*}{$\begin{array}{l}\text { Axial } \\
\text { Texture }\end{array}$} & \multirow[b]{2}{*}{$\begin{array}{c}\text { Axial } \\
\mathrm{G}_{3} \\
\end{array}$} & \multicolumn{4}{|c|}{$\begin{array}{c}\text { Percent Change in Length for } \\
\text { Various Cooling Media }\end{array}$} \\
\hline & & & & Air & $\begin{array}{l}25^{\circ} \text { Poco } \\
\text { No. } 2 \text { Oi } 1\end{array}$ & $\begin{array}{l}55^{\circ} \mathrm{C} \\
\text { Water }\end{array}$ & $\begin{array}{l}13^{\circ} \mathrm{C} \\
\text { Water }\end{array}$ \\
\hline Ingot & Cold-swaged (Q) & 010 & +0.50 & -2.00 & -1.07 & -0.98 & -0.90 \\
\hline Ingot & Warm-rolled (K) & $\begin{array}{c}100-010 \\
\text { (balanced) }\end{array}$ & +0.03 & -0.35 & -0.45 & -0.05 & -0.06 \\
\hline Ingot & $\begin{array}{l}\text { Very hot- }(S) \\
\text { extruded } \\
\text { (pressure- } \\
\text { transformed) }\end{array}$ & $\begin{array}{l}\text { quasi - } \\
\text { random }\end{array}$ & $\approx 0^{*}$ & +0.05 & +0.08 & +0.03 & +0.03 \\
\hline Ingot & Hot-extruded (C) & 110 & -0.32 & +0.20 & +0.43 & +0.62 & +0.64 \\
\hline pingot & Hot-extruded (DC) & 110 & -0.33 & +0.47 & +0.40 & +0.55 & +0.55 \\
\hline
\end{tabular}

$*_{G_{3}}$ unreliable owing to very coarse grain size.

A qualitative explanation of these length changes may be seen by examining Fig. 7 and by consideration of thermal expansions associated with the two as-fabricated texture extremes (rods

axia1 contraction of cold swaged rod
$Q$ and $C$ or $D C$ ). Cold swaged rod $Q$ had a strong 010 axial texture (upper diagram). The 010 pole (or b crystallographic direction) contracts on heating to the alpha-beta transformation temperature, but after transformation the axial texture is found 

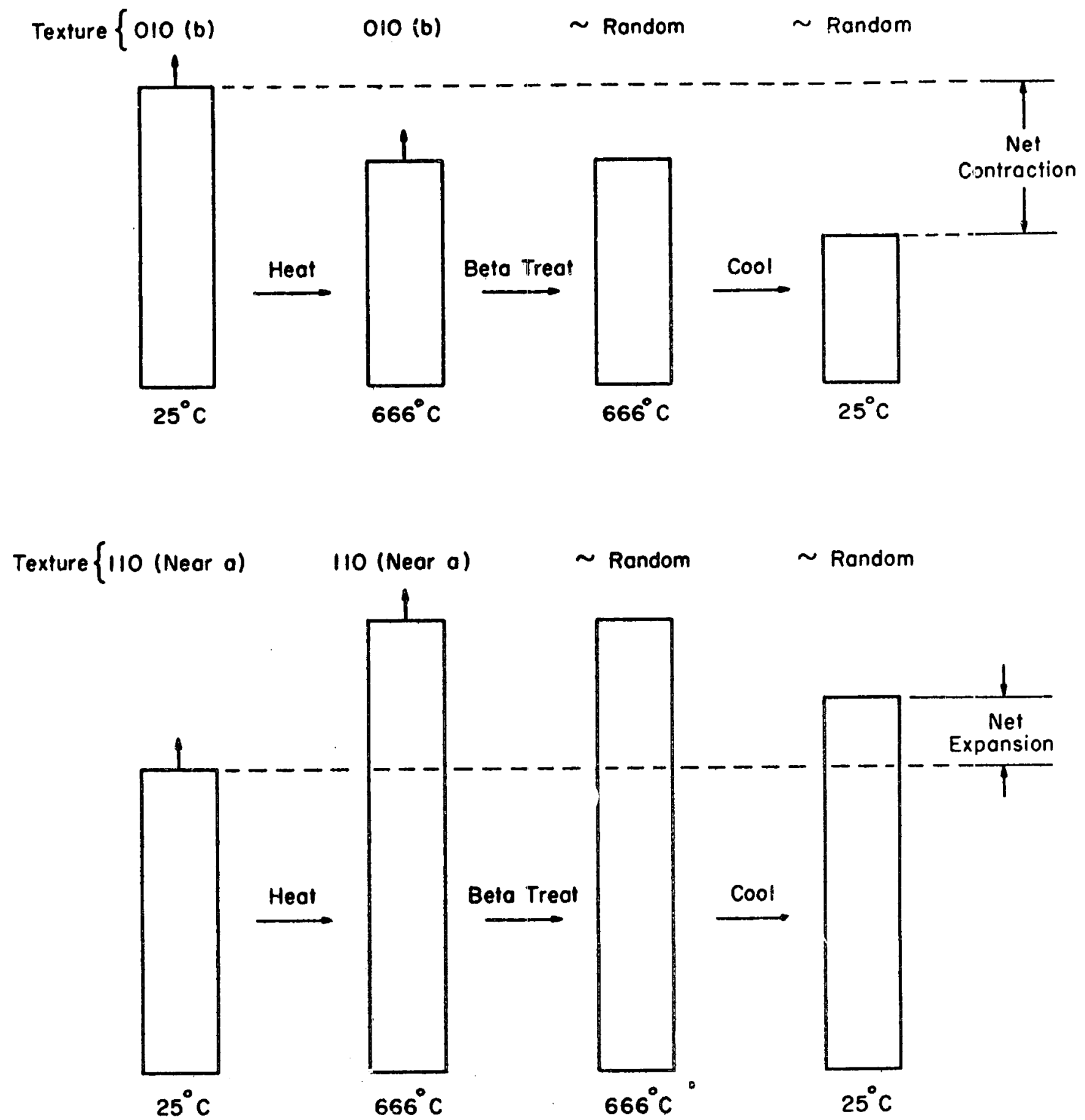

Fig. 7 - Schematic of length changes resulting from beta treatments of an 010 axial texture (cold-swaged rod) and a 110 axial texture (hot-extruded rod) Drawing No. RA-2204 
axial expansion of hot extruded rod

radial distortion in rods

relation between distortion and prior axial $\mathrm{G}_{3}$ in rods to be quasi-random. A random texture will contract on cooling to room temperature. The result of two net contractions in the alpha phase will of course mean a net contraction after beta treatment. Rod $Q$ showed a 0.9 to 2.0 percent contraction in length for a range of cooling rates.

Hot-extruded rods $\mathrm{C}$ and $\mathrm{DC}$ have a strong 110 axial texture (lower diagram). This texture will expand strongly on heating to the alpha-beta transformation. After transformation the axial texture becomes quasi-random, as does the 010, but, on cooling to room temperature, will contract less strongly than the original texture expanded on heating, so that there will be a net expansion in length. Rods C and DC showed 0.20 to 0.64 percent length increases. There seems to be little difference in distortion between ingot (C) and dingot (DC) rods. Fina1ly, an original random texture (e.g. beta-treated rod) should experience the least length change in beta treatment. Rod S showed only 0.03 to 0.08 percent length increase.

The same correlative tendencies can be shown for diameter changes. The usual as-fabricated radial texture is near the 151 pole, which has a weak positive coefficient of thermal expansion (about 10 percent of that for the 110 pole). Consequently, a very small radial expansion on heating to the alpha-beta transformation, followed by a relatively large radial contraction on cooling after transformation, will cause a net radial contraction (similar to the axial contraction shown by rod Q). Dingot rod $\mathrm{C}$, origina $11 \mathrm{y}$ having a 151 radial texture, contracted 0.05 to 0.35 percent in diameter in a 11 the different cooling media.

The relation between percent length and diameter changes $(\triangle \mathrm{L}, \Delta \mathrm{D})$ and the original axial $\mathrm{G}_{3}$ is shown in Fig. 8 for air, oil and water quenches. Approximate linear relations for these ingot rods are shown by the two straight lines which have the equations: 


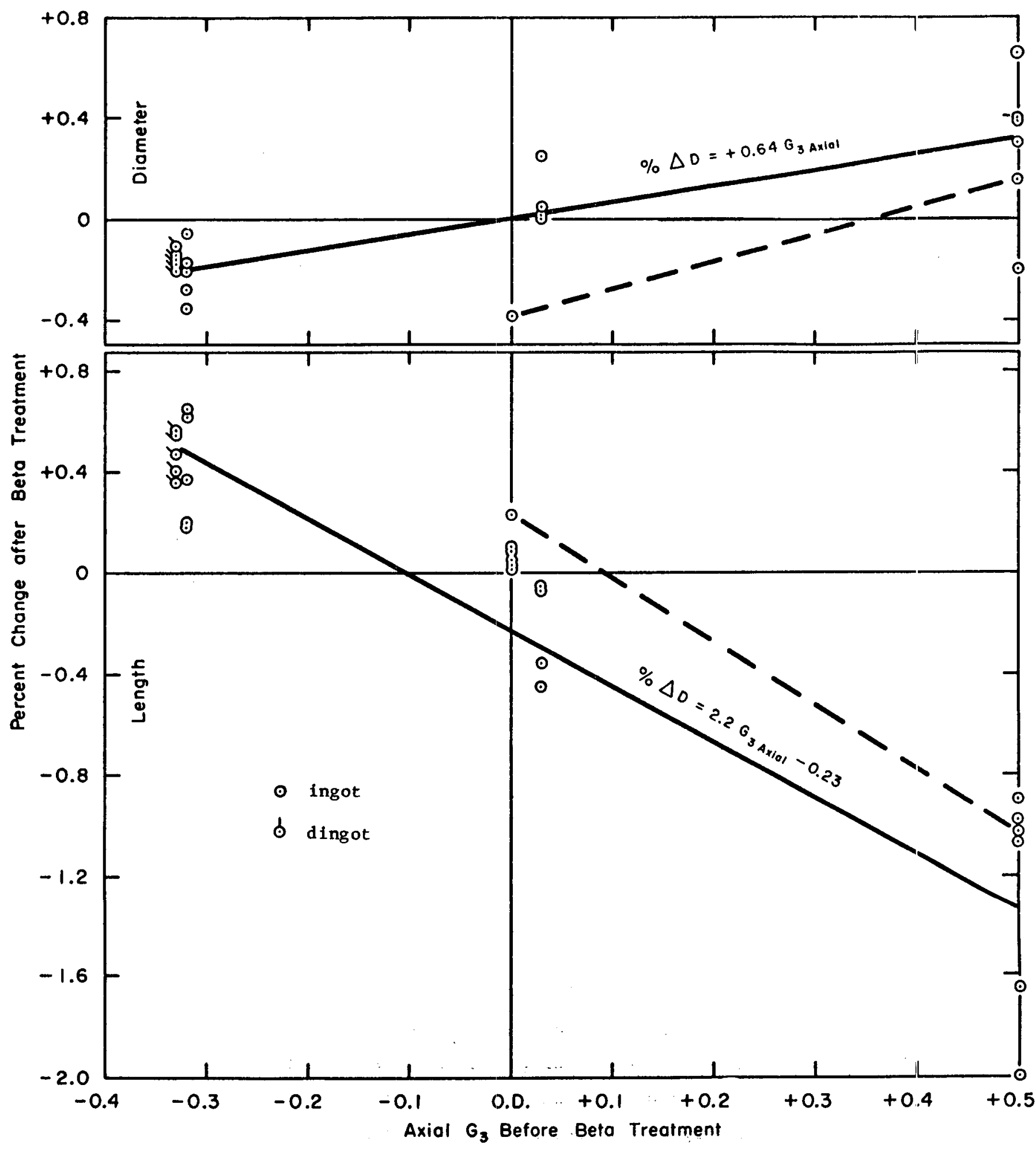

Fig. 8 - Relation between prior axial $G_{3}$ and dimensional changes caused by beta treatment of rods. Drawing No. $R A-2404$ 


$$
\begin{aligned}
& \% \triangle L=-2.2 G_{3 A x}-0.23 \\
& \% \triangle D=+0.64 G_{3 A x}
\end{aligned}
$$

It is believed that dingot rods should show the same distortion properties, but insufficient data are available to plot the relationship.

In order to demonstrate the striking dependence of beta-treatment distortion on prior texture, a 6.000-inch long by 0.540 -inch diameter section of rod $Q$ (having the strong 010 axial texture) was beta treated and quenched in room temperature Poco No. 2 oil. The section was found to have contracted 1.03 percent in length and expanded 0.15 percent in diameter. The length was machined to 5.757-inch long by 0.504 -inch diameter, beta treated and quenched in cold water. After this second heat treatment the length expanded 0.23 percent and the diameter contracted 0.38 percent. The results for the two heat treatments are connected by a dashed line approximately parallel to the solid line representing the general distortion $-G_{3}$ relation given in Fig. 8.

\section{Relative Effect of Severity of Cooling on Distortion}

distortion in reds and cooling rate
The group of rods described above shows an interesting effect of different cooling media. Except for the rod having a quasi-random original texture, the effect of increasing the cooling rate was to increase the tendency of the rods to lengthen or to decrease the tendency to shorten. If the amount of distortion were due exclusively to the difference in texture before and after beta treatment, the oil-quenched rod should be an exception to this tendency, since it will be shown [see p.53] that oil-quenched ingot rod contains considerably less induced texture than air-cooled or water-quenched ingot rods. It is therefore probable that the stress distribution 
differences among the rods cooled in different media but having the same prior texture have accounted for the differences in distortion.

\section{Effect of Texture Changes on Distortion in Tubes}

distortion in tubes
In tubes, the case is much more complex. Although the length changes in air-cooled tubes can be correlated with prior axial $G_{3}$ (as in the case of rods), the length change- $G_{3}$ correlations in the oil- and waterquenched tubes are very poor. The relation between OD wall thickness changes and texture is very obscure and requires further analysis.

Radial distortion in air-cooled tubes showed much less end-swelling than in oil- or water-quenched tubes.

Axial distortion (length changes) increased in the order: oil quench, air coo $1,55^{\circ} \mathrm{C}$ water quench, $12^{\circ} \mathrm{C}$ water quench .

If tube distortion were due exclusively to texture changes by beta treatment, it would be expected that the percent change in wall thickness would be proportional to the integrated net texture $\pi_{r}$, but no such relation was discovered. Evidently the effect of different stresses, undoubtedly caused by different cooling rates, is even more important in tube distortion than in rod distortion.

\section{Texture and Growth Index $\left(G_{3}\right)$}

\section{Growth Index}

The preferred orientation (or texture) of crystallites of a metal may influence strongly the properties of the meta1. One of the properties of uranium that is very sensitive to texture is growth under neutron irradiation. This growth can be predicted by the growth index, which is determined 
by an x-ray diffraction analysis of the texture. The value of the growth index is based on the fact that an alpha uranium single crystal under neutron irradiation shrinks in the [100] or a crystallographic direction, expands approximately an equal amount in the [010] or $\underline{b}$ direction, but remains dimensionally stable in the [001] or $\subseteq$ direction. In calculating the growth index of polycrystalline uranium, the a component of the texture is given a weight of -1 , the $\underline{b}$ component a weight of +1 and the $\underline{c}$ component, 0 , so that the value of the index may vary between -1 and +1 . A negative index indicates that the uranium will shrink in the direction for which the index is given, a positive value indicates growth in this direction, and a value of zero predicts dimensional stability. In practice, the amount by which the growth index may depart from zero in any direction is dictated by the reactor requirements, but the aim, of course, is to assure that significant anisotropic irradiation growth of the reactor fuel is avoided.

Two indices, $G_{2}$ (Sturcken)* and $G_{3}$ (Morris), are presently being used in predicting irradiation growth behavior. $\mathrm{G}_{3}{ }^{* * *}$, which is employed in these studies, can be calculated on a desk calculator, but computation of $G_{2}$ requires the aid of a high-speed computer.

\section{Texture and Thermal Gradient}

Earlier work at MCW had shown, by a study of end-quenched Jominy bars, that a considerable growth index gradient occurs near the quenched end of the bar. (5) NMI studies have confirmed this. In both dingot and ingot uranium, * See ref. 3, Appendix B. **For a definition of $G_{3}$, see Appendix $B, p, B-5$. 
Texture and Growth Index

induced texture and therma 1 gradient
$100,10 \ell, 001$ series and gradient severe texture gradients have been found paralle1 to any thermal gradients that had formed during the cooling from the beta phase over a wide range of cooling rates (about $800^{\circ} \mathrm{C} /$ second to $1^{\circ} \mathrm{C} / \mathrm{sec}$ ond). These textures appear to be independent of the prior fabrication texture, and are always related to the direction of the thermal gradients. The thermal gradient texture is oriented in such a way that the preponderance of individual crystals would, if placed in a reactor, shrink in the direction of the prior therma 1 gradient and grow at right angles to this direction. The characteristic surface texture in the direction of the prior thermal gradient is shown for the case of a drastically quenched tube in Fig. 9. This has a typically strong 100 pole density (or strong a axis concentration) which causes a large negative $G_{3}(-0.51)$. As the prior thermal gradient decreased to zero, the monoplex 100 texture degenerates through the series $100,10 l, 001,0 \mathrm{k} l$, to quasi-random. At the center of a rod or at the midwall of a tube, where the thermal gradients tend to vanish, the texture is essentially random, so that the $G_{3}$ tends to approach zero. Figure 10 illustrates the realtive absence of texture $\left(G_{3}=\right.$ -0.02) at the midwall of the same tube whose surface texture was shown in Fig. 9.

\section{Sensitivity of Radial $\mathrm{G}_{3}$}

It was established at both $\mathrm{NMI}^{(6)}$ and $\mathrm{NLO}^{(7)}$ that the radial variation of $G_{3}$ in the radial direction, i.e. parallel to the prior thermal gradients, of both tubes and rods, is considerably greater than the radial variation of either the axial or tangential $\mathrm{G}_{3}$ 's.

\section{Relation Between $\mathrm{G}_{3}$ and Grain Size}

The realtion between grain size and $G_{3}$ parallel to the thermal gradient has been examined in the case of 1 -inch 


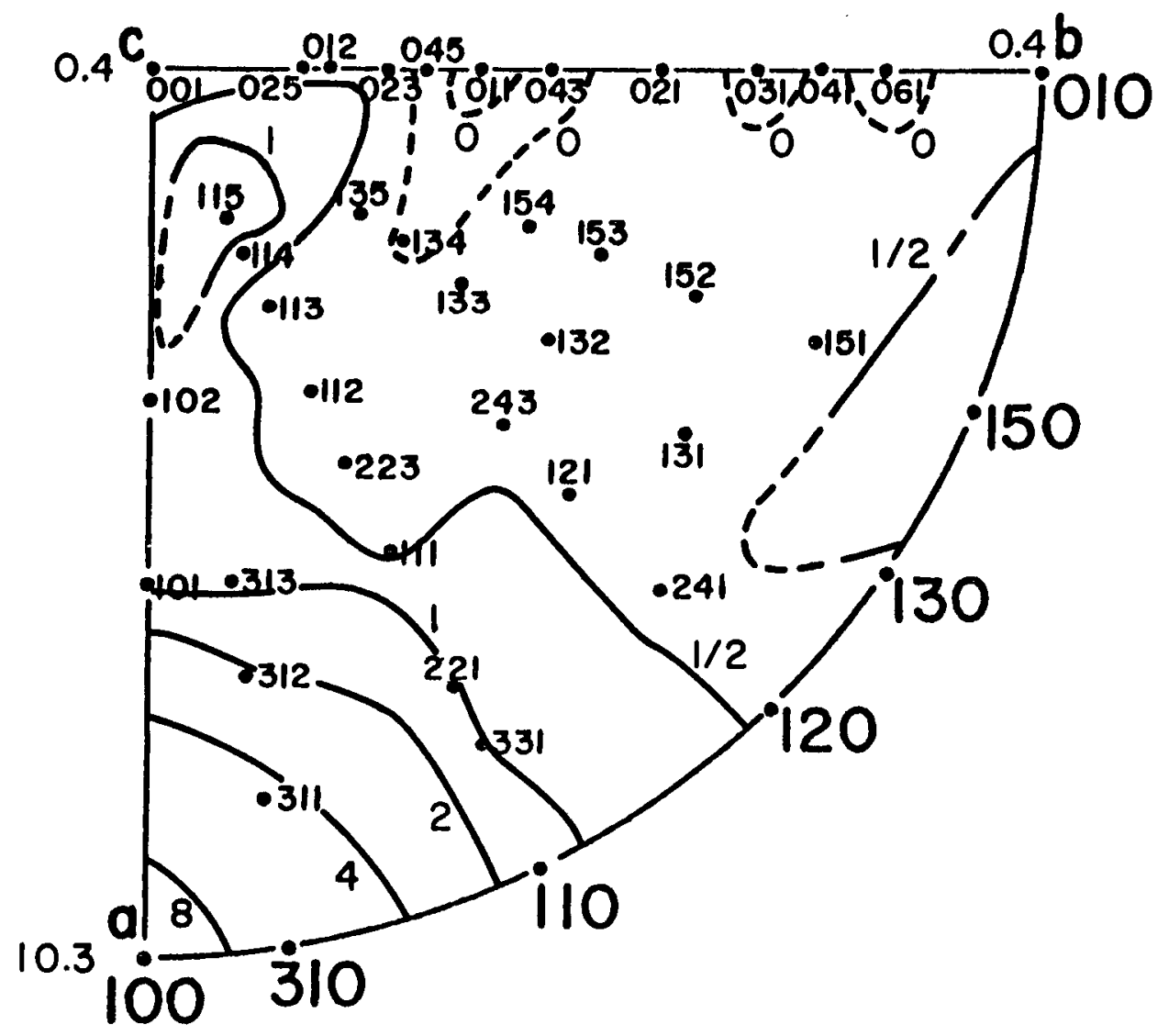

Fig. 9 - Crystallographic (inverse) cadial pole figure at ID surface of 4-inch oD by 3 -inch ID by 4-inch long ingot tube $(E-4)$ quenched from the beta phase into $55^{\circ} \mathrm{C}$ water. Note stron: 100 pole density. Drawing No. RA-2115

$$
G_{3}=-0.51
$$




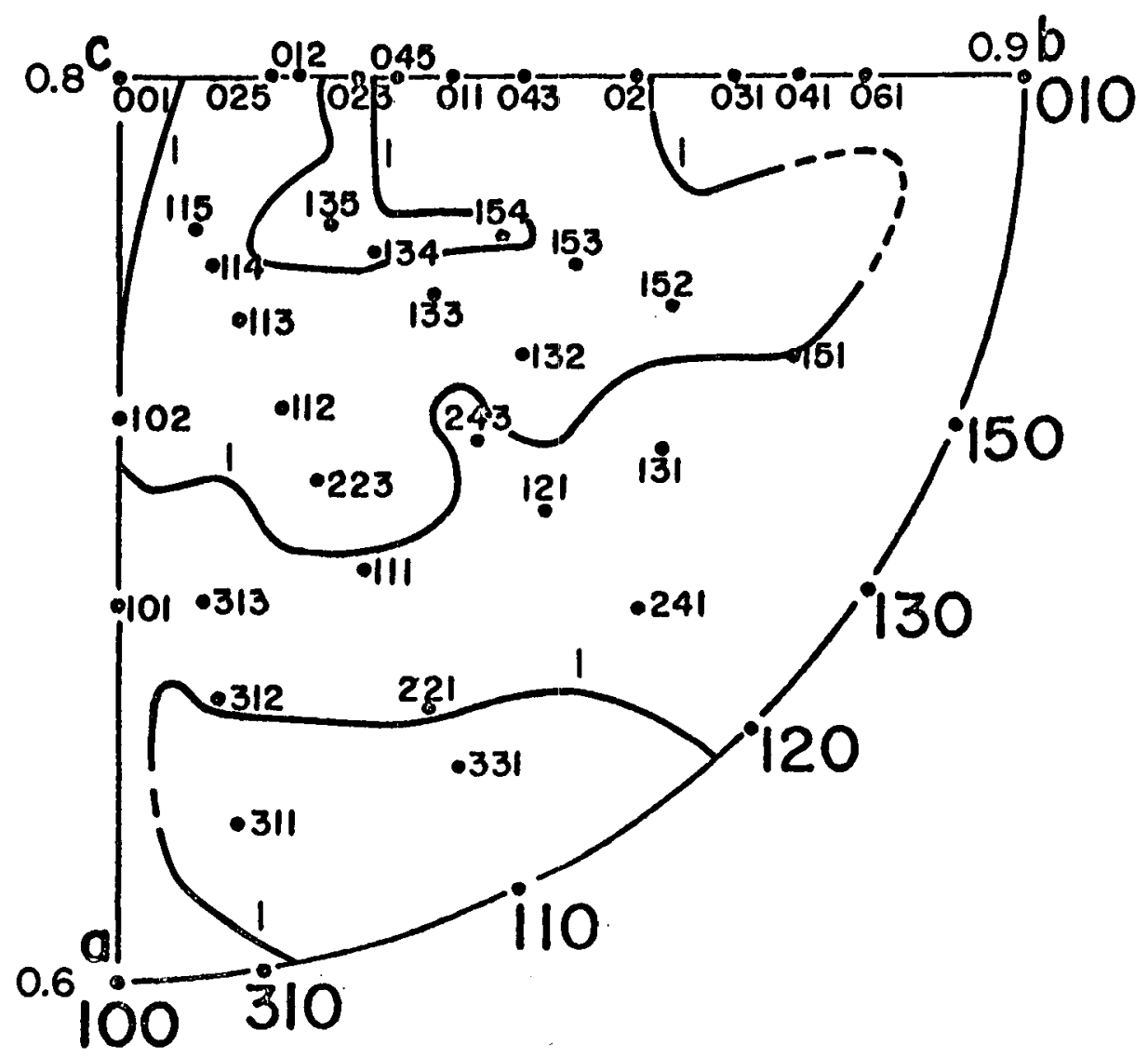

Fig. 10 - Same as Fig. 9, but at midwa11 (0.247 inch below OD). Note:almost complete absence of texture. Drawing No. RA-2114.

$$
G_{3}=-0.02
$$


slight increase in $\mathrm{G}_{3}$ with coarser grains inverted $U$ shape of radial $\mathrm{G}_{3}$ depth curve dianeter by $1 / 4-i n c h$ thick ingot discs which were quenched from the beta phase into room-temperature mineral oil, (8) as well as for 1.1-inch diameter ingot bars to different delta conditions before being beta treated and water quenched to room temperature. (9) In both cases, there seems to be a slight increase in $G_{3}$ with an increase in grain size, to the extent of about $0.01 \mathrm{G}_{3}$ per decrease in FEDC grain size number. Figure 5 has illustrated this for discs. Figures 1 la and $11 \mathrm{~b}$ show the more positive radial $G_{3}$ distribution associated with coarser grains in the ingot and dingot bars previously heat treated for a greater delta precipitate agglomeration. How ever, it should be emphasized that the slight increase in $\mathrm{G}_{3}$ with coarser grains is restricted to cases in which the cooling rate from the beta phase was the constant and where the grain size change was caused by some variable other than cooling rate. In a 11 other cases where the cooling rate varied substantially, the grain size and $G_{3}$ are not simply related. (For example, coarse grains formed by slow air cooling and fine grains formed by rapid water quenching usually exhibit large negative radia $1 G_{3}$ penetration, although moderately fine grains formed at intermediate cooling rates usually show a much sha1lower $G_{3}$ penetration. [see Fig. 12])

Grain columnarization, often found on the OD after some of the more rapid quenches, and particularly enhanced after prior delta agglomerizing treatments, ${ }^{(5)}$ is not a good indication of the severity of radial texture penetration, since, when columnarization is absent at the $O D$, severe texture penetration may have occurred.

\section{Distribution of Radia1 $G_{3}$, Radia1 Merit, Integrated Radia1 Texture}

A plot of radial $G_{3}$ vs. radial depth from the OD of a beta-treated rod or tube shows the characteristic invertèd " $U$ " shape. Minimum radial $G_{3}$ values (large negative) 


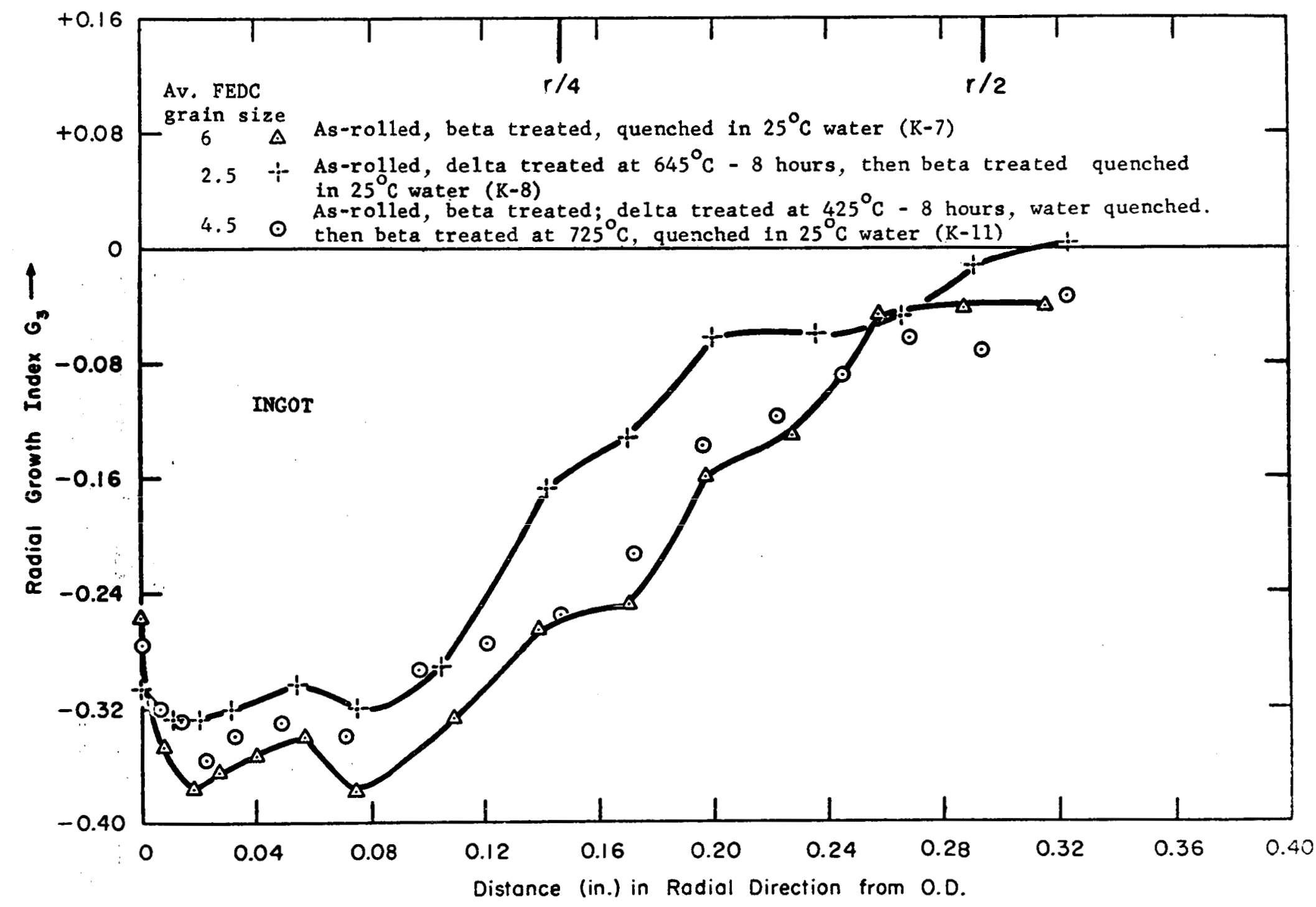

Eig. 11A - Radial distribution of radial $G_{3}$ in $20^{\circ}$ sector from the center two inches of 1.1-inch diamerer by 4-inch long ingot rod (size $K$ ), as affected by different delta treatments before final beta treatment and quenching in room temperature water. Drawing No. RA-2308 


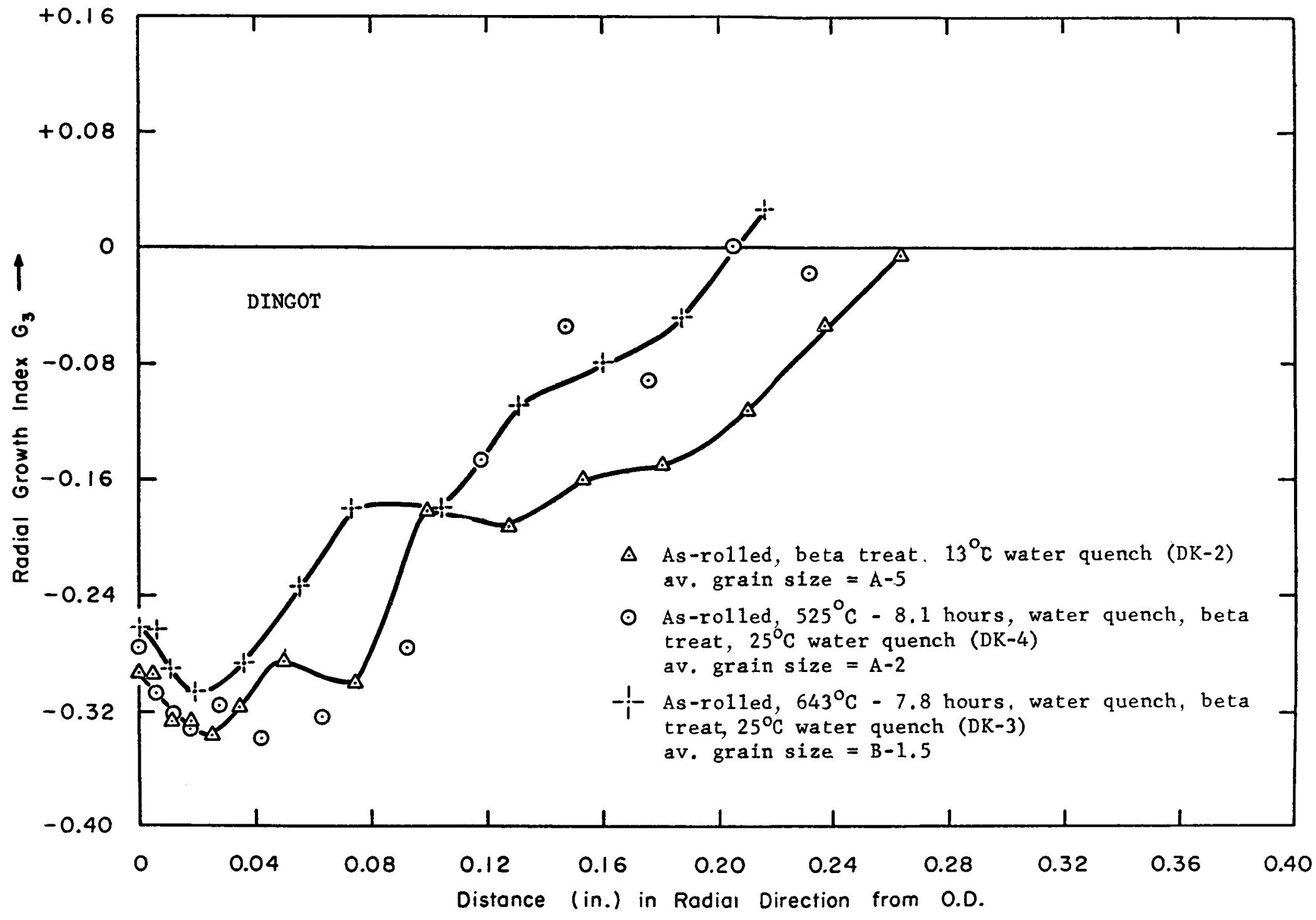

Fig. 11B - Same as Fig. 1la, except dingot rod. Drawing No. RA-2420 


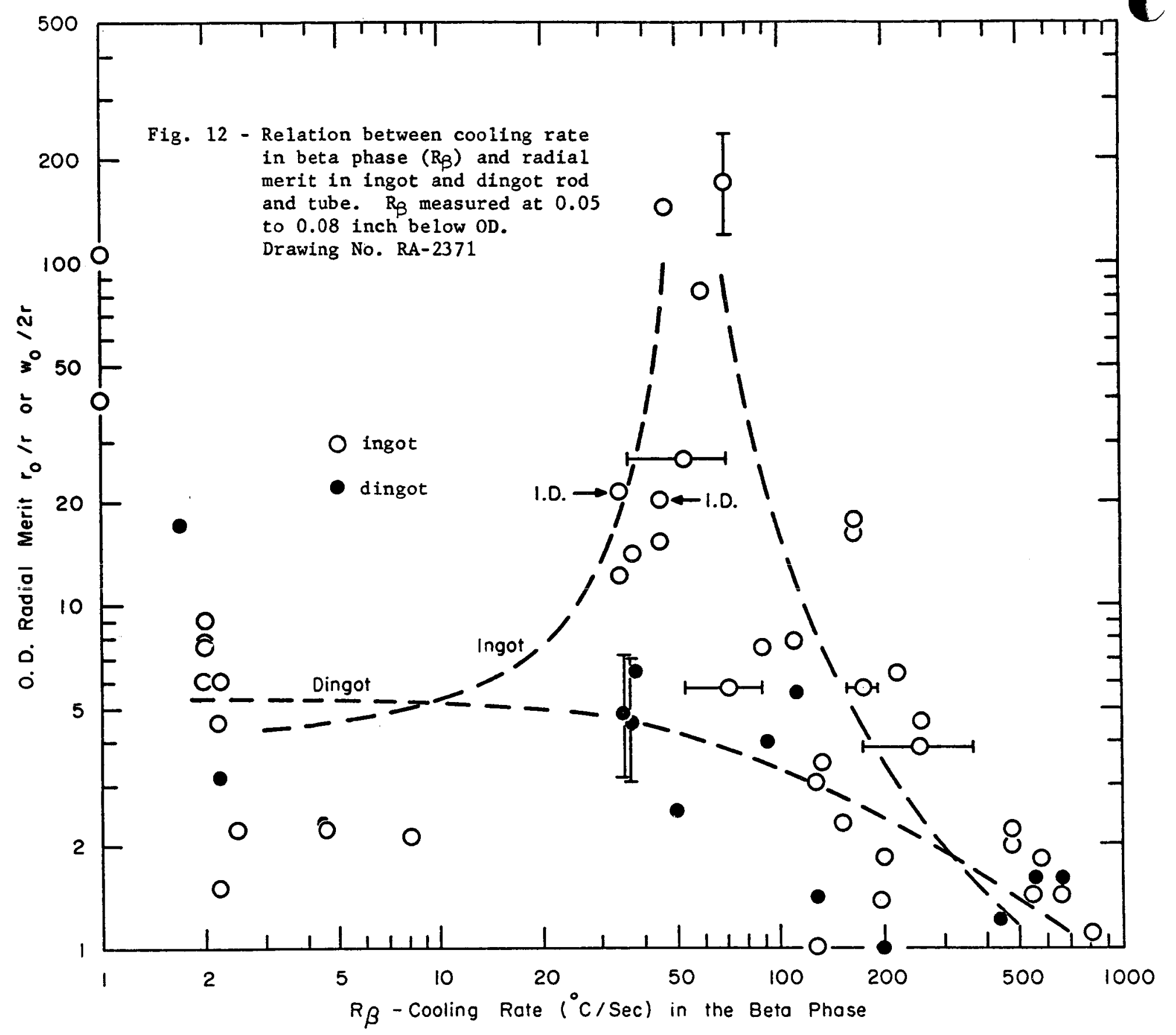


radial merit $r_{0} / r$ or $w_{0} / 2 r$

integrated net radia 1 texture $\mathrm{II}_{\mathrm{r}}$ generally occur at the OD-ID surfaces, with maximum values (near zero) at center or midwall. A number of radial $G_{3}$ distribution curves for a variety of dingot and ingot rod and tube sizes for a number of beta treatments are given in the Appendix, Figs. A-1 to A-12. The data were normalized so that radial $G_{3}$ distribution could be plotted over a range of sizes for the same cooling medium. These normalized curves are given in the Appendix, Figs. A-13 to A-23.

Certain parameters derived from the distribution of radial $G_{3}$ are useful in additional characterizations of the induced textures in beta treated uranium. The penetration of radial texture in a rod or tube can be quantitatively described by a new parameter, the radial merit, or the ratio $r_{0} / r$ (rods) or $w_{0} / 2 r$ (tubes) where $r$ is the radial depth where radial $G_{3}$ has increased to -0.10 , and $r_{0}$ or $w_{0}$ is the rod radius or tube wall thickness, respectively. A large radial merit, therefore, represents a relatively shallow radial texture penetration. The concept of radial merit does not satisfy the question of how much radial texture is actually introduced into the tube wall thickness by cooling from the beta phase. It was decided to express the total or integrated relative radial texture by another parameter which can be derived from a normalized plot of radial $G_{3}$ vs. $\left(2 \mathrm{r} / \mathrm{w}_{\mathrm{o}}\right)$. In such a plot all radial $\mathrm{G}_{3}$ distributions of different tube sizes can be compared for the same cooling medium by taking the integrated net radial texture, $\Pi_{r}$ as

$$
\int_{0}^{W} G_{3}\left(2 r / w_{0}\right) d r .
$$

Values of $\Pi_{r}$ are obtained by measuring the area between the normalized $G_{3}$ vs. $\left(2 \mathrm{r} / \mathrm{w}_{0}\right)$ curves and $\mathrm{G}_{3}=0$ and expressing this area as arbitrary units of positive or negative values. 
integrated absolute radial texture $\left|I_{r}\right|$
Often it may be helpful. to know simply the total induced texture, but without regard to sign. Instead of the integrated net texture, we may consider the integrated absolute radial texture, $\left|I_{r}\right|$, which is obtained the same as $\Pi_{r}$ except by adding areas arithmetically, not algebraically:

$$
\left|I_{\mathrm{r}}\right|=\int_{0}^{\mathrm{w}} \mathrm{G}_{3}\left(2 \mathrm{r} / \mathrm{w}_{\mathrm{o}}\right) \mathrm{dr} \mid
$$

\section{a. Effect of Composition}

Difference in composition, by itself, between dingot and ingot has not been shown to alter the characteristic radial $G_{3}$ distribution. (10) Some of the texture and $G_{3}$ responses of both compositions to intermediate cooling rates will be shown to be different (see p. 53) possibly because of either a different delta phase effect or different TTT characteristics, or both.

\section{b. Prior Condition}

No effect of prior texture has been found. The texture induced by beta treatment has always been found to be similar and directed by the beta-alpha thermal gradients so that, for example, the axial $G_{3}$ gradient at the flat end of a fabricated rod after beta treatment is similar to the radial $\mathrm{G}_{3}$ gradient in the same rod. (Obviously a fabricated rod would have strikingly different axial and radial textures before beta treatment.)

The prior delta condition (which drastically modifies the grain size that can be expected from beta treatment) has a minor but definite effect on the radial $G_{3}$ distribution in ingot and dingot (see p. 42). 
low ID:wal1 ratio and asymmetry in radial $\mathrm{G}_{3}$ distribution

"hooks" near surface

possible effect of $\beta$ grain size on TTT curves

\section{c. Geometry}

The inherent difference in the accessibility of the outer and inner tube surfaces to the cooling medium would be expected to cause some asymmetry in the radial $G_{3}$ distribution. It is found that in general the tubes with the lowest ID:wall ratio show the least symmetrical curves for air cools and water quenches, although for oil quenches the symmetry for all ratios is markedly better -- probably because the radial $G_{3}$ penetration is much less in oil.

No systematic effect of wall thickness within the range of tube sizes studied (walls of 0.498 and 0.115 inch) was found on either the surface $G_{3}$ or the most negative $G_{3}$. It is possible that any systematic effect may have been obscured by the near-surface "hooks" (region of abrupt increase in negative radial $G_{3}$ just below the cooling surface) in the $G_{3}$ distribution. (These hooks have been found by other workers. (11) No explanation has yet been offered for their existence.) However, a systematic effect of "wall" thickness was found in the case of surface $G_{3}$ perpendicular to the flat face of brine-quenched 1 -inch diameter ingot discs. Figure 13 shows the regular decrease of surface $G_{3}$ with increasing thickness from 0.030 to 0.125 inch.

\section{d. Heat Treatment}

(1) Delta Treatment. The slight increase in radial $G_{3}$ with increase in temperature and time of delta treatment has already been described (see p. 42). MCW has demonstrated that it is highly probable that the beta grain size is affected by the size and distribution of delta precipitates. It is also possible that the grain size of the beta phase prior to transformation may affect the TTT characteristics of the 


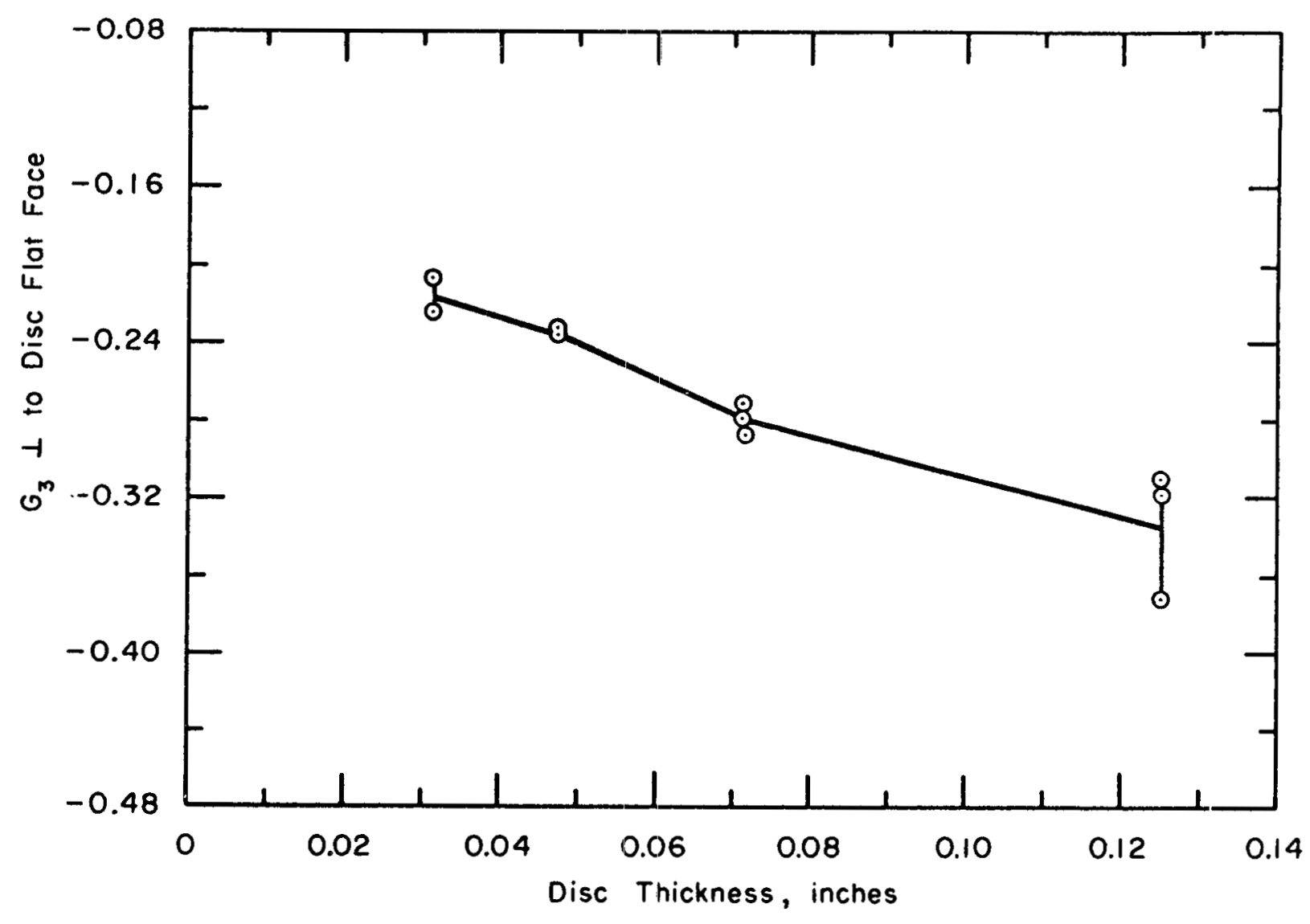

Fig. 13 - Effect of thickness on surface $G_{3}$ of beta treated 1-inch diameter ingot discs quenched into room temperature saturated (Nu-Sa1) brine. Drawing No. RA-2385 
Texture and Growth Index

uranium $^{*}$, so that for a given cooling rate, a different initial beta grain size may permit the transformation to occur at a different region on the TTT curve. If this happens, there is good reason to believe that the $G_{3}$ values may be different for different delta treatments. Minty and Butcher have already suggested the possibility of permitting the transformation of dilute U-Cr alloys to occur in that part of the TTT curve where the product is not orientation dependent. (13) (For effect of double beta treatment, see p. 68.)

\section{(2) Beta Temperature. For a constant}

sample size and quench, beta temperatures between about 695 and $755^{\circ} \mathrm{C}$ did not appear to affect $\mathrm{G}_{3}$ statistically. (14) (See Fig. 5.)

(3) Time at Beta Temperature. For a constant sample size and quench, beta treatment times longer than 8 to 10 minutes do not appreciably affect the $G_{3}$. Shorter beta treatments seem to depress $\mathrm{G}_{3}$ slightly. (15)

\section{(4) Continuous Cooling to Room Temperature.}

The effect of cooling rate from the beta phase has a marked effect on the radial distribution of radial $G_{3}$. A study of the distribution curves (given in the Appendix) has led to several. methods of summarizing the data.

\section{(a) Radial Merit vs. Cooling Medium}

and Size. Figures 14 and 15 show the radial merit of several sizes of ingot and dingot for different cooling media. From such plots it is seen that:

* For example, it is known that the austenite grain size can affect the rate of subsequent transformation in steel. Since Donzé (12) has shown that at quasi-equilibrium cooling rates, $\beta \rightarrow \alpha$ occurs by nucleation and grain growth, rather than by a martensitic process, it would be expected that a smaller grain size would shift the TTT characteristics to shorter times especially in the case of slow cooling rates. 
O.D. Radial Merit, $r_{0} / r$ or $w_{0} / 2 r$ for $G_{3}=-0.10$

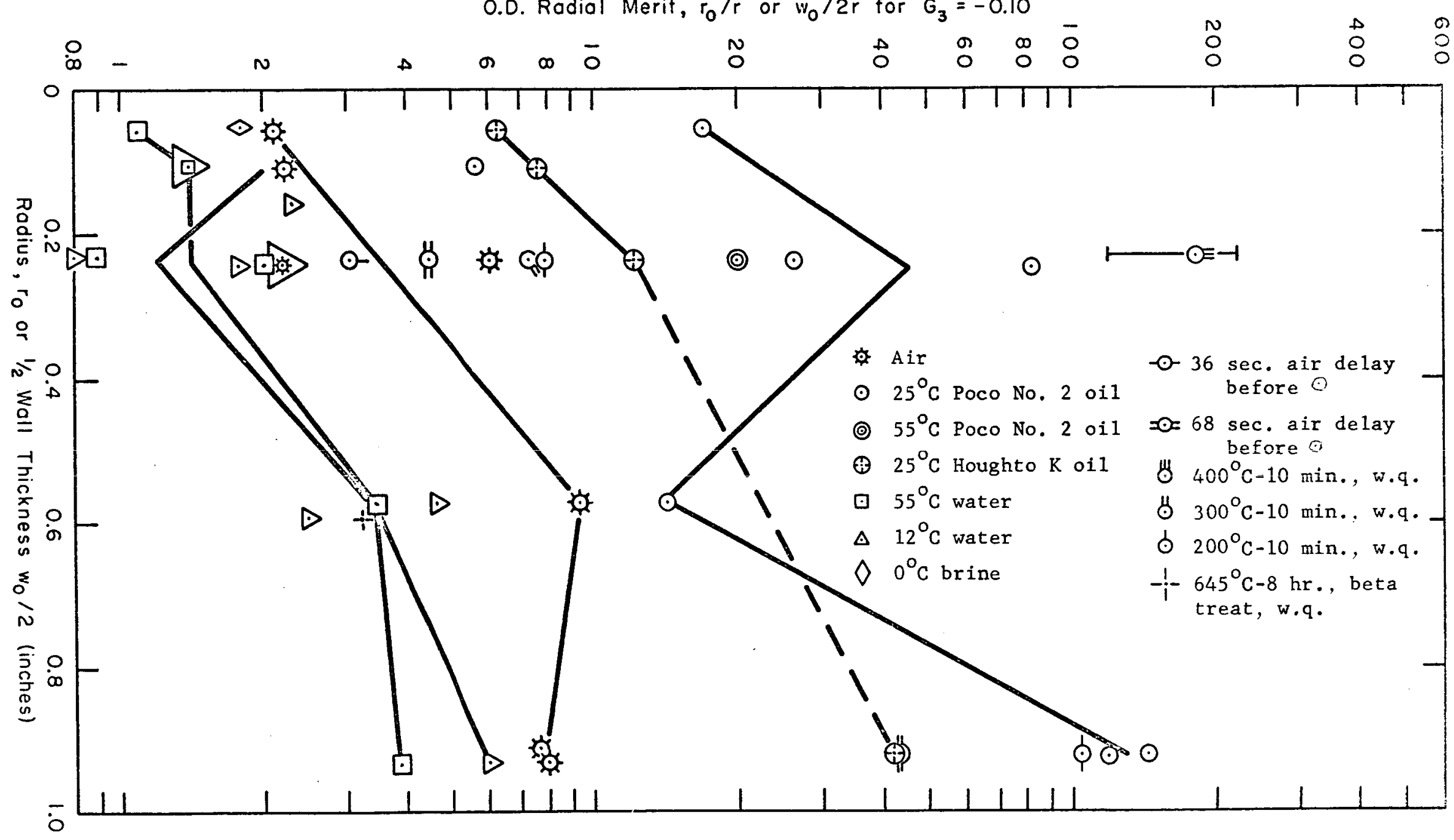

Fig. 14 - Effect of method of cooling ingot rod and tube, after beta treatment on the radia1 merit, $r / r$ or $w_{0} / 2 r$, where $r$ is depth below $O D$ where $G_{3}$ first reaches -0.10 , and where $r_{0}$ and $w_{0}$ are rod radius and tube wall thickness, respectively. Drawing No. RA-2380 


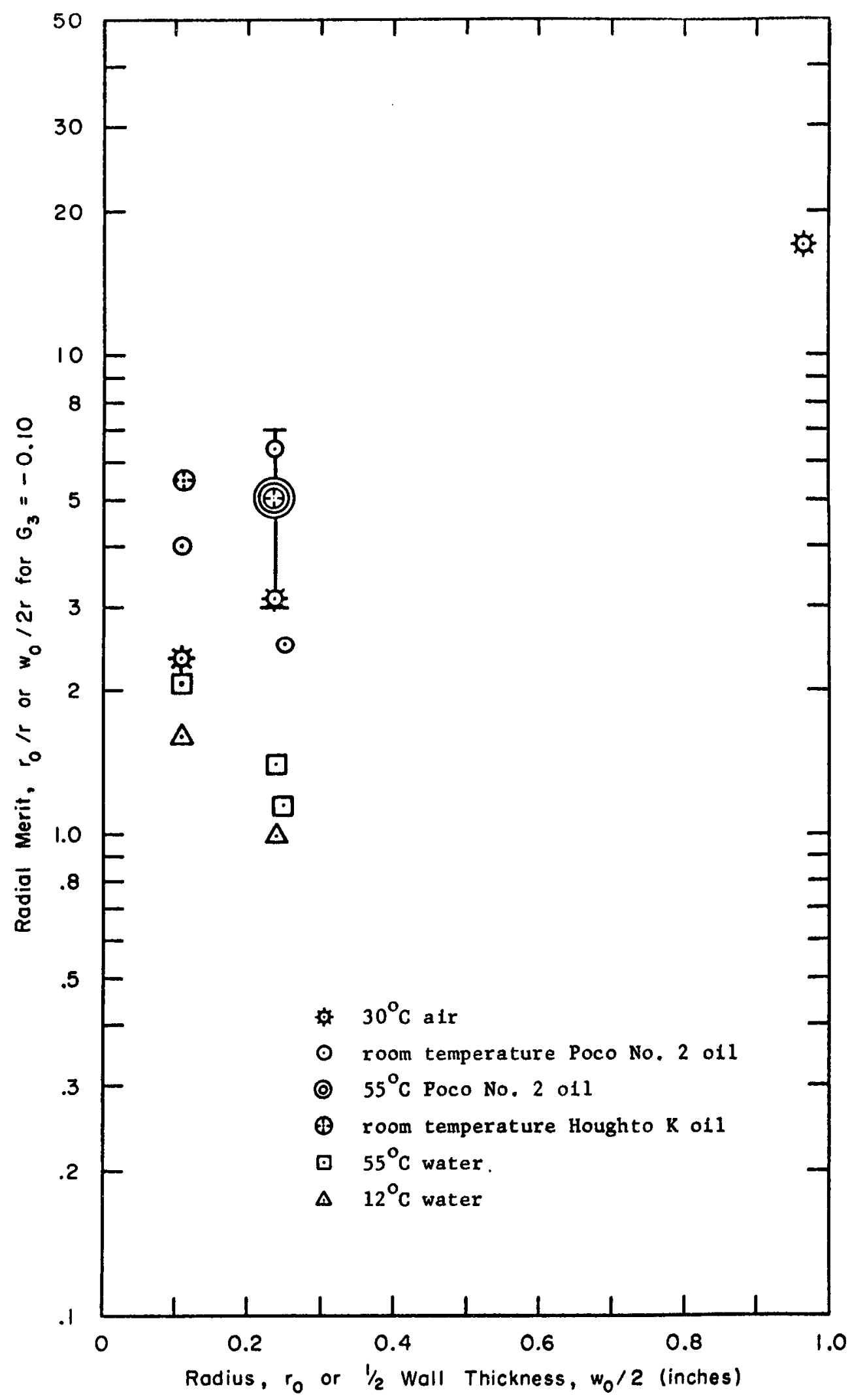

Fig. 15 - Same as Fig. 14, except for dingot uranium. Drawing No. RA-2320. 
(i) The radial merit of oil-quenched ingot is generally greater than about 10 , whereas for air cooling and water quenching the merit is less than 10 .

(ii) The radial merit for all cooling media increases; somewhat with increasing rod diameter or wall thickness.

(iii) The radial merit of oil-quenched ingot is substantially greater than that of oil-quenched dingot .

(iv) The radial merit found in air-cooled metal is generally intermediate between that of the oiland the water-quenched metal.

(b) Radial Merit vs. Cooling Rate.

Figure 12 shows the relation between radial merit and cooling rate $R_{B}$ (about 0.06 inch below $0 D$ surface) for dingot and ingot continuously cooled from the beta phase. The rates below about $10^{\circ} \mathrm{C} / \mathrm{sec}$. were obtained by air cooling, between $10^{\circ} \mathrm{C} / \mathrm{sec}$. and $100^{\circ} \mathrm{C} / \mathrm{sec}$. generally by oil quenching, and over $100^{\circ} \mathrm{C} / \mathrm{sec}$. by

efficacy of intermed iate cooling rates water quenching. It is seen that intermediate rates (about 50 to $100^{\circ} \mathrm{C} / \mathrm{sec}$.) enhance radial merit of ingot, but that radial merit of dingot does not seem to maximize at this rate. (See hot-salt quenching, page 63.)

\section{(c) Integrated Radial Texture in}

Tubes. Figure 16 illustrated the relation* between cooling rate $R_{\beta}$ and integrated net radial texture, $I_{\mathfrak{r}} \cdot$ It is noted

* Attempts were made to find concomitant relations between $\mathrm{IT}_{\mathrm{r}}$ and wall thickness, $\mathbb{I r}_{r}$ and $I D$ :wall thickness ratio, and $\mathbb{I}_{r}^{r}$ and that part of II formed in the oD regions. In all of these relations, the quantitative scatter was too great to make the relation significant. 


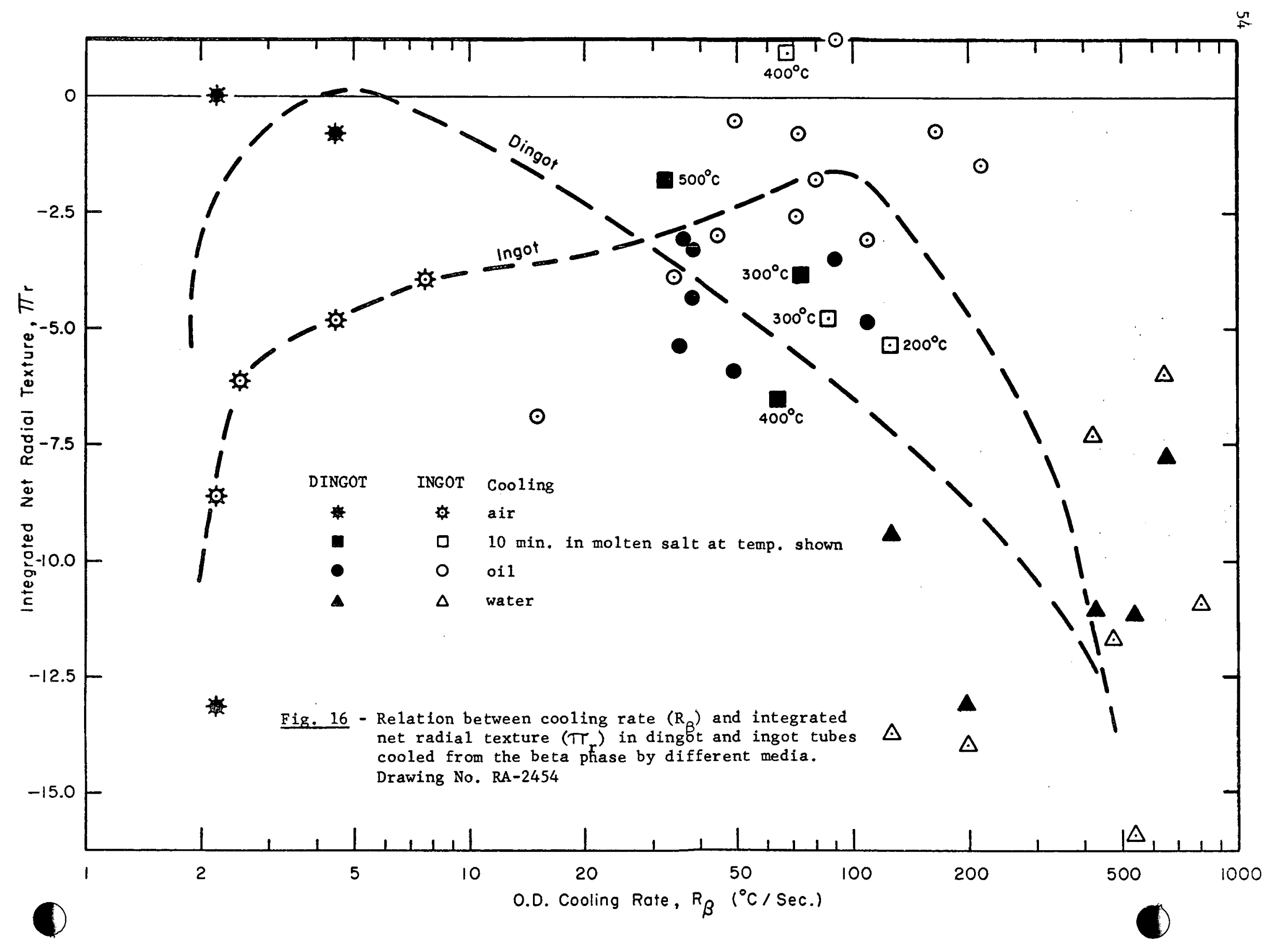


that water quenching produces the largest amount of integrated net texture (most negative $\pi_{r}$ ), but that the ingot curve may pass through a minimum $\operatorname{Ir}_{r}$ (most positive) at the intermediate cooling rates characteristic of oil quenching. Dingot is seen to be relatively less sensitive in its ability to reduce the amount of texture at intermediate rates. On this basis, the difference between the two compositions is less definte than on the basis of radial merit, but there is a tendency for ingot to contain less integrated texture at intermediate cooling rates. (The two dingot points at 2.2 and $4.5^{\circ} \mathrm{C} / \mathrm{sec}$ were obtained from very asymmetrical radial $G_{3}$ distribution curves with large negative OD regions and equally large positive midwall regions, so it is possible that they are not representative dingot air cools.)

The effect of $O D$ cooling rate on $\left|\pi_{r}\right|$ is shown in Fig. 17. We see that a minimum of oD cooling rate of $\sim 70^{\circ} \mathrm{C} /$ sec. produces the least amount of radial integrated absolute texture, and the disparity between ingot and dingot is somewhat less than in the plot of integrated net texture. It is still true, however, that for intermediate cooling rates dingot contains somewhat more radial integrated texture than ingot, since the dingot group lie in general above the ingot group.

If a tube contained a symmetrical radial texture distri-

asymetry in $I_{r}$ distribution bution throughout the wall, the $\pi_{r}$ 's associated with the OD and ID would be equal, so that the fraction of $\Pi_{r}$ (OD) would be 50 percent. Some measure of the asymmetry may be appreciated by the departure from 50 percent actually found. In a group of 45 dingot and ingot tubes cooled in air, molten salt, oil and water, it was found that the $I_{r}$ (OD) averaged 63 percent of the total $\left|I r_{r}(O D+I D)\right|$ texture, and had the 


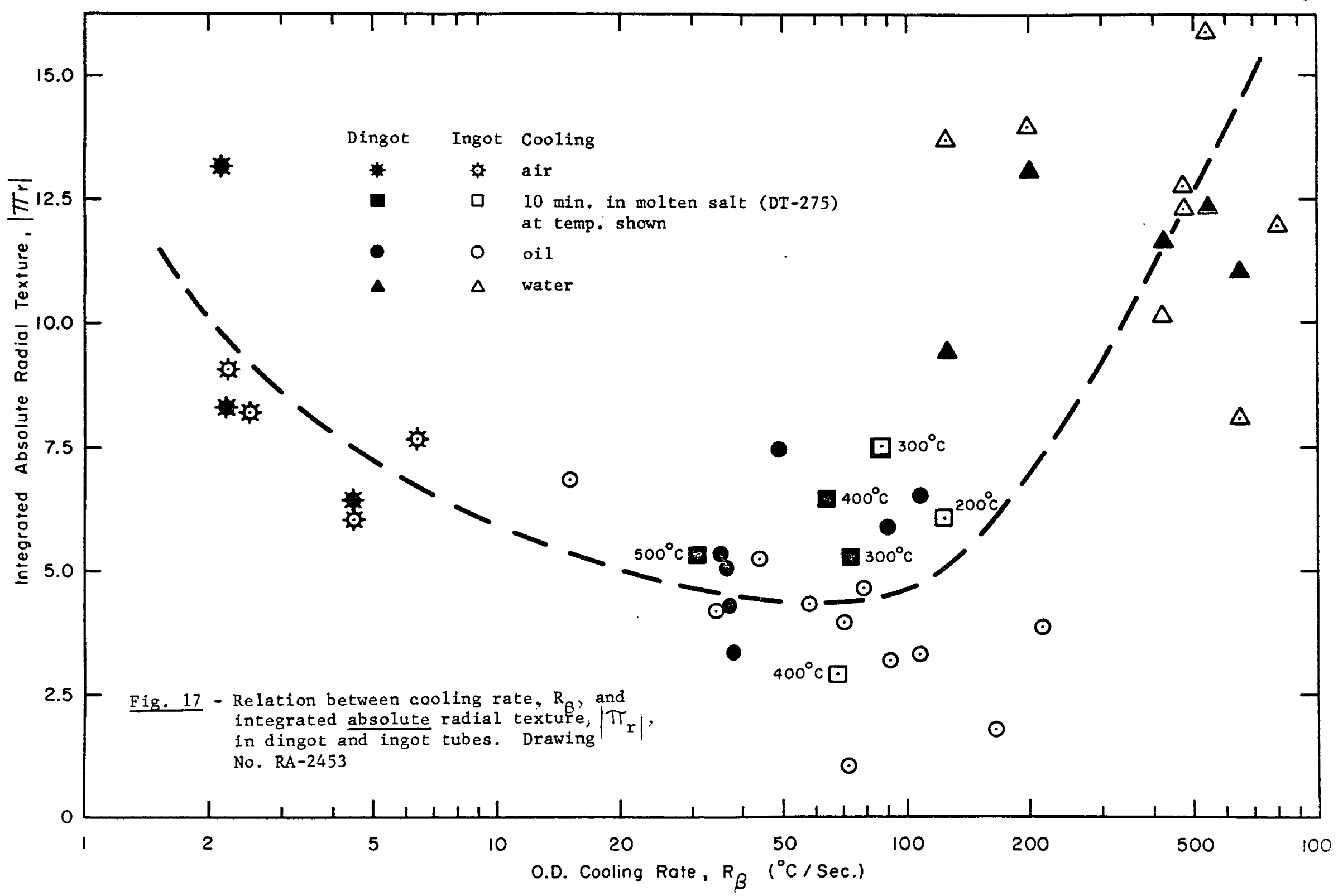

1 
distribution as shown in Table II. We can see from this table that nearly half $(42 \%)$ of the cases fell in the 41-60\% quasi-symmetrical region, but that, on the average, for all cooling media, the texture induced by beta treatinent will tend to be concentrated on the outer surface of the tube. This is naturally expected more for tubes with smialler inside diameters.

An examination of the same group of tubes also revealed that the percentage of integrated radial texture contributed by the OD wing to the total absolute radial texture across the entire wall averaged $54 \%$ ranging from 11 to $95 \%$.

(d) Normalized Radial $G_{3}$ Distribution in Rods. Appendix Figs. A-20 through A-23 illustrate the normalized texture penetration in dingot and ingot rods (1.1and 1.8-inch diameter, respectively) cooled in air, oil, hot water and cold water, respectively. The marked difference difference be- between dingot and ingot in response to cooling rate is shown tween oil-quenched dingot and ingot $\operatorname{rods}$ only for the oil quenches. At rates permitted by air, cold or hot water, no essential difference between the two conpositions is noted.

\section{(5) Interrupted Cooling to Room Tempera-} ture (air delays and hot salt quenching)

(a) Air Delay. Experiments on 1.8-

air delay inch diameter ingot and 1.5-inch oD by 0.5 -inch ID ingot tube showed that an air delay before quenching into Poco No.? oil merely increased the texture penetration to the maximum ishown by an infinite delay in air (air cool). At about 0.08 inch below the OD and ID (Fig. 18) and about 0.06 inch below the rod surface (Fig. 19), the effect of air delay disappeared. 
TABLE II

Percent of oD Radial Integrated Texture of

Total (OD + ID) Radial Integrated Absolute Texture in Tubes

\begin{tabular}{|l|c|c|c|c|c|c|c|c|c|c|c|} 
& \multicolumn{1}{c|}{$0-10$} & $11-20$ & $21-30$ & $31-40$ & $41-50$ & $51-60$ & $61-70$ & $71-80$ & $81-90$ & $91-100$ & Total \\
\hline Cooling med ium: & & & & & & & & & & & \\
Air & 0 & 0 & 0 & 0 & 1 & 2 & 1 & 1 & 1 & 1 & 7 \\
Molten sa1t & 0 & 1 & 0 & 0 & 1 & 0 & 1 & 1 & 1 & 1 & 6 \\
Oil & 0 & 0 & 0 & 3 & 4 & 5 & 4 & 1 & 1 & 1 & 19 \\
Water & 0 & 0 & 0 & 0 & 2 & 4 & 0 & 4 & 2 & 1 & 13 \\
\hline \multirow{2}{*}{ TOTAL } & 0 & 1 & 0 & 3 & 8 & 11 & 6 & 7 & 5 & 4 & 45 \\
\hline
\end{tabular}

*For results and discussion see p. 55. 


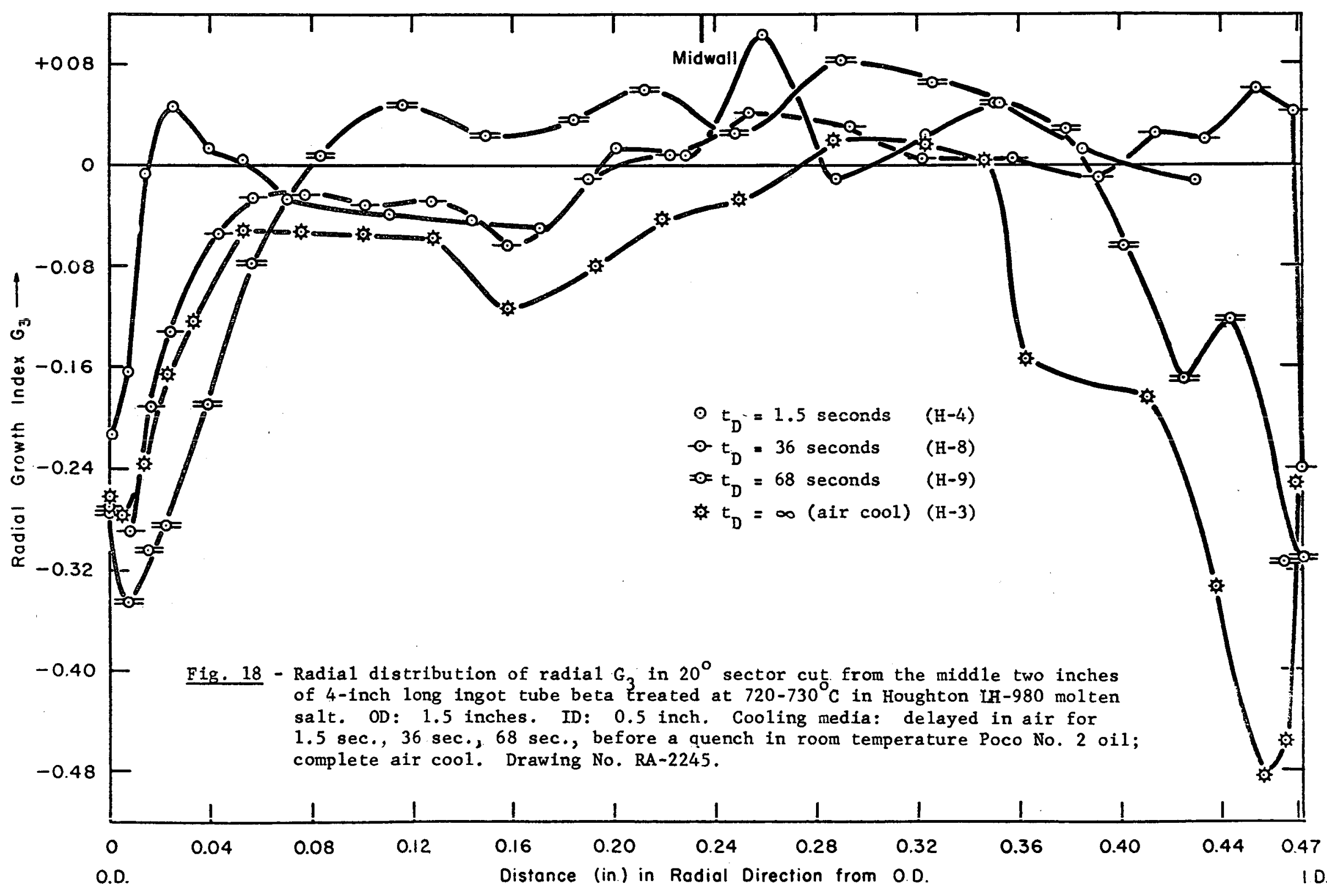




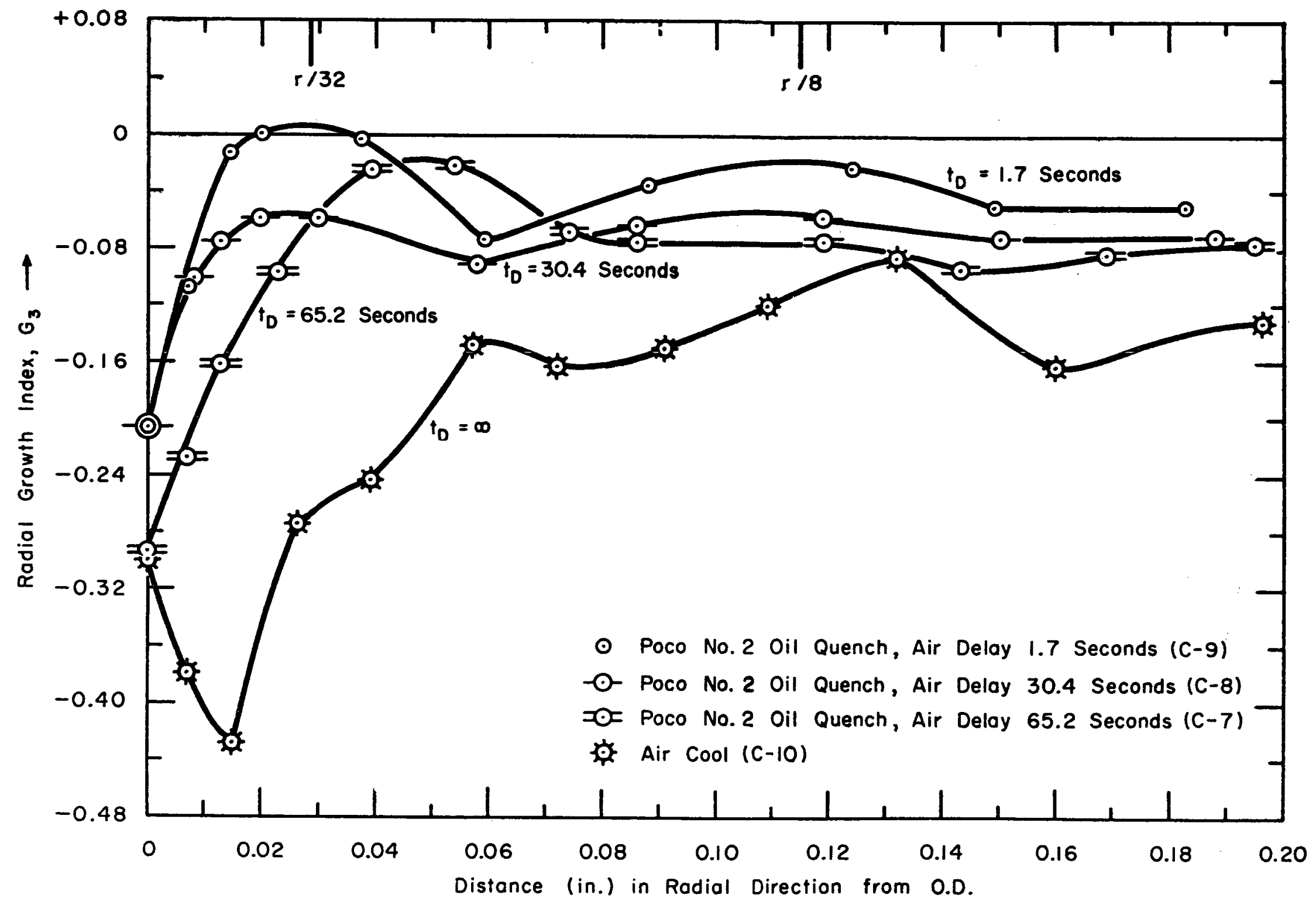

Fig. 19 - Same as Fig. 18 except:

Ingot rod, 1.8 inches diameter

Cooling media;: delayed in air for $1.7 \mathrm{sec}, 30.4 \mathrm{sec}$, and $65.2 \mathrm{sec}$.

before a quench in room temperature Poco No. 2 oil; complete air cool

Drawing No. RA-2125 
Texture and Growth Index

Below these radial depths, the fully air-cooled uranium had about the same $G_{3}$ level as the oil-quenched piece.

(b) The Possibility of Isothermal

Transformation. We have seen from experience with different cooling media that the formation of minimum texture penetration is critically dependent on cooling rate. The OD cooling rate, $\mathbf{R}_{\beta}$, indicated is between about 50 and $100^{\circ} \mathrm{C} / \mathrm{sec}$. According to Duwez, ${ }^{(16)}$ who studied the effect of cooling rate on the allotropic transformation temperature of uranium, a rate of $50^{\circ} \mathrm{C} / \mathrm{sec}$. would cause beta-to-alpha transformation at about $600^{\circ} \mathrm{C}$. He found that transformation at $500^{\circ} \mathrm{C}$ could be obtained with a rate of about $2000^{\circ} \mathrm{C} / \mathrm{sec}$. and transformation at $400^{\circ} \mathrm{C}$ at about $6000^{\circ} \mathrm{C} / \mathrm{sec}$. It was felt that it would be constructive to determine whether this dependence on cooling rate indicates that a certain isothermal transformation temperature yields the least orientation-dependent transformation product in thin uranium discs. Dingot and ingot discs (1-inch diameter by 0.030 -inch thick) were quenched into brine at 0 to $100^{\circ} \mathrm{C}$, Houghton Draw-Temp $275^{*}$ at 175 to $400^{\circ} \mathrm{C}$, or Houghton Liquid Heat $235^{* *}$ at 425 to $660^{\circ} \mathrm{C}$. The results for the first study

surface $\mathrm{G}_{3}$ of hot-salt quenched thin discs on ingot discs ${ }^{(17)}$ showed that the least surface texture was obtained in the quench-temperature range of 425 to $550^{\circ} \mathrm{C}$. Since this range was obtained by using on ly LH-235 salt and the effect might be due to the choice of salt, DT-275 salt with the lower working range was extended into the higher temperature region. The results for both dingot and ingot are shown in Fig. 20. It is seen that the ingot and one branch of the dingot curves are parallel for the same salt quenches, and that the ingot discs have slightly less surface texture

- - - - - - - -

* Working range $175-540^{\circ} \mathrm{C}$

** Working range $425-760^{\circ} \mathrm{C}$ 


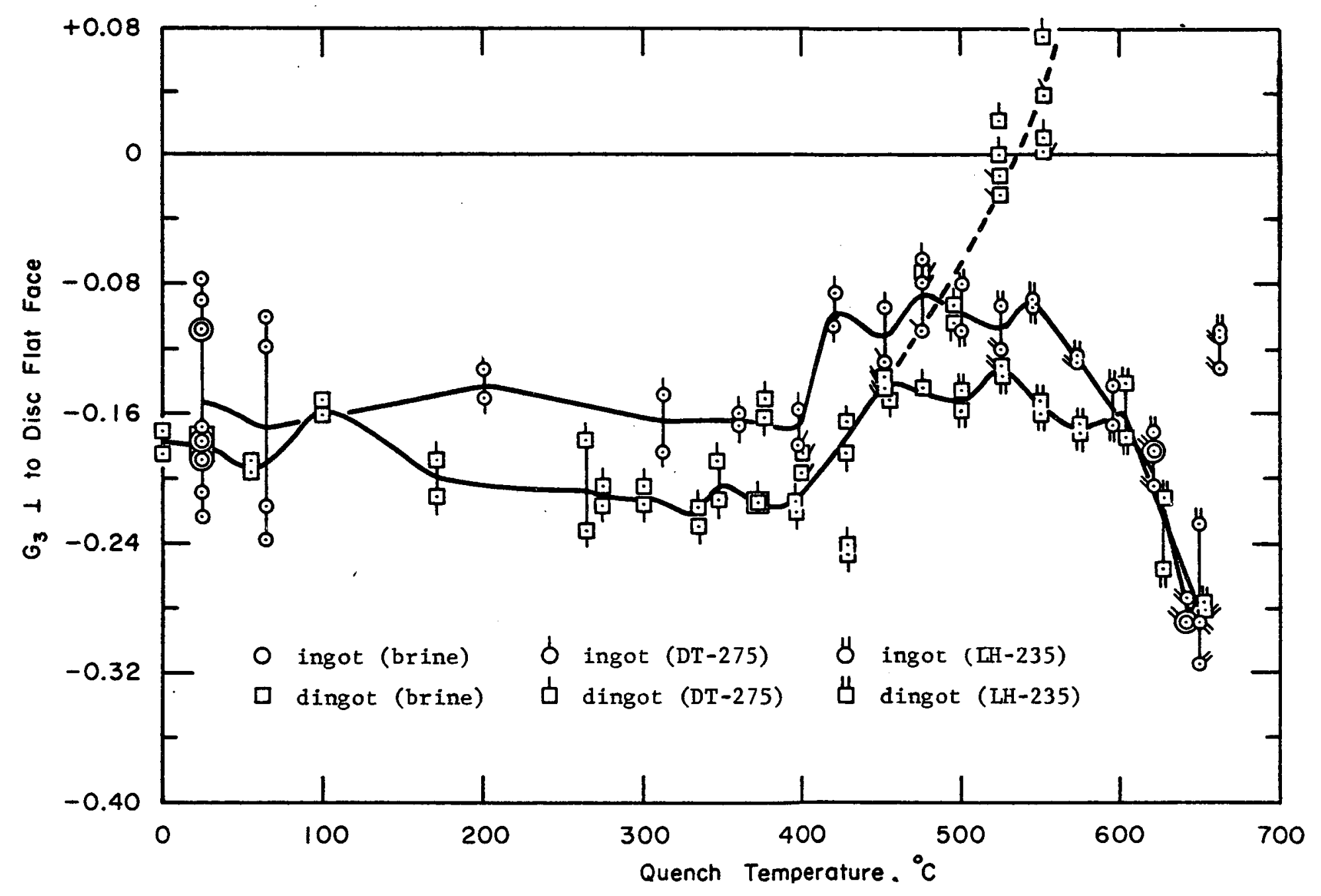

i

Fig. 20 - Effect of temperature and type of molten salt quench (10 minutes at temperature) on surface $G_{3}$ of beta treated ingot and dingot discs ( 1 -inch diameter by 0.030 -inch thick.) Drawing No. RA-2386 
$\mathrm{G}_{3}=0$ on surface dingot discs after $535^{\circ} \mathrm{C}$ quench $500^{\circ} \mathrm{C}-200^{\circ} \mathrm{C}$ hot salt quenches of dingot and ingot tubes (as indicated by a somewhat less negative $G_{3}$ ). However, when DT-275 salt is used on dingot discs up to $550^{\circ} \mathrm{C}$, the $G_{3}$ increases to zero at about $535^{\circ} \mathrm{C}$. It was observed that the DT-275 frothed somewhat at the upper end of its working temperature (" $540^{\circ} \mathrm{C}$ "). This may have had the effect of slowing the cooling rate, with the result that the actual transformation temperature may easily have been higher than the actual molten salt temperature. Yet is is not clear why the use of LH-235 salt (which did not froth) would not have provided an equivalent cooling rate at some higher molten salt: temperature. Does the existence of surface $G_{3}=0$ prove the absence of thermal gradients during transformation? It is difficult to believe that a combination of poor heat transfer (owing to the frothing action of the molten salt) and recales. cence effort could have eliminated surface thermal gradients during transformation. The possibility that DT-275 corroded the disc surface more than $L H-235$ to give a more positive $G_{3}$ was eliminated by a careful thickness check of the discs before and after heat traatment. (No more than 0.0015 inch per surface could have been lost by corrosion.) The results with DT-275 on dingot discs encouraged an investigation of hot: salt quenches of 500,400 and $300^{\circ} \mathrm{C}$ on dingot tubes of the same size used in a study of 400,300 and $200^{\circ} \mathrm{C}$ hot-sa1t quenched $1.5-$ inch OD by 0.5 -inch ID ingot tubes.

\section{(c) Hot Salt Quenching of Dingot and}

Ingot. Radial $G_{3}$ distribition for hot salt quenching of 1.5 w inch OD by 0.5 -inch ID by 4-inch (size H) dingot and ingot tube are shown in Fig. 21 (Normalized curve, Appendix Fig. A-15b) and Fig. 22 (Normalized curve, Appendix Fig. A-15a), respectively. As-fabricated ingot tubes were beta treated, quenched in DT-275 at 400,300 or $200^{\circ} \mathrm{C}$, held for 10 minutes in the salt, then water quenched. As a result of the quenching of thin discs (see above), it was decided to study dingot tube 


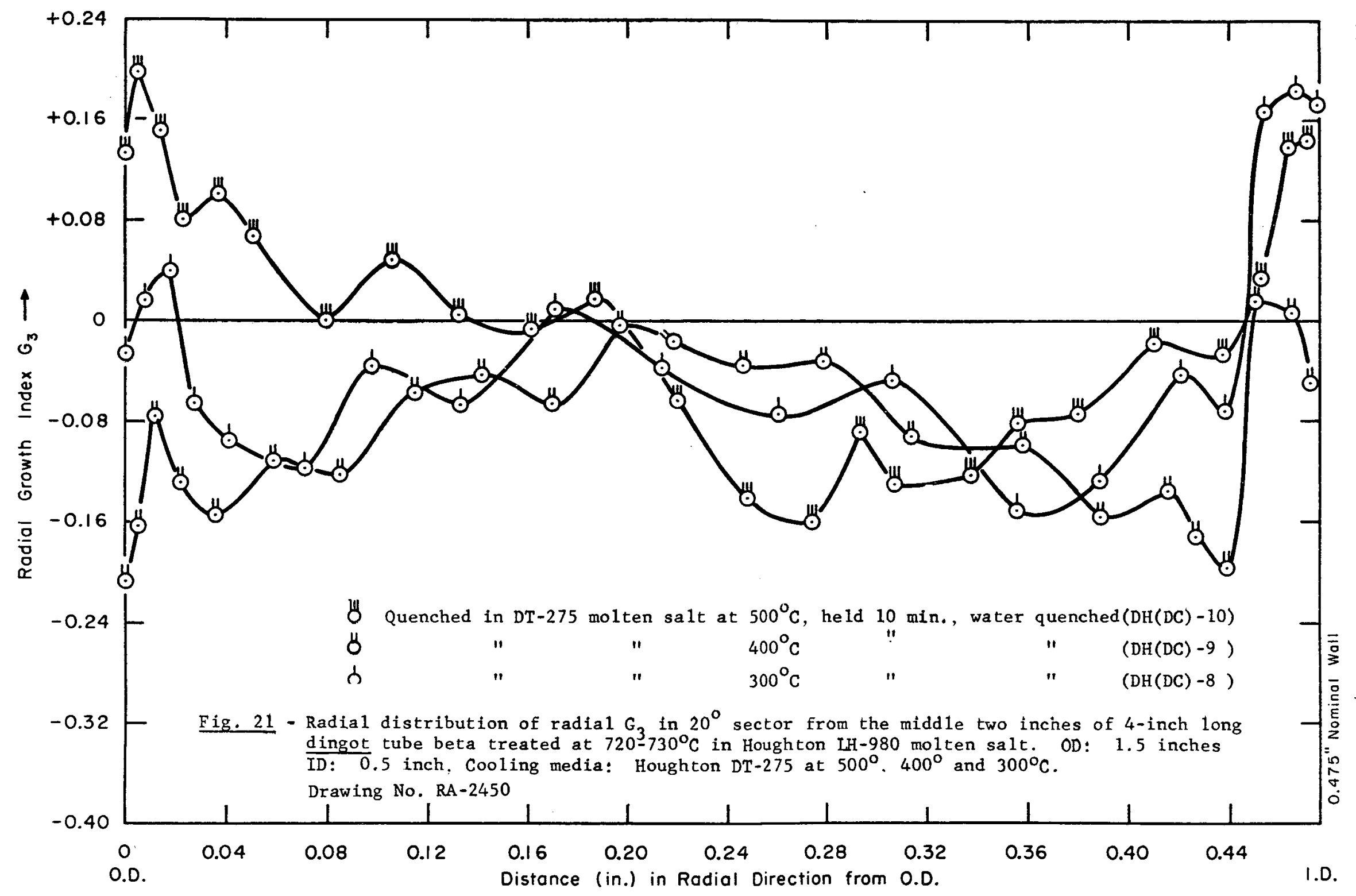




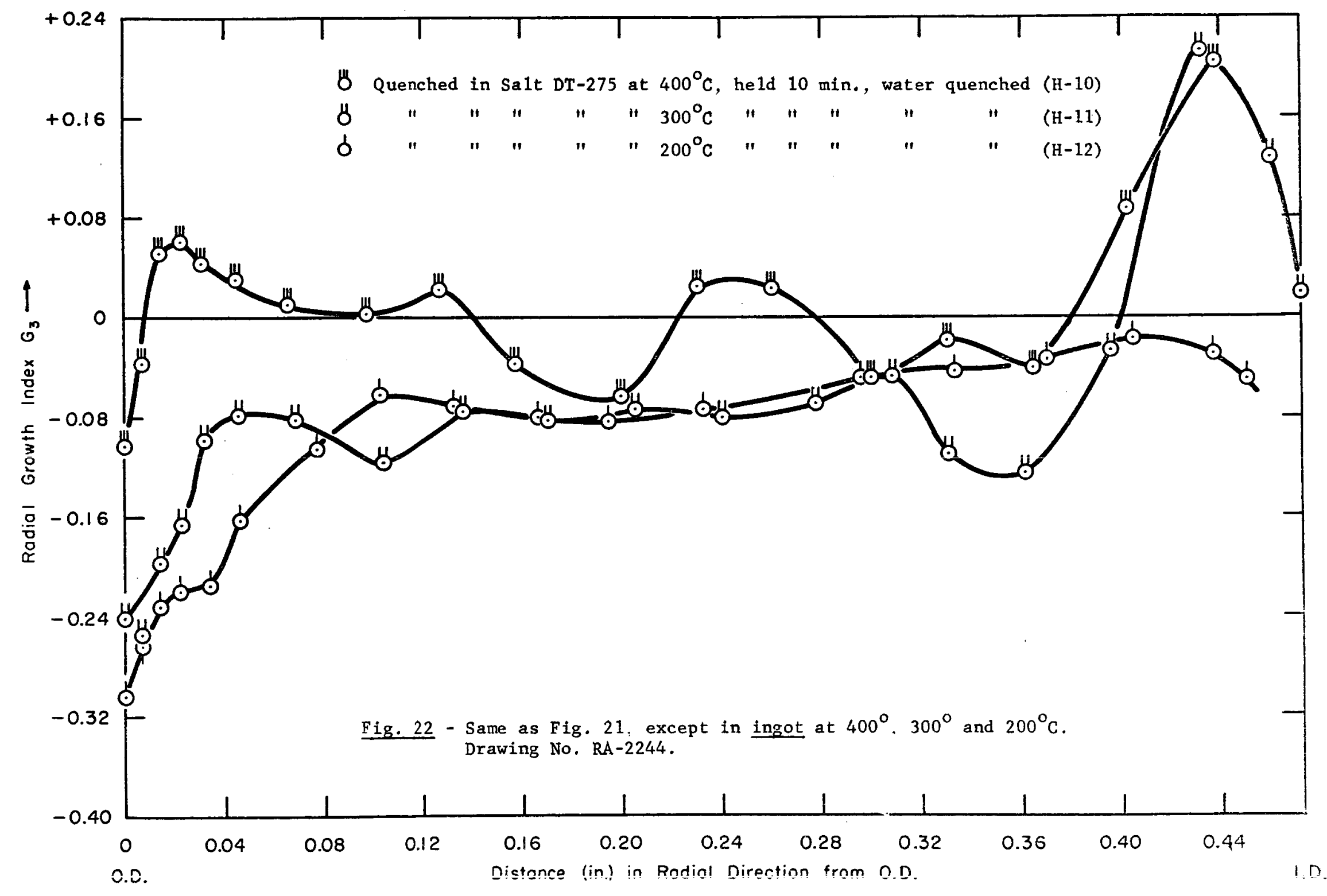


of the same size and under the same conditions, except quenched in 500,400 or $300^{\circ} \mathrm{C}$ salt. A comparison of the results for both dingot and ingot may be observed from the following:

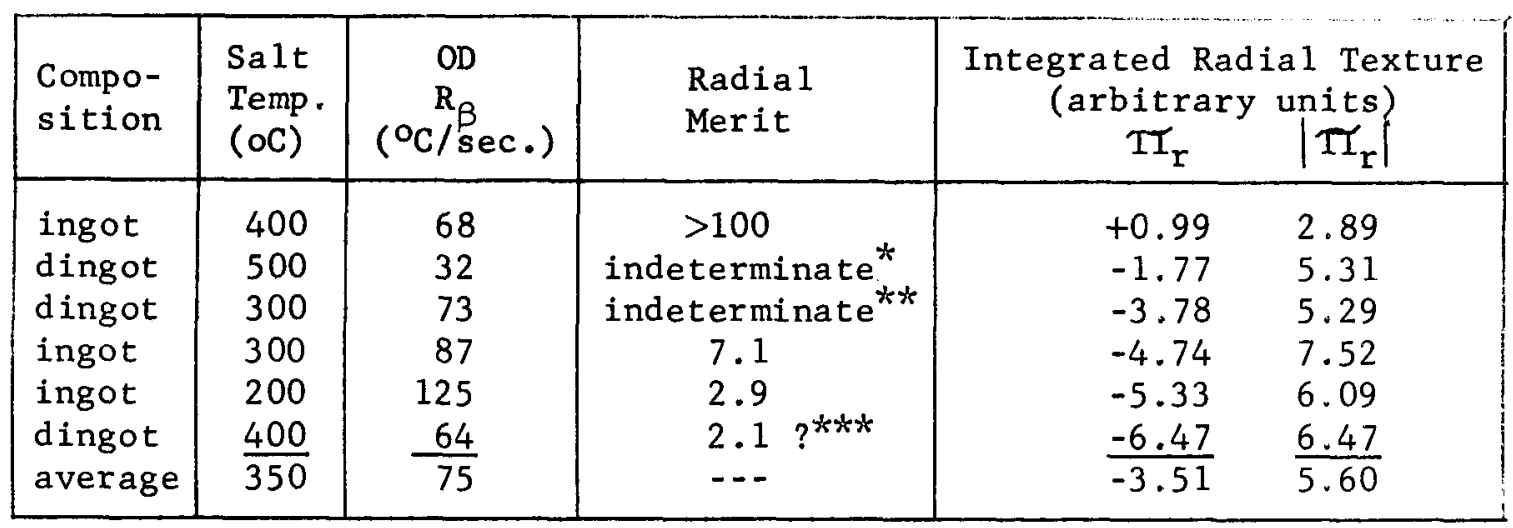

${ }^{*} \mathrm{G}_{3}$ positive $\quad * *$ initial $\mathrm{G}_{3}>-0.10 \quad * * * *$ unreliable

The principal characteristics and differences are as follows:

(i) A $300^{\circ} \mathrm{C}$ hot salt quench produced the only instance in this study, of a very shallow oD texture in betaquenched dingot.

(ii) A $500^{\circ} \mathrm{C}$ hot salt quench produced, also for the first time in this study, a positive radial $G_{3}$ at the $O D$ in dingot where there is a positive $G_{3}$ on both OD and ID with a negative $G_{3}$ at the ID side of midwall.

(iii)A $400^{\circ} \mathrm{C}$ quench of dingot produces a radial $\mathrm{G}_{3}$ distribution like that of an oil quench (see Fig. A-12).

(iv) The hot-salt quench producing the least integrated net texture seems to be $500^{\circ} \mathrm{C}$ salt for dingot and $400^{\circ} \mathrm{C}$ for ingot.

(v) The results for both ingot and dingot are similar (including positive radial $G_{3}$ 's at the ID), except that a $400^{\circ} \mathrm{C}$ quench produces a shallow texture in ingot, but a $300^{\circ} \mathrm{C}$ quench forms a shallower texture in dingot. 
Comparison of hot-salt quenched dingot and ingot tubes with intermediate $R_{\beta}$ cooling rates (averaging about $75^{\circ} \mathrm{C} / \mathrm{sec}$ ) similar to those attained in oils reveals (see Figs. 16 and 17) that:

(i) In ingot, the integrated net radial texture, $\mathbb{I}_{r}$, is improved only in the case of the $400^{\circ} \mathrm{C}$ hot-salt quench, whereas in the $300^{\circ} \mathrm{C}$ and $200^{\circ} \mathrm{C}$ hot-salt quenches, the $\boldsymbol{I I}_{r}$ is somewhat worse (more negative) than the average $\pi_{r}$ 's found in tubes quenched in oil at similar rates.

(ii) In dingot, although the $\pi_{r}$ as well as the $I I_{r}$ for the $500^{\circ} \mathrm{C}$ and $300^{\circ} \mathrm{C}$ hot-salt quenches are smaller than the corresponding average values for similar oil quenching rates, their values do not deviate from the mean of $T_{r}^{\prime}$ for intermediate quench rates so much as the $400^{\circ} \mathrm{C}$ value of $I I_{r}$ does for ingot.

critical value of cooling rate a primary variable in controlling amount of radial texture

(6) A Comparison Between Continuous and

Interrupted cooling. We conclude from a study of continuous cooling in different media, and interrupted cooling (air delays and hot-salt quenching), that a critical value of the cooling rate $\left(R_{\beta}\right)$, regardless of how it is achieved, is the primary variable in determining the amount of integrated texture induced by cooling from the beta phase.

There is also some evidence that the penetration and amount of radial texture in dingot is slightly greater than in ingot for the same intermediate cooling rates which induce the minimum texture.

(7) Post-Beta-Treatment Annealing; at

$600^{\circ} \mathrm{C}$ post $-\beta$ annea 1

$600^{\circ} \mathrm{C}$. No significant effect of a $600^{\circ} \mathrm{C}$ anneal on radial $G_{3}$ of ingot rods or of tubes previously water quenched from 
double $\beta$ treatment effect of bending and applied tensile stress the beta phase was found. (18)

(8) The Effect of a Double Beta Treatment.

The effect of a second beta treatment was studied in the case of a 2.9-inch oD by 2.5-inch ID ingot tube, which had already been quenched in $12^{\circ} \mathrm{C}$ water $(M-8 \mathrm{~A})$. The radial $\mathrm{G}_{3}$ distribution was unchanged between the OD-ID surfaces and to a depth of about 0.025 inch. Below this depth, the $G_{3}$ curve of the doublebeta-treated sample was found to be slightly more positive (about $0.06 \mathrm{G}_{3}$ above the curve of single beta treated sample). (See Fig. A-6.)

$$
\begin{aligned}
& \text { e. Effect of Stress Applied in Beta, Beta- } \\
& \frac{\text { Alpha, and in High-Temperature Alpha }}{\text { Phases. }} \\
& \text { During beta treatment and quenching, con- }
\end{aligned}
$$
siderable stresses can be built up in localized volumes of the sample. Some of the possible origins of stress are: steep temperature gradients, texture changes (that could lead to mechanical and thermal anisotropic changes which would result in geometric restraints), and allotropic volume changes. Since these stresses may influence the resulting $G_{3}$ profile of a sample, the effect of applied stresses on these properties was studied.

\section{(1) Effect of the Application of Bending}

Stresses During Cooling From the Beta Phase. The radial dis = tribution of $G_{3}$ in an ingot rod bent presumably in the beta phase, (19). then air cooled, is compared with $G_{3}$ in an unstressed air-cooled rod. Fig. 23. It is seen that the radial $\mathrm{G}_{3}$ is considerably more positive down to a radial depth of about 0.2 inch (Region A) from the OD at the convex side of the bent bar. The radial texture in this region was found to be (150 to $15 \mathrm{~h})$, which is the same texture observed in the 


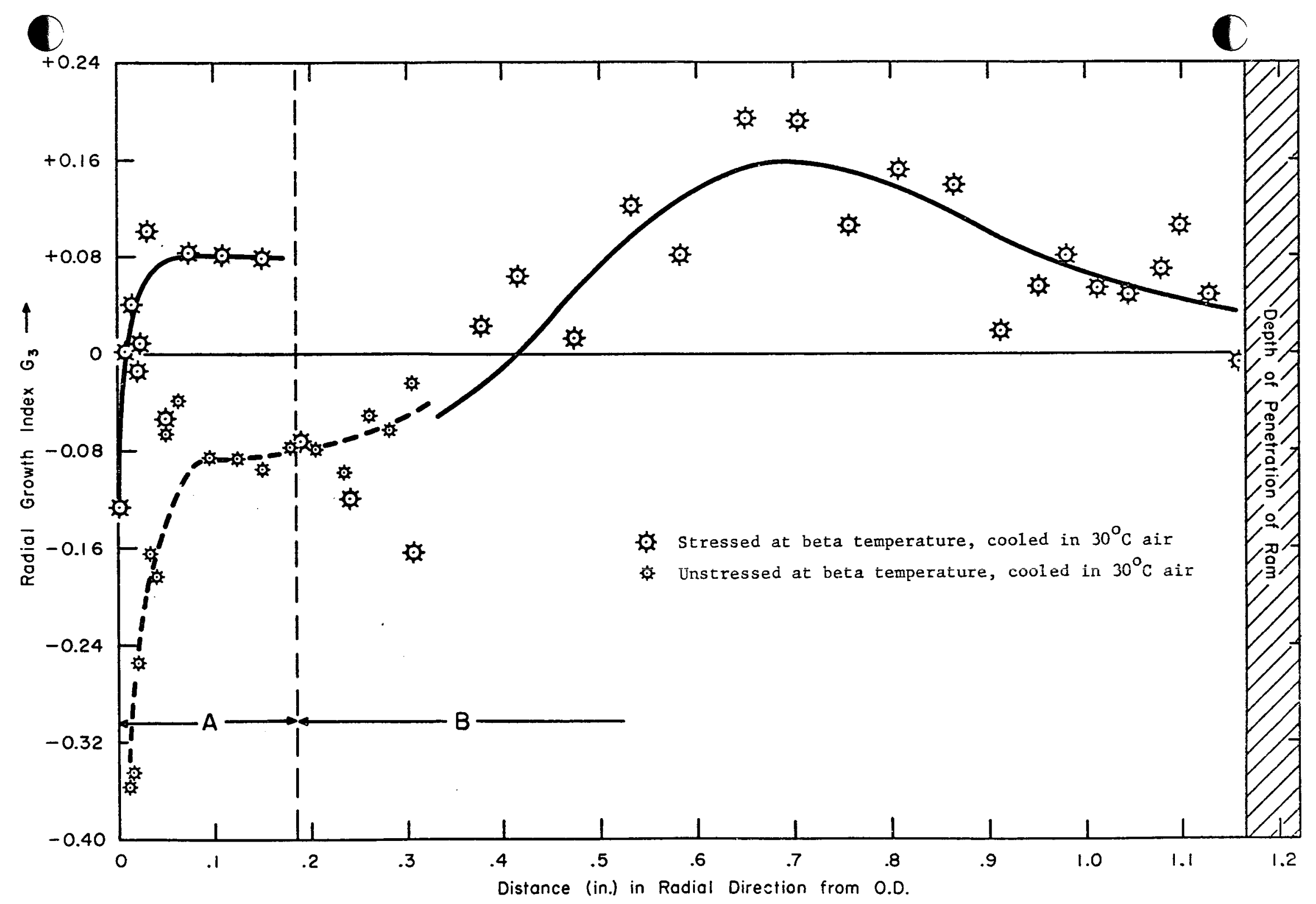

Fig. 23 - Effect of high temperature bend stress on radial $G_{3}$ distribution (solid 1 ine) in 1.1 -inch diameter air-cooled ingot rod compared with radial $G_{3}$ distribution in unstressed condition (dashed line). Zero radial depth $180^{\circ}$ from loading point. Region A presumed to have been in alpha, $B$ in beta phase during bending. Increase in radial $G$ in region $A$ due to $(150+15 \chi)$ compression texture normally found in hot-compressed alpha phase. Drawing No. 3 RA-2195. 
radial direction in extruded rods, and has been predicted and previously observed as the compression texture in alpha uranium. It is believed, therefore, that the outside shell was not bent in the beta phase but that the surface had had time to transform before bending. The radial texture at the same radial depths in the unstressed bar was the expected 100 type which is always found paralle1 to the thermal gradient. Below about 0.2 inch the textures in both bars were virtually the same (Region $\mathrm{B}$ ).

\section{(2) The Effect of Externa11y Applied}

Tensile Stress During and After Cooling from the Beta Phase. The effect on $G_{3}$ of applied stress (up to about 5 percent strain) was studied in a 0.7-inch diameter tensile specimen for varying temperatures of application. (20) A plot of the radial distribution of radial $G_{3}$ is shown in Fig. 24 for stress applied at room temperature $(W-1)$, in the beta phase (W-2), in the beta plus alpha (during transformation) and in the high alpha $(\mathrm{W}-3)$, and finally, in the beta and alpha phases separately, but not during transformation (W-4). A1l samples were cooled in helium at 1 to $2^{\circ} \mathrm{C} / \mathrm{sec}$, which simulated an air cool. The $G$ results are difficult to interpret, but since the $G_{3}$ axial and radial distributions in tensile specimens stressed at non-transformation temperatures are sinilar to each other ( $W-1, W-2, W-4)$ but much different from the distribution in a specimen stressed during transformation $(W-3)$, it can be concluded that such a limited tensile strain (5\%) during allotropic transformation is more effective in changing texture than is strain at any other temperature. The radial texture found in the region of large negative $G_{3}$ (about -0.37) is 100 to 101 , and in the axial direction where the $G_{3}$ is strongly positive (about +0.24 ) is 001 to 010 . Curiously, although both of these textures in the two directions are characteristic of textures induced by a thermal gradient in unstressed metal, the amount of texture has 


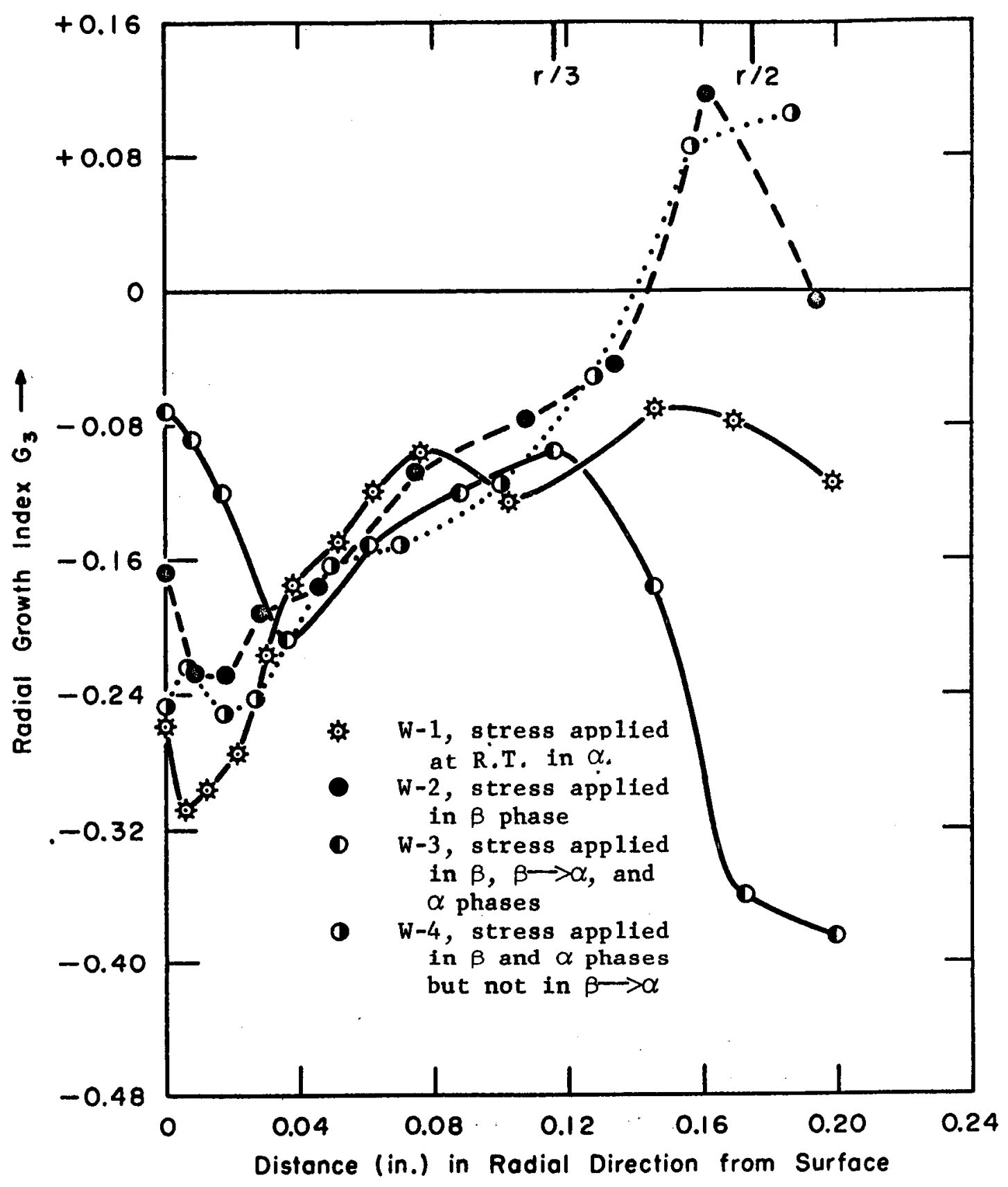

Fig. 24 - Distribution of radial $G_{3}$ with radial depth below oD in 1-1/4 inch long $x 30^{\circ}$ wide sectors cut from middle of 0.70 -inch dia. x 3.25-inch gage length tensile samples, axially strained during 1 to $2{ }^{\circ} \mathrm{C} / \mathrm{sec}$ cool from beta phase. Drawing No. RA-2321. Axial $G_{3}: W-1(+0.063)$

$\mathrm{W}-2(-0.029)$

$\mathrm{W}-3 \quad(+0.242)$

$\mathrm{W}-4(+0.001)$ 
$\mathrm{G}_{3}$ and free surfaces in a jointed, drastically quenched bar increased with radial depth, rather than decreased as in the unstressed sample.

\section{f. Effect of Internal Free Surface}

(1) In a Jointed Ingot Bar $(\mathrm{C}-11)$.

The fact that the most pronounced changes in texture are noted at or near the former cooling surface had led to the speculation that the unique stress and thermal conditions generated by a free surface may be responsible for an in duced texture parallel to the thermal gradient. To investigate the effects of free surfaces at high, moderate and low thermal gradients, a jointed 1.8-inch diameter ingot bar (C-11) was prepared and pinned together as shown in Fig. 25. The bar was beta treated at $720^{\circ} / 730^{\circ} \mathrm{C}$ and dras tically quenched into $13^{\circ} \mathrm{C}$ water. After heat treatment the 0.995-inch core was machined out of the center and the "free" surfaces were found to be covered with a thin scale of $\mathrm{UO}_{2}$, indicating imperfectly tight joints. The insulating effect of the thin scale should be kept in mind during consideration of the results. Figure 26 displays the axial $G_{3}$ distribution across the surface 4-3B (in a region of high thermal gradient) and includes the same $G_{3}$ distribution from a solid bar of the same dimensions and heat treatment. Figure 27 shows the radial distribution of radial $G_{3}$ from 0.425 inch to 0.68 inch below the OD in a jointed region (1B) and compares this dis" tribution with a neighboring, unjointed region (1A) in the same bar and in the same direction; in addition, comparison is made with a solid bar $(\mathrm{C}-1)$ of the same size, composition and heat treatment. At 0.4 -inch below the oD of a 1.8-inch diameter bar, the thermal gradients ought to be only moderate. Finally, an axial distribution of axial $\mathrm{G}_{3}$ across the region $2 \mathrm{~A}-2 \mathrm{~B} / 3 \mathrm{~A}$, the geometrical midlength where the thermal gradients were supposedly at a minimum, is given in Fig. 28. 


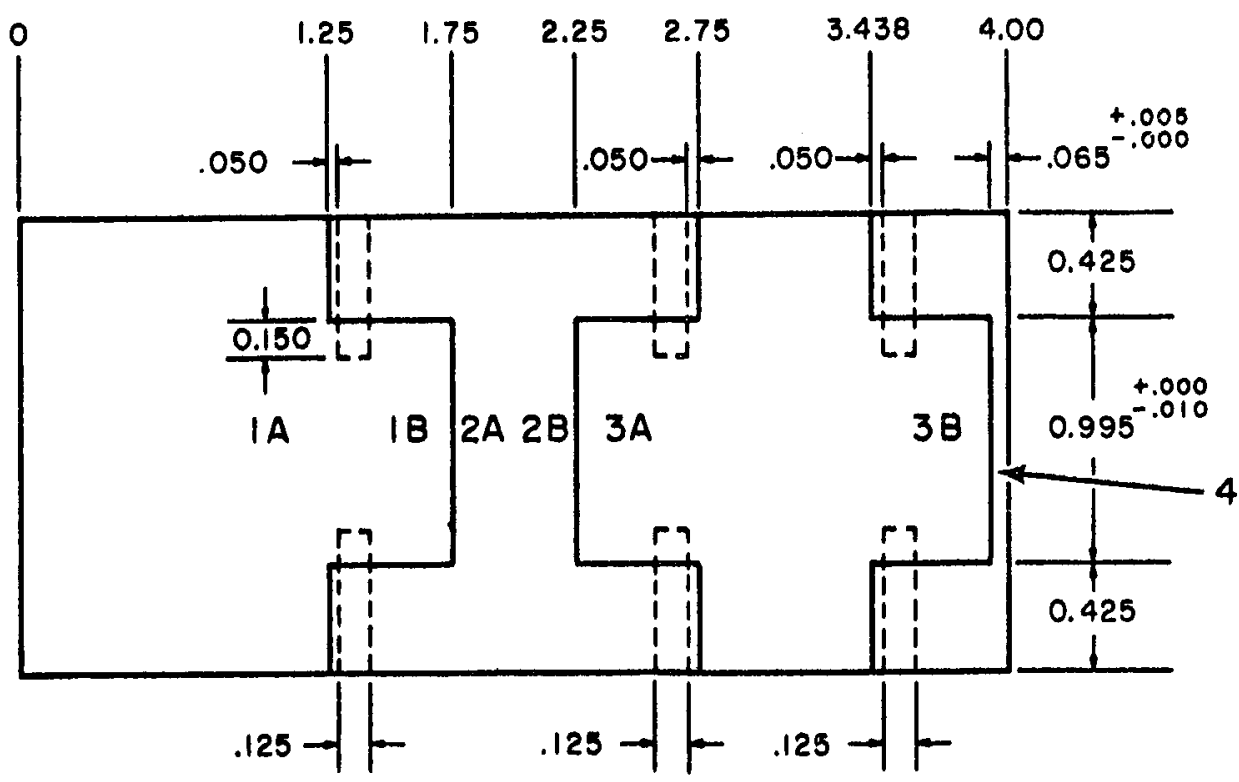

F1g. 25 - Design of jointed 1.845-1nch diameter $\times 4.000-$ inch long ingot bar (C-11) to study effect of "free surface" in and out of thermal gradient. Drawing No. RA-2262. 


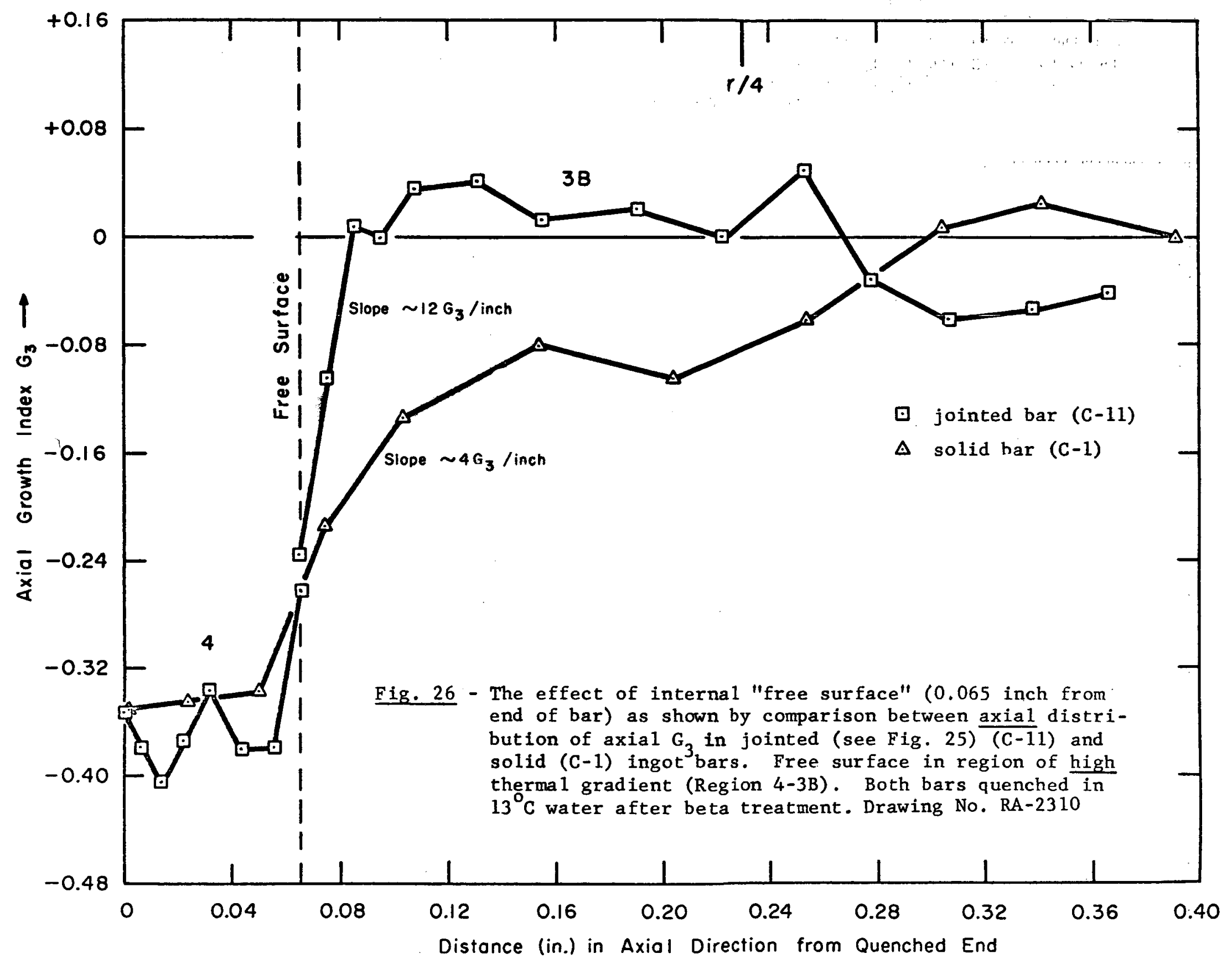




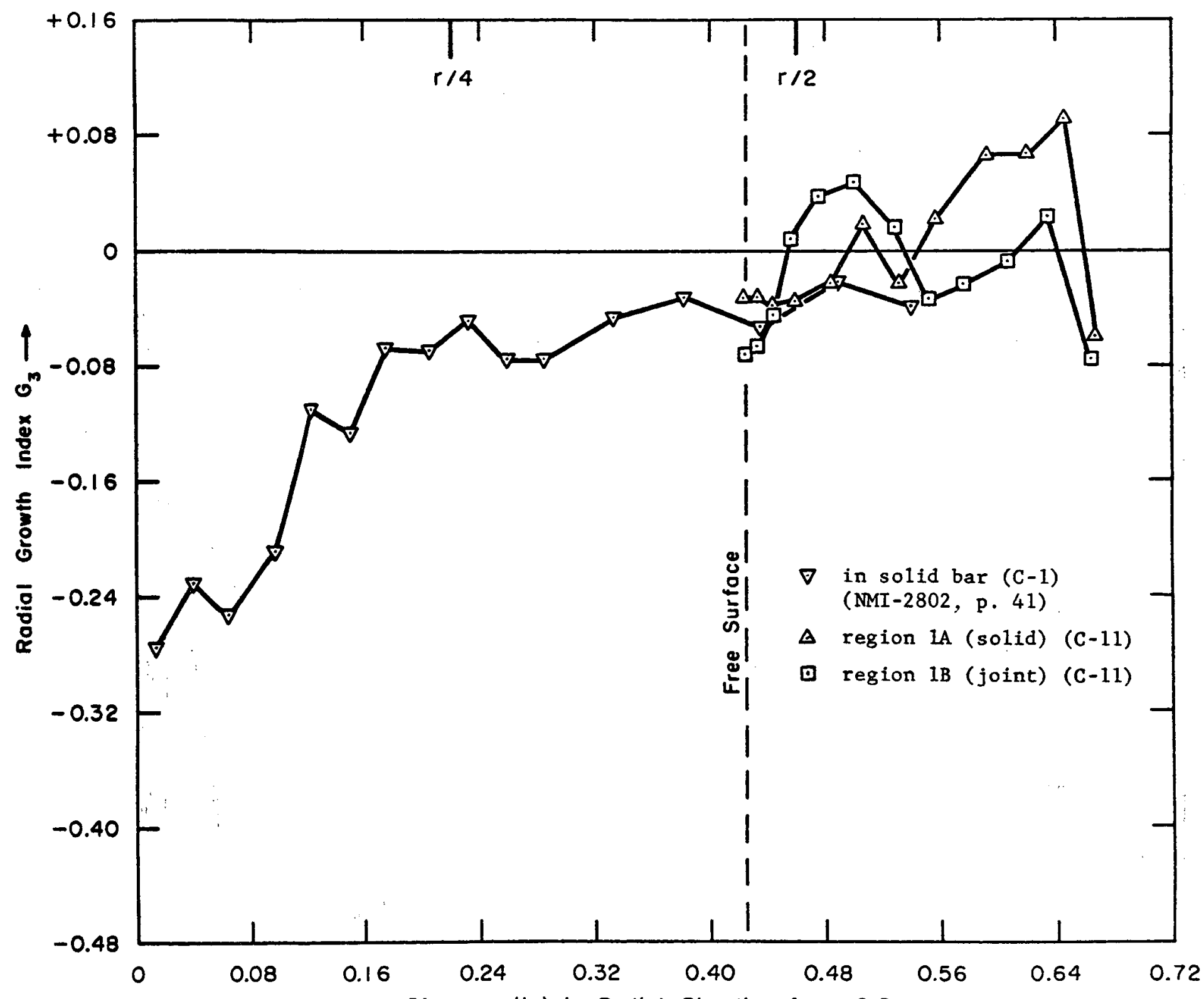

O.D. Distance (in.) in Radial Direction from 0.D.

Fig. 27 - The effect of an internal free surface in a moderate radial thermal gradient (Region 1B) $(0.425$ inch below the OD of bar C-11) is shown in radial direction by comparison with a solid region (1A) of same bar. Data from another solid bar $(C-1)$ also included. $G_{3}$ data from 20 sec-

tors. Radial surface is 1.25 to 1.75 inches from end of bar. Draving No. RA-2341 
(at 2.000)

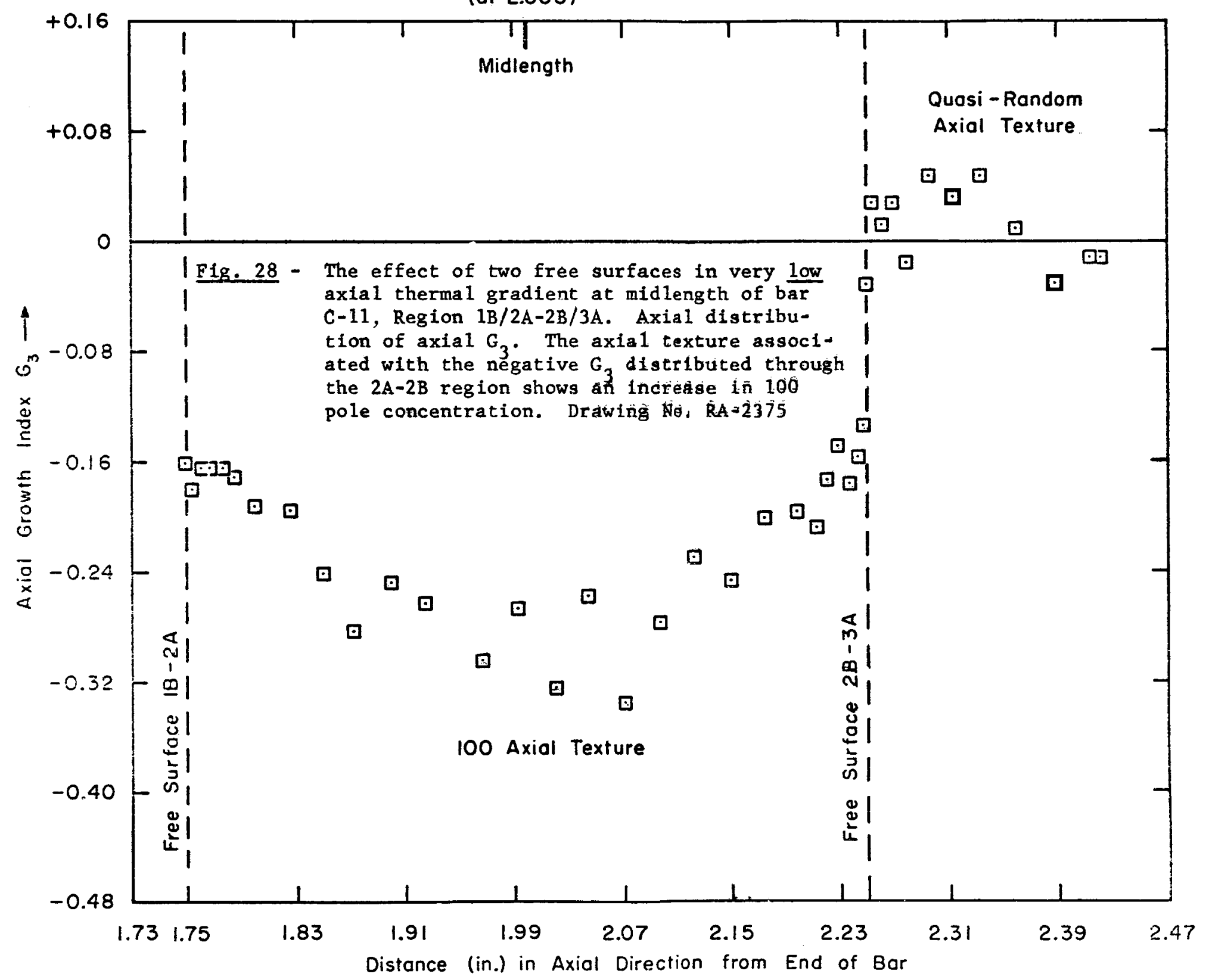


Texture and Growth Index

From examination of the axial distribution of $G_{3}$ in a high therma 1 gradient, Fig. 26, and of the radial distribution of $\mathrm{G}_{3}$ in a moderate therma 1 gradient, Fig. 27, we see that a "free" surface has made a marked difference in the $G_{3}$ gradient only where the former thermal gradient had been large. We might therefore conclude that the thermal gradient, which is ordinarily high only 0.065 inch from the water-quenched end in a solid bar, has, by the introduction of an insulated free surface, been sharply reduced behind the free surface so that the thermal environment is similar to the center of a quenched bar or the midwall of a quenched tube, where the texture vanishes $\left(G_{3}=0\right)$. Moreover, we could conclude that since the introduction of a free surface across a region of moderate prior thermal gradient makes ro difference to the $G_{3}$ distribution, the prior thermal gradients were already too low, anyway, for a strong induced tex ture to be formed. However, we find in Fig. 28 that ir the half inch between the two internal joints $1 B-2 A$ and $2 B-3 A$, where there should be almost no axial thermal gradient, there is a strong axial $G_{3}$ gradient with a minimum (max. negative) at the exact thermal center of the bar. The axial texture at this position is 100, the same type that is found parallel to the thermal gradients near a cooling surface. At the joint: $2 \mathrm{~B}-3 \mathrm{~A}$ there is a sharp increase of axial $\mathrm{G}_{3}$ to about $\mathrm{G}_{3}=0$, very reminiscent of the shaxp increase in axial $G_{3}$ at the joint 0.065 inch below the end of the bar (Fig. 26). The dis tribution of axial $G_{3}$ in this region is very puzzling, because, based on prior experience, it implies that a thermal gradient. had existed between the joints $1 B-2 A / 2 B-3 A$, with the lowest temperature midway between. Presumably a thermal gradient would exist only in the radial direction at this point, yet if the radial $G_{3}$ distribution down to a depth of 0.68 inch (Fig. 27) is any indication of radial thermal gradient, this cannot be appreciable. 
$G_{3}$ under nickel or Zircaloy cladding
(2) Under Nickel or Zircaloy II Cladding.

The effect of an internal free surface on $G_{3}$ distribution 0.065 inch below the quenched end of an ingot bar encouraged a study of the $G_{3}$ distribution beneath a 0.002 -inch film of nickel electroplated on dingot (DK-1-P) and ingot (K-14-P) 1.0-inch diameter by 4.0 -inch long bars quenched in $13^{\circ} \mathrm{C}$ water fiom the beta phase. Each bar had been plated over half its length, and outgassed (but not diffusion bonded). The results are shown in Fig. 29. The points for the plated and bare metal were taken from adjacent 1 -inch long $20^{\circ}$ sectors on both sides of the midlength position. The results show a definite increase in $G_{3}$ under the plated sections, and that the plating in both dingot and ingot definitely decreases the radial texture penetration compared to that at and near the bare surface. The effect of plating is twice as deep for ingot (about 0.20 inch) as for dingot $(0.10 \mathrm{inch})$.

The effect of a much thicker cladding between the quench. ing medium and uranium was examined in a 2.0 -inch OD by 1.8 inch ID by 4-3/4 inch long ingot tube clad (by coextrusion) with about 0.025 -inch Zircaloy-2. Bands 1 inch wide were machined off the oD to give $0.000-, 0.005-, 0.010-$ and 0.020 inch clad thicknesses. The tube was beta treated and quenohed into $13^{\circ} \mathrm{C}$ water. The radial distribution of radial $\mathrm{G}_{3}$ across the tube wall is given in Fig. 30. No appreciable effect of the cladding was found. A possible explanation is that the metallurgical bonding between the Zircaloy and the uranium was much better than between the non-diffused nickel plating and wranium, or that the greater similarity of thermal conductivity between Zircaloy and uranium, would cause little or no change in thermal gradient at the Zircaloy-uranium interface compared with a nicke1-uranium interface. 


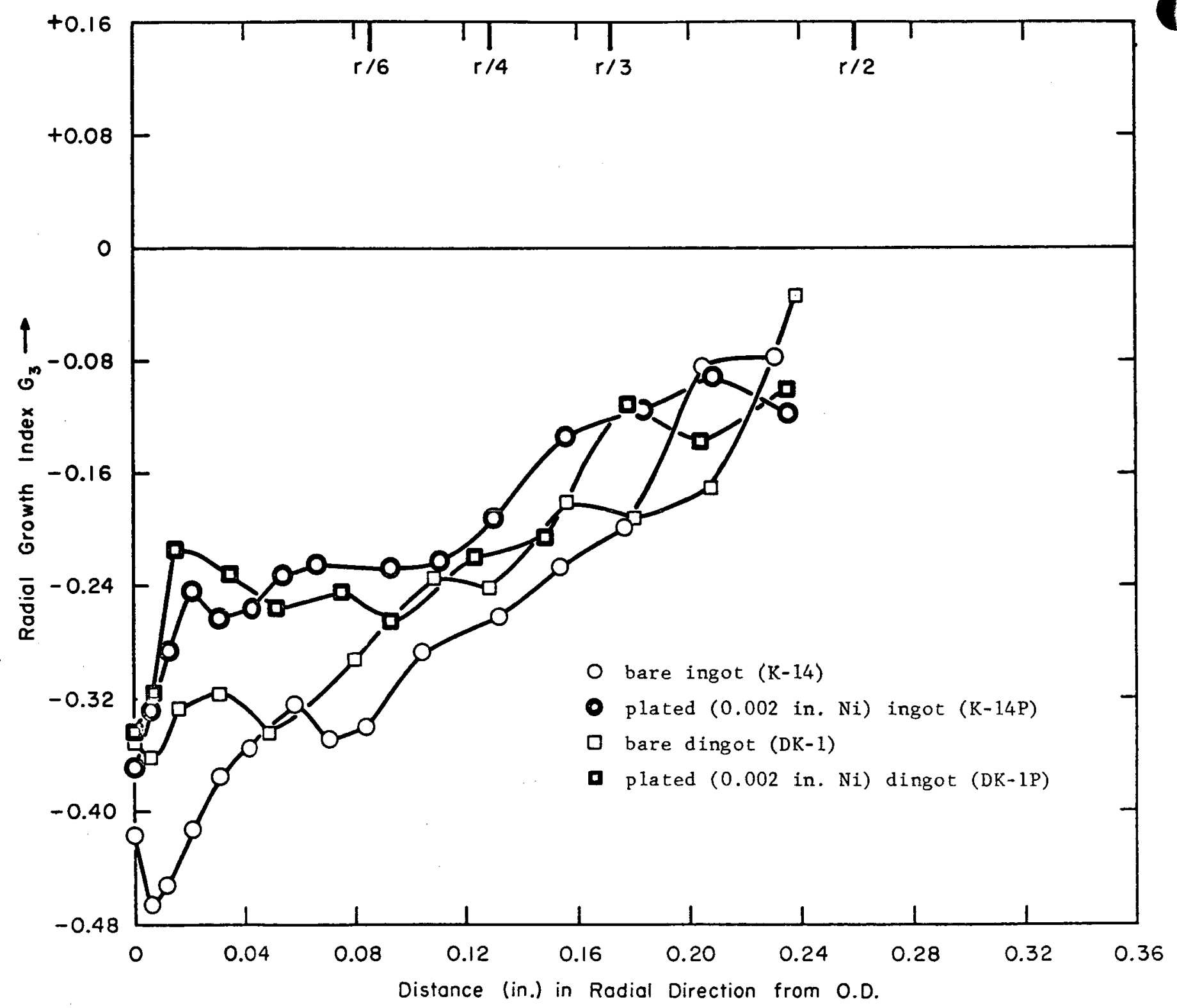

Fig. 29 - Radia1 distribution of radia1 $G_{3}$ under bare and 0.002-inch nicke1plated ingot and dingot 1.0-inch diameter by 4-inch long bars quenched in $12^{\circ} \mathrm{C}$, water after beta treatment. $G$ data from $20^{\circ}$ - wide by 1 -inch long sectors. Exactly half the length ${ }^{3}$ of the bars was plated before beta treatment. Drawing No. RA-2378 


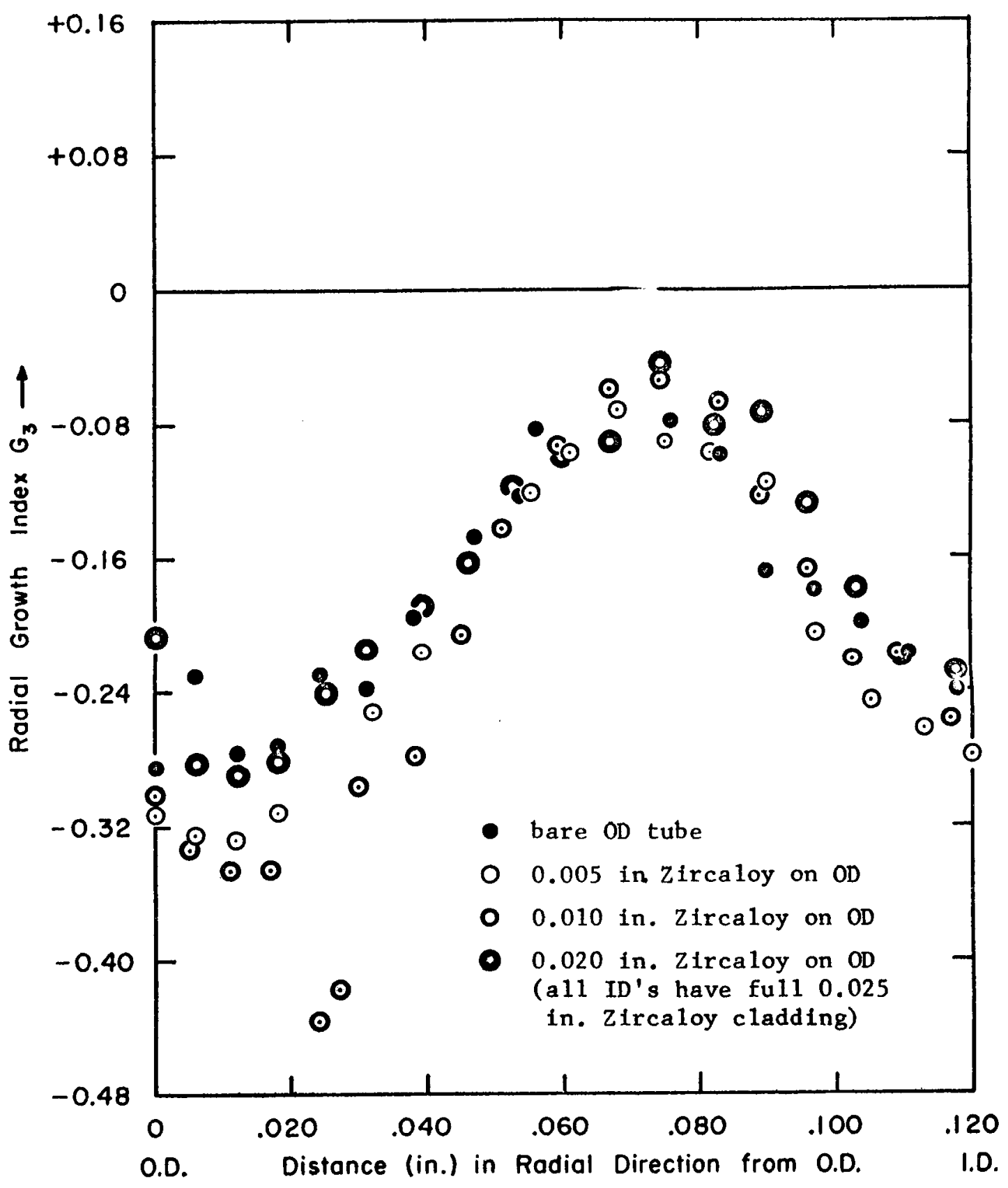

Fig. 30 - Radial distribution of radial G in $10^{\circ}$ sectors under $0.020-$ inch, $0.010-$ inch and $0.005-$ inch Zircaloy-2 clad 2-inch OD by 1.8-inch ID by 4-3/4 inch long ingot tube $(T-6)$. Radial $G_{3}$ under bare surface included for comparison. Tube quenched from the beta in $13^{\circ} \mathrm{C}$ water. Drawing No. RA-2382 
IV. RECOMMENDATIONS FOR FURTHER STUDY

1. If it is desired to decrease the degree of radial texture penetration in beta-treated uranium rods and tubes, it may be possible to do so by altering the direction of the thermal gradient experienced by the mecal. on cooling from the beta phase during a rapid lateral quench. One interesting possibility is that of a controlled longitudinal insertion rate into a suitable quenching oil. In this case, the thermal gradients near the surface(s) would tend to be reoriented toward a direction $45^{\circ}$ from the axial direction (instead of the $90^{\circ}$ or radial orientation caused by the usual lateral quench), and the resulting radial $G_{3}$ should be less negative near the surface(s).

2. It has been shown that there is an important relation between distortion found after beta treatment and the change in over-all radial and axial texture caused by beta treatment. A better understanding of the distortion problem in both tubes and rods would be possible by predicting the distortion that would be caused solely by a texture change. This could be computed by using the calculated thermal ex:pansion coefficients which apply to heating or cooling.

3. Determine the TTT characteristics of unalloyed dingot and ingot in the form of very thin (0.005-inch thick?) uranium sheet.

a. Study the effect of beta grain size (vary beta grain size by means of prior delta treatment) on the TTT characteristics.

b. Determine whether there is an isothermal transformation whose product is nonorientation dependent. If so, relate the: results to the texture distribution in $a$ thick plate (0.1-inch) cooled so as to trans form in this region. 
4. Determine in a beta-phase metastable alloy whether there is any empirical relation between the beta texture and the texture of the alpha phase transformed from it. The results should indicate whether the alpha texture induced in unalloyed uranium by cooling from the beta phase is due to the reorientation of alpha crystallites by the thermal gradient on cooling, or whether the final inducéd alpha texture is due to the reorientation of beta crystal. lites on heating well into the beta phase.

5. Chiswik $(21,22)$ has found that extensive microstructural changes occur on thermal cycling. It would be expected that texture changes would also occur in betatreated uranium during thermal cycling. Shupe ${ }^{(23)}$ has shown that the 110 axial texture in rods tends to change toward 010 axial texture during irradiation. It would be useful to know whether this change could be due primarily to the thermal cycling parameter of irradiation. Accordingly, a study of the effect of thermal cycling on the texture of uranium dras tically quenched from the beta phase, would be valuable.

6. It had been suggested earlier that a possible cause of the 100 texture found parallel to the prior thermal gradient is a cooperative rotation of crystallites toward the direction in which two of the three alpha phase thermal coefficients contracted on cooling from the beta phase. (24) For the pur pose of obtaining more clues to the origin of this induced texture, so that such textures may be controlled, two experiments are suggested.

\section{a. Beta treatment of polycrysta11ine uranium} containing dispersed refractory compound. It may be profitable to test the cooperative hypothesis by beta treatment of a polycrystalline uranium in which the grains are somewhat mechani. cally isolated from each other by a coating of uranium oxide. 
If the cooperative hypothesis is correct, then such uranium should exhibit considerably less induced texture than ordinary uranium subjected to the same heat treatment.

b. Study of other elements cooled through an allotropic phase change. Another cause of induced texture may be associated with some peculiar mode of crystallographic transformation between beta and alpha uranium. It may be possible: to determine in which general aspect the primary cause lies by discovering whether a texture is induced in face-centered cutic/ body-centered cubic or in body-centered cubic/close-packed hexagonal transformations. For the FCC/BCC case, gamma/alpha. iron transformation could be studied. For the $\mathrm{BCC} / \mathrm{HCP}$ case, beta/alpha zirconium transformation would be informative. Ir iron (cubic) the thermal expansion coefficient is isotropic and does not depend on direction. In HCP zirconium, therma 1 expansion in the direction of the c-axis is about twice that for the expansion along the a -axis, and is therefore anisotropic (like alpha uranium). The discovery of a texture parallel to the transformation thermal gradient in polycrystalline alpha zirconium, but not in polycrystalline alpha iron, would suggest that thermal expansion anisotropy is a likely origin of induced texture. 


\section{ACKNOWLEDGEMENTS}

The authors wish to acknowledge the guidance and helpful suggestions offered during the program by Dr. V. I. MontenyohI (SRL) who has acted as Liaison officer for the Working Committee of FEDC; to thank Mr. L. R. Aronin (NMI), Project Manager, for his patient direction of the studies; and, finally, to thank both Mr. R. McCusker and Mr. P. F. Corkery for their very careful work in carrying out the $\mathrm{X}$ ray diffraction, heat treatment and distortion measurements of the samples. The authors are further indebted to Mrs. Elizabeth Churchill (NMI) for editorial assistance throughout the preparation of this report. 
VI. REFERENCES

M. D. Jepson and others, Proc. 2nd U. N. International Conference on the Peaceful Uses of Atomic Energy, Vo1. 6: Basic Metallurgy and Fabrication of Fuels, United Nations, 1958, pp. 42-54 (A/Conf. $15 / \mathrm{P} / 27)$.

2. Uranium Grain Size Standards Kit, rev. No. 1 (Dec. 7, 1961).

Prepared for the Fuel Element Development Committee by General Electric Co. (HAPO).

3. J. F. Boland, H. C. Kloepper, Jr., N. F. Neumann, "The Alloying Influence of Iron and Silicon on the Grain Size of Beta-Treated Dingot Uranium", pp. 31-43 in Process Development Quarterly Progress Report, April-June 1961. MCW-1465 (Aug. 1, 1961).

4. NMI-2805, p. 20.

5. R. Kornfeld, Mallinckrodt Chemica1 Works, May 1, 1959, unpub1ished data.

6. NMI-2805, p. 24.

7. V. Morton, R. Thudium, "Texture Gradients in Uranium Fuel Cores", NLCO-840 (1961) pp. 66-71.

8. NMI-2804, p. 16.

9. NMI-2806, p. 17.

10. NMI-2805, p. 24 .

11. V. Morton and others, "Texture Gradients in Oil Quenched, Mark V-B Outer Fuel Cores", NLCO-850 (Apri1 1962), pp. 61-67.

12. G. Donzé, "Nature de la transformation $\alpha \leq \beta$ de 1 'uranium au voisinage de l'equilibre", J. Nuc1. Mat. 5 (1962)150.

13. D. C. Minty, B. R. Butcher, "Grain Refinement of Uranium-Chromium Alloys by Continuous Cooling" [AERE-R 3896 (January 1962).] React. Sci. Tech. 16 (1962) 369.

14. NMI-2803, p. $15,48$.

15. NMI-2803, p. 12,35 . 
References (continued)

16. P. Duwez, "The Effect of the Rate of Cooling on the Allotropic Transformation Temperatures of Uranium", J.App1. Phys. 24 (1953) 152.

17. NMI -2805, p. 30 .

18. NMI -2804, p. 29 .

19. NMI -2805, p. 29 .

20. NMI-2806, p。 26.

21. H. H. Chiswik, R. M. Mayfield, "Growth Rates and Microstructural Characteristics of $300^{\circ} \mathrm{C}$ Rolled Uranium Rods on Thermal Cycling", ANL-4956 (June 1953).

22. H. H. Chiswik, "Effects of Preferred Orientation and Grain Size on Dimensional Stability of Uranium on Thermal Cycling and Irradiation", ANL-4955 (March 1956).

23. O. K. Shupe and others, "Effects of Various Preferred Orientations on the Dimensional Stability of Uranium,"HW-54605 (January 1958).

24. NMI-2804, p. A-1. 


\section{APPENDIX A}

Note: Figures A-1 through A-12 show radial distribution of radial $G_{3}$ in sectors cut from the middle two inches of 4-inch long tubes and rods beta treated at $720-730^{\circ} \mathrm{C}$ in Houghton $\mathrm{LH}-980$ molten salt and cooled in different media. In each figure, size is constant, but cooling medium varies. 


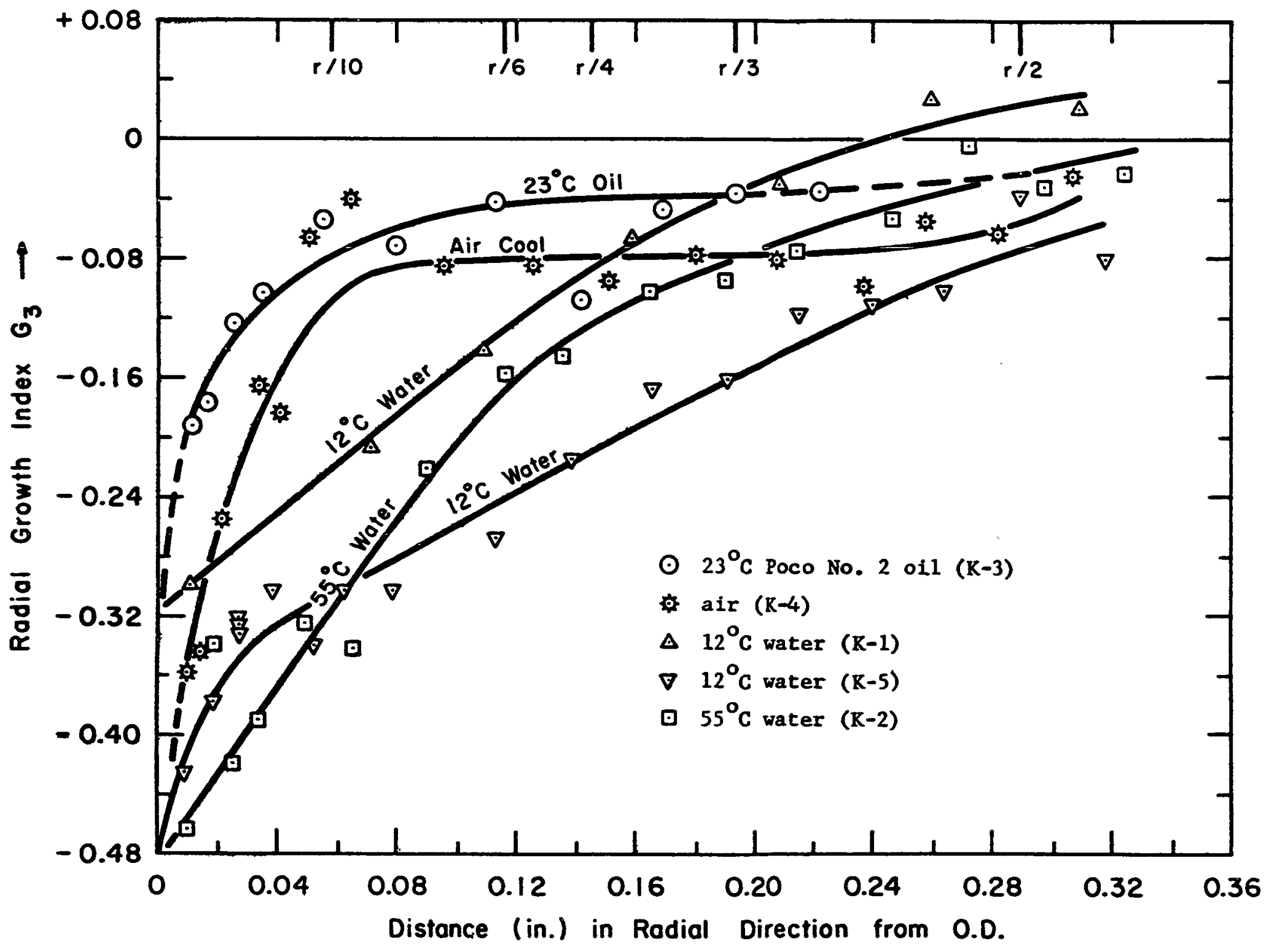

Fig. A-1 - Ingot rod, Diameter: 1.1 inch. Sector angle: 20․ Drawing No. RA-1915 


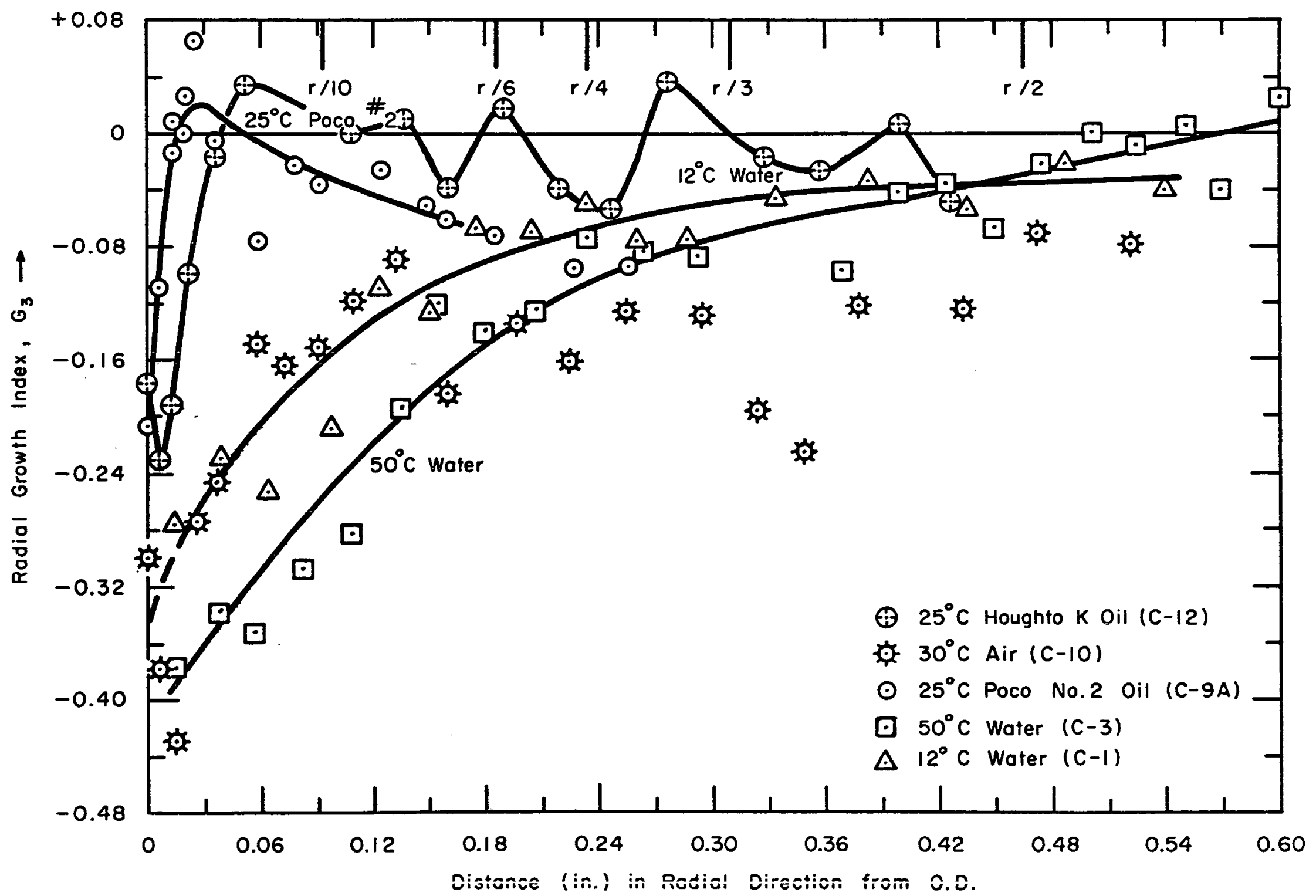

Fig. A-2 - Ingot rod, Diameter: 1.8 inch. Sector angle: 20 . Drawing No. RA-2124 


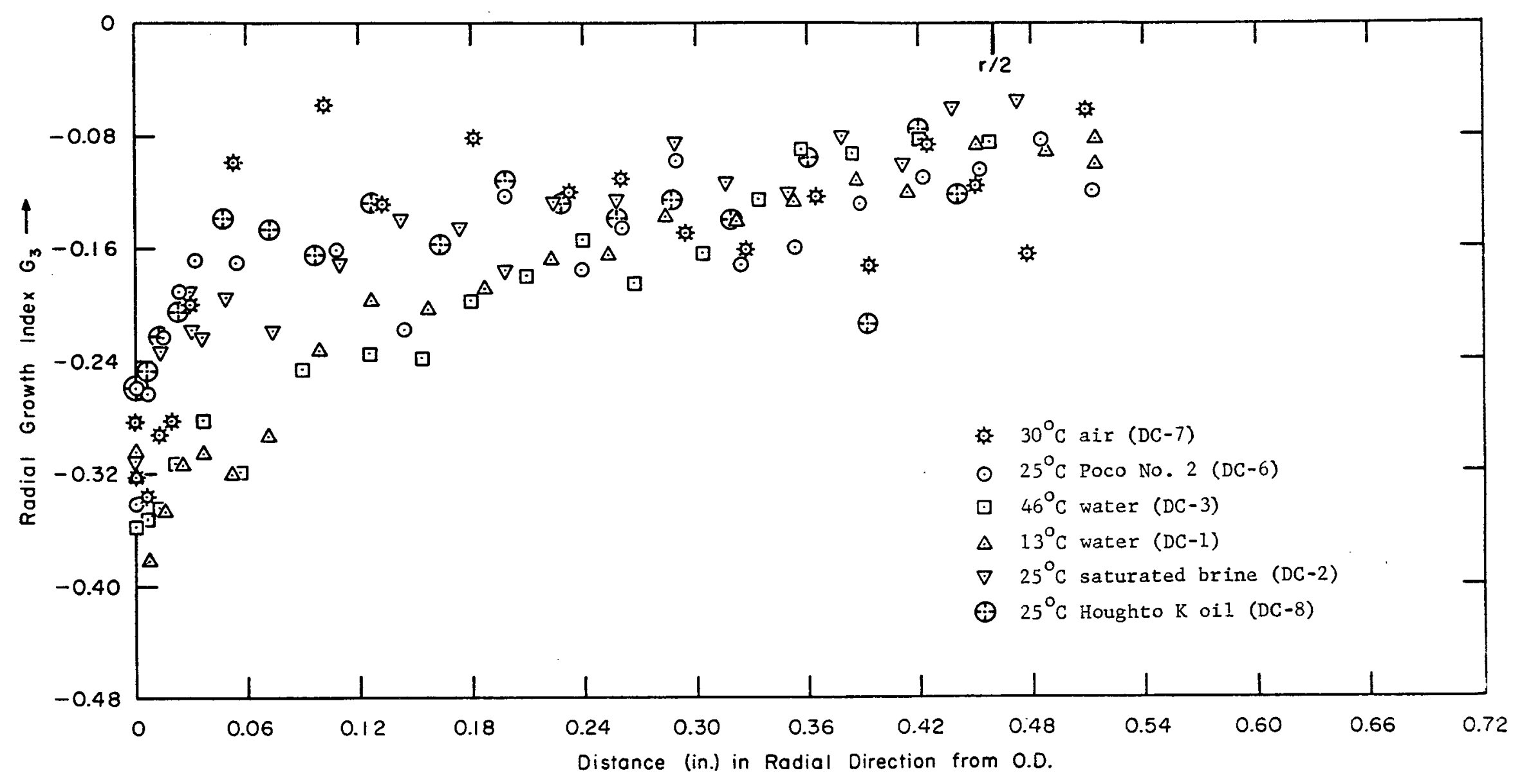

Fig. A-3 - Dingot rod, Diameter: 1.8 inch. Sector angle: $20^{\circ}$. Drawing No. RA-2194 


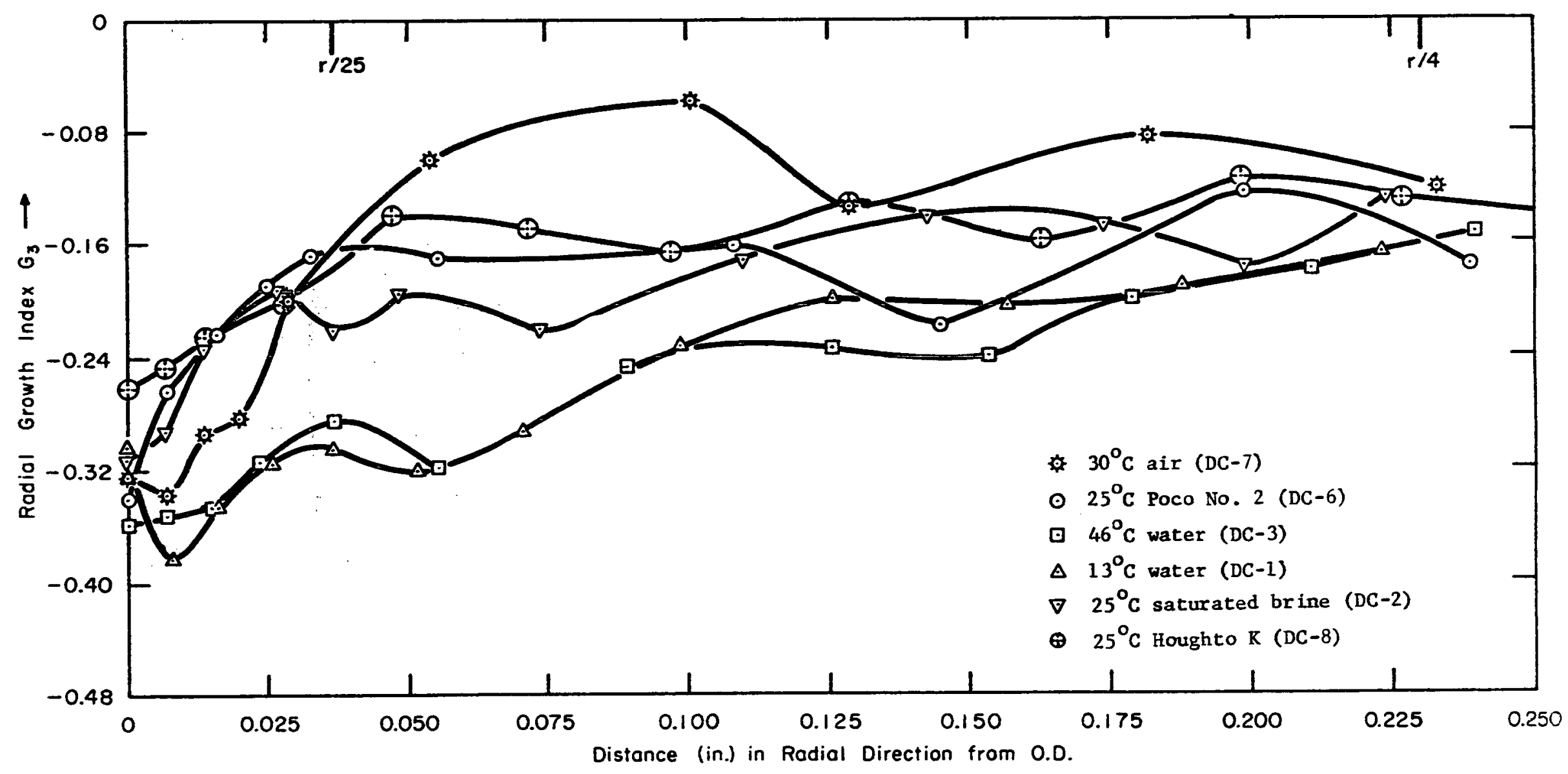

Fig. A-4 - Same as Fig. A-3, except on expanded abscissa to a depth of about r/4. Drawing No. RA-2193 


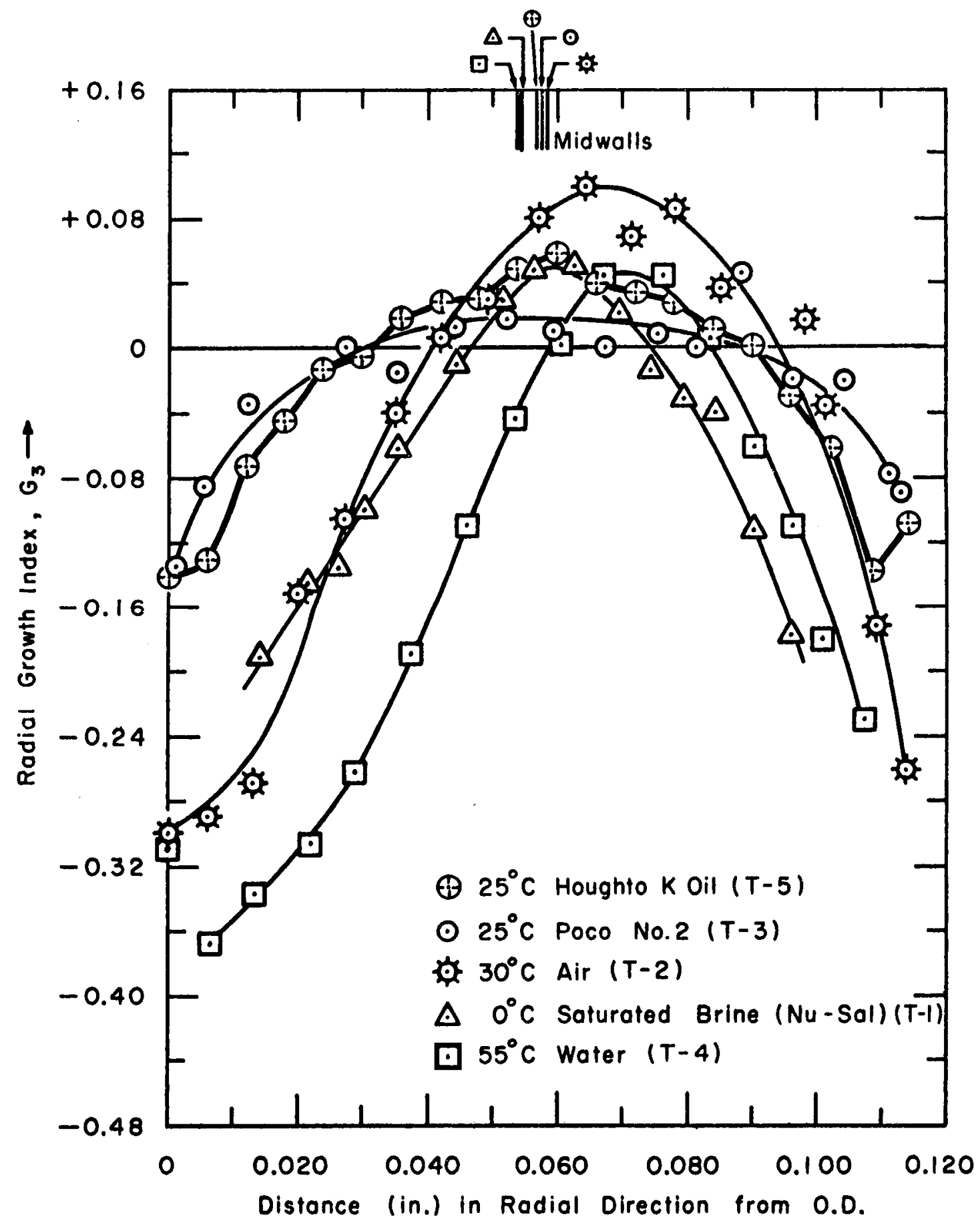

F1g. A-5 - Ingot tube, OD: 2 inches. ID: 1.8 inches. Sector angle: $10^{\circ}$. Drawing No. RA-2053 
C

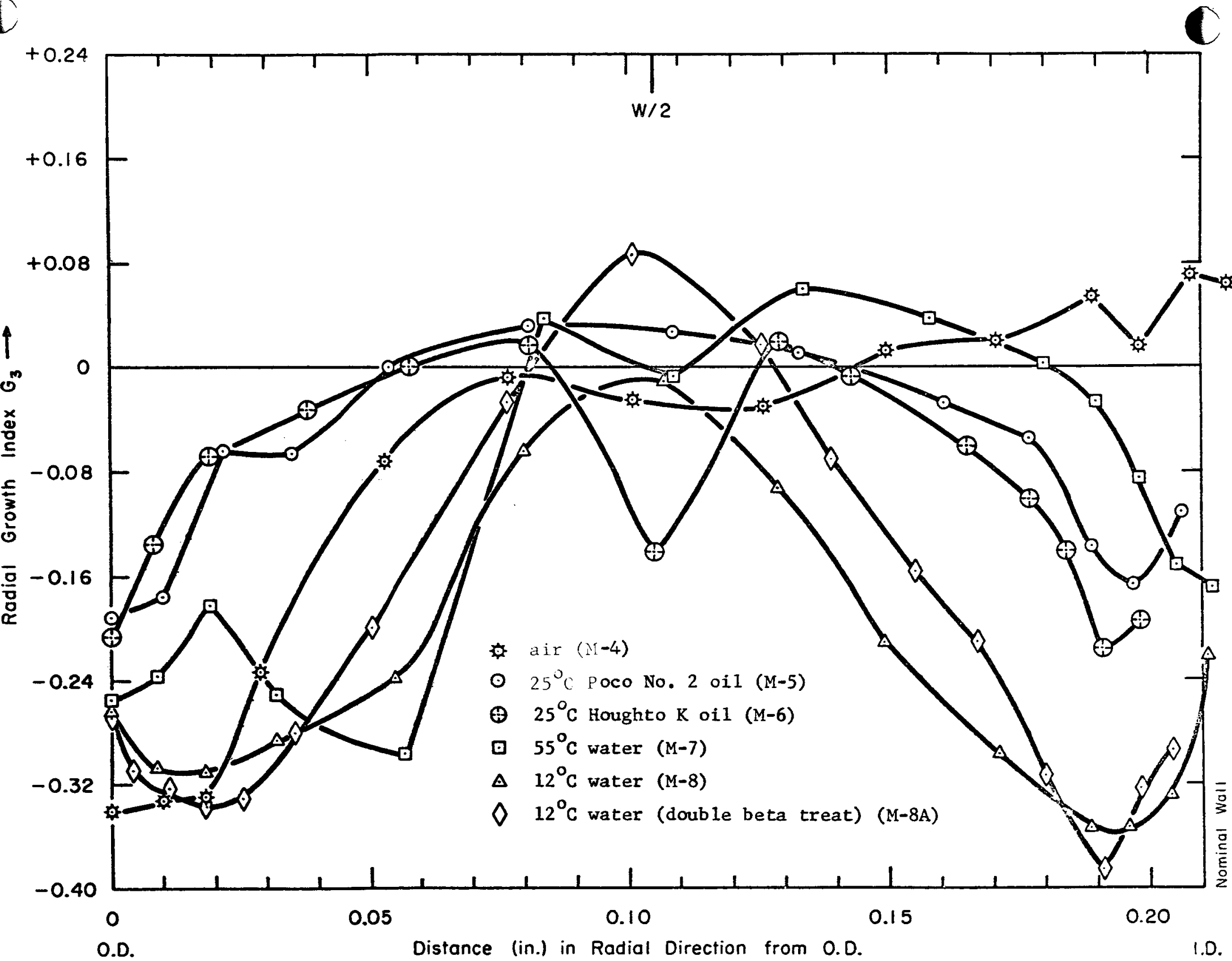

Fig. A-6 - Ingot tube, OD: 3 inches. ID: 2.5 inches. Sector angie: $10^{\circ}$. Urawing No. KA-Zj3j 


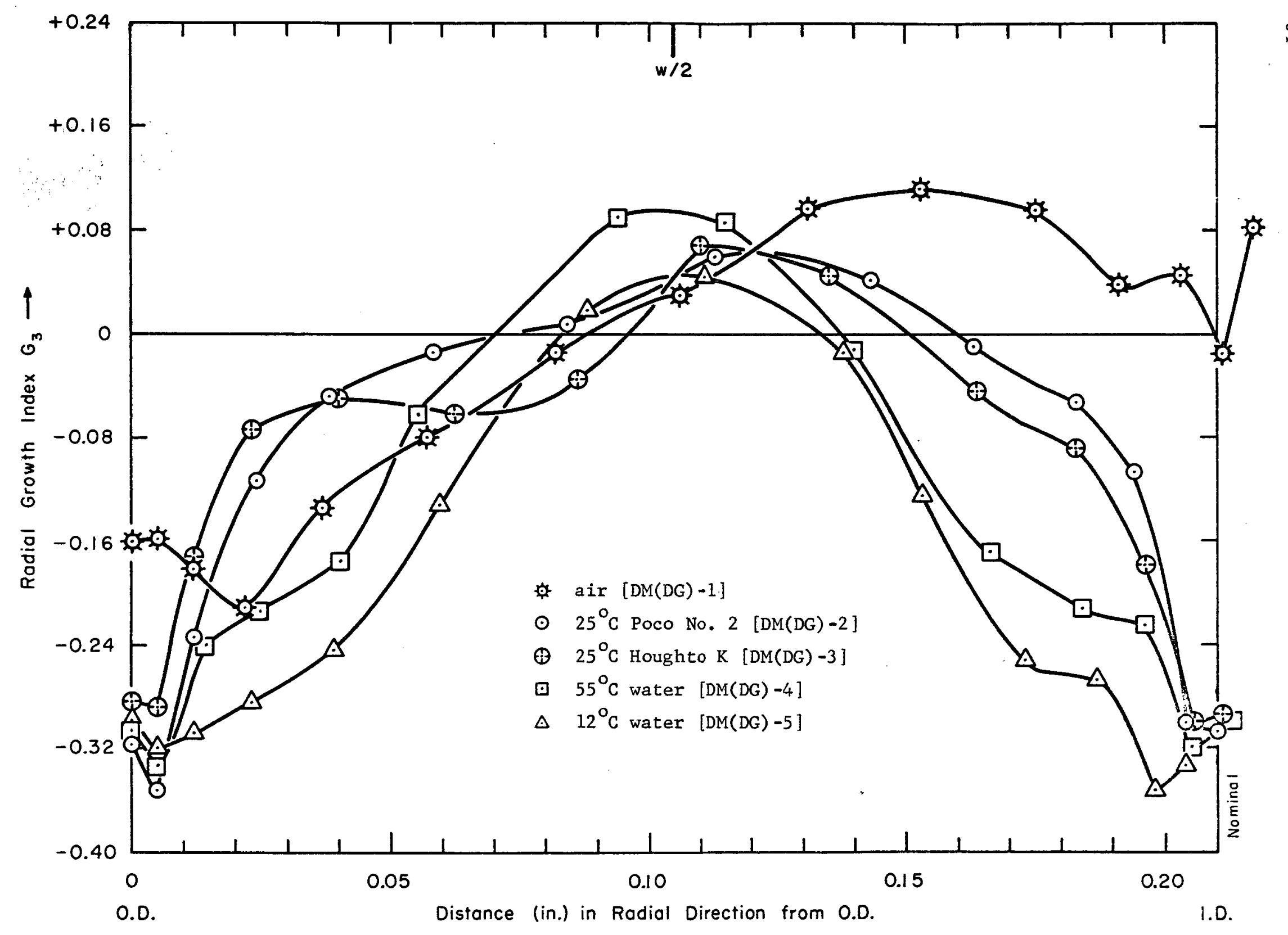

Fig. A-7 - Dingot tube, OD: 3 inches. ID: 2.5 inches. Sector angle: $10^{\circ}$. Drawing No. RA-2383 


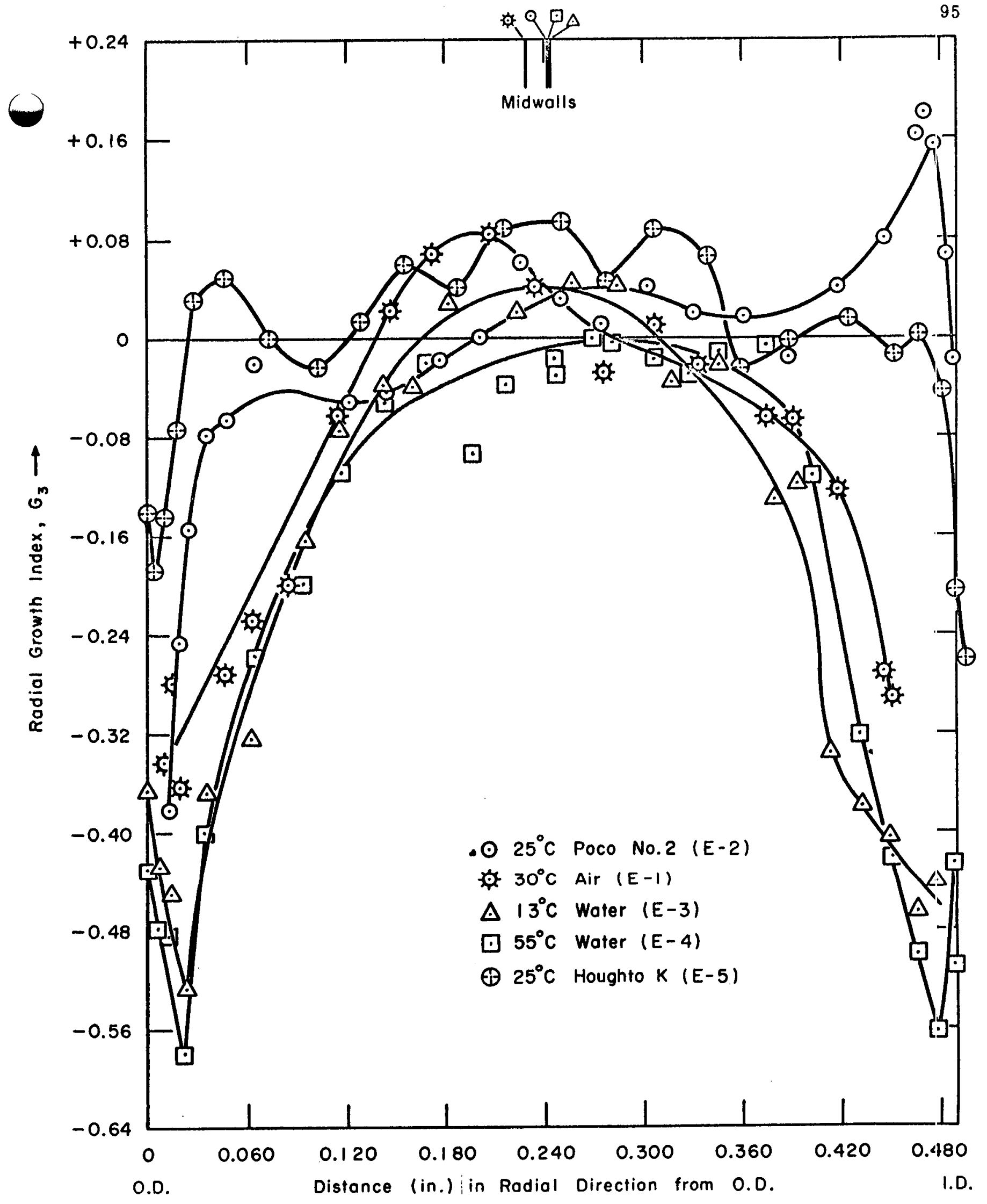
Fig. A-8 - Ingot tube, OD: 4 inches. ID: 3 inches. Sector angle: $10^{\circ}$ Drawing No. RA-2120 


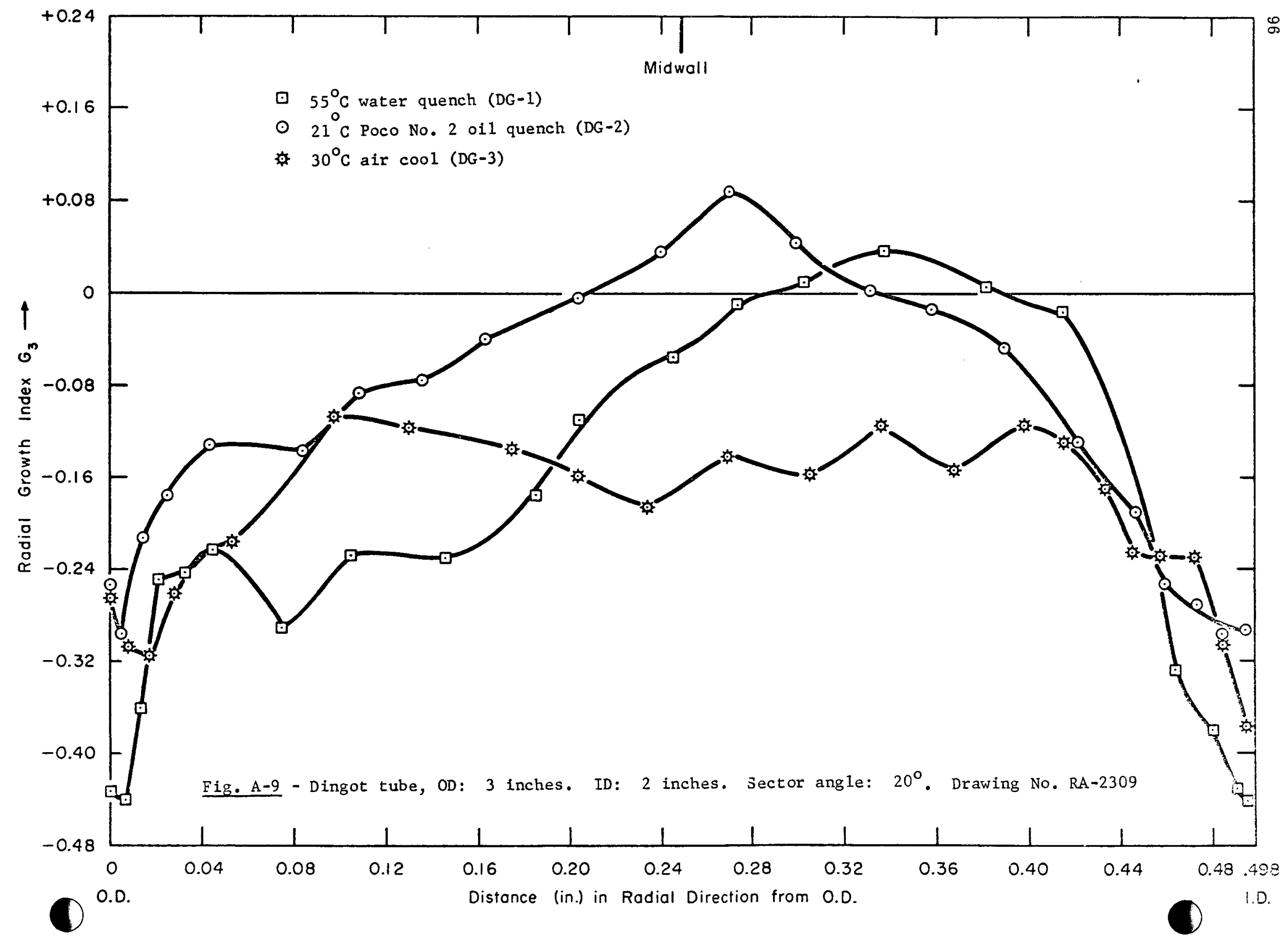




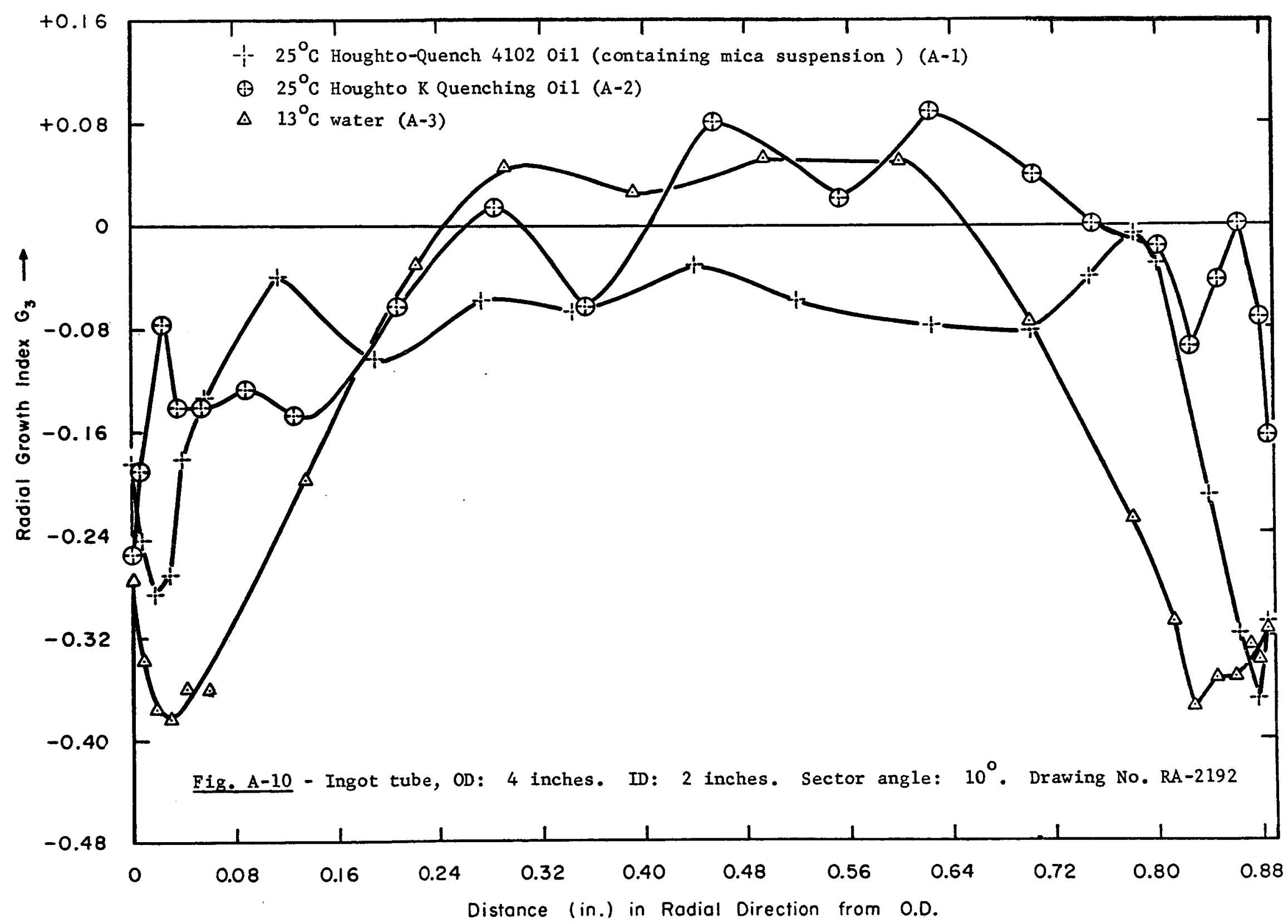




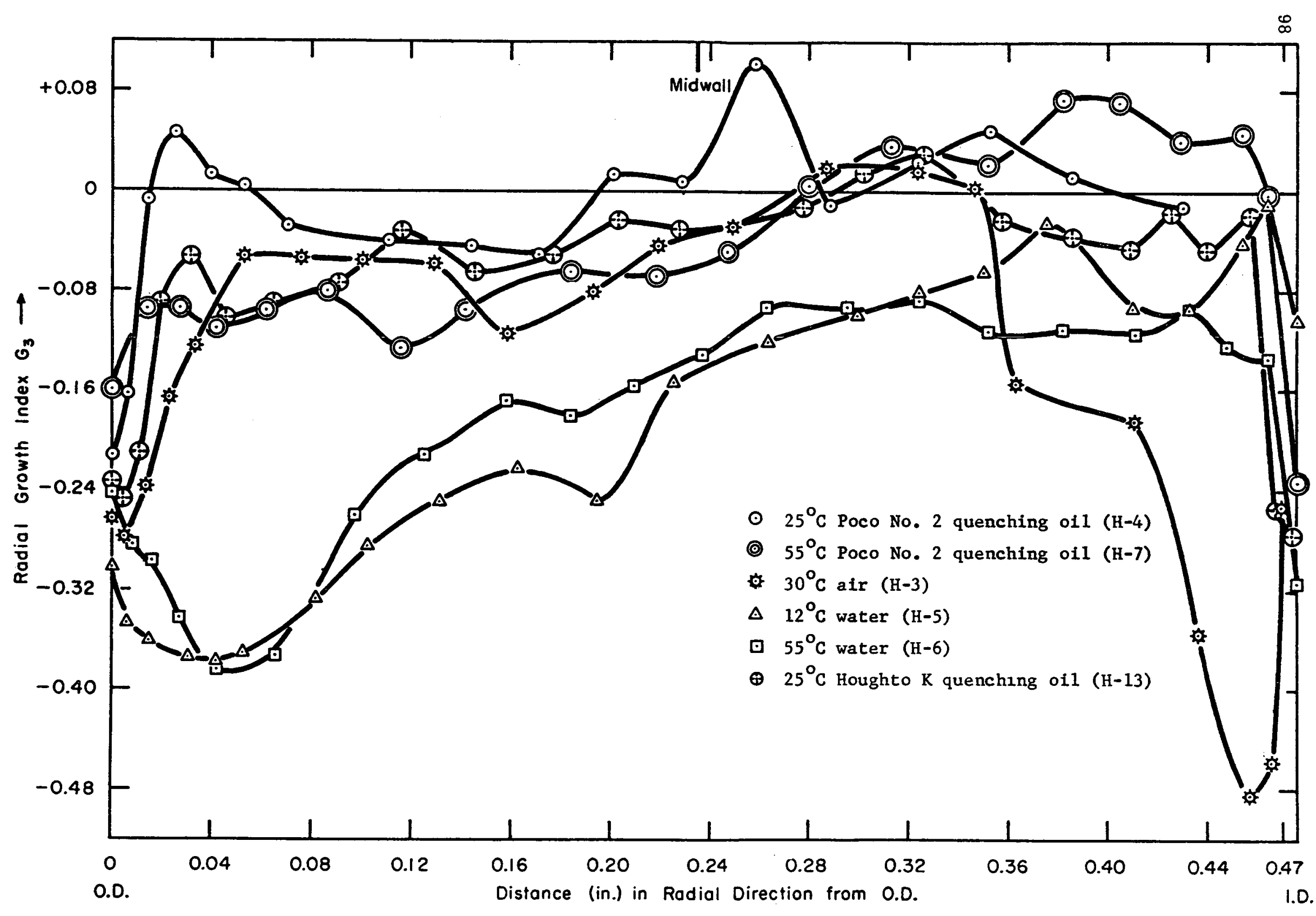

Fig. A-11 - Ingot tube, OD: 1.5 inches. ID: 0.5 inch. Sector angle: $20^{\circ}$. Drawing No. RA-2192 


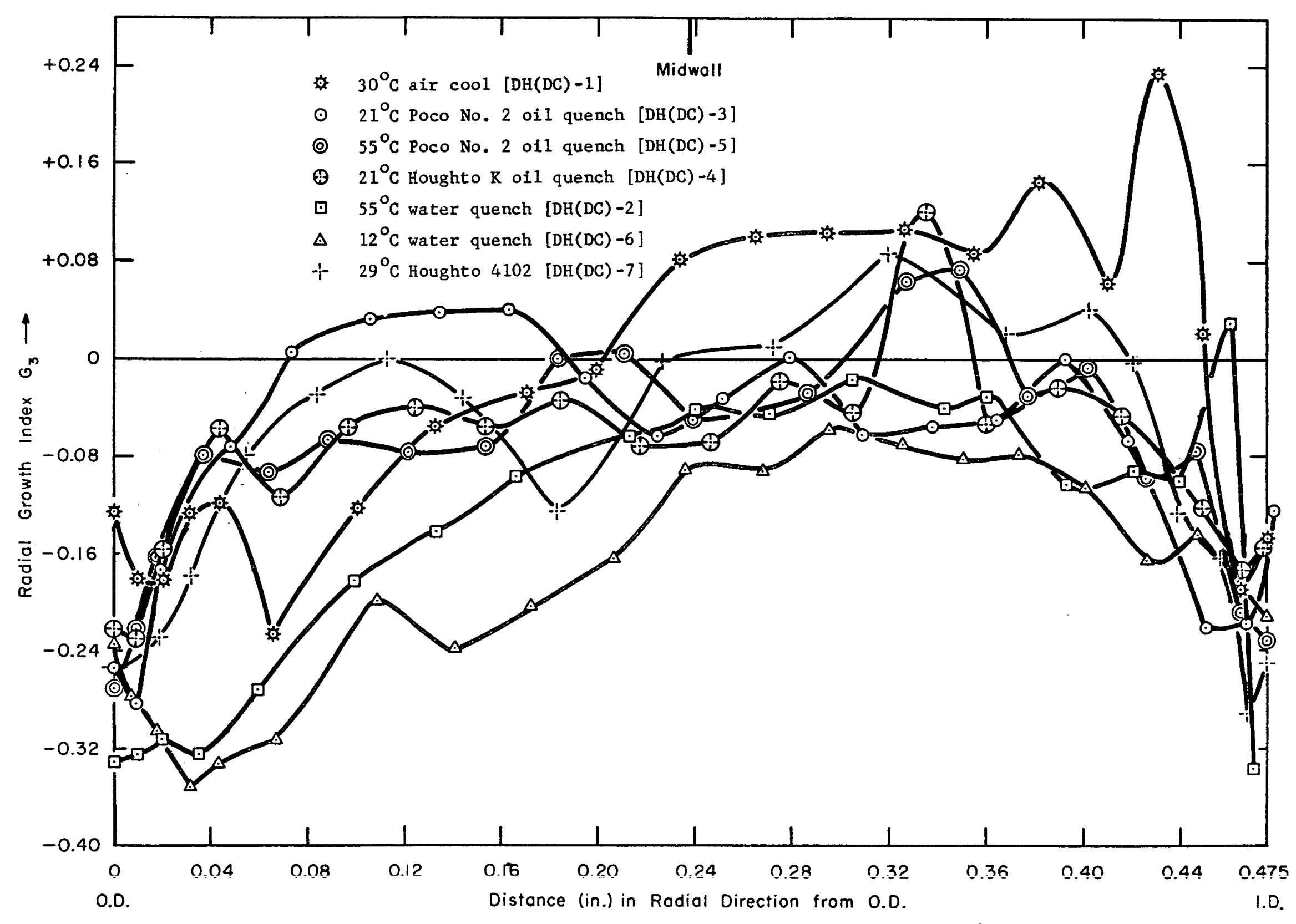

Fig. A-12 - Dingot tube, OD: 1.5 inches. ID: 0.5 inch. Sector angle: $20^{\circ}$. Drawing No. RA-2311 
Note: Figures A-13 through A-24 show radial distribution of radial $G_{3}$ in tubes and rods of different sizes beta treated at $720^{\circ}-730^{\circ} \mathrm{C}$ in Houghton LH-980 molten salt and cooled in media described. Radial depth plotted as $2 \mathrm{r} / \mathrm{w}_{0}$ from $O D$. In each figure, cooling medium is constant, but size varies. 


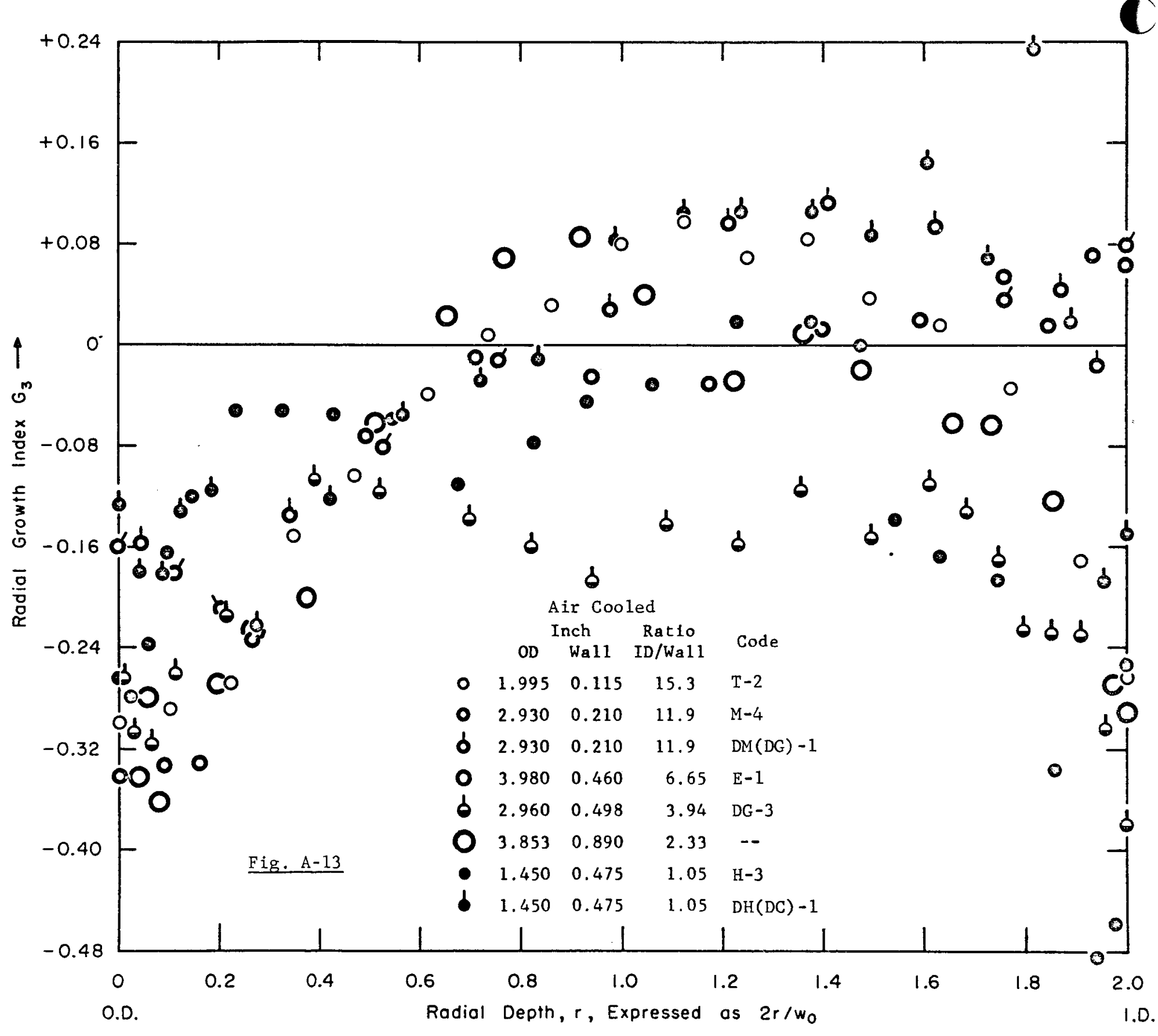




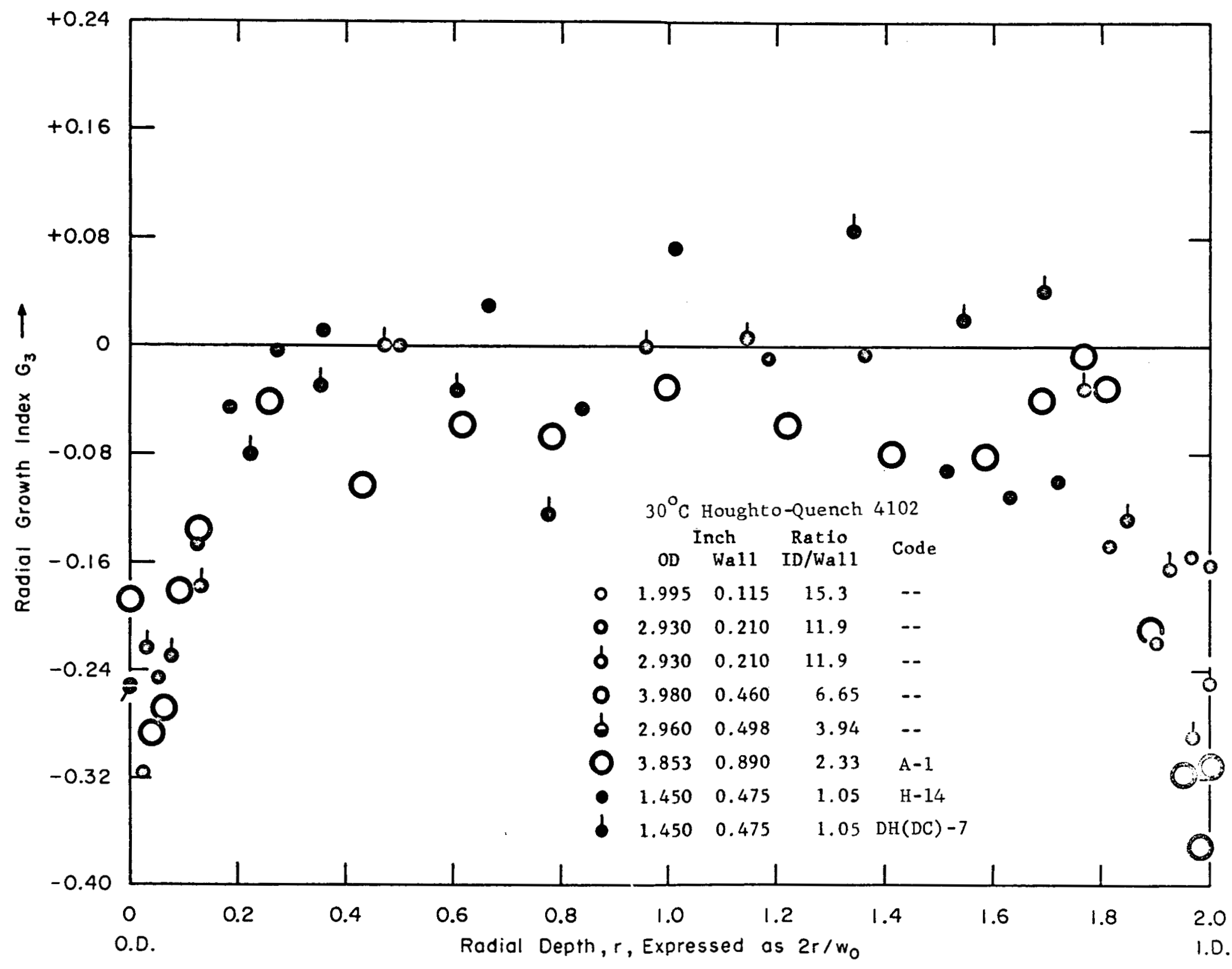




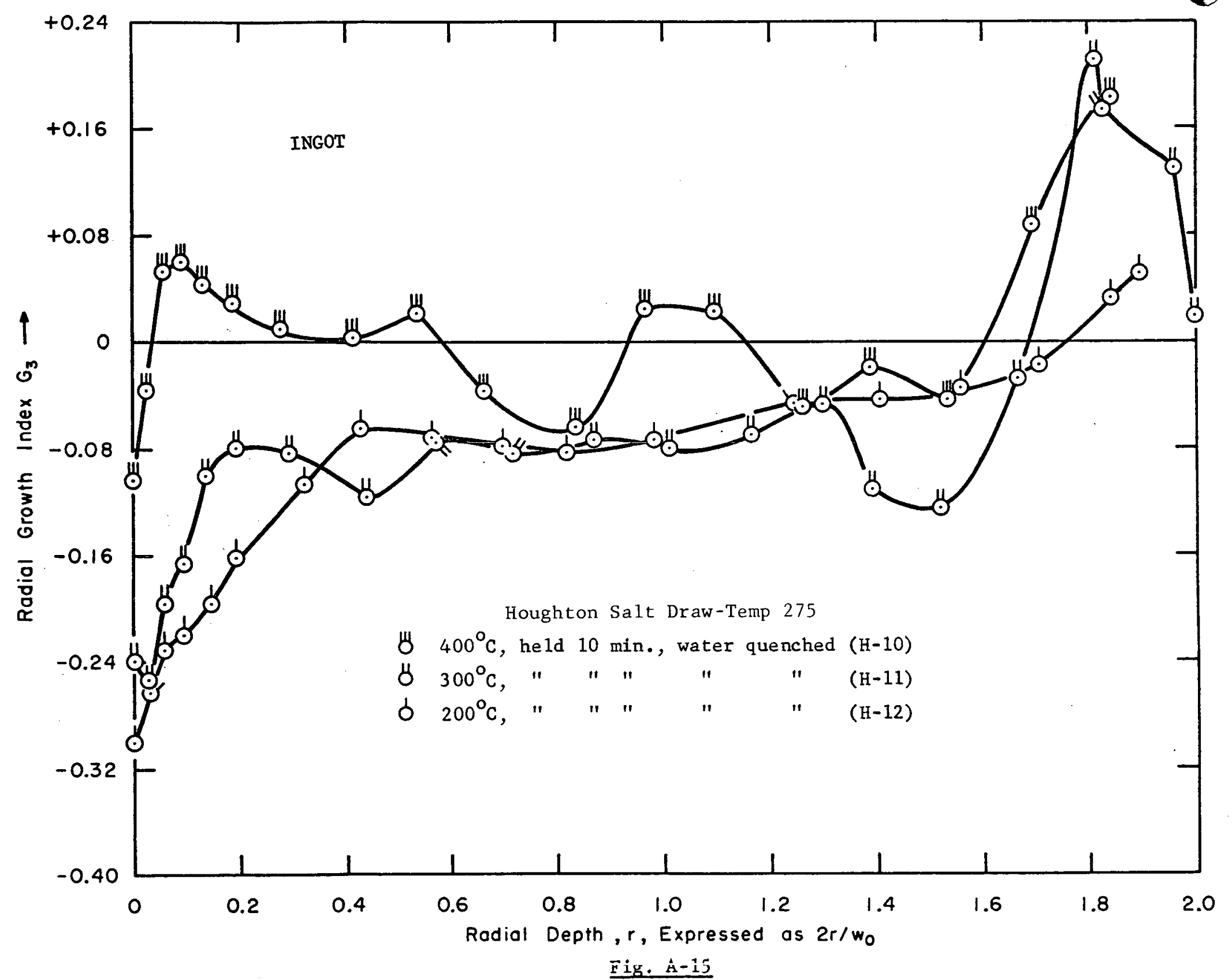




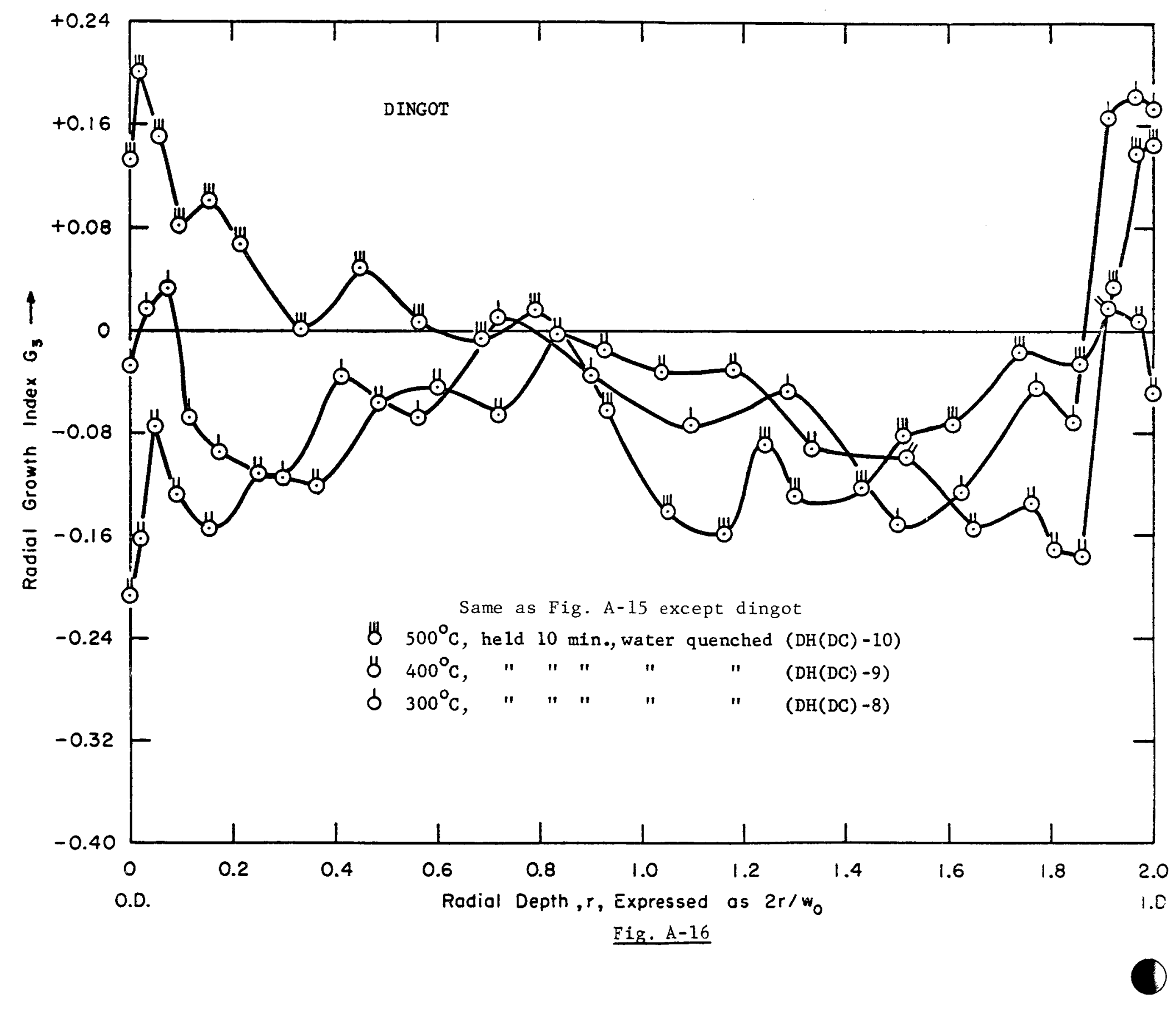




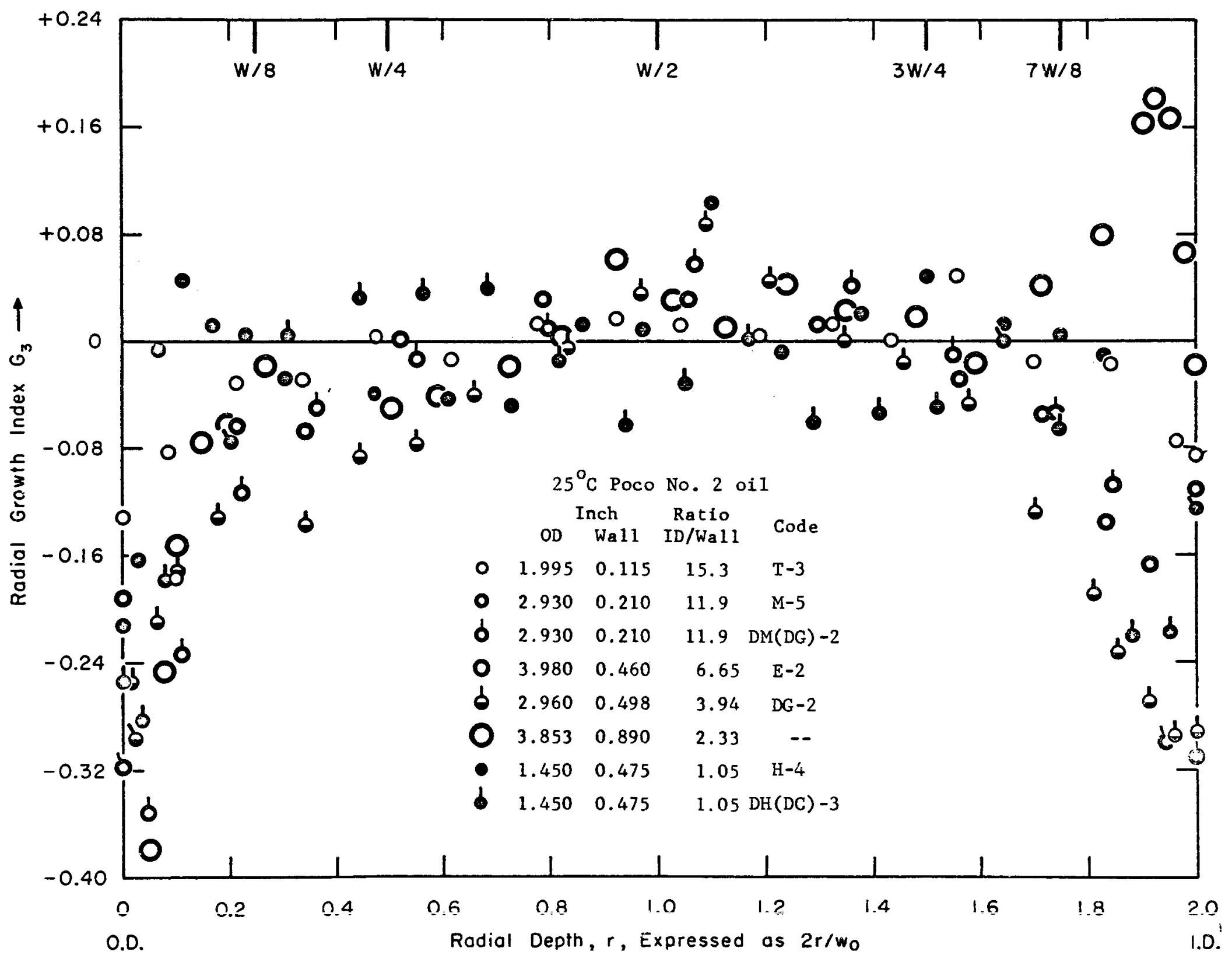

Fig. A-17 


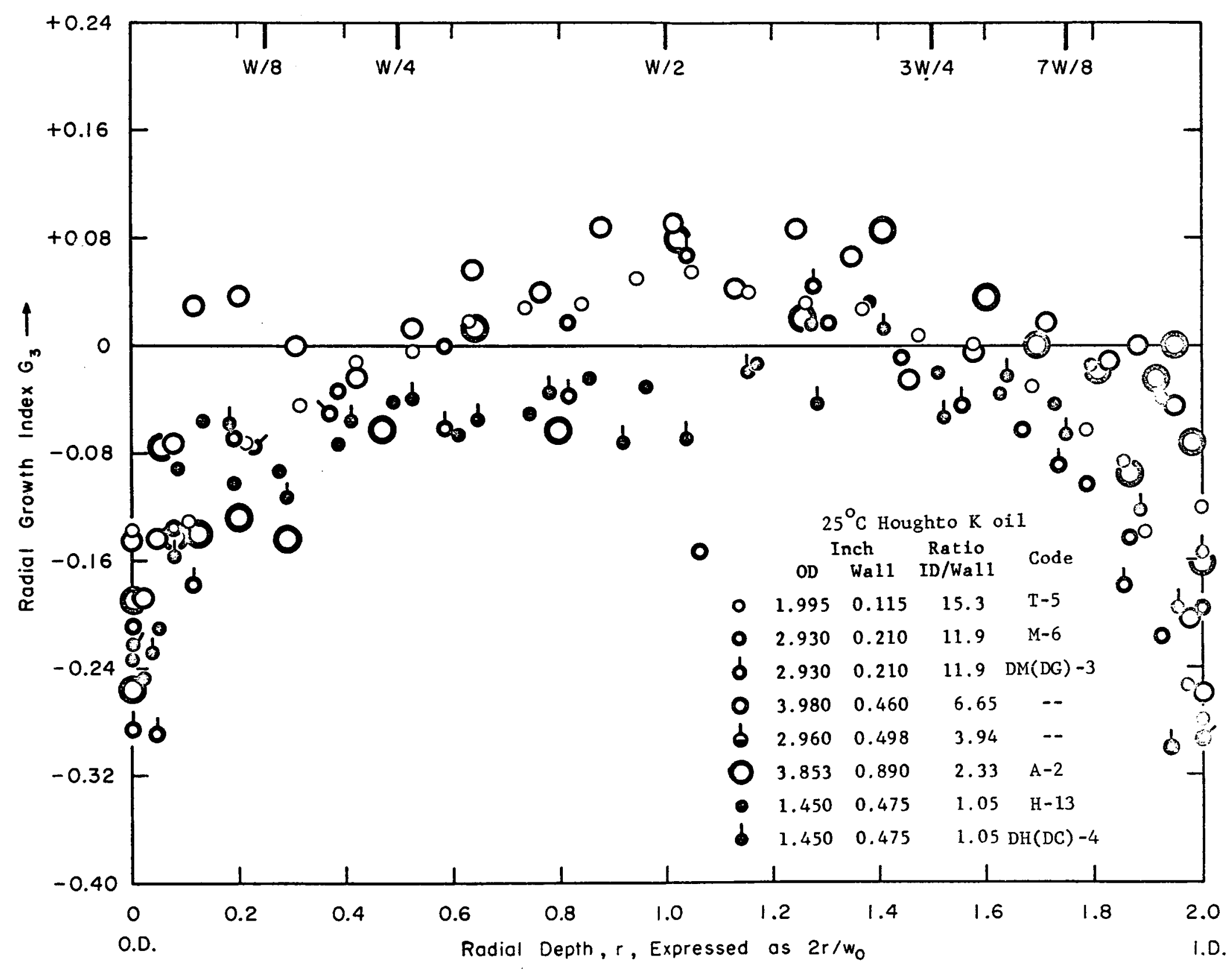

홍

Fig. A-18 


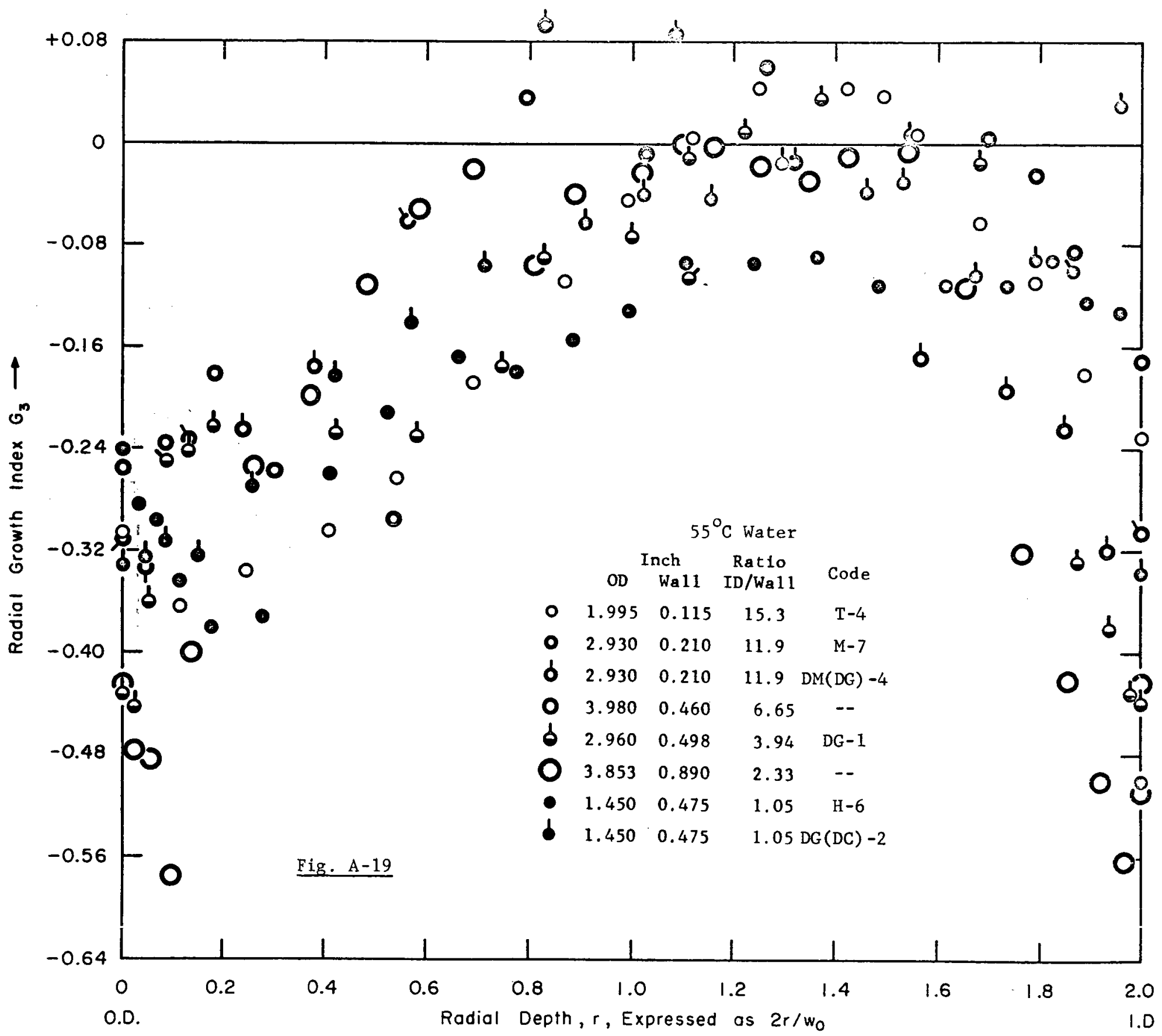




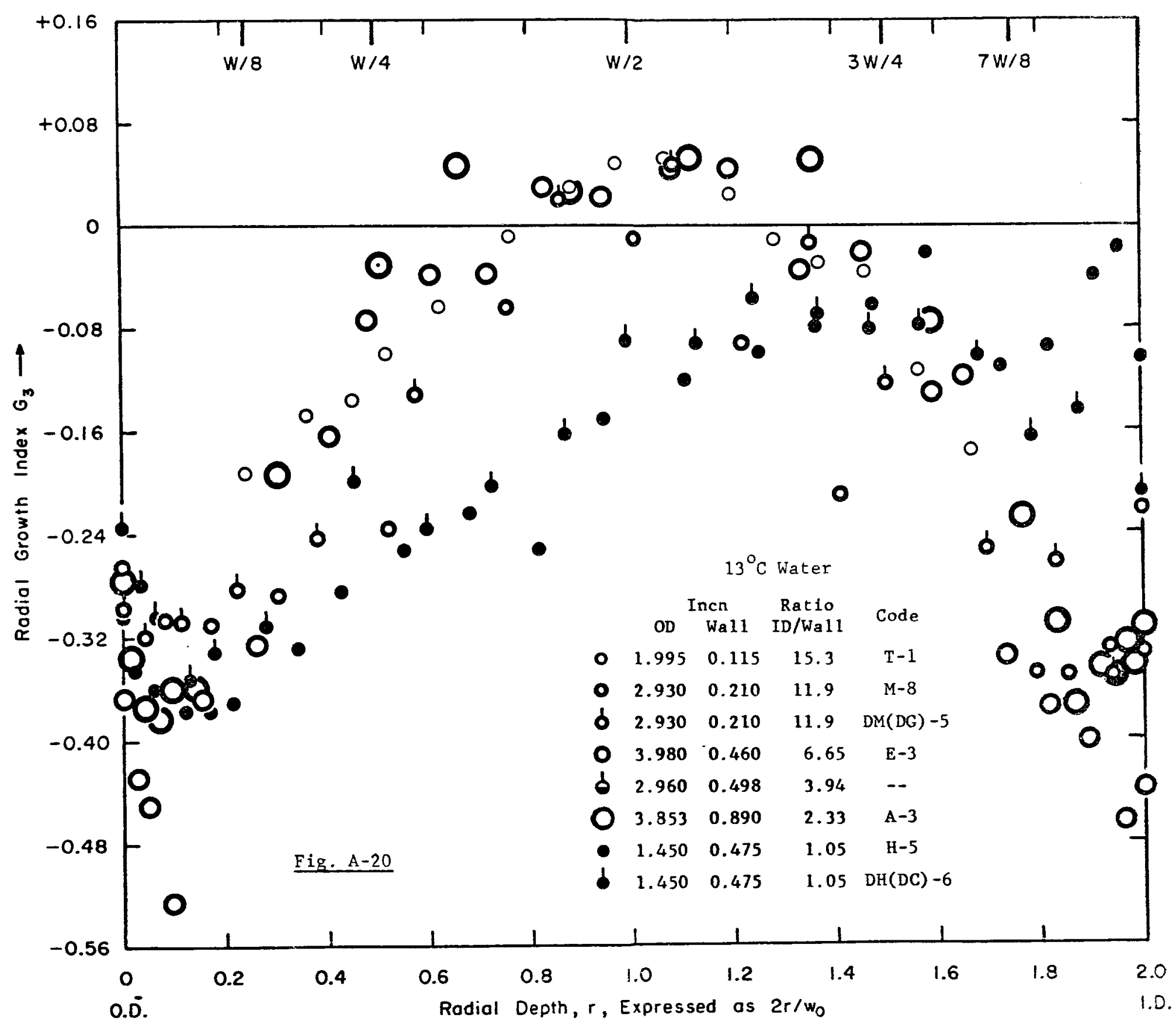


109

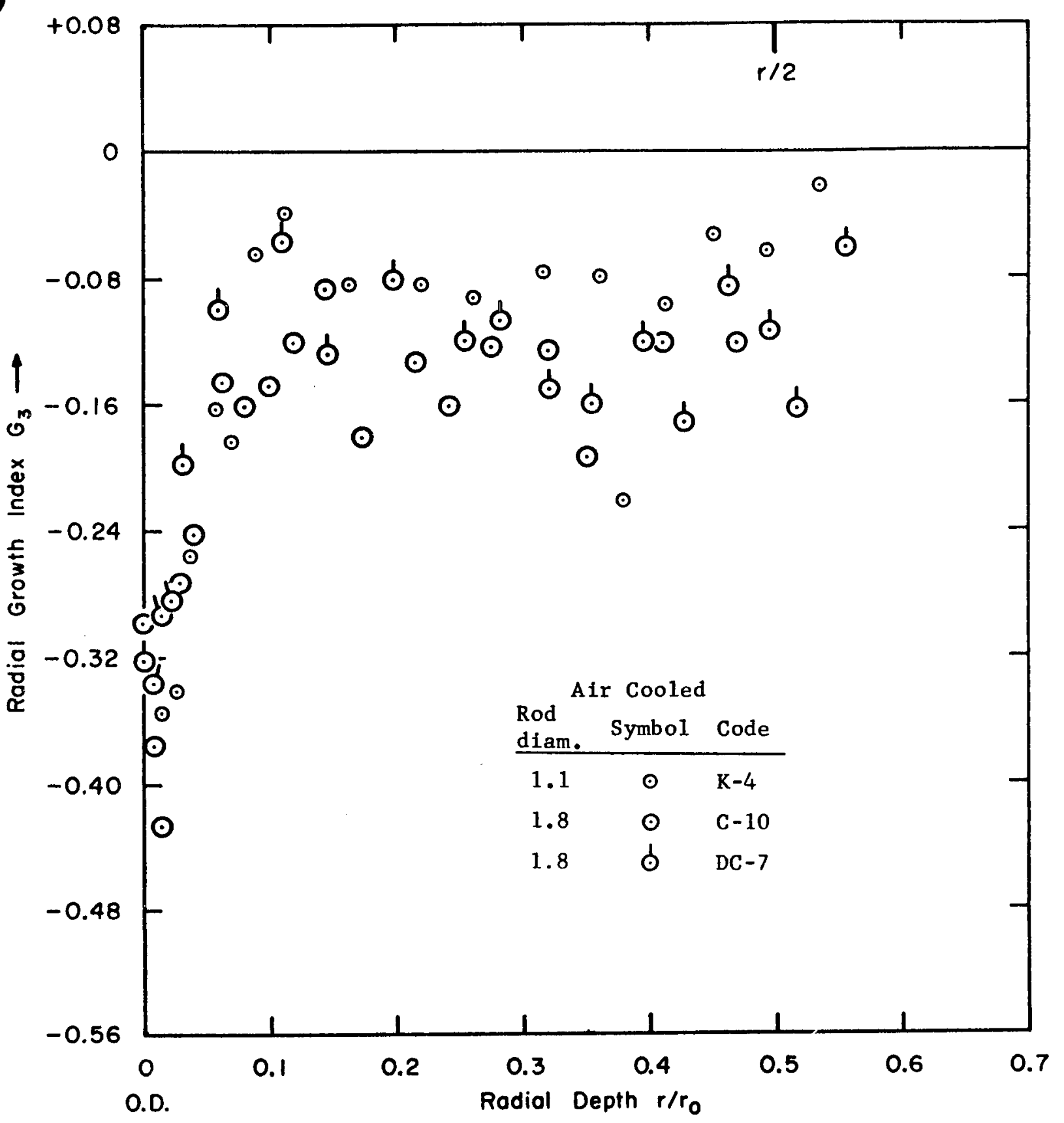

Fig. A-21 


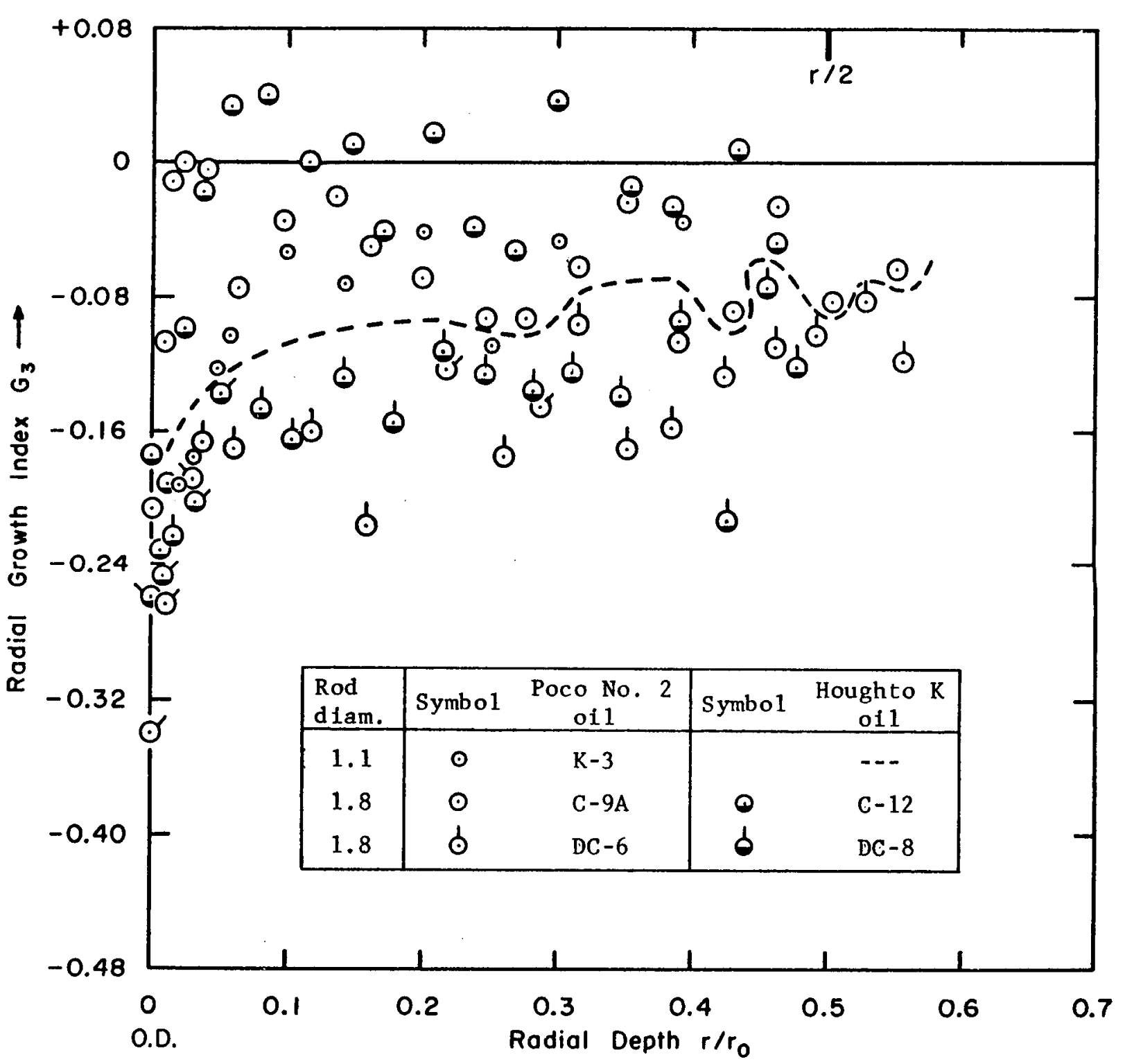

Fig. A-22 
11.1

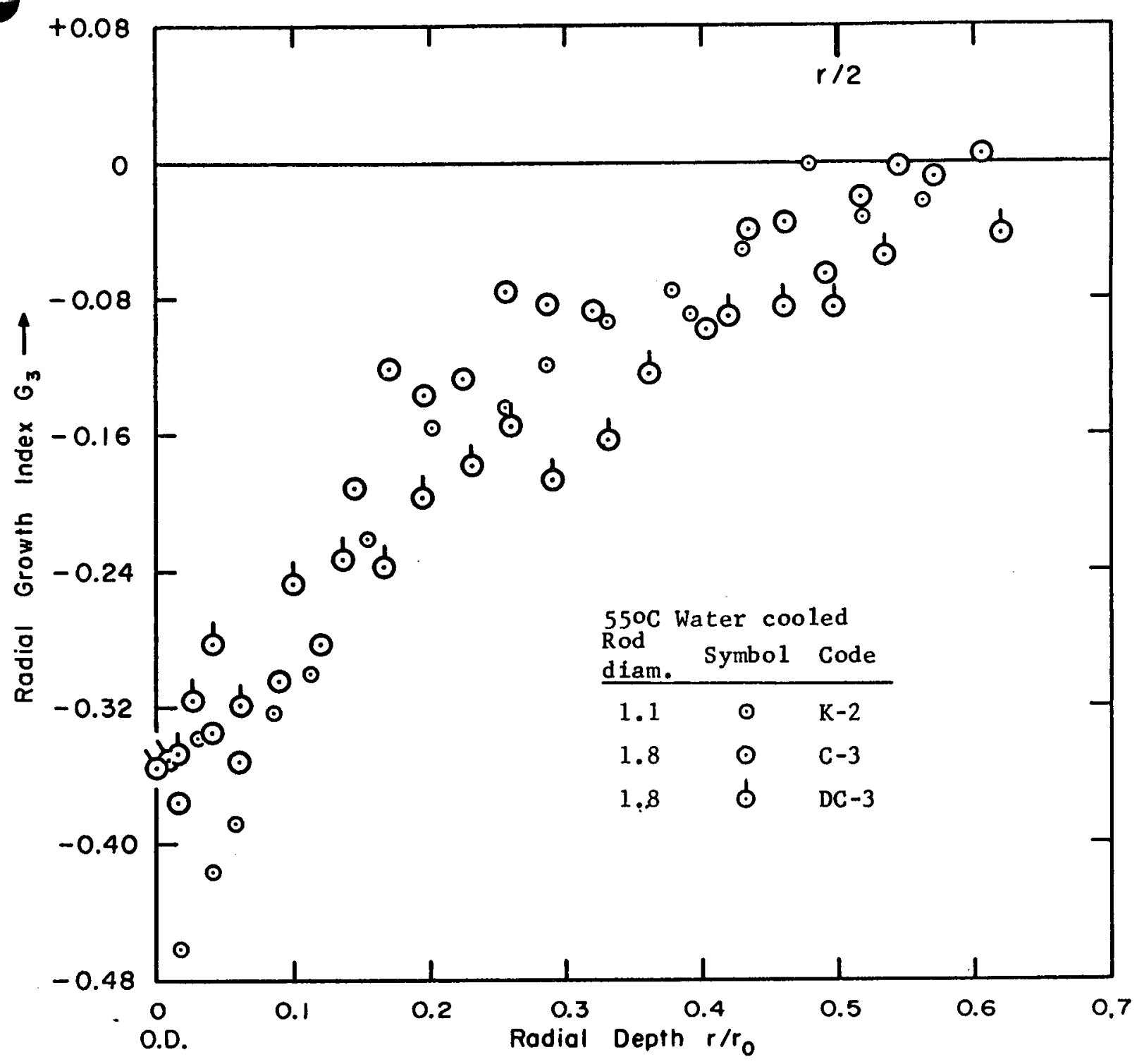

Fig. A-23 


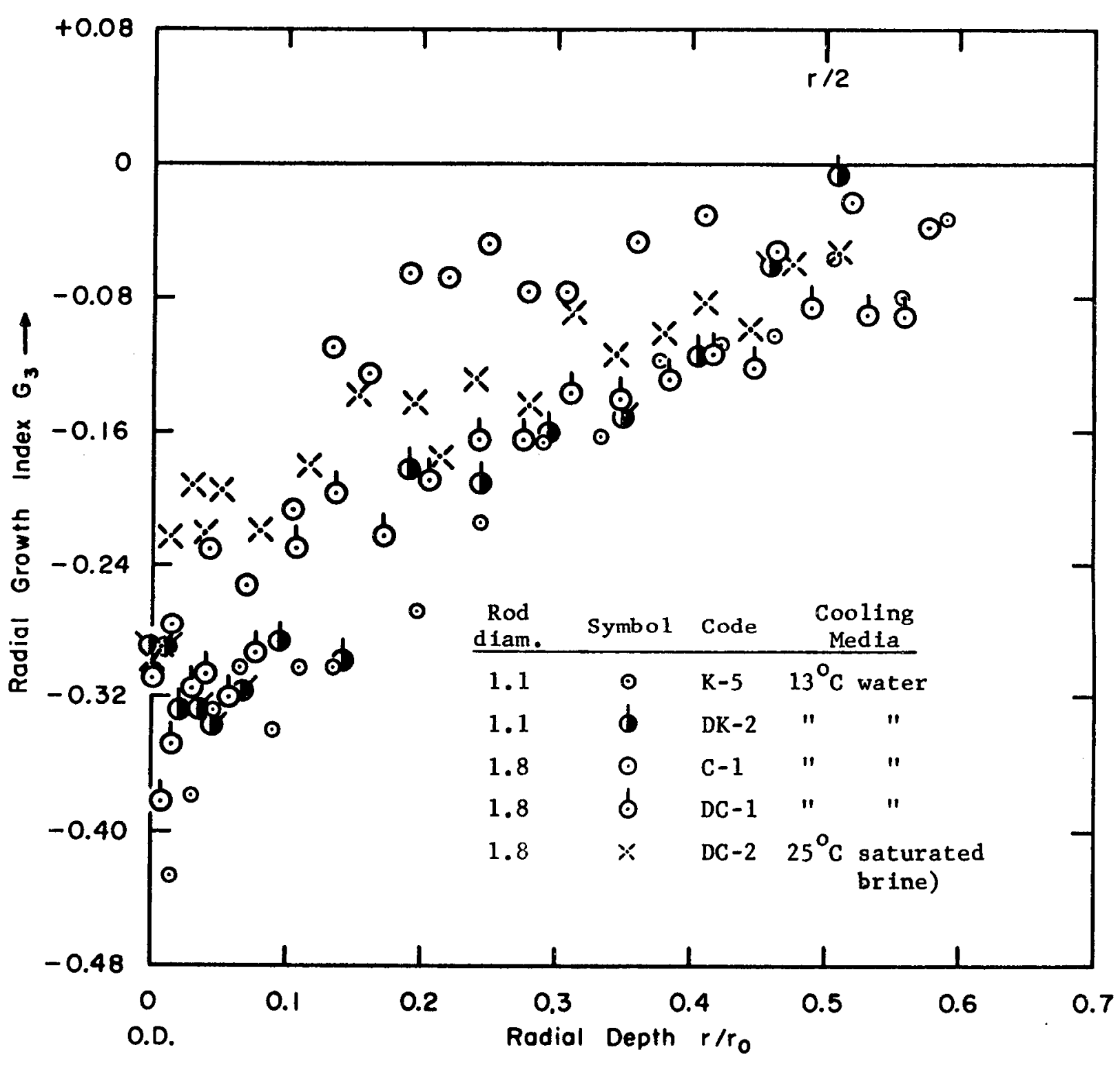

Fig. A-24 
Technical Description and Tabular Data

I. EQUIPMENT

A. Gages (distortion measurements)

(1) Hole Gage (Federal Mode1 1242 P-1)

(2) Wal1 Gage (Federa1 Mode1 KP-120-R1)

(3) OD Gages (Starrett, 3 in./4 in., 2 in./3 in., 0 in./2 in. micrometers)

B. Brush Oscillograph (thermal measurements)

\section{Temperature Recording}

Rapid temperature recording was performed with a Brush rectilinear, thermal writing oscillograph (Model RD-2684-50). Six of eight possible recording channels were installed. The response is flat up to 70 cycles per second. The maximum sensitivity of the instrument is 0.1 millivolt per millimeter of chart, or, when using a Chrome1Alumel thermocouple, about $2.5^{\circ} \mathrm{C}$ per milimeter. Thus, at maximum sens itivity, a temperature range of $100^{\circ} \mathrm{C}$ is displayed on a $40-\mathrm{mm}$ wide chart: but in order to obtain the predicted $530^{\circ} \mathrm{C}$ thermal arrest in samples cooled as fast as $1000^{\circ} \mathrm{C}$ per second as we 11 as the $720^{\circ} \mathrm{C}$ beta treating temperature, the sensitivity had to be lowered at least to $5^{\circ}$ per milimeter of chart.

\section{Elimination of 60-cycle Pickup by Filtering}

Some 60-cycle pickup noted during the initial operation of the oscillograph at maximum sensitivity was eliminated by placing across each input terminal a 60-cycle filter arranged as follows: 


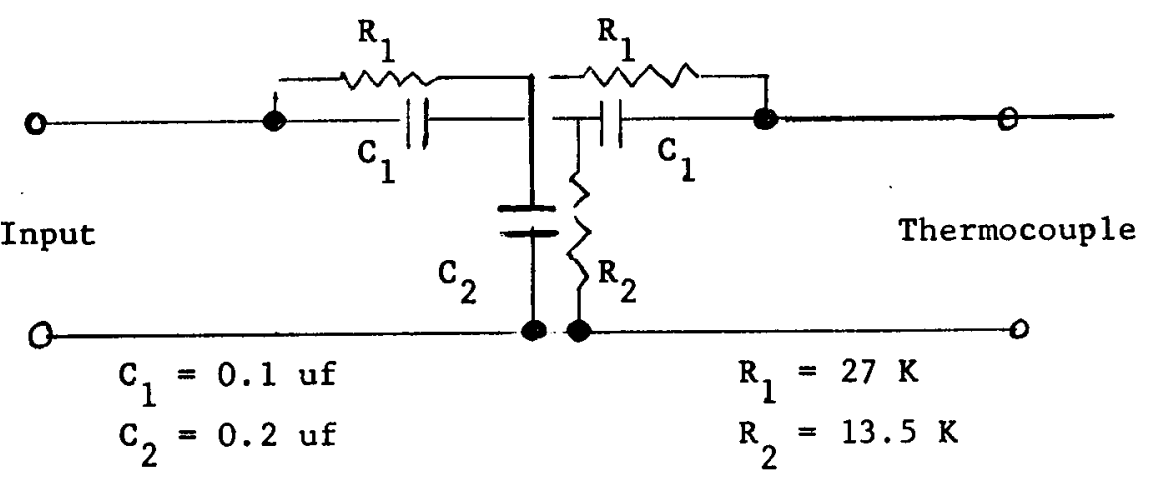

\section{Thermocouples}

i-22-20BK9B24 AerOpak Chrome1-Alume1, 1/16-inch OD, Incone1 clad, ungrounded.

\section{X-ray Diffractometer}

Philips High Angle Goniometer, NaI(T1) scintillation counter, pulse height analyzer (type 5233230), copper high-intensity target (Type 32147).

\section{E. X-ray Automation: Programmer and Print-out}

The $x$-ray automation equipment was constructed at SRL by Mr. L. H. Cook. The automation unit consists of a punched Mylar tape which is coded to give direction and rate of scan, stop, print-out, etc. This tape is fed through a sensing head connected to each of the instruction relays. The Philips goniometer is driven by a reversible motor with a high-speed gear $\left(7.5^{\circ}(2 \theta)\right.$ per minute) and a low speed (scanning) gear $\left(0.5^{\circ}(2 \theta)\right.$ per minute). The accumulated count from the regular Philips scintillation counter-amplifier-pulse height analyzer circuits is fed into a Baird Atomic high-speed scaler (Model 134). The operation of Philips scaler-rate meter section is bypassed but may, however, be used simultaneously to make a regular strip chart recording. When the signal is given by the tape, an adding machine prints out the number of counts accumulated during the scan of the diffraction profile. After the print-out is complete, the tape instructs the goniometer driver to move the goniometer rapidly to the next diffraction 
profile starting position, at which point the tape instructs the driver to scan slowly. Altogether, 21 diffraction profiles and 7 backgrounds are scanned (about 1 hour is required) and the accumulated print-out strip is sent to an IBM 704 for the $G_{3}$ computation. * Included in these 21 profiles are extra profiles which may be used to calculate the older (now discarded) $G I^{(1,2)}$ as well as the newer $G_{2}{ }^{(3)}$ Growth Index.

II. INVENTORY AND CHEMICAL ANALYSES OF METAL RECEIVED

A tabular description of size and weight of dingot and ingot tubes and rods received is given in Table $B-1$.

All the available chemical analyses and densities are given in Table B-2.

III. EXPERIMENTAL METHODS

A. Heat Treatments

1. De1ta Treatment

Delta treatment refers to the heat treatment given to alter the size and distribution of the delta particles (see text, p.21, Section III B. 2). It consists of heating the uranium for fairly lorg times at a desired temperature in the alpha phase to precipitate and/or agglomerate the delta particles. The delta may be largely dissolved by prior beta treatment.

\section{Beta Treatment}

The standard beta treatment consisted of heating the uranium to $720^{\circ} / 730^{\circ} \mathrm{C}$ for 10 to 15 minutes at temperature in some suitable molten salt, such as Houghton Liquid Heat 980 .

\section{Continuous Cooling from Beta Phase by Total Immersion.}

Continuous cooling was performed in the following media: $30^{\circ} \mathrm{C}$ air, room temperature Houghto-Quench 4102 (a suspension of mica in Houghton Martemp Oil No. 2), $55^{\circ} \mathrm{C}$ and room temperature

* see Section III C of Appendix B 
Poco No. 2 Quenching 0il, room temperature Houghto $\mathrm{K}$ oil, $55^{\circ} \mathrm{C}$ and $13^{\circ} \mathrm{C}$ water. In some cases room temperature and $0^{\circ} \mathrm{C}$ saturated (Nu-Sa1) brine was used.

Comparisons among relative quenching speeds of several quenching oils are given ${ }^{(4)}$ as follows:

Quenching 0il

Houghto $\mathrm{K}$

Shel1 Voluta 921

Sohivis $\mathrm{J}-53$

Martemp No. 2

Houghto-Quench 4102
Company

E. F. Houghton

She 11

Standard Ohio

E. F. Houghton

E. F. Houghton
G. M. Quenchometer (seconds)

$$
6.25
$$$$
7.8
$$

12

17

56

*Cannot be used to compare with quenchometer data published by General Motors Corporation.

\section{Interrupted Cooling from Beta Phase}

In several experiments, continuous cooling from the beta phase was interrupted.

(1) Air delays of about 2, 30 and 60 seconds before oil quenching to room temperature.

(2) Quench into molten salt.

(a) Houghton Liquid Heat 235 (working range $760^{\circ} / 425^{\circ} \mathrm{C}$ )

(b) Houghton Draw-Temp 275 (working range $540^{\circ} \mathrm{C} / 175^{\circ} \mathrm{C}$ )

\section{Annealing after Beta Treatment}

The effect of annealing on beta treated grain size and $\mathrm{G}_{3}$ was studied by heating a sample at $600^{\circ} \mathrm{C}$ in vacuo.

\section{B. Routine Sample Preparation}

The routine beta-treated sample preparation for grain size estimate and $x$-ray study was carried out as follows: 
(1) Prepare true hemicylinder of tube or rod for full 4-inch length.

(2) Macro-etch in concentrated HC1 (protect cylindrical surface from attack). Rinse. Macro-etch in concentrated $\mathrm{HNO}_{3}$ for optimum contrast for photomacrography at $3 \mathrm{X}$.

(3) Cut sectors 10 to $20^{\circ}$ wide from center 2 inches.

(4) Electropolish ${ }^{*}$ cylindrical surface to remove all oxide before making radia $1 G_{3} x$-ray scan at surface.

(5) Grind surface to desired depth, electropolish to guarantee removal of all traces of cold work as detected by examination of peak intensity profiles of (110), (021) and (002).

C. Definition and Determination of the Growth Index $G_{3}$

The expression for the Morris Growth Index $G_{3}{ }^{(5,6)}$ is defined in accordance with the report of the X-ray Preferred Orientation Meeting of November 9 and 10, 1959.(7)

$$
G_{3}=\frac{\sum_{i=1}^{n}\left(A_{w_{i}} I_{i} / I_{o_{i}}\right)\left(\cos ^{2} \beta-\cos ^{2} \alpha\right)}{\sum_{i=1}^{n} A_{w_{i}} I_{i} / I_{o_{i}}}
$$

Where $i$ refers to a given diffraction peak (hk1), $\mathrm{A}_{\mathrm{w}_{i}}$ is the normalized area weight factor (see Table B-3). $I_{i}$ is the experimental integrated intensity of the diffraction peak (hk 1$) \cdot \mathrm{I}_{\mathrm{o}_{i}}$ is the calculated integrated intensity of the diffraction peak (hkl) (see Table B-3). $\alpha, \beta$ are the angles between the (hk1) pole and the $\underline{a}$ and $\underline{b}$ crystallographic directions, respectively. The 18 unique diffraction peaks, area weight factors, calculated intensities and $\cos ^{2}$ factors are given in Table B-3 together with the $2 \theta$ values for the backgrounds and the $2 \theta$ ranges over which the counts are accumulated at a scanning rate of $1 / 2^{\circ}(20) /$ minute.

*Electrolyte is $\mathrm{H}_{3} \mathrm{PO}_{4}$ (conc.): $\mathrm{H}_{2} \mathrm{SO}_{4}$ (conc.): $\mathrm{H}_{2} \mathrm{O}:: 1: 2: 2$ (vo1.) 
IV. EXPER IMENTAL DATA

Experimental data for thermal, grain size and distortion results are contained in Tables B-4, B-5 and B-6 respectively. Certain data derived from radial $G_{3}$ distributions are given in Table $B-7$ and $B-8$. The $G_{3}$ - positional data have not been tabulated, but are given only in graphical form. 


\section{TABLE B-1}

Designation, Dimensions, Weights of Uranium Received for Beta Treatment Study

\begin{tabular}{|c|c|c|c|c|c|c|c|c|c|c|}
\hline \multirow{3}{*}{$\begin{array}{l}\text { Letter } \\
\text { Desig- } \\
\text { nation }\end{array}$} & \multicolumn{6}{|c|}{ As Received } & \multirow{2}{*}{\multicolumn{3}{|c|}{ Machined Size (in.) }} & \multirow{3}{*}{$\begin{array}{c}\text { ID/Wa11 } \\
\text { Ratio }\end{array}$} \\
\hline & \multicolumn{3}{|c|}{ Size (in.) } & \multirow{2}{*}{$\begin{array}{r}\text { Length } \\
\text { (in.) }\end{array}$} & \multirow{2}{*}{$\begin{array}{r}\text { Weight } \\
\text { (1bs.) }\end{array}$} & \multirow[b]{2}{*}{ Condition } & & & & \\
\hline & $\mathrm{OD}$ & ID & Wall & & & & $O D$ & ID & Wa11 & \\
\hline $\mathrm{A}$ & 3.87 & 1.94 & 0.97 & 780 & 4,720 & Extruded ingot & 3.853 & 2.073 & 0.890 & 2.33 \\
\hline DB & 3.125 & 1.03 & 1.05 & 128 & 598 & Extruded dingot & $\cdots$ & -- & $\cdots$ & -- \\
\hline - & 3.0 & 0 & 1.5 & 36 & 174 & Ingot & $\cdots$ & $\cdots$ & -- & $\cdots$ \\
\hline C & 1.87 & 0 & 0.938 & 134 & 251 & Ingot & 1.845 & 0 & -- & --- \\
\hline DC & 2.085 & 0 & 1.043 & 119 & 279 & Extruded dingot & 1.845 & 0 & -- & -- \\
\hline D & $I^{\prime \prime} \mathrm{dia}$ & . $\times 1 /$ & ' disc: & cut fr & om $\operatorname{rod} K$ & & -- & $\ldots$ & $\ldots$ & $\ldots$ \\
\hline $\mathbf{E}$ & 3.94 & 2.81 & 0.56 & 389 & 1,590 & Extruded ingot & 3.980 & 3.060 & 0.460 & 6.65 \\
\hline $\mathbf{F}$ & Design & ates a & fabri & ated me & Ea 1 & & $\cdots$ & $\cdots$ & --- & -- \\
\hline$D G$ & 3.125 & 1.84 & 0.64 & 146 & 499 & Extruded dingot & 2.960 & 1.965 & 0.498 & 3.94 \\
\hline $\mathrm{H}$ & 1.50 & 0.38 & 0.55 & 494 & 558 & Ingot & $1: 450$ & 0.500 & 0.475 & 1.05 \\
\hline $\mathrm{DH}(\mathrm{DC})$ & & eparec & from & od DC & & Extruded dingot & 1.450 & 0.500 & 0.475 & 1.05 \\
\hline DH & 2.078 & 0.885 & 0.60 & 224 & 427 & Extruded dingot & --- & --- & -- & --- \\
\hline $\mathrm{K}$ & 1.22 & 0 & 0.61 & 360 & 289 & Rolled ingot & 1.18 & 0 & $\cdots$ & $\cdots$ \\
\hline DK & 1.09 & 0 & 0.55 & 278 & 178 & Extruded dingot & 1.05 & 0 & -- & $\cdots$ \\
\hline $\mathrm{J}$ & $1^{\prime \prime} \mathrm{dia}$ & Jomi & bar, & prepare & from $r$ & $\mathrm{dd} \mathrm{K}$ & 1.00 & --- & -- & -- \\
\hline L & 3.94 & 3.32 & 0.31 & 989 & 2,430 & Extruded ingot & 3.890 & 3.497 & 0.197 & 17.7 \\
\hline M & 3.13 & 2.50 & 0.31 & 487 & 930 & Ingot & 2.930 & 2.510 & 0.210 & 11.9 \\
\hline DM (DG) & Prepar & ed fro & tube & G & & Dingot & 2.930 & 2.510 & 0.210 & 11.9 \\
\hline $\mathbf{N}$ & 2.13 & 1.34 & 0.39 & 494 & 727 & Ingot & 2.000 & 1.380 & 0.310 & 4.45 \\
\hline $\mathbf{P}$ & 1.09 & 0.44 & 0.33 & 485 & 259 & Ingot & 1.000 & 0.500 & 0.250 & 2.00 \\
\hline Q & 0.59 & 0 & 0.28 & 120 & 22.15 & Cold swaged ingot & var. & -- & -- & $\cdots$ \\
\hline QQ & 0.63 & 0 & 0.31 & 424 & 90 & Ingot & var. & -- & --- & -- \\
\hline $\mathbf{s}$ & 0.48 & 0 & 0.24 & 127 & 15.7 & Hot extruded ingot & var. & -- & -- & -- \\
\hline $\mathrm{T}$ & $-\cdots$ & -- & -- & -- & -- & Extruded ingot & 1.995 & 1.765 & 0.115 & 15.3 \\
\hline
\end{tabular}


TABLE B-2

Chemical Analyses and Densities of Unalloyed Dingot and Ingot Received for NMI Beta Treatment Study (ppm weight)

[Analyses for $\mathrm{B}, \mathrm{P}, \mathrm{Cu}, \mathrm{Zn}, \mathrm{Mo}, \mathrm{Sn}, \mathrm{Pb}$ are omitted]

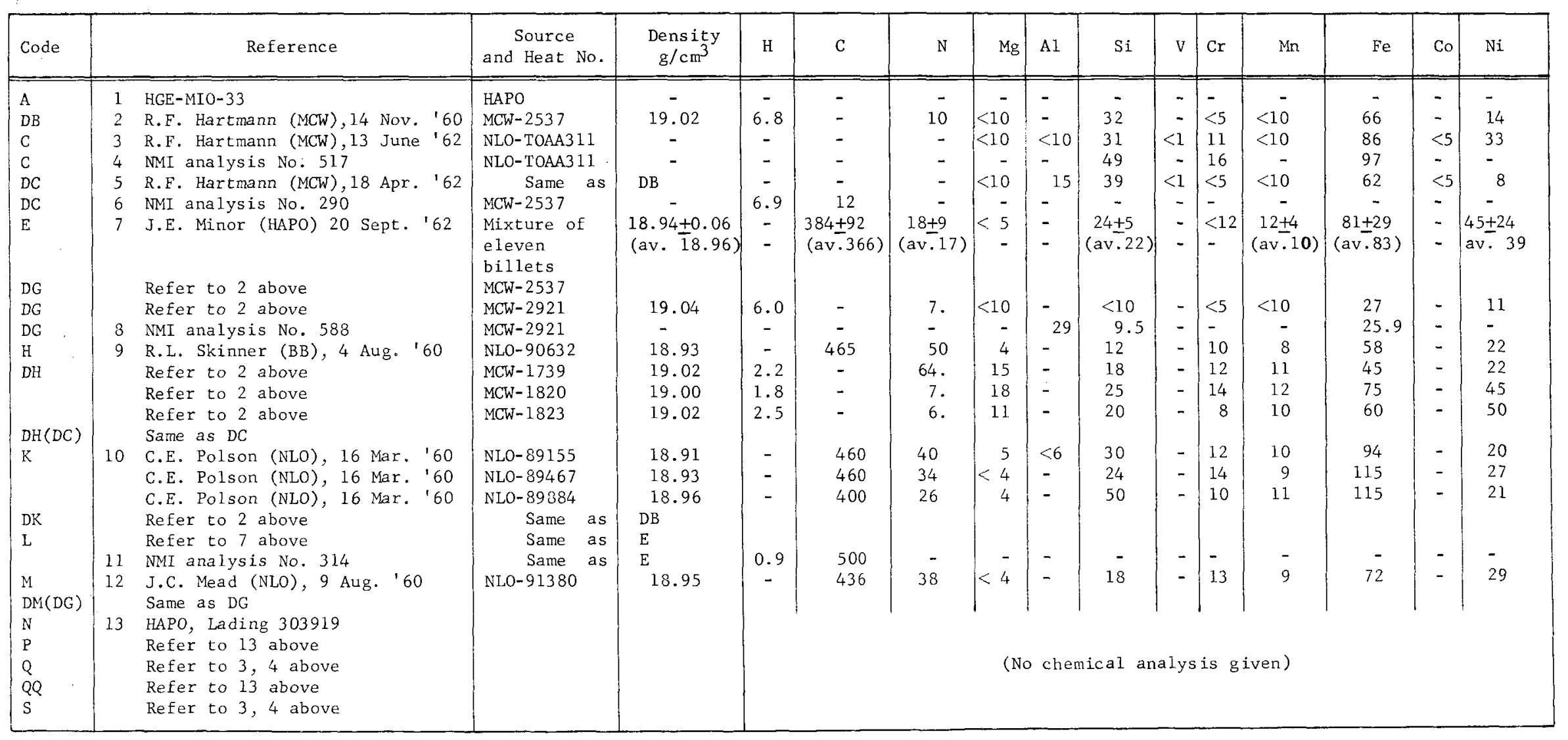


TABLE B-3

$2 \theta$ Positions for Diffraction Profiles and Background,

Calculated Intensities $\left(I_{0}\right)$, Area Weight Factors $\left(A_{w_{i}}\right)$ and $\mathrm{Cos}^{2}$ Factors Needed to Compute $G_{3}$

Note: The scanning rate is $1 / 2^{\circ}(2 \theta) /$ minute)

\begin{tabular}{|c|c|c|c|c|}
\hline$(\mathrm{hkl})$ & Range $(2 \theta)$ & $\mathrm{I}_{\mathrm{O}}(5)$ & $\mathrm{A}_{\mathrm{W}}(7)$ & $\cos ^{2} \mathrm{~B}-\cos ^{2} \alpha$ \\
\hline \hline $\mathrm{B}$ & 29.70 & & & \\
020 & $30.00-31.00$ & 6.34 & 0.0318 & 1 \\
110 & $34.50-35.35$ & 72.7 & 0.0634 & -0.6175 \\
021 & $35.36-36.00$ & 100 & 0.0608 & 0.7403 \\
002 & $36.01-36.85$ & 51.4 & 0.0304 & 0 \\
111 & $39.00-40.00$ & 58.3 & 0.0738 & -0.4869 \\
$\mathrm{~B}$ & 41.00 & & & \\
$022 *$ & $46.75-48.65$ & $(3.58)$ & & \\
112 & $50.75-51.75$ & 48.3 & 0.0522 & -0.2979 \\
130 & $56.50-57.50$ & 3.37 & 0.0357 & 0.3606 \\
$\mathrm{~B}$ & 59.50 & & & \\
131 & $59.85-60.85$ & 40.0 & 0.0684 & 0.3260 \\
040 & $63.00-64.00$ & 6.93 & & \\
023 & $64.25-65.15$ & 16.8 & 0.0659 & 0.2406 \\
200 & $65.16-66.00$ & 8.82 & 0.0234 & -1 \\
$041 *$ & $66.01-67.00$ & $(4.83)$ & & \\
113 & $67.34-68.00$ & 11.6 & 0.0477 & -0.1809 \\
$\mathrm{~B}$ & 69.00 & & & \\
132 & $69.00-70.25$ & 3.65 & 0.0529 & 0.2532 \\
133 & $83.25-84.50$ & 15.3 & 0.0795 & 0.1845 \\
$\mathrm{~B}$ & 86.50 & & & \\
114 & $86.80-88.05$ & 10.2 & 0.0749 & -0.1167 \\
150 & $90.00-91.25$ & 7.43 & 0.0372 & 0.7106 \\
223 & $98.50-99.75$ & 12.2 & 0.0487 & -0.3851 \\
152 & $101.10-102.35$ & 12.8 & 0.0689 & 0.5962 \\
$\mathrm{~B}$ & 102.50 & & & \\
$\mathrm{~B}$ & 121.50 & & & \\
312 & $122.00-123.50$ & 8.85 & 0.0845 & -0.8296 \\
\hline & & & & \\
\hline
\end{tabular}

$B=$ for background count accumulated for 1 minute.

* = also acquired for calculation of different growth index, GI. 
TABLE B-4a

Thermal Data for Continuous Cooling of Uranium Tubes and Rods from $720 / 730^{\circ} \mathrm{C}$ Molten Salt (Houghton LH-980)

\begin{tabular}{|c|c|c|c|c|c|c|c|c|c|c|c|c|c|c|c|c|c|c|c|c|}
\hline \multirow[b]{2}{*}{ Parameter } & \multirow[b]{2}{*}{$\begin{array}{l}\text { Quench } \\
\text { Medium }\end{array}$} & \multicolumn{9}{|c|}{ 1.8" Dia. Ingot Rod (C) } & \multicolumn{5}{|c|}{ 1.8" Dia. Dingot Rod (DC) } & \multicolumn{5}{|c|}{ 1. I"Dia, Ingot Rod (K) } \\
\hline & & $0.080^{a}$ & 0.231 & 0.234 & 0.344 & 0.461 & 0.692 & 0.703 & $\begin{array}{r}\text { Dept } \\
0.923^{b} \\
\end{array}$ & $\begin{array}{l}\text { (in.) } \\
0.938^{\mathrm{b}} \\
\end{array}$ & $0.080^{\mathrm{a}}$ & 0.231 & 0.461 & 0.692 & $0.923^{\mathrm{b}}$ & $0.061^{\mathrm{a}}$ & 0.150 & 0.300 & 0.460 & $0.610^{b}$ \\
\hline $\begin{array}{l}{ }_{A_{c} \text { (av.) }} \\
\text { (seconds) }\end{array}$ & Air, oil, water & 171 & 173 & 176 & 168 & 176 & 176 & 180 & 187 & 191 & 150 & 160 & 160 & 163 & 170 & 101 & 102 & 104 & 109 & 112 \\
\hline $\begin{array}{l}t_{\beta / \alpha} \\
\text { (seconds) }\end{array}$ & 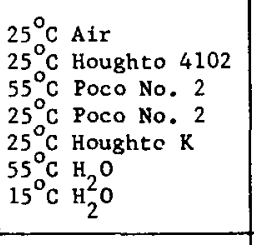 & $\begin{array}{l}28^{\mathrm{d}} \\
- \\
1.0 \\
2.0^{\mathrm{e}} \\
1.0 \\
0.1 \\
0.2\end{array}$ & $\begin{array}{c}44.5 \\
- \\
- \\
2.0 \\
\text { n } \\
- \\
-\end{array}$ & $\begin{array}{l}55 \\
- \\
4.5 \\
4.3^{d} \\
--d^{d} \\
1.1 \\
1.1\end{array}$ & $\begin{array}{l}46 \\
- \\
3.8 \mathrm{~d} \\
3.4^{\mathrm{d}} \\
- \\
1 . \mathrm{d}^{\mathrm{d}} \\
0.5\end{array}$ & $\begin{array}{c}\mathrm{n} \\
- \\
- \\
2.5 \\
2.2 \\
- \\
\mathrm{n}\end{array}$ & $\begin{array}{c}21 \\
- \\
- \\
n \\
3.8 \\
- \\
-\end{array}$ & $\begin{array}{l}46 \\
- \\
5.2 \mathrm{~d} \\
4.6 \\
- \\
1.1 \mathrm{~d} \\
0.3\end{array}$ & $\begin{array}{c}61.5 \\
- \\
- \\
5.9 \\
4.0 \\
- \\
-\end{array}$ & $\begin{array}{l}44 \\
- \\
9.0 \\
7.3^{\mathrm{d}} \\
- \\
2.1^{\mathrm{d}} \\
1.4\end{array}$ & $\begin{array}{c}25 \\
- \\
- \\
0.4 \\
2.5 \\
\text { n } \\
\text { n }\end{array}$ & $\begin{array}{c}31.5 \\
- \\
- \\
1.4 \\
n \\
n \\
0.2 \\
\left(1 . i^{\mathbf{f}}\right) \\
\end{array}$ & $\begin{array}{c}n \\
- \\
- \\
1.0 \\
2.7 \\
n \\
0.4\end{array}$ & $\begin{array}{c}56.5 \\
- \\
- \\
2.3 \\
4.0 \\
0.4 \\
1.1 \\
\left(0.8^{f}\right)\end{array}$ & $\begin{array}{c}67 \\
- \\
- \\
3.9 \\
3.2 \\
\square \\
1.7 \\
\left(1.9^{\mathrm{f}}\right)\end{array}$ & $\begin{array}{l}22^{d} \\
- \\
0.7 \\
3.5 \\
-.^{d} \\
0.1\end{array}$ & $\begin{array}{l}21^{\mathrm{d}} \\
- \\
09 \\
1.9 \\
0.4_{\mathrm{d}}^{\mathrm{d}} \\
0.1^{\mathrm{d}}\end{array}$ & $\begin{array}{c}29 \\
- \\
2.1 \\
3.3 \\
- \\
0.4 \\
0.1\end{array}$ & $\begin{array}{l}32 \\
- \\
3.1 \\
3.4^{d} \\
-.6^{d} \\
0.4\end{array}$ & $\begin{array}{c}30 \\
- \\
3.7 \\
5.1 \\
. \\
0.9 \\
0.7\end{array}$ \\
\hline $\begin{array}{l}{ }^{A} \mathbf{r} \\
\left({ }^{\circ} \mathrm{C}\right)\end{array}$ & $\begin{array}{l}25^{\circ} \mathrm{C} \text { Air } \\
25{ }^{\circ} \mathrm{C} \text { Houghto } 4102 \\
55{ }^{\circ} \mathrm{C} \text { Poco No. } 2 \\
25{ }^{\circ} \mathrm{C} \text { Poco No. } 2 \\
255^{\circ} \mathrm{CHoughto} \mathrm{K} \\
55^{\circ} \mathrm{C} \mathrm{H} \mathrm{H}_{2} \mathrm{O} \\
15{ }^{\circ} \mathrm{C} \mathrm{H} \mathrm{H}_{2} \mathrm{O}\end{array}$ & $\begin{array}{l}649^{d} \\
- \\
638^{e} \\
638^{e} \\
654 \\
621 \\
641\end{array}$ & $\begin{array}{c}650 \\
- \\
- \\
631 \\
n \\
- \\
-\end{array}$ & $\begin{array}{l}659 \\
- \\
643 \\
652 \\
- \\
633^{d} \\
637\end{array}$ & $\begin{array}{l}655 \\
- \\
648 \\
648 \\
- \\
6522^{\mathrm{d}} \\
652\end{array}$ & $\begin{array}{c}n \\
- \\
- \\
625 \\
652 \\
\dot{619}\end{array}$ & $\begin{array}{c}642 \\
- \\
- \\
n \\
618 \\
- \\
-\end{array}$ & $\begin{array}{l}653 \\
- \\
647 \\
637^{d} \\
- \\
642 d \\
636\end{array}$ & $\begin{array}{c}657 \\
- \\
629 \\
630 \\
- \\
-\end{array}$ & $\begin{array}{l}653 \\
- \\
644 \mathrm{~d} \\
646^{2} \\
- \\
636_{d}^{d} \\
629\end{array}$ & $\begin{array}{l}651 \\
- \\
- \\
670 \\
621 \\
n \\
n\end{array}$ & $\begin{array}{c}645 \\
- \\
- \\
643 \\
n \\
n \\
637 \\
\left(631^{f}\right) \\
\end{array}$ & $\begin{array}{c}n \\
- \\
- \\
622 \\
642 \\
617 \\
626\end{array}$ & $\begin{array}{c}642 \\
- \\
- \\
626 \\
640 \\
632 \\
627 \\
\left(631^{\mathrm{f}}\right) \\
\end{array}$ & $\begin{array}{c}648 \\
- \\
- \\
633 \\
628 \\
n \\
623 \\
(628 \mathrm{f}) \\
\end{array}$ & $\begin{array}{l}645^{d} \\
- \\
626{ }^{d} \\
634^{d} \\
- \\
634^{d} \\
663^{d}\end{array}$ & $\begin{array}{l}649^{d} \\
- \\
645 \\
640^{d} \\
-{ }^{d} \\
645^{d} \\
654^{d}\end{array}$ & $\begin{array}{l}651 \\
- \\
634 \\
633^{d} \\
- \\
630 \\
646^{d}\end{array}$ & $\begin{array}{l}647^{\mathrm{d}} \\
- \\
630 \mathrm{~d} \\
635^{\mathrm{d}} \\
-\bar{x}^{\mathrm{d}} \\
624^{\mathrm{d}}\end{array}$ & $\begin{array}{l}652 \\
- \\
640 \\
641 \\
636^{d} \\
627^{d}\end{array}$ \\
\hline $\begin{array}{l}{ }_{\beta}{ }_{\beta} \\
\left({ }^{\mathrm{C}} \mathrm{C} / \mathrm{sec}\right)\end{array}$ & $\begin{array}{l}25^{\circ} \mathrm{C} \text { Air } \\
25{ }^{\circ} \mathrm{C} \text { Houghto } 4102 \\
55^{\circ} \mathrm{C} \text { Poco No. } 2 \\
255^{\circ} \mathrm{C} \text { Poco No. }{ }^{2} \\
25^{\circ} \mathrm{C} \text { Houghto } \mathrm{K} \\
55^{\circ} \mathrm{C} \mathrm{H}_{2} \mathrm{O} \\
15^{\circ} \mathrm{C} \mathrm{H} \mathrm{H}_{2} \mathrm{O}\end{array}$ & $\begin{array}{c}1.6^{\mathrm{d}} \\
- \\
32 \\
36 \mathrm{e} \\
51 \mathrm{~d} \\
263^{\mathrm{d}} \\
62^{\mathrm{d}}\end{array}$ & $\begin{array}{l}1.5 \\
- \\
- \\
27 \\
n \\
- \\
-\end{array}$ & $\begin{array}{l}1.4 \\
- \\
9.5 \\
15 \\
- \\
47^{\mathrm{d}} \\
107^{\mathrm{d}}\end{array}$ & $\begin{array}{l}1.4 \\
-12 \mathrm{~d} \\
13 \\
-{ }^{\mathrm{d}} \mathrm{d} \\
44^{\mathrm{d}}\end{array}$ & $\begin{array}{l}\mathrm{n} \\
- \\
- \\
14 \\
19 \\
- \\
-\end{array}$ & $\begin{array}{l}1.5 \\
- \\
- \\
12 \\
15 \\
- \\
-\end{array}$ & $\begin{array}{l}1.4 \\
- \\
12 \mathrm{~d} \\
12 \mathrm{~d} \\
- \\
32 \mathrm{~d} \\
35\end{array}$ & $\begin{array}{l}1.4 \\
- \\
- \\
11 \\
14 \\
- \\
-\end{array}$ & $\begin{array}{l}1.2 \\
- \\
7.2 \mathrm{~d} \\
9.2 \\
-{ }^{\mathrm{d}} \\
19^{\mathrm{d}} \\
20^{\mathrm{d}}\end{array}$ & $\begin{array}{c}1.7 \\
- \\
73 \\
53 \\
379 \\
474 \\
\left(143^{\mathrm{f}}\right) \\
\end{array}$ & $\begin{array}{c}1.6 \\
- \\
- \\
25 \\
n \\
n \\
79 \\
\left(41^{f}\right) \\
\end{array}$ & $\begin{array}{l}\mathrm{n} \\
- \\
- \\
14 \\
13 \\
30 \\
40\end{array}$ & $\begin{array}{c}1.6 \\
- \\
- \\
15 \\
13 \\
24 \\
29 \\
\left(23^{\mathrm{f}}\right) \\
\end{array}$ & $\begin{array}{l}1.4 \\
- \\
13 \\
11 \\
n \\
24 \\
\left(18^{\mathrm{f}}\right) \\
\end{array}$ & $\begin{array}{l}2.2^{\mathrm{d}} \\
- \\
80 \\
50^{\mathrm{d}} \\
-{ }^{\mathrm{d}} \mathrm{d} \\
255^{\mathrm{d}}\end{array}$ & $\begin{array}{c}2.3^{\mathrm{d}} \\
- \\
34 \mathrm{~d} \\
43^{\mathrm{d}} \\
\overline{9}^{\mathrm{d}} \\
165^{\mathrm{d}}\end{array}$ & $\begin{array}{l}2.1 \\
- \\
25 \\
25 \\
- \\
64 \\
84\end{array}$ & $\begin{array}{l}2.3^{\mathrm{d}} \\
\overline{22} \\
22 \mathrm{~d} \\
\overline{5} \\
57^{\mathrm{d}} \mathrm{d} \\
60^{\mathrm{d}}\end{array}$ & $\begin{array}{l}1.9^{\mathrm{d}} \\
22 \mathrm{~d} \\
22 \\
- \\
80 \\
79\end{array}$ \\
\hline $\begin{array}{l}\mathrm{R}_{\alpha} \\
\left({ }^{\circ} \mathrm{c} / \mathrm{sec}\right)\end{array}$ & $\begin{array}{l}25^{\circ} \mathrm{C} \text { Air } \\
25^{\circ} \mathrm{C} \text { Houghto } 4102 \\
55^{\circ} \mathrm{C} \text { Poco No. } 2 \\
25^{\circ} \mathrm{C} \text { Poco No. } 2 \\
25^{\circ} \mathrm{C} \text { Houghto } \mathrm{K} \\
55^{\circ} \mathrm{C} \mathrm{H} \mathrm{H}^{\circ} \\
15^{\circ} \mathrm{C} \mathrm{H} \mathrm{H}_{2} \mathrm{O}\end{array}$ & $\begin{array}{l}0.8^{\mathrm{d}} \\
- \\
18 \\
19^{\mathrm{e}} \\
48_{\mathrm{d}} \\
181_{\mathrm{d}} \\
149^{\mathrm{d}}\end{array}$ & $\begin{array}{l}1.0 \\
- \\
- \\
22 \\
n \\
-\end{array}$ & $\begin{array}{l}0.9 \\
-- \\
12 \\
26^{\mathrm{d}} \\
- \\
59^{\mathrm{d}} \\
77^{\mathrm{e}}\end{array}$ & $\begin{array}{l}0.9 \\
- \\
9.0 \mathrm{~d} \\
15 \\
-\bar{d} \\
48 \mathrm{~d} \\
63\end{array}$ & $\begin{array}{l}n \\
- \\
- \\
20 \\
23 \\
- \\
-\end{array}$ & $\begin{array}{l}0.9 \\
- \\
- \\
n \\
28 \\
- \\
-\end{array}$ & $\begin{array}{l}0.9 \\
- \\
7.8 \mathrm{~d} \\
15 \\
- \\
38 \mathrm{~d} \\
62\end{array}$ & $\begin{array}{l}1.0 \\
- \\
- \\
25 \\
32 \\
- \\
-\end{array}$ & $\begin{array}{l}1.0 \\
- \\
10 \\
15^{\mathrm{d}} \\
-6^{\mathrm{d}} \\
34^{\mathrm{d}}\end{array}$ & $\begin{array}{l}1.1 \\
- \\
- \\
46 \\
n \\
\text { n } \\
n\end{array}$ & $\begin{array}{c}1.0 \\
- \\
- \\
35 \\
n \\
n \\
95 \\
(495) \\
\end{array}$ & $\begin{array}{l}\text { n } \\
- \\
- \\
24 \\
23 \\
47 \\
49\end{array}$ & $\begin{array}{c}1.0 \\
- \\
- \\
25 \\
27 \\
40 \\
45 \\
\left(38^{f}\right) \\
\end{array}$ & $\begin{array}{l}1.1 \\
- \\
- \\
27 \\
28 \\
n \\
42 \\
\left(43^{f}\right)\end{array}$ & $\begin{array}{l}1.6^{\mathrm{d}} \\
19 \\
18^{\mathrm{d}} \\
-{ }^{\mathrm{d}} 15^{\mathrm{d}} \\
435^{\mathrm{d}}\end{array}$ & $\begin{array}{c}1.7^{\mathrm{d}} \\
- \\
20 \mathrm{~d} \\
20^{\mathrm{d}} \\
-7^{\mathrm{d}} \\
817^{\mathrm{d}}\end{array}$ & $\begin{array}{l}1.6 \\
- \\
23 \mathrm{~d} \\
25^{\mathrm{d}} \\
- \\
34 \mathrm{~d} \\
93^{\mathrm{d}}\end{array}$ & $\begin{array}{l}1.6^{\mathrm{d}} \\
- \\
30 \mathrm{~d} \\
28^{\mathrm{d}} \\
- \\
61^{\mathrm{d}} \\
67^{\mathrm{d}}\end{array}$ & $\begin{array}{c}1.8^{d} \\
- \\
37 \\
18 \\
- \\
34 \\
54\end{array}$ \\
\hline
\end{tabular}

$a=$ near oD

$b=$ midwall or center

(Table continued on next page.)

$c=$ near ID

$\mathrm{d}=$ average of 2 values

$e=$ average of 3 values

$\mathrm{F}=0^{\circ} \mathrm{C}$ brine quench

$g=$ dat brine quench

- = not studied 
TABLE B-4a (continued)

Thermal Data for Continuous Cooling of Uranium Tubes and Rods from $720 / 730^{\circ} \mathrm{C}$ Molten Salt (Houghton LH-980)

\begin{tabular}{|c|c|c|c|c|c|c|c|c|c|c|c|c|c|c|c|}
\hline \multirow[b]{2}{*}{ Parameter } & \multirow[b]{2}{*}{$\begin{array}{l}\text { Quench } \\
\text { Medium }\end{array}$} & \multicolumn{3}{|c|}{$3.9^{\prime \prime}$ OD, 2.0" ID Ingot (A) } & \multicolumn{3}{|c|}{$4.0^{\prime \prime}$ OD, 3.0" ID Ingot (E) } & \multicolumn{5}{|c|}{$3.0^{\prime \prime} \mathrm{OD}, 2.0^{\prime \prime}$ ID Dingot (DG) } & \multicolumn{3}{|c|}{$1.5 "$ OD $\times 0.5 "$ ID Ingot $(\mathrm{H}$} \\
\hline & & $0.060^{\mathrm{a}}$ & $0.447^{b}$ & $0.835^{c}$ & $0.060^{\mathrm{a}}$ & $0.249^{\mathrm{b}}$ & $0.398^{c}$ & $0.060^{\mathrm{a}}$ & 0.124 & $0.249^{\mathrm{b}}$ & 0.368 & $0.432^{c}$ & $0.080^{2}$ & $0.238^{b}$ & $0.395^{c}$ \\
\hline $\begin{array}{l}{ }_{A_{c}\left(a v_{0}\right)} \\
\text { (seconds) }\end{array}$ & Air, ofl, water & 198 & 204 & 203 & 101 & 101 & 100 & 99 & 98 & 100 & 98 & 100 & 103 & 105 & 109 \\
\hline $\begin{array}{l}t_{B / \alpha} \\
\text { (seconds) }\end{array}$ & $\begin{array}{l}25^{\circ} \mathrm{C} \text { Alr } \\
25^{\circ} \mathrm{C} \text { Houghto } 4102 \\
55^{\circ} \mathrm{C} \text { Poco No. } 2 \\
25^{\circ} \mathrm{C} \text { Poco No. } 2 \\
25^{\circ} \mathrm{C} \text { Houghto } \mathrm{K} \\
55^{\circ} \mathrm{C} \mathrm{H} \mathrm{H}_{2} \mathrm{O} \\
15^{\circ} \mathrm{C} \mathrm{H} \mathrm{H}_{2}\end{array}$ & $\begin{array}{c}- \\
4.3 \\
- \\
- \\
0.6 \\
- \\
0.1\end{array}$ & $\begin{array}{l}- \\
10 \\
- \\
- \\
1.6 \\
- \\
0.7\end{array}$ & $\begin{array}{c}- \\
\mathrm{n} \\
- \\
- \\
0.6 \\
- \\
0.2\end{array}$ & $\begin{array}{c}18 \\
- \\
- \\
\mathrm{n} \\
1.2 \\
\mathrm{n} \\
\mathrm{n}\end{array}$ & $\begin{array}{c}24 \\
- \\
- \\
1.2 \\
1.2 \\
0.2 \\
0.3\end{array}$ & $\begin{array}{l}34 \\
- \\
- \\
n \\
n \\
n \\
n\end{array}$ & $\begin{array}{c}16 \\
- \\
- \\
2.1 \\
- \\
n \\
-\end{array}$ & $\begin{array}{c}20 \\
- \\
- \\
2.1 \\
- \\
n \\
-\end{array}$ & $\begin{array}{l}15 \\
- \\
- \\
1.0 \\
- \\
n \\
-\end{array}$ & $\begin{array}{c}20 \\
- \\
- \\
1.5 \\
- \\
0.8 \\
-\end{array}$ & $\begin{array}{c}20 \\
- \\
- \\
n \\
- \\
2.0 \\
-\end{array}$ & $\begin{array}{l}27 \\
n \\
n \\
n \\
1.5 \\
0.2 \\
n\end{array}$ & $\begin{array}{l}25 \\
5.1 \\
1.2 \\
1.0 \\
1.7 \\
0.5 \\
\mathrm{n}\end{array}$ & $\begin{array}{l}32 \\
4.6 \\
2.6 \\
0.9 \\
1.2 \\
0.7 \\
0.4\end{array}$ \\
\hline $\begin{array}{l}{ }^{A} r \\
\left({ }^{\circ} \mathrm{C}\right)\end{array}$ & $\begin{array}{l}25^{\circ} \mathrm{C} \text { Alr } \\
25^{\circ} \mathrm{C} \text { Houghto } 4102 \\
55^{\circ} \mathrm{C} \text { Poco No. } 2 \\
25{ }^{\circ} \mathrm{C} \text { Poco No. } 2 \\
25^{\circ} \mathrm{C} \text { Houghto } \mathrm{K} \\
55^{\circ} \mathrm{C} \mathrm{H} \mathrm{H}_{2} \mathrm{O} \\
15^{\circ} \mathrm{C} \mathrm{H} \mathrm{H}_{2}^{\circ}\end{array}$ & $\begin{array}{c}- \\
642 \\
- \\
- \\
646 \\
- \\
607\end{array}$ & $\begin{array}{c}- \\
641 \\
- \\
- \\
628 \\
- \\
629\end{array}$ & $\begin{array}{c}- \\
n \\
- \\
- \\
643 \\
- \\
607\end{array}$ & $\begin{array}{c}647 \\
- \\
- \\
n \\
626 \\
n \\
n\end{array}$ & $\begin{array}{c}648 \\
- \\
- \\
622 \\
621 \\
618 \\
621\end{array}$ & $\begin{array}{c}642 \\
- \\
- \\
n \\
n \\
n \\
n\end{array}$ & $\begin{array}{c}624 \\
- \\
- \\
607 \\
- \\
n \\
-\end{array}$ & $\begin{array}{c}646 \\
- \\
- \\
630 \\
- \\
n \\
-\end{array}$ & $\begin{array}{c}644 \\
- \\
- \\
627 \\
- \\
588 \\
-\end{array}$ & $\begin{array}{c}632 \\
- \\
- \\
625 \\
- \\
631 \\
-\end{array}$ & $\begin{array}{c}643 \\
- \\
- \\
n \\
- \\
635 \\
-\end{array}$ & $\begin{array}{c}647 \\
n \\
n \\
640 \\
634 \\
n \\
n\end{array}$ & $\begin{array}{l}647 \\
645 \\
626 \\
617 \\
625 \\
658 \\
597\end{array}$ & $\begin{array}{l}645 \\
630 \\
622 \\
599 \\
615 \\
622 \\
606\end{array}$ \\
\hline $\begin{array}{l}\mathrm{R}_{\beta} \\
\left({ }^{\mathrm{O}} \mathrm{C} / \mathrm{sec}\right)\end{array}$ & $\begin{array}{l}25^{\circ} \mathrm{C} \text { Air } \\
25{ }^{\circ} \mathrm{C} \text { Houghto } 4102 \\
55^{\circ} \mathrm{C} \text { Poco No. } 2 \\
25^{\circ} \mathrm{C} \text { Poco No. } 2 \\
25{ }^{\circ} \mathrm{C} \text { Houghto K } \\
55^{\circ} \mathrm{C} \mathrm{H}_{2} \mathrm{O} \\
15^{\circ} \mathrm{C} \mathrm{H} \mathrm{H}^{2} \mathrm{O}\end{array}$ & $\begin{array}{c}- \\
15 \\
- \\
- \\
79 \\
- \\
420\end{array}$ & $\begin{array}{l}- \\
10 \\
- \\
- \\
30 \\
- \\
56\end{array}$ & $\begin{array}{l}- \\
10 \\
- \\
- \\
75 \\
- \\
395\end{array}$ & $\begin{array}{c}2.5 \\
- \\
- \\
58 \\
91 \\
474 \\
474\end{array}$ & $\begin{array}{c}2.6 \\
- \\
- \\
39 \\
50 \\
115 \\
158\end{array}$ & $\begin{array}{c}2.6 \\
- \\
- \\
80 \\
63 \\
345 \\
441\end{array}$ & $\begin{array}{c}2.2 \\
- \\
- \\
49 \\
- \\
428 \\
-\end{array}$ & $\begin{array}{c}2.3 \\
- \\
- \\
46 \\
- \\
n \\
-\end{array}$ & $\begin{array}{c}2.4 \\
- \\
- \\
53 \\
- \\
72 \\
-\end{array}$ & $\begin{array}{c}2.5 \\
- \\
- \\
47 \\
- \\
134 \\
-\end{array}$ & $\begin{array}{c}2.3 \\
- \\
- \\
76 \\
- \\
121 \\
-\end{array}$ & $\begin{array}{l}2.2 \\
\text { n } \\
n \\
72 \\
34 \\
126 \\
197\end{array}$ & $\begin{array}{l}2.2 \\
22 \\
39 \\
54 \\
33 \\
66^{d} \\
89^{d}\end{array}$ & $\begin{array}{r}2.2 \\
18 \\
44 \\
36 \\
34 \\
52 \\
72\end{array}$ \\
\hline $\begin{array}{l}\mathrm{R}_{\alpha} \\
\left({ }^{\mathrm{o}} \mathrm{c} / \mathrm{sec}\right)\end{array}$ & $\begin{array}{l}25^{\circ} \mathrm{C} \text { Air } \\
25{ }^{\circ} \mathrm{C} \text { Houghto } 4102 \\
55{ }^{\circ} \mathrm{C} \text { Poco No. } 2 \\
25{ }^{\circ} \mathrm{C} \text { Poco No. } 2 \\
25{ }^{\circ} \mathrm{C} \text { Houghto X } \\
555^{\circ} \mathrm{CH} \text { H } 0 \\
15{ }^{\circ} \mathrm{C} \mathrm{H}_{2} \mathrm{O}\end{array}$ & $\begin{array}{l}- \\
- \\
- \\
76 \\
- \\
n\end{array}$ & $\begin{array}{l}- \\
- \\
- \\
n \\
96\end{array}$ & $\begin{array}{l}- \\
- \\
- \\
64 \\
- \\
n\end{array}$ & $\begin{array}{l}1.5 \\
- \\
- \\
n \\
67 \\
n \\
n\end{array}$ & $\begin{array}{l}1.7 \\
- \\
- \\
65 \\
75 \\
126 \\
190\end{array}$ & $\begin{array}{l}1.6 \\
- \\
- \\
\mathrm{n} \\
\mathrm{n} \\
\mathrm{n} \\
\mathrm{n}\end{array}$ & $\begin{array}{l}1.4 \\
- \\
- \\
\mathrm{n} \\
- \\
\mathrm{n} \\
-\end{array}$ & $\begin{array}{l}1.4 \\
- \\
- \\
66 \\
- \\
n \\
-\end{array}$ & $\begin{array}{c}1.4 \\
- \\
- \\
73 \\
- \\
\mathrm{n} \\
-\end{array}$ & $\begin{array}{c}1.5 \\
- \\
- \\
71 \\
- \\
134 \\
-\end{array}$ & $\begin{array}{c}1.5 \\
- \\
- \\
n \\
- \\
292 \\
-\end{array}$ & $\begin{array}{l}1.5 \\
n \\
n \\
40 \\
37 \\
158 \\
n\end{array}$ & $\begin{array}{r}1.4 \\
14 \\
45 \\
57 \\
40 \\
88 \\
110\end{array}$ & $\begin{array}{r}1.5 \\
16 \\
70 \\
46 \\
46 \\
90 \\
202\end{array}$ \\
\hline
\end{tabular}

(Table continued on next page.) 
TABLE B-4a (continued)

Thermal Data for Continuous Cooling of Uranium Tubes and Rods from $720 / 730^{\circ} \mathrm{C}$ Mol ten Salt (Houghton LH-980)

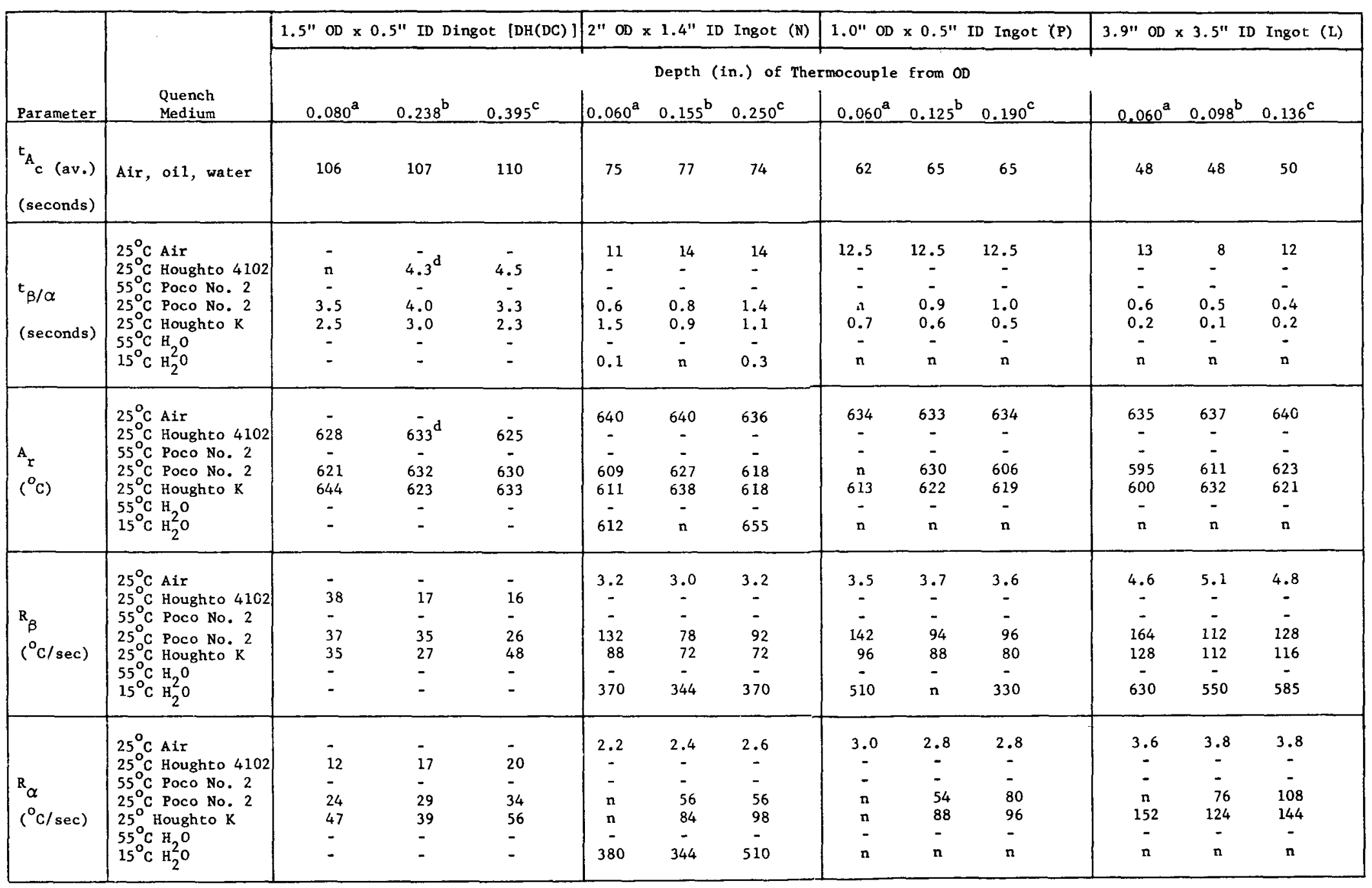

(Table continued on next page.) 
CABLE B-4a (continued)

Thermal Data for Continuous Cooling of Uranium Tubes and Rods from $720 / 730^{\circ} \mathrm{C}$ Molten Salt (Houghton LH-980)

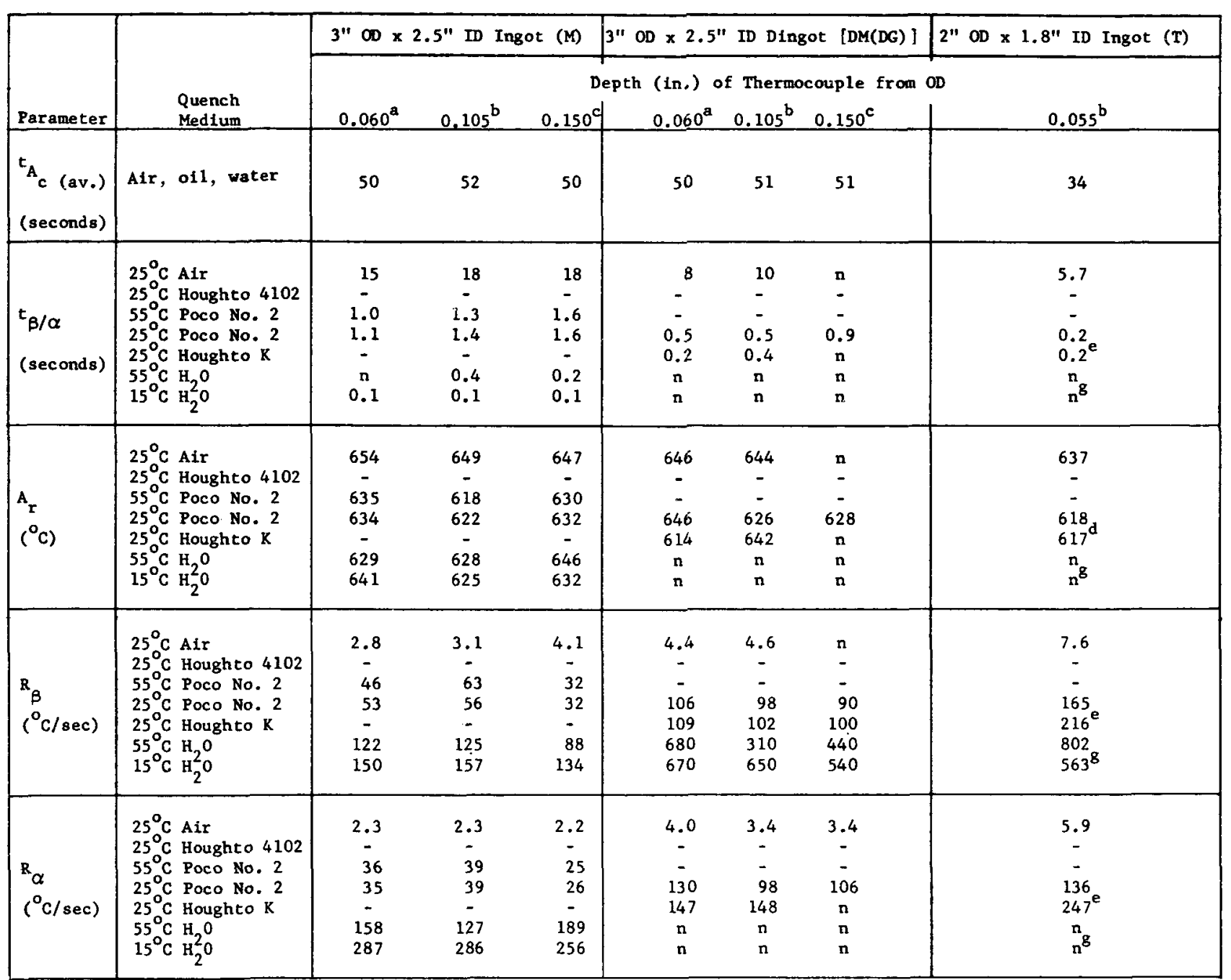


TABLE B-4b

Thermal Data for Interrupted Cooling of Uranium Tubes and Rods

\begin{tabular}{|c|c|c|c|c|c|c|c|c|c|c|c|c|}
\hline \multirow[b]{3}{*}{ Parameter } & \multirow[b]{3}{*}{$\begin{array}{l}\text { Quench } \\
\text { Med ium }\end{array}$} & \multicolumn{5}{|c|}{ 1.8" Dtameter Ingot (C) } & \multicolumn{3}{|c|}{$1.5 "$ OD $\times 0.5 "$ ID Ingot $(\mathrm{H})$} & \multicolumn{3}{|c|}{ 1.5" oD $\times 0.5 "$ ID Dingot [DH(DC)] } \\
\hline & & \multicolumn{11}{|c|}{ Depth $\left(I_{n}\right)$ of Thermocouple from OD } \\
\hline & & $0.080^{\mathrm{a}}$ & 0.231 & 0.461 & 0.692 & $0.923^{\mathrm{b}}$ & $0.080^{\mathrm{a}}$ & $0.238^{\mathrm{b}}$ & $0.395^{\mathrm{c}}$ & $0.080^{\mathrm{a}}$ & $0.238^{\mathrm{b}}$ & $0.395^{c}$ \\
\hline $\begin{array}{l}{ }^{{ }^{A_{C}}} \text { (av.) } \\
\text { (seconds) }\end{array}$ & Air, oil, water & 164 & 164 & 178 & 184 & 185 & 99 & 107 & 112 & 105 & 110 & 112 \\
\hline $\begin{array}{l}t_{\beta / \alpha} \\
(\sec o n d s)\end{array}$ & 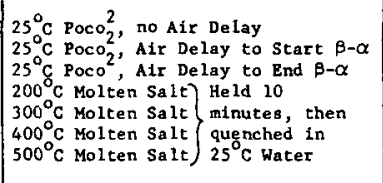 & $\begin{array}{l}2.0^{e} \\
0.8 \\
25 \\
\vdots \\
\vdots \\
-\end{array}$ & $\begin{array}{c}2.0 \\
1.3 \\
23 \\
\vdots \\
\vdots\end{array}$ & $\begin{array}{l}2.59 \\
1.6^{6} \\
221 \\
\vdots \\
\vdots\end{array}$ & $\begin{array}{l}n \\
3.0^{d} \\
29 \\
: \\
\vdots \\
:\end{array}$ & $\begin{array}{l}5.9 \mathrm{~d} \\
4.0^{\mathrm{d}} \\
10 \\
- \\
- \\
-\end{array}$ & $\begin{array}{c}n \\
n \\
30 \\
2.6 \\
3.0 \\
4.2\end{array}$ & $\begin{array}{l}1.0 \\
n^{\mathrm{n}} \\
21_{\mathrm{d}}^{\mathrm{d}} \\
1.7^{\mathrm{d}} \\
1.6_{\mathrm{d}}^{\mathrm{d}} \\
2.6^{\mathrm{d}}\end{array}$ & $\begin{array}{l}0.9 \\
0.6 \\
18 \\
1.8 \\
1.9 \\
3.5 \\
-\end{array}$ & $\begin{array}{c}3.5 \\
: \\
\vdots \\
n \\
7.2 \\
13.5\end{array}$ & $\begin{array}{l}4.0^{\mathrm{d}} \\
: \\
-.^{\mathrm{d}} \\
4 . ._{\mathrm{d}}^{\mathrm{d}} \\
8.0^{\mathrm{d}}\end{array}$ & $\begin{array}{l}3.3 \\
: \\
- \\
3.8 \\
4.8 \\
10\end{array}$ \\
\hline $\begin{array}{l}A_{R} \\
\left({ }^{\circ} \mathrm{C}\right)\end{array}$ & 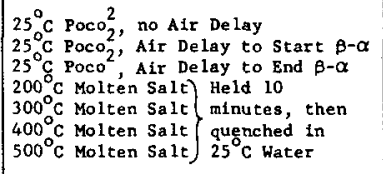 & $\begin{array}{l}638^{\circ} \\
636 \\
638 \mathrm{~A} 1 \mathrm{r} \\
- \\
- \\
-\end{array}$ & $\begin{array}{c}631 \\
640 \text { A1r, } \\
621 \text { oi1 } \\
\vdots \\
\vdots\end{array}$ & 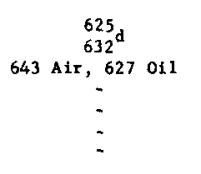 & 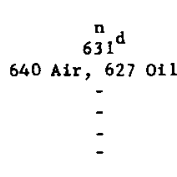 & $\begin{array}{c}629 \mathrm{~d} \\
634^{\mathrm{d}} \\
653 \text { Air., } \\
\vdots \\
- \\
-\end{array}$ & $\begin{array}{l}640 \\
n \\
638 \text { Air } \\
624 \\
621 \\
620 \\
-\end{array}$ & 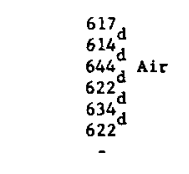 & $\begin{array}{l}599 \\
595 \\
642 \text { A1r } \\
617 \\
635 \\
627\end{array}$ & $\begin{array}{c}621 \\
: \\
- \\
- \\
624 \\
630\end{array}$ & $\begin{array}{l}632^{\mathrm{d}} \\
\vdots \\
-\overline{64} 1^{\mathrm{d}} \\
636^{\mathrm{d}} \\
634^{\mathrm{d}}\end{array}$ & $\begin{array}{l}630 \\
: \\
\vdots \\
643 \\
624 \\
638\end{array}$ \\
\hline $\begin{array}{l}\mathrm{R}_{\mathrm{B}} \\
\left.{ }^{\circ} \mathrm{C} / \mathrm{sec}\right)\end{array}$ & 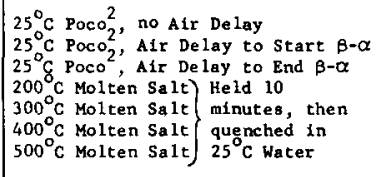 & $\begin{array}{c}36^{\mathrm{e}} \\
1.6^{\mathrm{d}} \mathrm{Alr}^{\mathrm{d}}, 5^{\mathrm{d}} \text { oil } \\
1.7^{\mathrm{Air}} \\
\vdots \\
\vdots \\
\vdots\end{array}$ & $\begin{array}{c}27 \\
1.5^{\mathrm{d}} \mathbf{A 1 r}^{27}, 24 \text { o11 } \\
1.6 \mathrm{Alr}, 18 \text { O11 } \\
\vdots \\
\vdots\end{array}$ & $\begin{array}{c}1.6^{\mathrm{d}} \mathrm{Alr},{ }^{\mathrm{d}} \mathrm{d} \text { o11 } \\
1.6 \mathrm{Alr}, 9.6^{\circ} \text { o11 } \\
\vdots \\
\vdots\end{array}$ & $\begin{array}{c}12 \\
1.7^{\mathrm{d} A i r}, 10011 \\
1.7 \text { Air, } 4.6011 \\
\vdots \\
\vdots\end{array}$ & $\begin{array}{c}1.4^{\mathrm{d}} \mathrm{AIr}, 9.4^{\mathrm{d}} \text { o11 } \\
1.4 \mathrm{Air}, 6.2011 \\
= \\
-\end{array}$ & $\begin{array}{c}72 \\
2.0 \text { Air, } 63011 \\
2.2 \\
125 \\
87 \\
68 \\
-\end{array}$ & $\begin{array}{c}5.0 \mathrm{Air}, 18^{\mathrm{d}} 0 \mathrm{il} \\
2.2 \mathrm{~d}^{\mathrm{d}} \\
50^{\mathrm{d}} \\
52 \mathrm{~d} \\
33^{\mathrm{d}} \\
-\end{array}$ & $\begin{array}{c}36 \\
2.0 \mathrm{Air}, 34 \text { oil } \\
2.0 \\
49 \\
27 \\
27 \\
-\end{array}$ & $\begin{array}{l}37 \\
: \\
7 \\
73 \\
64 \\
32\end{array}$ & $\begin{array}{l}35^{\mathrm{d}} \\
\vdots \\
-1^{\mathrm{d}} \\
28^{\mathrm{d}} \\
22^{\mathrm{d}}\end{array}$ & $\begin{array}{l}26 \\
\vdots \\
\vdots \\
54 \\
41 \\
28\end{array}$ \\
\hline $\begin{array}{l}{ }_{\alpha}{ }_{\alpha} \\
\left({ }^{\circ} \mathrm{C} / \mathrm{sec}\right)\end{array}$ & 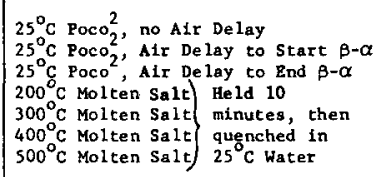 & $\begin{array}{l}19^{\mathrm{e}} \\
41^{\mathrm{d}} \\
65 \\
\vdots \\
\vdots\end{array}$ & $\begin{array}{l}22 \mathrm{~d} \\
22 \\
29 \\
- \\
-\end{array}$ & $\begin{array}{l}200^{2} \\
22^{2} \\
\vdots \\
\vdots \\
-\end{array}$ & $\begin{array}{l}\mathrm{n}_{21^{d}} \\
27 \\
\vdots \\
\vdots\end{array}$ & $\begin{array}{l}25 \mathrm{~d} \\
20^{\mathrm{d}} \\
23 \\
- \\
\vdots \\
-\end{array}$ & $\begin{array}{l}40 \\
\text { n } \\
84 \\
26 \\
\text { n } \\
15 \\
-\end{array}$ & $\begin{array}{l}57 \\
27^{\mathrm{d}} \\
45_{\mathrm{d}}^{\mathrm{d}} \\
42_{\mathrm{d}} \\
36_{\mathrm{d}}^{\mathrm{d}} \\
20^{\mathrm{d}}\end{array}$ & $\begin{array}{l}46 \\
37 \\
52 \\
41 \\
40 \\
21\end{array}$ & $\begin{array}{l}24 \\
- \\
- \\
- \\
7.0 \\
3.0\end{array}$ & $\begin{array}{l}29^{d} \\
\vdots \\
30^{d} \\
13^{d} \\
40^{d}\end{array}$ & $\begin{array}{c}34 \\
\vdots \\
\vdots \\
33 \\
13 \\
3.0\end{array}$ \\
\hline
\end{tabular}

$a=$ near on
$b=$ midwalit
$d=2$

$d=$ average of 2 values
$e=$ average of 3 values
a

$\mathrm{f}=25^{\circ} \mathrm{C}$ brine quench

$\mathrm{g}=0^{\circ} \mathrm{C}$ brine quench
$\mathrm{n}=\mathrm{dara}$ unavallable
$-\mathrm{O}$ not studied 


\section{TABIE B-5}

Grain Sizes ${ }^{\dagger}$ of Uranium Rods and Tubes After Beta Treatment at $725^{\circ} \mathrm{C}$ for $10-15$ Minutes

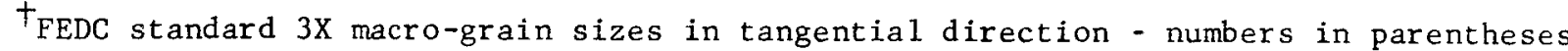
indicate grain sizes after post-beta recrystallization $\left(600^{\circ} \mathrm{C}, 2\right.$ t.rs ).

\begin{tabular}{|c|c|c|c|c|c|}
\hline \multirow{2}{*}{$\begin{array}{l}\text { Designation } \\
\text { and } \\
\text { Chemistry }\end{array}$} & \multicolumn{2}{|c|}{$\begin{array}{c}\text { Dimensions } \\
\text { (in) }\end{array}$} & \multirow[b]{2}{*}{ Cooling Medium } & $\therefore \quad$ Grain Size & Ci-umrar \\
\hline & $O D$ & Wa11 & & OD $\mathrm{mid}$-wall/mid-radius ID/center & OD ID \\
\hline $\begin{array}{c}\text { C } \\
\text { Ingot }\end{array}$ & 1.8 & Rod & $\begin{array}{l}\text { air } \\
\text { R. T. Poco No. } 2 \\
30 \text { sec. air delay, R. T. Poco No, } 2 \\
65 \text { sec. air delay, R. T. Poco No. } 2 \\
\text { R. T. Houghto } \mathrm{K} \\
\text { warm water } \\
\text { cold water }\end{array}$ & 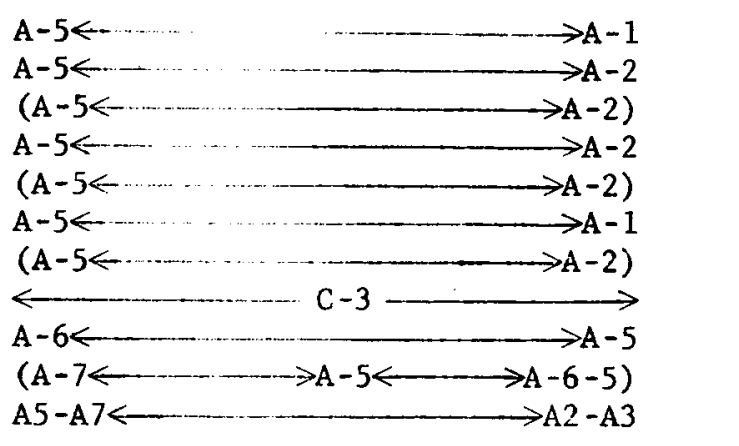 & 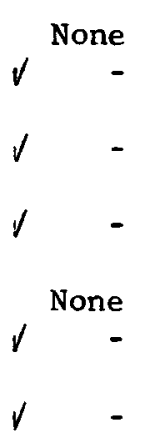 \\
\hline $\begin{array}{c}D-C \\
\text { Dingot }\end{array}$ & 1.8 & Rod & $\begin{array}{l}\text { air } \\
\text { R. T. Poco No. } 2 \\
\text { R. T. Houghto } \mathrm{K} \\
\text { warm water } \\
\text { cold water } \\
\text { R. T. Brine }\end{array}$ & 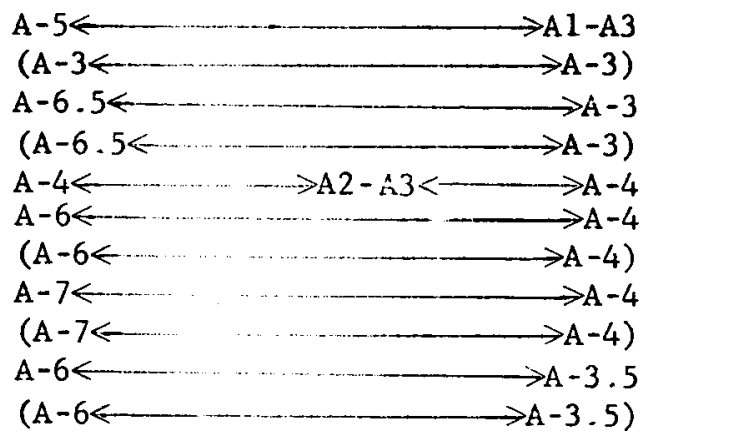 & $\begin{array}{l}\text { None } \\
\text { None } \\
\text { None } \\
\text { None } \\
\text { None } \\
\text { None }\end{array}$ \\
\hline
\end{tabular}

(Table continued on next page) 
Grain Sizes ${ }^{\dagger}$ of Uranium Rods and Tubes After Beta Treatment at $725^{\circ} \mathrm{C}$ for $10-15$ Minutes

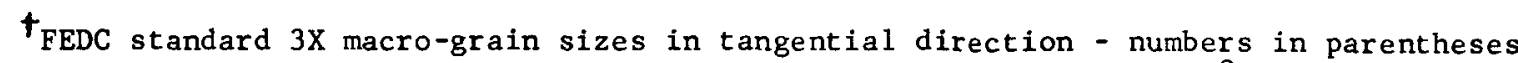
indicate grain sizes after post-beta recrystallization $\left(600^{\circ} \mathrm{C}, 2\right.$ hrs.).

\begin{tabular}{|c|c|c|c|c|c|}
\hline \multirow{2}{*}{$\begin{array}{l}\text { Designation } \\
\text { and } \\
\text { Chemistry }\end{array}$} & \multicolumn{2}{|c|}{$\begin{array}{l}\text { Dimensions } \\
\text { (in) }\end{array}$} & \multirow[b]{2}{*}{ Cooling Medium } & Grain Size & Columnar \\
\hline & OD & Wa11 & & mid-wal1/mid-radius ID/center & OD ID \\
\hline $\begin{array}{c}K \\
\text { Ingot }\end{array}$ & 1.2 & Rod & $\begin{array}{l}\text { air } \\
\text { R. T. Poco No. } 2 \\
\text { warm water } \\
\text { cold water } \\
\left(8 \mathrm{hrs}, 645^{\circ} \mathrm{C}, \mathrm{wq}\right)^{*} ; \mathrm{R} . \mathrm{T} \text {. water } \\
\left(8 \mathrm{hrs}, 645^{\circ} \mathrm{C}, \mathrm{wq} ; 8 \mathrm{hrs}, 525^{\circ} \mathrm{C}, w q\right)^{*} ; \mathrm{R} . \mathrm{T} \text {. water } \\
\left(\beta \text { treat, wq; } 8 \mathrm{hrs}, 525^{\circ} \mathrm{C}, w q\right) * ; \text { cold water } \\
\left(\beta \text { treat, wq; } 8 \mathrm{hrs}, 425^{\circ} \mathrm{C} \text {, wq }\right) * ; \text { cold water } \\
\left(\beta \text { treat, wq; } 8 \mathrm{hrs}, 325^{\circ} \mathrm{C} \text {, wq }\right) * ; \text { cold water }\end{array}$ & 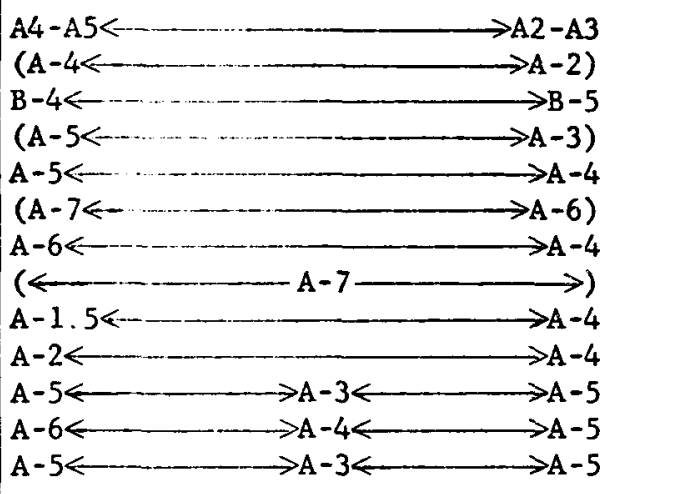 & 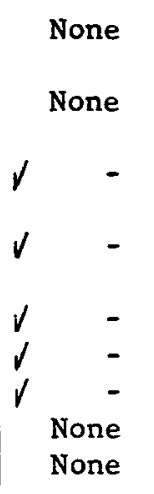 \\
\hline $\begin{array}{c}\text { D-K } \\
\text { Dingot }\end{array}$ & 1.04 & Rod & $\begin{array}{l}(\beta \text { treat, wq }) * ; \text { cold water } \\
\left(7-8 \mathrm{hrs} \text { at } 525^{\circ} \mathrm{C} \text {, wq }\right) * ; \text { cold water } \\
\left(8-9 \mathrm{hrs} \text { at } 645^{\circ} \mathrm{C} \text {, wq }\right) * ; \text { cold water }\end{array}$ & 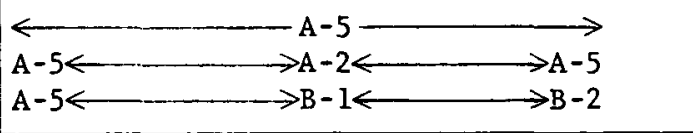 & $\begin{array}{l}\text { None } \\
\text { None } \\
\text { None }\end{array}$ \\
\hline $\begin{array}{c}\text { S } \\
\text { Ingot }\end{array}$ & 0.48 & Rod & $\begin{array}{l}\text { air } \\
\text { R. T. Poco No. } 2 \\
\text { warm Poco No. } 2 \\
\text { warm water } \\
\text { cold water }\end{array}$ & 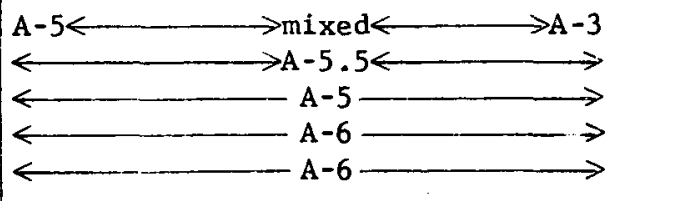 & $\begin{array}{l}\text { None } \\
\text { None } \\
\text { None } \\
\text { None } \\
\text { None }\end{array}$ \\
\hline $\begin{array}{c}Q \\
\text { Dingot }\end{array}$ & 0.59 & Rod & $\begin{array}{l}\text { air } \\
\text { R. T. Poco No. } 2 \\
\text { warm Poco No. } 2 \\
\text { warm water } \\
\text { cold water }\end{array}$ & 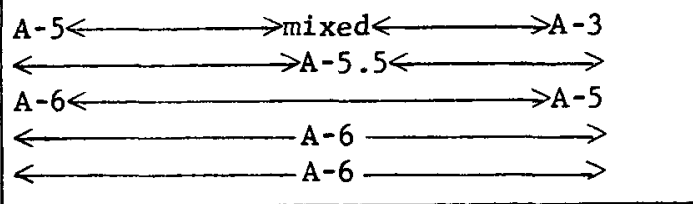 & $\begin{array}{l}\text { None } \\
\text { None } \\
\text { None } \\
\text { None } \\
\text { None }\end{array}$ \\
\hline
\end{tabular}

* Treatment prior to final beta treatment.

(Table continued on next page.) 


\section{TABLE B-5 (cont inued)}

Grain Sizes ${ }^{\dagger}$ of Uranium Rods and Tubes After Beta Treatment at $725^{\circ} \mathrm{C}$ for $10-15$ Minutes

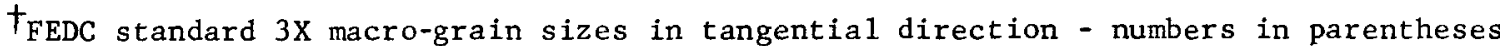
indicate grain sizes after post-beta recrystallization $\left(600^{\circ} \mathrm{C}, 2 \mathrm{hrs}.\right)$.

\begin{tabular}{|c|c|c|c|c|c|}
\hline \multirow{2}{*}{$\begin{array}{l}\text { Designation } \\
\text { and } \\
\text { Chemistry }\end{array}$} & \multicolumn{2}{|c|}{$\begin{array}{c}\text { Dimensions } \\
\text { (in) }\end{array}$} & \multirow[b]{2}{*}{ Cooling Medium } & Grain size & Columnar \\
\hline & OD & Wa11 & & OD mid-wa1l/mid-radius ID/center & OD ID \\
\hline $\begin{array}{c}\text { A } \\
\text { Ingot }\end{array}$ & 3.9 & 1.0 & $\begin{array}{l}\text { R. T. Houghto } 4102 \\
\text { R. T. Houghto } \mathrm{K} \\
\text { cold water }\end{array}$ & 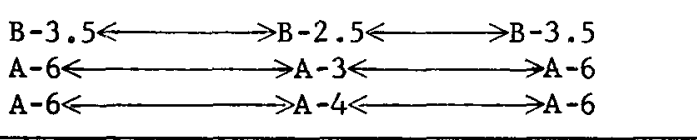 & $\begin{array}{l}\text { None } \\
\text { None } \\
\quad \text { None }\end{array}$ \\
\hline $\begin{array}{c}E \\
\text { Ingot }\end{array}$ & 4.0 & 0.5 & $\begin{array}{l}\text { air } \\
\text { R. T. Poco No. } 2 \\
\text { R. T. Houghto K } \\
\text { warm water } \\
\text { cold water }\end{array}$ & $\begin{array}{l}\mathrm{A}-5 \longleftrightarrow \mathrm{A} 1-\mathrm{A} 3 \longleftrightarrow \mathrm{A}-4 \\
(\mathrm{~A}-4 \longleftrightarrow \mathrm{A} 1-\mathrm{A} 3 \longleftrightarrow \mathrm{A}-4) \\
\stackrel{\mathrm{A}-3.5}{\longrightarrow} \mathrm{A}-3.5 \longleftrightarrow \mathrm{A}-5) \\
\stackrel{\mathrm{A}-5 \longleftrightarrow}{\longleftrightarrow} \mathrm{C}-3 \longrightarrow \\
\stackrel{\mathrm{A}-3.5 \longrightarrow}{\longleftrightarrow} \\
\stackrel{\mathrm{A}-3 \longrightarrow}{\longrightarrow}\end{array}$ & $\begin{array}{ll} & \text { None } \\
v & v \\
v & V \\
v & v \\
v & v\end{array}$ \\
\hline $\begin{array}{c}D-G \\
\text { Dingot }\end{array}$ & 3.0 & 0.5 & $\begin{array}{l}\text { air } \\
\text { R. T. Poco No. } 2 \\
\text { warm water }\end{array}$ & $\begin{array}{l}\stackrel{B}{\longleftrightarrow}-2 \longrightarrow \\
\mathrm{A}-5.5 \longrightarrow\end{array}$ & $\begin{array}{l}\text { None } \\
\text { None } \\
\text { None }\end{array}$ \\
\hline $\begin{array}{c}\mathrm{H} \\
\text { Ingot }\end{array}$ & 1.5 & 0.5 & $\begin{array}{l}\text { air } \\
\text { warm Poco No. } 2 \\
\text { R. T. Houghto } 4102 \\
\text { R. T. Houghto } \mathrm{K} \\
\text { R. T. Poco No. } 2 \\
36 \text { sec. delay R. T. Poco No. } 2 \\
68 \text { sec. delay R. T. Poco No. } 2 \\
\text { warm water } \\
\text { cold water } \\
400^{\circ} \mathrm{C} \text { salt R. T. Water } \\
300^{\circ} \mathrm{C} \text { salt R. T. Water } \\
200^{\circ} \mathrm{C} \text { salt R. T. water }\end{array}$ & 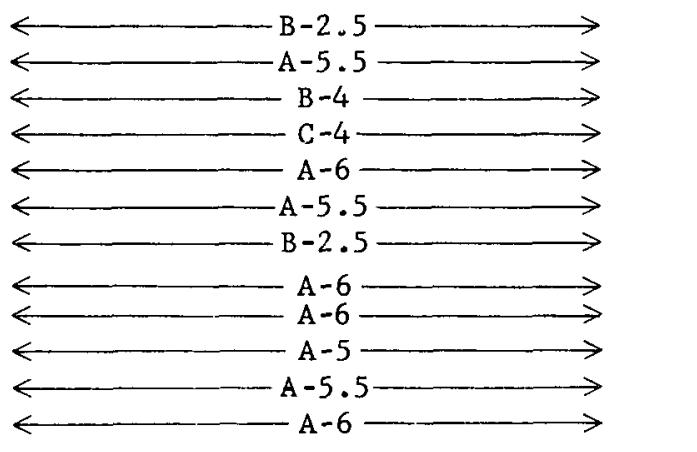 & $\begin{array}{l}\text { None } \\
\text { None } \\
\text { None } \\
\text { None } \\
\text { None } \\
\text { None } \\
\text { None } \\
\text { None } \\
\text { None } \\
\quad \text { None } \\
\text { None } \\
\text { None }\end{array}$ \\
\hline
\end{tabular}


TABLE B-5 (continued)

Grain Sizes ${ }^{\dagger}$ of Uranium Rods and Tubes After Beta Treatment at $725^{\circ} \mathrm{C}$ for $10-15$ Minutes

$t_{\text {FEDC }}$ standard $3 \mathrm{X}$ macro-grain sizes in tangential direction - numbers in parentheses indicate grain sizes after post-beta recrystallization $\left(600^{\circ} \mathrm{C}, 2\right.$ lurs.).

\begin{tabular}{|c|c|c|c|c|c|}
\hline \multirow{2}{*}{$\begin{array}{l}\text { Designation } \\
\quad \text { and } \\
\text { Chemistry }\end{array}$} & \multicolumn{2}{|c|}{$\begin{array}{c}\text { Dimensions } \\
\text { (in) }\end{array}$} & & Grain size & Columnar \\
\hline & OD & Wa 11 & Cooling Medium & OD mid-wa 11/mid-radius ID/center & OD ID \\
\hline $\begin{array}{c}\mathrm{D}-\mathrm{H} \\
\text { Dingot }\end{array}$ & 1.5 & 0.5 & $\begin{array}{l}\text { air } \\
\text { warm Poco No. } 2 \\
\text { R. T. Houghto } 4102 \\
\text { R. T. Poco No. } 2 \\
\text { R. T. Houghto } \mathrm{K} \\
\text { warm water } \\
\text { cold water } \\
500^{\circ} \mathrm{C} \text { salt } \mathrm{R} \text {. T. Water } \\
400^{\circ} \mathrm{C} \text { salt } \mathrm{R} \text {. T. Water } \\
300^{\circ} \mathrm{C} \text { salt } \mathrm{R} \text {. T. water }\end{array}$ & 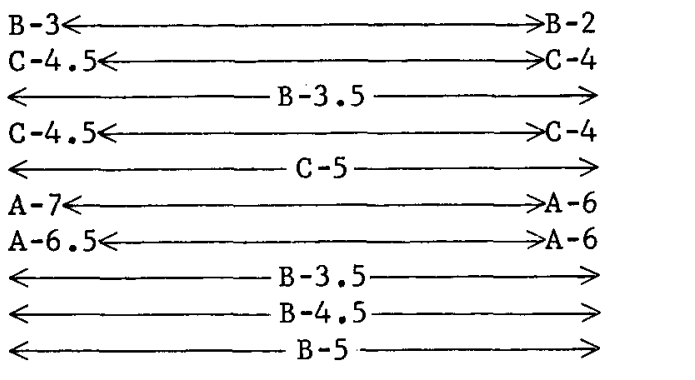 & $\begin{array}{l}\text { None } \\
\text { None } \\
\text { None } \\
\text { None } \\
\text { None } \\
\text { None } \\
\text { None } \\
\text { None } \\
\text { None } \\
\text { None }\end{array}$ \\
\hline $\begin{array}{c}\mathrm{N} \\
\text { Ingot }\end{array}$ & 2.0 & 0.3 & $\begin{array}{l}\text { air } \\
\text { R. T. Poco No. } 2 \\
\text { R. T. Houghto K } \\
\text { cold water }\end{array}$ & 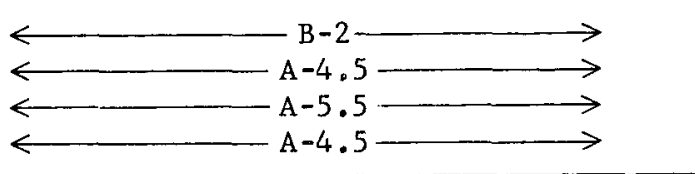 & $\begin{array}{r}\text { None } \\
\text { None } \\
\text { None } \\
\sqrt{ }\end{array}$ \\
\hline $\begin{array}{c}\mathrm{p} \\
\text { Ingot }\end{array}$ & 1.0 & 0.25 & $\begin{array}{l}\text { air } \\
\text { R. T. Poco No. } 2 \\
\text { R. T. Houghto } \mathrm{K} \\
\text { cold water }\end{array}$ & 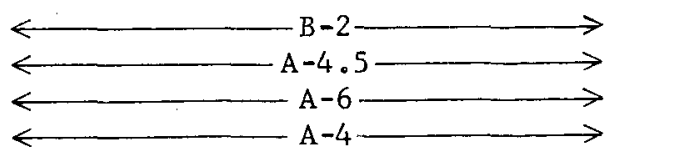 & $\begin{array}{c}\text { None } \\
\text { None } \\
\text { None } \\
\checkmark \quad \text { None }\end{array}$ \\
\hline
\end{tabular}

(Table continued on next page.) 
TABLE B-5 (continued)

Grain Sizes ${ }^{\dagger}$ of Uranium Rods and Tubes After Beta Treatment at $725^{\circ} \mathrm{C}$ for $10-15$ Minutes

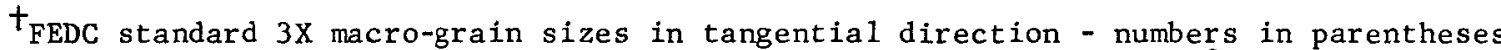
indicate grain sizes after post-beta recrystallization $\left(600^{\circ} \mathrm{C}, 2\right.$ irs.).

\begin{tabular}{|c|c|c|c|c|c|}
\hline \multirow{2}{*}{$\begin{array}{l}\text { Designation } \\
\text { and } \\
\text { Chemistry }\end{array}$} & \multicolumn{2}{|c|}{$\begin{array}{c}\text { Dimensions } \\
\text { (in) }\end{array}$} & & Grain Size & Columnar \\
\hline & $\mathrm{OD}$ & Wa 11 & Cooling Medium & mid-wa $11 /$ mid-radius ID/center & $\mathrm{OD} \quad \mathrm{ID}$ \\
\hline $\begin{array}{c}\mathrm{L} \\
\text { Ingot }\end{array}$ & 3.9 & 0.2 & $\begin{array}{l}\text { air } \\
\text { R. T. Poco No. } 2 \\
\text { R. T. Houghto } \mathrm{K} \\
\text { cold water }\end{array}$ & $\begin{aligned} \longleftrightarrow & B-3 \longrightarrow \\
\longleftrightarrow & A-5 \longrightarrow \\
\longleftrightarrow & \longrightarrow \\
\longleftrightarrow & \longrightarrow\end{aligned}$ & $\begin{array}{l}\text { None } \\
\text { None } \\
\text { None } \\
\text { None }\end{array}$ \\
\hline $\begin{array}{c}\text { M } \\
\text { Ingot }\end{array}$ & 3.0 & 0.2 & $\begin{array}{l}\text { air } \\
R . T \text {. Poco No. } 2 \\
\text { R. T. Houghto } \mathrm{K} \\
\text { warm water } \\
\text { cold water } \\
\text { cold water repeat }\end{array}$ & 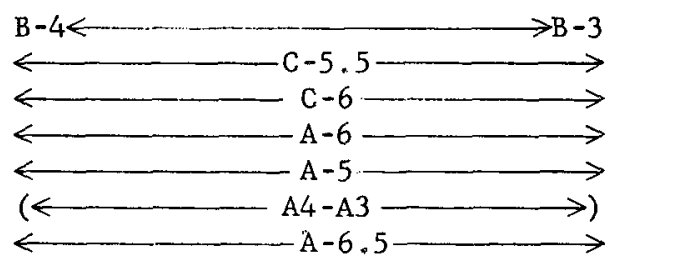 & $\begin{array}{l}\text { None } \\
\text { None } \\
\text { None } \\
\text { None } \\
\text { None } \\
\text { None }\end{array}$ \\
\hline $\begin{array}{c}\text { D-M } \\
\text { Dingot }\end{array}$ & 3.0 & 0.2 & $\begin{array}{l}\text { air } \\
\text { R. T. Poco No. } 2 \\
\text { R. T. Houghto } K \\
\text { warm water } \\
\text { cold water }\end{array}$ & 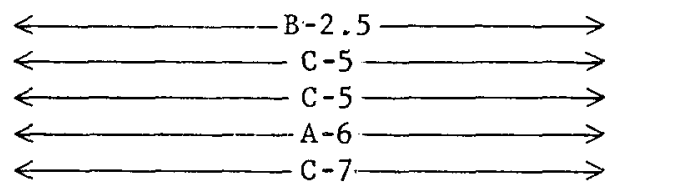 & $\begin{array}{l}\text { None } \\
\text { None } \\
\text { None } \\
\text { None } \\
\text { None }\end{array}$ \\
\hline $\begin{array}{c}\mathrm{T} \\
\text { Ingot }\end{array}$ & 2.0 & 0.1 & $\begin{array}{l}\text { air } \\
\text { R. T. Poco No. } 2 \\
\text { R. T, Houghto } \mathrm{K} \\
\text { warm water } \\
0^{\circ} \mathrm{C} \text { Brine } \\
\text { cold water } \\
9 \mathrm{mils} \text { Zircaloy clad; cold water } \\
20 \mathrm{mils} \text { Zircaloy clad; cold water } \\
45 \mathrm{mi} \text { is Zircaioy ciad; cold water }\end{array}$ & 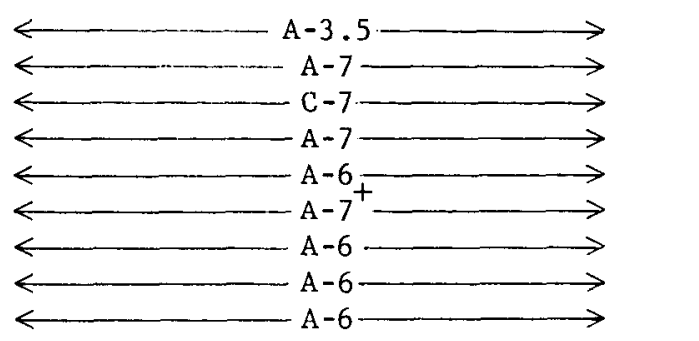 & \begin{tabular}{lc} 
None \\
None \\
None \\
$\downarrow$ & None \\
$\checkmark$ & None \\
\multicolumn{2}{c}{ None } \\
$\checkmark$ & None \\
$\checkmark$ & $\checkmark$ \\
$\checkmark$ & $\checkmark$
\end{tabular} \\
\hline
\end{tabular}


Relation Between Texture and Dimensional Changes Caused by Beta Treatment of Rods

[Table shows $\%$ changes in length $(\Delta \mathrm{L})$ and diameter $(\Delta \mathrm{D})$. ]

\begin{tabular}{|c|c|c|c|c|c|c|c|c|c|c|c|c|c|c|}
\hline \multirow[b]{3}{*}{ Code } & \multirow{2}{*}{\multicolumn{2}{|c|}{$\begin{array}{l}\text { Prior Texture: } \\
\text { hk } 1 \quad\left(G_{3}\right)\end{array}$}} & \multicolumn{12}{|c|}{ Cooling Medium } \\
\hline & & & \multicolumn{2}{|c|}{$\begin{array}{l}30^{\circ} \mathrm{C} \\
\text { Air }\end{array}$} & \multicolumn{2}{|c|}{$\begin{array}{c}55^{\circ} \mathrm{C} \\
\text { Poco No. } 2 \\
\text { Oi1 } \\
\end{array}$} & \multicolumn{2}{|c|}{$\begin{array}{c}25^{\circ} \mathrm{C} \\
\text { Poco No. } 2 \\
\text { Oi } 1\end{array}$} & \multicolumn{2}{|c|}{$\begin{array}{c}25^{\circ} \mathrm{C} \\
\text { Houghto } \mathrm{K} \\
\text { Oil } \\
\end{array}$} & \multicolumn{2}{|c|}{$\begin{array}{r}55^{\circ} \mathrm{C} \\
\text { Water }\end{array}$} & \multicolumn{2}{|c|}{$\begin{array}{r}13^{\circ} \mathrm{C} \\
\text { Water }\end{array}$} \\
\hline & Radia 1 . & Axia 1 & $\Delta \mathrm{L}$ & $\triangle \mathrm{D}$ & $\Delta \underline{L}$ & $\Delta D$ & $\triangle \mathrm{L}$ & $\Delta D$ & $\Delta \mathrm{I}$ & $\Delta \mathrm{D}$ & $\Delta \mathrm{L}$ & $\Delta D$ & $\triangle L$ & $\Delta D$ \\
\hline Q & --- & $010(+0.50)$ & -2.00 & +0.65 & -1.65 & +0.30 & -1.07 & +0.40 & --- & -- & -0.98 & -0.20 & -0.90 & +0.39 \\
\hline$Q-6$ & --- & $010(+0.50)$ & -- & -- & -- & -- & -1.03 & +0.15 & -- & -- & -- & -- & -- & --- \\
\hline$Q-6-1$ & assumed rand & $\mathrm{G}_{3} \sim 0$ & Prior & conditi & n: as & quenched & d in 25 & ${ }^{\mathrm{O}} \mathrm{P}$ Poco & No. 2 & & & & +0.23 & -0.38 \\
\hline K & $100(-0.11)$ & $100-010(+0.03)$ & -0.35 & +0.25 & -- & -- & -0.45 & 0.00 & -- & -- & -0.05 & 0.00 & -0.06 & +0.05 \\
\hline S & quasi-random & $(\sim 0)$ & +0.05 & -- & +0.08 & -- & +0.08 & -- & -- & -- & +0.03 & -- & +0.03 & --- \\
\hline C & $151(+0.19)$ & $110(-0.32)$ & +0.20 & -0.05 & --- & --- & +0.43 & -0.20 & +0.19 & -0.17 & +0.62 & -0.35 & +0.64 & -0.25 \\
\hline DC & $151(+0.29)$ & $110(-0.33)$ & +0.47 & -0.10 & -- & -- & +0.40 & -0.15 & +0.36 & -0.17 & +0.55 & -0.15 & $\begin{array}{l}+0.55 \% \\
+0.47\end{array}$ & $\begin{array}{l}-0.20 \\
-0.20\end{array}$ \\
\hline
\end{tabular}

${ }^{*} 25^{\circ} \mathrm{C}$ brine 


\section{TABLE B-6}

Same as Table B-6 except for tubes [Table shows \% changes in length $(\Delta L)$, OD $(\Delta O D)$, wall $(\Delta W)$ ]

\begin{tabular}{|c|c|c|c|c|c|c|c|c|c|c|c|c|c|c|c|c|c|c|c|c|c|}
\hline \multirow[b]{3}{*}{ Code } & \multirow{2}{*}{\multicolumn{3}{|c|}{ Prior Texture: hkl $\left(G_{3}\right)$}} & \multicolumn{18}{|c|}{ Cooling Medium } \\
\hline & & & & \multicolumn{3}{|c|}{$\begin{array}{r}30^{\circ} \mathrm{c} \\
\mathrm{Air} \\
\end{array}$} & \multicolumn{3}{|c|}{$\begin{array}{c}55^{\circ} \mathrm{C} \\
\text { Poco No. } 2 \text { Oil } \\
\end{array}$} & \multicolumn{3}{|c|}{$\begin{array}{c}25^{\circ} \mathrm{C} \\
\text { Poco No. } 2 \text { Oil } \\
\end{array}$} & \multicolumn{3}{|c|}{$\begin{array}{l}25^{\circ} \mathrm{C} \\
\text { Houghto } \mathrm{K} \text { Oil } \\
\end{array}$} & \multicolumn{3}{|c|}{$\begin{array}{l}55^{\circ} \mathrm{C} \\
\text { Water }\end{array}$} & \multicolumn{3}{|c|}{$\begin{array}{l}12^{\circ} \mathrm{C} \\
\text { Water } \\
\end{array}$} \\
\hline & OD Radial & Tangentia 1 & Axial & $\Delta \mathbf{L}$ & $\Delta(O D)$ & $\Delta \mathrm{w}$ & $\Delta L$ & $\Delta(O D)$ & $\Delta W$ & $\Delta \mathrm{L}$ & $\Delta(O D)$ & $\Delta \mathrm{w}$ & $\Delta L$ & $\Delta(\mathrm{OD})$ & $\Delta \mathrm{w}$ & $\Delta L$ & $\Delta(O D)$ & $\Delta w$ & $\Delta \mathrm{L}$ & $\triangle(O D)$ & $\Delta \mathrm{w}$ \\
\hline E & $135(+0.06)$ & $001(+0.12)$ & $110(-0.21)$ & -0.03 & -2.30 & -.020 & - & - & - & -0.19 & +0.32 & -0.40 & +0.11 & +0.28 & +0.02 & +0.40 & -2.02 & -0.10 & +0.42 & -2.02 & -0.10 \\
\hline L & $151(+0.12)$ & $001(+0.10)$ & $110(-0.23)$ & -0.13 & +0.21 & +0.51 & - & - & - & +0.08 & +0.31 & -0.36 & +0.11 & +0.36 & -0.46 & - & - & - & +0.44 & +0.62 & -0.51 \\
\hline DG & $151(+0.24)$ & $001(+0.13)$ & $110(-0.33$ & +0.32 & +0.33 & -0.40 & - & - & - & -0.12 & +0.53 & -0.20 & - & - & - & 0.00 & +0.57 & -0.40 & - & - & - \\
\hline A & $151(+0.16)$ & - & $110(-0.32)$ & - & - & - & $-0.09^{\dagger}$ & $+0.22^{+}$ & $+0.15^{\dagger}$ & - & - & - & +0.04 & +0.31 & -0.67 & - & - & - & +0.21 & +0.29 & -1.12 \\
\hline $\mathrm{N}$ & $151(+0.26$ & $001(+0.13)$ & $110(-0.40)$ & +0.34 & +0.20 & -0.65 & - & - & - & +0.48 & +0.30 & -0.97 & +0.52 & +0.25 & -0.97 & - & - & - & +0.73 & +0.45 & -1.61 \\
\hline T & $151(+0.38)$ & $001(+0.11)$ & $110(-0.40)$ & +0.43 & +0.50 & -0.59 & - & - & - & +0.36 & +0.45 & -2.0 & +0.33 & +0.40 & -3.48 & +0.62 & +0.70 & -1.0 & $+0.54^{*}$ & $-0.65^{*}$ & $-1.00^{*}$ \\
\hline $\begin{array}{l}\text { H (see } \\
\text { below) }\end{array}$ & $151(+0.36)$ & $001(+0.22)$ & $110(-0.46)$ & +0.56 & -0.14 & -0.80 & +0.57 & -0.14 & -0.80 & +0.56 & -0.14 & -1.0 & -0.13 & -0.21 & -0.42 & +0.70 & -0.07 & -1.0 & +0.68 & -0.07 & -1.60 \\
\hline $\mathbf{P}$ & $151(+0.14)$ & $001(+0.17)$ & $110(-0.39)$ & +0.27 & +0.10 & -0.01 & - & - & - & +0.57 & +0.01 & -0.80 & +0.48 & +0.10 & -0.60 & - & - & - & +0.79 & +0.10 & -1.20 \\
\hline $\mathrm{DH}(\mathrm{DC})$ & $151(+0.29)$ & - & $110(-0.46)$ & -0.33 & +0.12 & +0.21 & +0.35 & -0.005 & -0.21 & +0.43 & +0.07 & -0.15 & +0.45 & +0.21 & -0.21 & +0.06 & +0.21 & -0.63 & +0.27 & +0.14 & -1.05 \\
\hline
\end{tabular}

Note: Tube H a1so quenched in DT-275 molten salt:

\begin{tabular}{|l|ccc|ccc|ccc|}
\hline \multirow{8}{*}{ Code } & \multicolumn{8}{|c|}{ DT-275 molten 8alt } \\
\cline { 2 - 9 } & \multicolumn{3}{|c|}{$400^{\circ} \mathrm{C}$} & \multicolumn{3}{|c|}{$300^{\circ} \mathrm{C}$} & \multicolumn{3}{c|}{$200^{\circ} \mathrm{C}$} \\
\hline$H$ & $\Delta(O D)$ & $\Delta W$ & $\Delta L$ & $\Delta(O D)$ & $\Delta W$ & $\Delta L$ & $\Delta(O D)$ & $\Delta W$ \\
\hline$H$ & +0.48 & -0.41 & -1.20 & +0.55 & -0.21 & -0.80 & +0.62 & -0.14 & -0.60 \\
\hline
\end{tabular}

$+30^{\circ} \mathrm{C}$ Houghto-Quench 4102 011

* $0^{\circ} \mathrm{C}$ brine 


\section{$\underline{\text { TABLE B-7 }}$}

Integrated Radial Texture, $\pi_{1}$ in Tubes Cooled from the Beta Phase in Different Media $\pi_{r}=\int G_{3}\left(\frac{2 r}{20}\right) d r$

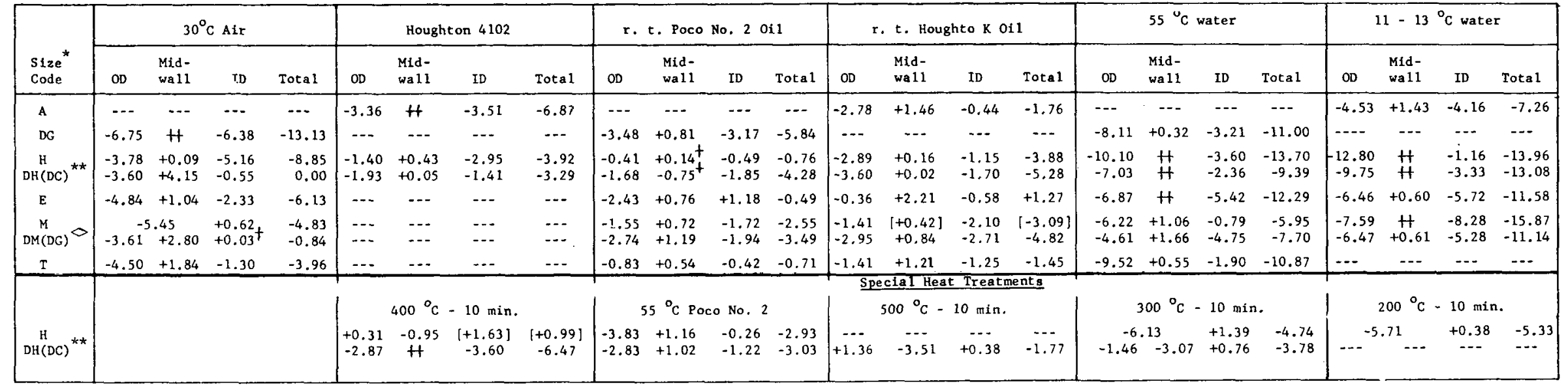

+ net value but scatters through $G_{3}=0$

* Letter preceded by $D$ shows dingot; all others ingot

$\checkmark$ made from dingot received as size $D C$
$H \pi_{r}$ for OD and $I D$ separated by max. $G_{3}$ near midwall

** made from dingot received as size $D C$

( ) uncertain 
$\underline{\text { TABLE B-8 }}$

Effect of Cooling Medium on Certain Characteristics of Radial Texture Distribution

\section{in Dingot and Ingot Tubes}

Po $=$ Poco No. 2 Quenching 0il

Ho = Houghto $\mathrm{K}$ Quenching $0 i 1$

4102 = Houghto-Quench 4102 0i1

SDT = Houghton Draw-Temp. 275 molten salt

$\mathrm{SLH}=$ Houghton Liquid Heat 235 molten salt

$\mathrm{D}=$ Preceding letter of size code signifies unalloyed dingot.
* midwal1 region below $\mathrm{G}_{3}=0$

** no values; $\mathrm{G}_{3}$ always less than -0.1

$\mathrm{N}=$ not determined, since radial $\mathrm{G}_{3}$ at $\mathrm{OD}$ is more positive than -0.1 , or since $G_{3}$ near OD fluctuates radically with radial depth.

\begin{tabular}{|c|c|c|c|c|c|c|c|}
\hline \multirow{3}{*}{$\begin{array}{l}\text { Size } \\
\text { Code }\end{array}$} & \multirow{3}{*}{$\begin{array}{l}\text { Cooling } \\
\text { Medium } \\
\left({ }^{\circ} \mathrm{C} \text { type }\right)\end{array}$} & \multicolumn{2}{|c|}{ At $\mathrm{OD}$} & \multirow{2}{*}{\multicolumn{2}{|c|}{ Integrated Radial Texture }} & \multirow{3}{*}{$\begin{array}{l}\text { Percent } \\
\text { of }|\pi r| \\
\text { at } \mathrm{OD}^{2} \mid\end{array}$} & \multirow{3}{*}{$\begin{array}{l}\text { Percent } \\
\text { of }\left|\pi_{\text {oD }}+\pi_{\text {ID }}\right| \\
\text { at oD }\end{array}$} \\
\hline & & \multirow{2}{*}{$\begin{array}{l}\text { Cooling } \\
\text { Rate }\left(\mathrm{R}_{\beta}\right) \\
{ }^{\circ} \mathrm{C} / \sec ^{\circ}\end{array}$} & \multirow{2}{*}{$\begin{array}{l}\text { Radia } 1 \\
\text { Merit } \\
\mathrm{w}_{0} / 2 \mathrm{r} \\
\end{array}$} & & & & \\
\hline & & & & Net $\left(\pi_{r}\right)$ & Absolute $\left(\left|\pi_{r}\right|\right)$ & & \\
\hline$E-5$ & oil(25Ho) & 91. & 16.5 & +1.27 & 3.15 & 11 & 38 \\
\hline $\mathrm{H}-10$ & saIt (400SLH) & 68. & $>100$ & +0.99 & 2.89 & 11 & 16 \\
\hline $\mathrm{DH}(\mathrm{DC})-1$ & $\operatorname{air}(30)$ & 2.2 & 3.1 & 0.00 & 8.30 & 43 & 87 \\
\hline $\mathrm{E}-2$ & oil (25Po) & 58. & 81. & -0.49 & 4.37 & 56 & 67 \\
\hline$T-3$ & oil (25Po) & 165. & 17. & -0.71 & 1.79 & 46 & 66 \\
\hline $\mathrm{H}-4$ & oil(25Po) & 72 & 26. & -0.76 & 1.04 & 39 & 48 \\
\hline$D M(D G)-1$ & $\operatorname{air}(30)$ & 4.5 & 2.3 & -0.84 & 6.44 & 56 & 99 \\
\hline $\mathrm{T}-5$ & oil (25Ho) & 216 & 6.3 & -1.45 & 3.87 & 36 & 53 \\
\hline$A-2$ & oil(25Ho) & 79. & 2.5 & -1.76 & 4.68 & 59 & 86 \\
\hline $\mathrm{DH}(\mathrm{DC})-10$ & salt (500SDT) & 32 & $\mathrm{~N}$ & -1.77 & 5.31 & 26 & 78 \\
\hline$M-5$ & oil (25Po) & 90. to 53. & 5.7 & -2.55 & 3.99 & 39 & 47 \\
\hline $\mathrm{H}-7$ & oil (55Po) & 44. (ID) & 20 & -2.93 & 5.25 & 73 & 94 \\
\hline $\mathrm{DH}(\mathrm{DC})-5$ & oil(55Po) & 36. (ID) & 7. to 3 . & -3.03 & 5.07 & 56 & 70 \\
\hline$M-6$ & oil (25Ho) & 109 & 7.6 & -3.09 & 3.93 & 46 & 40 \\
\hline $\mathrm{DH}(\mathrm{DC})-7$ & $\operatorname{oil}(254102)$ & 38 . & 4.9 & -3.29 & 3.39 & 57 & 58 \\
\hline $\mathrm{DM}(\mathrm{DG})-2$ & oil(25Po) & 90. & 4.0 & -3.49 & 5.87 & 47 & 59 \\
\hline $\mathrm{DH}(\mathrm{DC})-8$ & salt (300SDT) & 73 . & $\mathrm{N}$ & -3.78 & 5.29 & 28 & 66 \\
\hline $\mathrm{H}-13$ & oi $1(25 \mathrm{Ho})$ & 34. & 12. & -3.88 & 4.20 & 59 & 72 \\
\hline$H-14$ & oil (25 4102) & --- & 6.6 & -3.92 & 4.78 & 29 & 32 \\
\hline $\mathrm{T}-2$ & $\operatorname{air}(30)$ & 7.6 & 2.1 & -3.96 & 7.64 & 59 & 78 \\
\hline
\end{tabular}


TABLE B-8 (cont inued)

\begin{tabular}{|c|c|c|c|c|c|c|c|}
\hline \multirow{3}{*}{$\begin{array}{l}\text { Size } \\
\text { Code }\end{array}$} & \multirow{3}{*}{$\begin{array}{l}\text { Cooling } \\
\text { Medium } \\
\left({ }^{\circ} \mathrm{C} \text { type }\right)\end{array}$} & \multicolumn{2}{|c|}{ At OD } & \multirow{2}{*}{\multicolumn{2}{|c|}{ Integrated Radial Texture }} & \multirow{3}{*}{$\begin{array}{l}\text { Percent } \\
\text { of }\left|\pi_{\mathrm{OD}} \mathrm{r}\right| \\
\text { at }\end{array}$} & \multirow{3}{*}{ of $\left|\pi_{\text {OD }}^{\text {Percent }}+\pi_{\text {ID }}\right|$} \\
\hline & & \multirow{2}{*}{$\begin{array}{l}\text { Cooling } \\
\text { Rate }\left(R_{\beta}\right) \\
{ }^{\circ} / \text { sec. }\end{array}$} & \multirow{2}{*}{$\begin{array}{l}\text { Radial } \\
\text { Merit } \\
w_{o} / 2 r\end{array}$} & & & & \\
\hline & & & & Net $\left(\pi_{r}\right)$ & Absolute $\left(\left|\pi_{\mathrm{r}}\right|\right)$ & & \\
\hline $\mathrm{DH}(\mathrm{DC})-3$ & oi1(25Po) & 37. & 6.4 & -4.28 & 4.28 & 39 & 48 \\
\hline $\mathrm{H}-11$ & $\operatorname{salt}(300 \mathrm{SLH})$ & 87. & 7.1 & -4.74 & 7.52 & 82 & $82^{*}$ \\
\hline$D M(D G)-3$ & oil(25Ho) & 109 & 5.5 & -4.82 & 6.50 & 45 & 52 \\
\hline$M-4$ & $\operatorname{air}(30)$ & 4.5 & 2.2 & -4.83 & 6.07 & 90 & 53 \\
\hline $\mathrm{DH}(\mathrm{DC})-4$ & oil $(25 \mathrm{Ho})$ & 35 & 7. to 3 . & -5.28 & 5.32 & 68 & 68 \\
\hline $\mathrm{H}-12$ & salt (200SLH) & 125. & 2.9 & -5.33 & 6.09 & 94 & 94 \\
\hline DG -2 & oil(25Po) & 49 & 2.5 & -5.84 & 7.46 & 47 & 52 \\
\hline$M-7$ & water (55) & $650 . ?$ & 1.4 & -5.95 & 8.07 & 77 & 89 \\
\hline$E-1$ & $\operatorname{air}(30)$ & 2.5 & 2.2 & -6.13 & 8.21 & 59 & 68 \\
\hline $\mathrm{DH}(\mathrm{DC})-9$ & salt (400SDT) & 64. & $\mathrm{~N}$ & -6.47 & 6.47 & 44 & $44^{*}$ \\
\hline$A-1$ & oil $(254102)$ & 15 . & 5.8 & -6.87 & 6.87 & 49 & $49^{*}$ \\
\hline$A-3$ & water (12) & 420. & 2.4 & -7.26 & 10.12 & 45 & 52 \\
\hline $\mathrm{DM}(\mathrm{DG})-4$ & water (55) & $650 . ?$ & 2.1 & -7.70 & 11.02 & 42 & 49 \\
\hline $\mathrm{H}-3$ & $\operatorname{air}(30)$ & 2.2 & 6.0 & -8.85 & 9.03 & 42 & 42 \\
\hline $\mathrm{DH}(\mathrm{DC})=2$ & water (55) & 126. & 1.4 & -9.39 & 9.39 & $76^{*}$ & $76^{*}$ \\
\hline$T-4$ & water (55) & 802. & 1.1 & -10.87 & 11.97 & 80 & 83 \\
\hline $\mathrm{DG}-1$ & water (55) & 428. & 1.2 & -11.00 & 11.64 & 70 & 72 \\
\hline $\mathrm{DM}(\mathrm{DG})-5$ & water (12) & 540 . & 1.6 & -11.14 & 12.36 & 52 & 55 \\
\hline$E-3$ & water (12) & 474. & 2.2 & -11.58 & 12.78 & 51 & 53 \\
\hline$E-4$ & water (55) & 474. & 2.0 & -12.29 & 12.29 & $55^{*}$ & $55^{*}$ \\
\hline DH. (DC) -6 & water(12) & 197. & 1.0 & -13.08 & 13.08 & $75 *$ & $75^{*}$ \\
\hline$D G-3$ & $\operatorname{air}(30)$ & 2.2 & $x *$ & -13.13 & 13.13 & $51_{*}^{*}$ & $51_{*}^{*}$ \\
\hline$H-6$ & water (55) & 126. & $0.9 ?$ & -13.70 & 13.70 & $74^{*}$ & $74^{*}$ \\
\hline $\mathrm{H}-5$ & water (12) & 197. & $0.8 ?$ & -13.96 & 13.96 & $92^{*}$ & $92 *$ \\
\hline$M-8$ & water (12) & 540 . & 1.4 & -15.87 & 15.87 & $48^{*}$ & $48^{*}$ \\
\hline Averages & & 165. & $--\infty$ & -5.77 & 7.43 & 54 & 63 \\
\hline
\end{tabular}


Size Code for Rods and Tubes Studied in Beta Treatment Program

\begin{tabular}{|c|c|c|c|c|}
\hline \multirow[b]{2}{*}{ Code } & \multicolumn{3}{|c|}{$\begin{array}{l}\text { Size } \\
\text { (in) }\end{array}$} & \multirow[b]{2}{*}{ Composition } \\
\hline & $\mathrm{OD}$ & ID & $\mathrm{Wa} 11$ & \\
\hline A & 3.853 & 2.073 & 0.890 & Ingot \\
\hline C & 1.845 & 0 & rod & Ingot \\
\hline DC & 1.845 & 0 & rod & Dingot \\
\hline$E$ & 3.980 & 3.060 & 0.460 & Ingot \\
\hline DG & 2.960 & 1.965 & 0.498 & Ding ot \\
\hline $\mathrm{H}$ & 1.450 & 0.500 & 0.475 & Ingot \\
\hline $\mathrm{DH}(\mathrm{DC})$ & 1.450 & 0.500 & 0.475 & Dingot $\mathrm{DC}$ \\
\hline $\mathrm{K}$ & 1.18 & 0 & rod & Ingot \\
\hline DK & 1.05 & 0 & rod & Dingot \\
\hline L & 3.890 & 3.497 & 0.197 & Ingot \\
\hline M & 2.930 & 2.510 & 0.210 & Ingot \\
\hline $\mathrm{DM}(\mathrm{DG})$ & 2.930 & 2.510 & 0.210 & Dingot $D G$ \\
\hline $\mathrm{N}$ & 2.000 & 1.380 & 0.310 & Ingot \\
\hline $\mathrm{P}$ & 1.000 & 0.500 & 0.250 & Ingot \\
\hline$Q$ & 0.6 & 0 & rod & Ingot \\
\hline$Q Q$ & 0.6 & 0 & rod & Ingot \\
\hline$s$ & 0.5 & 0 & rod & Ingot \\
\hline $\mathrm{T}$ & 1.995 & 1.765 & 0.115 & Ingot \\
\hline
\end{tabular}




\section{REFERENCES FOR APPENDIX B}

1. Report DP-251 (De1.) (November 1957) (Declassified October 4, 1961); E. F. Sturcken, W. R. McDone11, "An X-ray Method for Predicting Anisotropic Irradiation Growth in Uranium", J. Nuc1. Mat. 7 (1962) 85-91.

2. E. F. Sturcken, "A Generalized Growth Index Formalism", pp. 9-11, Papers Presented at the X-Ray Preferred Orientation Meeting Held at National Lead Company of Ohio, November 9 and 10, 1959, NLCO-804, (July 15, 1960).

3. Reference 2, pp. 9-24.

4. C. E. Polson, (NLO), Apri1 27, 1960, personal communication.

5. P. R. Morris, 'Reducing the Effects of Nonuniform Pole Distribution In Inverse Pole Figure Studies"' J. App1. Phys. 30 (1959) 595-596.

6. R. N. Thudium and P. R. Morris, "Brief Description of the 'Area-Weight' Treatment for the 18-Plane Set", pp. 55-57, Papers and Discussion from the $X$-Ray Preferred Orientation Meeting. Held at Argonne Natlonal Laboratory, December 15 and 16, 1960, M. H. Mueller, Ed., ANL-6359 (May 1961).

7. Reference 2, pp. $20,22,57$. 